\title{
Lengua E IdenTIDAd EN EL CAMINO DE LA MIGRACIÓN DE INDÍGENAS TOBAS: \\ UNA PERSPECTIVA INTERDISCIPLINARIA
}

TESIS DE DOCTORADO

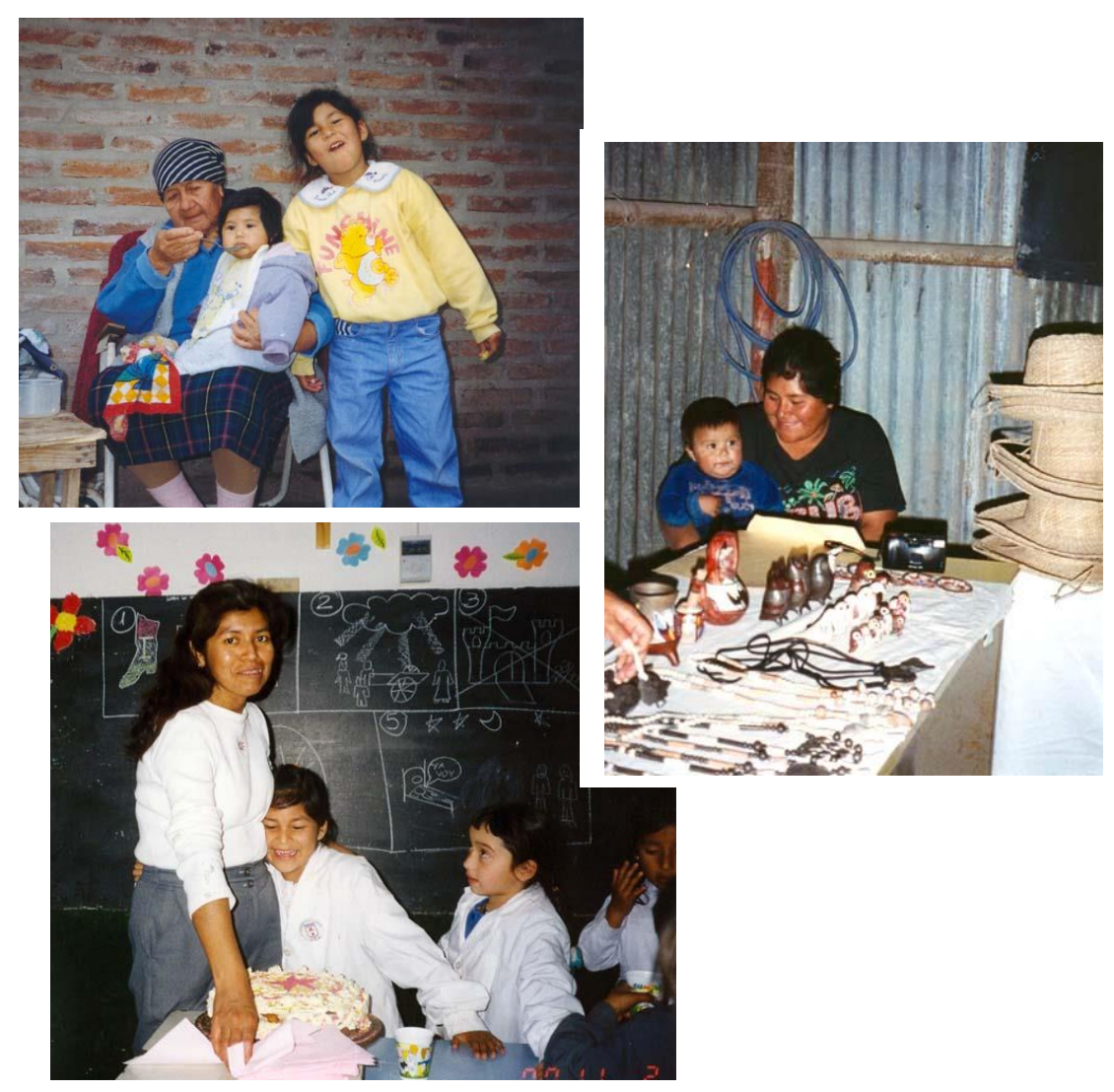

Por: Mg. María Amalia Ibáñez Caselli

Directora: Dra. Liliana Tamagno

Codirectora: Dra. Lucía Golluscio

Facultad de Ciencias Naturales y Museo

Universidad Nacional de La Plata 


\section{Agradecimientos}

Las ideas que a continuación se presentan son el resultado del diálogo fluido, constante y sostenido durante más de diez años con la gente toba del Barrio "Las Malvinas" de la ciudad de La Plata. Diálogo en el que confluyeron tanto los conocimientos que adquirí durante mi formación como antropóloga en la Universidad Nacional de La Plata y, luego, en la Maestría en Ciencias Sociales de la Escuela de Postgrado del Centro "Bartolomé de Las Casas" del Cusco/FLACSO, como las experiencias, saberes y prácticas de quienes aceptaron ser mis interlocutores. Entre ellos, agradezco a las familias que conforman el Barrio Toba "Las Malvinas" y miembros de la "Asociación Civil Toba Ntaunaq Nam Qom", de la ciudad de La Plata; especialmente a Julia Gómez, mi profesora de lengua toba y amiga, con quien compartí muchas horas intercambiando pensamientos y vivencias en distintos ámbitos de reflexión, discusión y recreación, como así también a Carina -su hija, a quien vi nacer y crecer; a don Julio Ramírez y su esposa doña Cristina por sus enseñanzas y sabios consejos; a Mary, Rogelio, Negrita, Jorgelina, Silverio, Delia, Norma y Laura por "estar ahi" siempre. A las familias del Barrio Toba de la ciudad de Resistencia, Chaco: a Emilia Fernández por su hospitalidad, a Silvia Gómez y Rosa por su ayuda y compañía; a Ignacio Rossi, Gabina Gersello, Bernal Flores por su apoyo, consideraciones e interés; a los maestros bilingües: Desiderio Lorenzo, Matías Aguirre, Rosa Martínez, Hermegilda Lagos, Patricio Carlos Gabriel, Luis Silvestre y maestros criollos y directivos de la UEP N 30 de Resistencia. A Nilda Farías y Gladis Rollkaiser de la Escuela N 894 del Barrio Nocayí, de J. J. Castelli. A Sandra Flores y Sergio Navarro del Instituto de Nivel Terciario CIFMA, de Sáenz Peña. A Juan Leiva de Olla Quebrada, Chaco. A la ex Directora del Área de Educación Especial y Atención a la Diversidad del Chaco, Alejandra Arcadini, por haberme facilitado las resoluciones y leyes de educación indígena de la provincia. A Ema Cuanieri del Lote 68, Formosa. A los maestros bilingües Ofelia Morales, Alberto Yordán y Alfredo de la ciudad de Rosario. A Tulia Fernández y Ceferino de la localidad de Dock Sur; a Eugenio Fernández, Amancio Rojas y Tito Alegre de la Asociación Civil Yecthakay, Talar de Pacheco, Tigre; y Lucio Medina de villa IAPI, Quilmes por las horas compartidas. 
Además, un especial agradecimiento a mis colegas Nora Arias, Marisa Censabella y Cristina Messineo por compartir información. Y al Dr. Rainer Enrique Hamel de la Universidad Autónoma de México -Iztapalapa- por su gran apoyo, estímulo, confianza y generosidad.

También debo agradecer a mis compañeras de equipo de investigación por su amistad, colaboración y horas de trabajo compartidas: a Stella García, Olga Brunatti, Adelaida Colángelo y María del Carmen García. Principalmente a las Dras. Liliana Tamagno y Lucía Golluscio -tutoras de esta tesis- por sus horas dedicadas, asesoramiento, guía, compresión y paciencia. A Amanda Zamuner, Oscar Ibáñez, Víctor Falcón, por sus lecturas, apreciaciones y apoyo. Y a mis padres, por su orientación y aliento en todos estos años. 


\section{ÍNDICE}

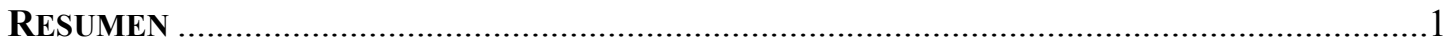

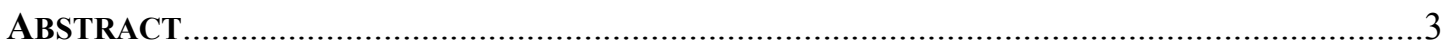

REFERENCIAS FONOLÓGICAS, ORTOGRÁFICAS Y DE TrASCRIPCiÓN .............................4

\section{CApítulo I}

el Pueblo Toba en el Camino de la Migración: SU DISTINTIVIDAD Y TRANSFORMACIONES

I.1. INTRODUCCIÓN.

- ObJetivos y Aspectos Centrales de la INVESTIGACIÓN

- ORGANIZACIÓN DE LOS CAPÍTULOS

I.2. LA CUESTIÓN INDÍGENA COMO POLÍTICA DE ESTADO .12

I.3. LOS TOBAS: HISTORIA Y PRESENTE.

- EN El TIEMPo de los ABUElos, EN El CHACO

- LA MIGRACIÓN A LA GRAN CIUDAD

- ViVIR EN LA CIUDAD

\section{CAPítulo II}

\section{ASPeCtos Metodológicos Y TeÓRICOS Generales de LA INVESTIGACión}

Parte 1. Principios Metodológicos y estrategias de CaMPo.

II.1.1. LOS PASOS EN LA INVESTIGACión Y LA CONSTRUCCión DEL OBJeTO DE ESTUDIO.

II.1.2. SOBRE EL TRABAJO DE

CAMPO

- De la ciudad de La Plata al Chaco

- De la ciudad de La Plata a otros nucleamientos tobas

- Superando algunos obstáculos

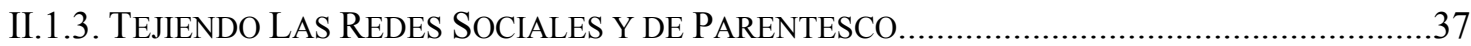

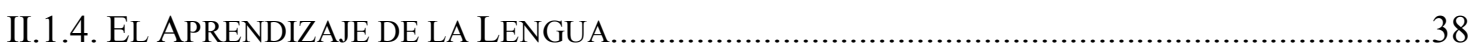

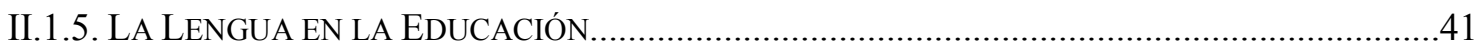

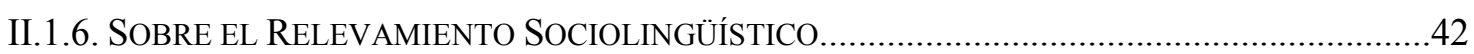

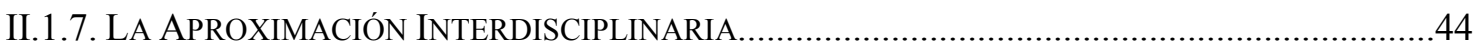

II.1.8. El TRABAJO DE INVESTIGACIÓN COMO DiÁLOGO INTERCULTURAL..................................46

PARTe 2. PRincipales Postulados EPISTEMológicos de la InVESTIGACión................50

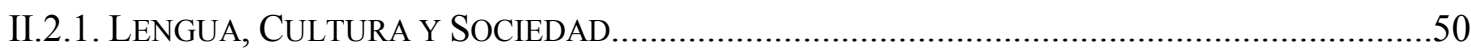

- Algunos antecedentes

- La aproximación al lenguaje en su contexto social

- Los avances de los últimos años

II.2.2. IDENTIDAD, ETNICIDAD Y LOS USOS DE LA LENGUA.

- Los procesos de adquisición de la lengua y la socialización

- El habitus en las prácticas socioculturales

- El habitus lingüístico en la dinámica de la sociedad

- Lengua y Discurso en el proceso de construcción social de la Identidad

II.2.3. LA LENGUA, EL BILINGÜISMO Y LA COMUNIDAD. 
- Comunidad: una construcción simbólica

- El grupo social como comunidad de habla

- La comunidad discursiva: un nuevo concepto

\section{CAPÍtulo III}

UNA APROXIMACIÓN ETNOGRÁFICA A LOS TOBAS DEL BARRIO "LAS MALVINAS"

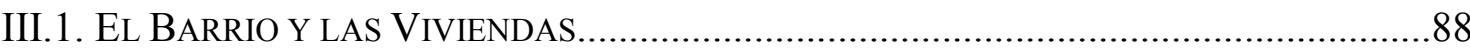

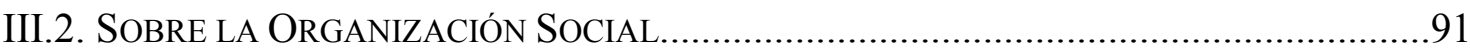

- La Huerta Comunitaria

- El Comedor Comunitario Qom Llalacpi: 'Los Hijos de los Tobas'

- El Ropero Comunitario

- El Horno de Barro

- Otras actividades, otros proyectos...

III.3. LA PRÁCTICA DE "El Evangelio"

- Aniversario de La Iglesia Unida Templo de Fe

- Cumpleaños de 15

III.4. FESTEJOS COLECTIVOS

- Día del Indio

- Día del Niño

III.5. ALGUNOS ASPECTOS DE LA SOCIALIZACIÓN......................................................... 110

III.6. EL BARRIO Y LA EDUCACIÓN FORMAL.............................................................. 113

- La Escuela de Adultos

III.7. MigRACIÓN (LA LLEGADA) Y LAS REDES DE ARTICULACIÓN SOCIAL.......................122

- Instancia I: La vida en el Chaco

- Instancia II: La llegada a Capital Federal y las primeras actividades

- Instancia III: Los primeros pasos en la búsqueda de tierras

- Instancia IV: El pueblo toba se organiza

- Instancia V: La llegada a La Plata y la organización

III.8. LAS RELACIONES DE PARENTESCO, AMISTAD, VECINDAD Y RELIGIOSIDAD.

\section{CApítulo IV}

\section{RECURSOS Y ESTRATEGIAS COMUNICATIVOS Y METACOMUNICATIVOS EN LA COMUNIDAD TOBA DEL BARRIO "LAS MALVINAS"}

IV.1. El RELEVAMIENTO SOCIOLINGÜÍSTICO

- Las primeras observaciones y registros en el campo

- Cumplida la autoconstrucción, el barrio alcanza una nueva dinámica

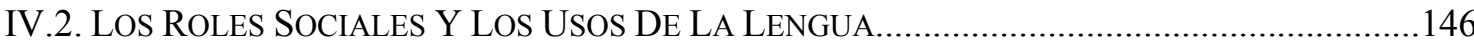

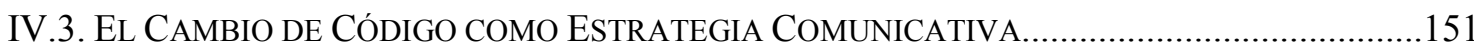

IV.4. LAS REDES DE RELACiÓN SOCIAL Y LOS USOS DE LA LENGUA A LO LARGO DE LA MIGRACIÓN

IV.5. RECURSOS VERBALES Y ESTRATEGIAS COMUNICATIVAS Y METACOMUNICATIVAS........158

- Discursos privados obtenidos en situación de entrevista

- Discurso público en contexto académico

IV.6. EVENTOS Y SiTUACIONES COMUNICATIVAS DONDE SE EXPRESA LA SIGNIFICACIÓN DEL HECHO DE HABLA

- Las Asambleas

- Sesiones de Culto 
- Celebraciones

- Las Visitas

- Actividades Comunales

- Reuniones y Talleres Interétnicos

- Charlas y Conferencias

- Situaciones educativas

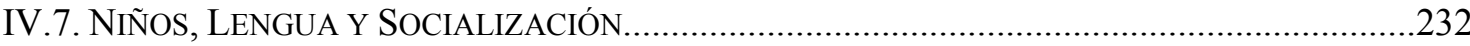

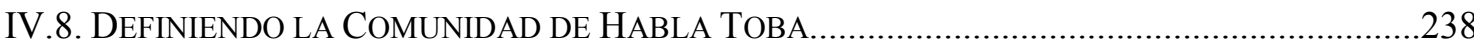

IV.9. LOS SIGNIFICADOS SOCIALES DEL USO DE LA LENGUA (IDEOLOGÍA) ................................241

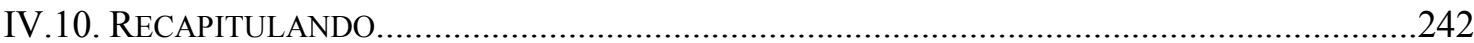

\section{CAPítulo V}

\section{LENGUA/ IDENTIDAD /MIGRACIÓN: CONSIDERACIONES FINALES}

V.1. Los Usos Y "DESUSOS” DE LA LENGUA TOBA EN EL CAMINO DE LA MigRACIÓN............244

V.2. El BARRIO TOBA "LAS MALVINAS": UNA COMUNIDAD DE HABLA...................................247

V.3. MODALIDADES DISCURSIVAS Y CONSTRUCCIÓN SOCIAL DE LA IDENTIDAD TOBA.............250

- La construcción de un nosotros

- La recurrencia de ciertos temas como signos ideológicos

- El silencio como estrategia comunicativa

- Los elementos de la prosodia

- Los cambios de código como estrategia discursiva

- La hipercorrección

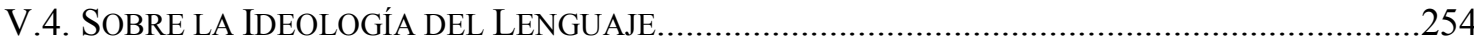

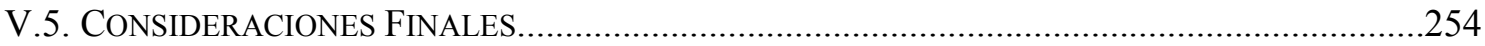

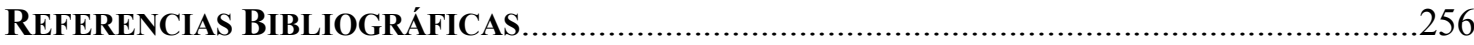

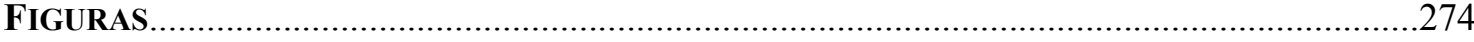

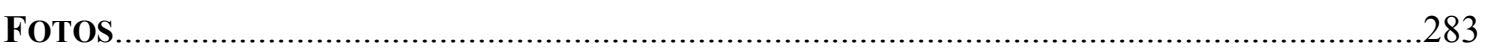

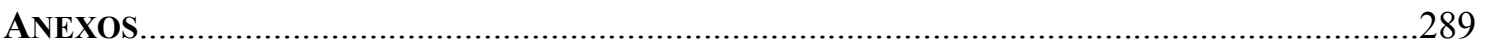




\section{RESUMEN}

\section{Lengua e Identidad en el CAMino de la Migración de Indígenas TOBAS: UNA PERSPECTIVA INTERDISCIPLINARIA}

A partir de la consideración de la lengua como un recurso cultural -signo diacrítico de identidad-, el habla como una práctica histórica y social y el discurso como el locus donde se expresa la relación concreta entre lengua, cultura y sociedad, esta investigación consiste en el estudio de la vigencia y los usos, las actitudes y valores que la lengua materna posee para la Comunidad Toba del Barrio "Las Malvinas", conformada por varios nucleamientos de familias tobas en la periferia de la ciudad de La Plata (Provincia de Buenos Aires). Al mismo tiempo se observan los modos en que se construye la identidad étnica, en un grupo de indígenas migrantes, lejos de su lugar de origen, a partir del análisis de los discursos públicos y privados generados tanto en el contexto del barrio como fuera del mismo y se identifican los principales recursos verbales $\mathrm{y}$ estrategias comunicativas y metacomunicativas que caracterizan a esta comunidad.

Lo que se conoce como Barrio Toba "Las Malvinas" comenzó a gestarse en 1991 y es el resultado de la organización indígena y su participación en un plan de autoconstrucción de viviendas de la Provincia de Buenos Aires. El núcleo principal está compuesto por 34 familias tobas que migraron, en su mayoría, desde la Provincia del Chaco y que conforman la Asociación Civil Toba Ntaunaq Nam Qom; sin embargo, en la actualidad son más de 100 las familias que lo componen. Algunas llegaron al conurbano bonaerense hace más de treinta años y otras, a la ciudad de la Plata, en los últimos diez. Hoy, a pesar de encontrarse distantes de su lugar de origen, la mayoría conserva y habla una lengua que se considera minoritaria y que no cuenta con prestigio en el contexto nacional.

Este estudio se inició en 1993 en el marco de la línea de investigación "Indígenas en la ciudad" desarrollada en el Laboratorio de Investigaciones en Antropología Social (LIAS) de la Universidad Nacional de La Plata (UNLP) y dirigida por la Dra. Liliana Tamagno. La situación de la gente toba viviendo en un medio urbano condujo a 
reflexionar sobre los conceptos de bilingüismo y "comunidad de habla"; de la socialización, en general, y la socialización lingüística, en particular; los roles sociales y lingüísticos; y, básicamente, sobre los significados e implicancias de hablar una lengua indígena y minoritaria en la ciudad.

Indagar sobre estas respuestas y sus fundamentos implicó realizar nuestro trabajo tanto desde una aproximación interdisciplinaria, como con la construcción conjunta del conocimiento con la gente toba. Lo primero significó, desde nuestra formación y visión antropológica, estudiar el lenguaje y el discurso en su contexto y dinámica sociocultural. De este modo, este estudio se enmarca dentro de lo que se denomina la Etnografía del Habla o Etnografía de la Comunicación y la Sociolingüística, áreas que se han desarrollado dentro de un campo mayor que es el de la Antropología Lingüística o Lingüística Antropológica. Y, lo segundo, un diálogo e intercambio constante y abierto con nuestros principales interlocutores: la Comunidad Toba del Barrio "Las Malvinas". 


\section{Astract}

\section{LANguage AND Identity In The Migratory Trail OF THE ToBA INDIGENOUS PeOPle: AN INTERdisciplinARY VieW}

From the notion of language as a cultural resource -a diacritical sign of identity-, speech as a historical and social practice and discourse as the locus where the relation between language, culture and society is expressed, this research focuses on the study of the validity and uses, attitudes and values that the mother tongue has, mainly in the Toba neighborhood "Las Malvinas", which is located in the outskirts of the city of La Plata (Province of Buenos Aires). At the same time, we observe the way that ethnic identity is built in a group of migrants indigenous, inside the neightborhood as outside it, and we identified the main verbal resources and comunicative and metacomunicative strategies that characterizes this community.

What we know as Toba neighborhood began to develop in 1991, being the result of indigenous organization and involvement in a self-assembly housing plan of the government of the Province of Buenos Aires. It is made up of 34 Toba families that migrated, most of them, from the province of Chaco. Some reached the Buenos Aires conurbation area more than thirty years ago, and others arrived in the city of La Plata, in the last ten years. Today, they are far from their place of origin; nevertheless, they keep and speak a minority language that is discredited in the national context. Their being "indigenous migrants in the city" has made us wonder about aspects of bilingualism and speech community, about socialization in general and linguistic socialization in particular, about social and linguistic roles, and, especially, about the meanings and implications of speaking an indigenous minority language in the city.

Investigating the answers to those questions and their grounds implied the performance of our work with an interdisciplinary approach, which implied -from our training and anthropological view- studying language and discourse in their dynamics and socio-cultural context. Thus, the current study is within the framework of what is known as Ethnography of Speech or Ethnography of Communication and Sociolinguistic, areas that have developed within a broader field, that of Linguistic Anthropology or Anthropological Linguistics. 


\section{REFERENCIAS FONOLÓGICAS, ORTOGRÁFICAS Y DE TrASCRIPCIÓN}

\section{SISTEMAS FONOLÓGICO Y ORTOGRÁFICO DEL QOM L'AQTAQA ${ }^{\text {, }}$}

En relación a los aspectos fonológicos de la lengua toba, Messineo (2000) destaca que la misma posee veinticuatro fonemas segmentales: veinte consonantes y cuatro vocales. Las consonantes se oponen en seis puntos de articulación (labial, alveolar, palatal, velar, uvular y laríngeo) y en seis modos (oclusivo, fricativo, nasal, lateral y semiconsonante). En tanto que el sistema ortográfico adoptado por los hablantes del qom l'aqtaqa' se basa en la grafía del español. Según la opinión de esta autora, esta grafía estaría presentando algunas inconsistencias que se relacionan con el principio de economía, utilizando, por ejemplo, dos o más grafemas para representar un solo fonema. El cuadro que se presenta a continuación sintetiza ambos sistemas. ${ }^{2}$

\section{- Consonantes:}

\begin{tabular}{|c|c|c|c|c|c|c|c|c|c|c|c|c|}
\hline & \multicolumn{2}{|c|}{ Labiales } & \multicolumn{2}{|c|}{ Alveolares } & \multicolumn{2}{|c|}{ Palatales } & \multicolumn{2}{|c|}{ Velares } & \multicolumn{2}{|c|}{ Uvulares } & \multicolumn{2}{|c|}{ Laríngeas } \\
\hline & sonora & sorda & sonora & sorda & sonora & sorda & sonora & $\begin{array}{l}\text { sorda } \\
\text { sol }\end{array}$ & sonora & sorda & sonora & sorda \\
\hline Oclusivas & $\begin{array}{l}\mathrm{p} \\
{[\mathrm{p}]}\end{array}$ & & $\begin{array}{l}\mathrm{t} \\
{[\mathrm{t}]}\end{array}$ & $\begin{array}{l}\mathrm{d} \\
\text { [d] }\end{array}$ & $\begin{array}{l}\text { č } \\
\text { [ch] }\end{array}$ & & $\begin{array}{l}\mathrm{k} \\
{[\mathrm{c} / \mathrm{qu}]}\end{array}$ & $\begin{array}{l}\mathrm{g} \\
{[\mathrm{g} / \mathrm{gu}]}\end{array}$ & $\begin{array}{l}\mathrm{q} \\
\text { [q] }\end{array}$ & $\begin{array}{l}\mathrm{G} \\
{[\mathrm{x}]}\end{array}$ & '['] & \\
\hline Fricativas & & & $\begin{array}{l}\mathrm{s} \\
{[\mathrm{s}]}\end{array}$ & & $\begin{array}{l}\text { š } \\
\text { [sh] }\end{array}$ & $\begin{array}{l}\text { ž } \\
\text { [y] }\end{array}$ & & & & & $\begin{array}{l}\text { (h) } \\
\text { [j] }\end{array}$ & \\
\hline Nasales & & $\begin{array}{l}\mathrm{m} \\
{[\mathrm{m}]}\end{array}$ & & $\begin{array}{l}\mathrm{n} \\
{[\mathrm{n}]}\end{array}$ & & $\begin{array}{l}\tilde{\mathrm{n}} \\
{[\tilde{\mathrm{n}}]}\end{array}$ & & & & & & \\
\hline Laterales & & & & $1[1]$ & & $\begin{array}{l}\lambda \\
{[11]}\end{array}$ & & & & & & \\
\hline Semiconsonantes & & $\begin{array}{l}\mathrm{w} \\
{[\mathrm{hu} /} \\
\mathrm{u} / \mathrm{v}]\end{array}$ & & & & $\begin{array}{l}\mathrm{y} \\
{[\tilde{y}]}\end{array}$ & & & & & & \\
\hline
\end{tabular}

- Vocales
\begin{tabular}{|cc|}
\hline $\mathrm{i}$ & $\mathrm{o}$ \\
{$[\mathrm{i} / \mathrm{ii}]$} & {$[\mathrm{o} / \mathrm{oo}]$} \\
$\mathrm{e}$ & \\
{$[\mathrm{e} / \mathrm{ee}]$} & \\
& \\
& $\mathrm{a}$ \\
& {$[\mathrm{a} / \mathrm{aa}]$} \\
\hline
\end{tabular}

\footnotetext{
${ }^{1}$ La lengua de los qom (tobas).

${ }^{2}$ Los grafemas en este cuadro aparecen representados entre corchetes. Cuadro basado en Messineo (2000).
} 


\section{CONVENCIONES PARA LAS TRASCRIPCIONES}

- $\quad$ // indican las unidades de entonación;

- las palabras con doble subrayado indican que hay un aumento de la velocidad en el habla;

- las palabras con un solo subrayado señalan mayor lentitud en el habla;

- $\quad$ un punto (.) es una pausa mínima;

- $\quad$ dos puntos o tres (..) (...), una pausa mayor;

- las palabras en negrita refieren acentuación;

- $\quad\{\}$ indican cambios en el volumen de la voz (se habla más bajo);

- [ ] acciones extralingüísticas

- vocablos en qom l'aqtaqa se escriben en itálica 


\title{
CAPítulo I
}

\section{el Pueblo Toba o Qom³ en el Camino de la Migración: SU DISTINTIVIDAD Y TRANSFORMACIONES}

\begin{abstract}
"Si no tenemos derecho a poseer la tierra como dueños definitivos, significa nuestra muerte final. Sin tierra no hay cultura, no hay idioma. Para sobrevivir como pueblos indigenas, la tierra tiene que pertenecer a nosotros. Por eso los de la ciudad corren el riesgo de desaparecer." (Conclusiones $1^{\text {er }}$ Encuentro de Aborígenes, Roque Sáenz Peña, 1986 - testimonio)
\end{abstract}

\section{I.1. INTRODUCCIÓN}

A pesar de que expresiones semejantes a las del epígrafe siguen apareciendo con frecuencia, deben ser interpretadas más como una advertencia aleccionadora y un llamado de atención que como un vaticinio. La presencia actual del pueblo Toba y sus organizaciones y la vigencia de la lengua en la ciudad así lo confirman.

Los pueblos indígenas se fueron configurando a lo largo de nuestra historia en un marco de desigualdad social. El supuesto "encuentro entre dos visiones de mundo" -la occidental, por un lado, y la americana, por el otro- implicó la imposición de la una sobre la otra dominando en las esferas política, económica, religiosa y lingüística, justificando su superioridad, legitimando su derecho de hegemonía, negando la riqueza y diversidad de los pueblos indígenas (Menéndez 1972). Como consecuencia de esa relación fatídica de dominación/ subordinación (Worsley 1966), estos pueblos han sufrido transformaciones abruptas de las condiciones de existencia, el deterioro y destrucción del medio ambiente, la imposición de la lógica de las relaciones económicas

\footnotetext{
${ }^{3}$ Qom o nam qom es el nombre con el que se autodenomina la etnia toba queriendo significar "nosotros la gente"; en tanto que toba es el nombre con el que sus vecinos guaraníes llamaban a los qom y que significa "aquellos que tienen la frente grande" -posiblemente por la práctica antigua que tenían los hombres de rasurarse la cabeza hasta la mitad del cráneo-; por esta razón han sido conocidos también en las crónicas con el nombre de "frentones". No obstante, toba es el nombre más difundido, y con el que se los conoce más comúnmente y el utilizado en la literatura antropológica.
} 
capitalistas y, por lo tanto, del trabajo asalariado. A esto se suman los efectos de la intervención de denominaciones religiosas que continúan intentando desplazar los vastos y complejos sistemas simbólicos nativos para reemplazarlos por los propios. De este modo, la conquista económica y espiritual continúa (Bartolomé 2000).

Por tal razón, uno de los conceptos fundamentales para el análisis ha sido el de identidad étnica entendida como la identificación generada en los procesos de contacto interétnico y como una construcción social cotidiana a lo largo de la historia (Tamagno 1991). De esta manera, analizar la situación del pueblo Toba en relación a la vigencia y usos de su lengua implicó entender que, a lo largo de este proceso, la identidad toba se fue construyendo social e históricamente en una articulación social, la más de las veces, negativa. Es decir, una articulación con la sociedad dominante marcada por el racismo (Menéndez 1972). La discriminación, la subestimación y la negación de los conocimientos, la lengua y la propia existencia amenazan la posibilidad de reproducción de valores y normas, como así también la autoestima. Sin embargo, esto no implicó pérdida de identidad si aceptamos que a lo largo de esa historia los pueblos indígenas fueron actualizando y recreando sus conocimientos, lengua, símbolos, valores y normas en un complejo proceso de aceptación/ rechazo de los modelos impuestos por el colonizador (Tamagno 1988; 2000; 2001). Desde esta perspectiva sostenemos que las culturas indígenas se han rediseñado, pero no desaparecido, como lo pretendían algunas ópticas basadas en la percepción exterior de las diferencias (Bartolomé 2000). En este sentido, los pueblos indígenas fueron asimilando algunos de los elementos que el sector dominante les fue presentando y rechazando otros, generando en ellos transformaciones en sus condiciones materiales de existencia y, en menor medida, en su producción simbólica. Y, a pesar de las transformaciones, no hay pérdida de identidad toda vez que un pueblo se reconoce en un origen en común y mantiene una memoria coherente (Tamagno 2001).

En síntesis, desde la línea de investigación desarrollada en el marco del LIAS $^{4}$ entendemos que el pueblo Toba ha sufrido cambios y se ha transformado, pero esta transformación no implica pérdida de identidad - y tampoco de la lengua- en tanto que mantiene su distintividad y desde ella se relaciona con los "otros". Aquellos que hoy se encuentran lejos del Chaco no han olvidado su origen. Éste está presente todo el tiempo

\footnotetext{
${ }^{4}$ Laboratorio de Investigaciones en Antropología Social de la Facultad de Ciencias Naturales y Museo de la Universidad Nacional de La Plata.
} 
en sus memorias y en sus prácticas. Muchos niños tobas, aun sin conocer la región, la reconocen como propia. Las familias se asumen y actúan como un conjunto, de modo comunitario (Tamagno 2001), vinculado a un conjunto mayor: "el pueblo toba". Las visitas constantes entre parientes, amigos, compadres, fieles de la Iglesia Evangélica Unida recrean constantemente la lengua y transmiten noticias de un lugar a otro. Las relaciones de parentesco, en tanto reconocidas en líneas de descendencia legitimadas por la presencia de algún chamán o cacique, vinculan a la gente toba de La Plata con familias del Gran Buenos Aires y de la ciudad de Rosario. Las redes de parentesco llegan hasta el Barrio Toba de Resistencia y se prolongan al interior de la provincia del Chaco (Ibíd.:203) y también hacia algunas localidades de Formosa.

\section{- Objetivos y Aspectos Centrales de la Investigación}

Uno de los objetivos generales planteados para esta investigación fue contribuir al estudio de las relaciones entre lengua, cultura y sociedad desde una perspectiva interdisciplinaria y partiendo de un estudio de caso. En este sentido, han sido muchos los estudios y las teorías desarrolladas desde mediados del siglo XX que han tratado esta temática. Sus vinculaciones no son objeto de dudas; sin embargo, su abordaje ha sido diverso según la época, especialidad o corriente teórica desarrollada. Nuestra investigación implicó una búsqueda y sistematización bibliográfica y una profundización en los conocimientos en torno a los avances hechos hasta la fecha desde la Antropología Sociocultural y la Antropología Lingüística y las disciplinas afines como la Sociolingüística, Etnografía de la Comunicación, la Filosofía del Lenguaje y el Análisis del Discurso, entre otras.

La teoría no estuvo desvinculada de la práctica. Desde 1992, y a medida que profundizábamos en los conocimientos teóricos y metodológicos, comenzamos a conocer, interactuar y dialogar con los miembros de la Comunidad Toba del Barrio "Las Malvinas" de la ciudad de La Plata. Un grupo de familias indígenas, originarias del Chaco, que mantenía su lengua y su cultura, al tiempo que se iba consolidando como comunidad en torno a un proyecto común: la autoconstrucción de sus viviendas, con una organización particular: la Asociación Civil Toba Ntaunaq Nam Qom, en un espacio definido y viviendo en "la gran ciudad".

Continuando con el interés despertado por la presencia de población Toba en el medio urbano expresada en trabajos de orientación antropológica y lingüística realizados en el conurbano bonaerense (Tamagno 1986a y 1986b) y la ciudad de 
Rosario (Bigot, Rodríguez y Vázquez 1992), este estudio se propone aportar al conocimiento de la cuestión indígena, en general, y toba, en particular, incorporando al análisis la problemática de "vivir en la ciudad". El mismo analiza las prácticas socioculturales, especialmente, las prácticas discursivas, en relación con los procesos de identificación étnica y la discriminación social. Con este propósito, se profundiza en el estudio de los significados sociales (actitudes y valores) que tienen la/s lengua/s y/o códigos lingüísticos tanto para los indígenas como para el conjunto de la sociedad a la que pertenecen. Destacamos la significación de la lengua como expresión de identidad y del ser toba en la ciudad. Asimismo, indagamos en torno a los significados de hablar una lengua minoritaria y minorizada en la ciudad y sobre las prácticas de socialización, en general, y las lingüísticas en particular.

La relación establecida con nuestros interlocutores, el diálogo constante con la academia y el abordaje del estudio legislativo de la cuestión indígena, nos permitieron problematizar y reflexionar sobre la noción de interculturalidad. Un concepto hoy en boga, aunque poco discutido en el país (Ibáñez Caselli 2005), que surgió en el contexto de las experiencias educativas bilingües con y para poblaciones indígenas en sus territorios de origen. La experiencia concreta de construir conocimiento junto con la gente toba nos posibilitó la profundización de este concepto.

Finalmente, la presencia de grupos indígenas en América manteniendo y aun recreando sus lenguas y, por ende, su cultura, ha llevado a los distintos gobiernos nacionales -en menor o mayor grado- a reconsiderar, entre otros aspectos, las políticas educativas que se venían implementando hacia este sector de la población en la búsqueda de mejores resultados. Con el fin de contribuir en este sentido, nos planteamos el propósito de proyectar la reflexión y los resultados obtenidos al Sistema Educativo a los efectos de la planificación de políticas educativas que contemplen la diversidad en el aula, en general, y la problemática de los niños tobas, en particular.

Las siguientes, fueron las hipótesis más relevantes que guiaron nuestro estudio:

- Concebir el tema indígena en toda su dimensión y el dinamismo de la lengua, en particular, implica conocer no sólo las particularidades de los grupos indígenas sino también la relación que éstos tienen con la sociedad de la que forman parte (en sus lugares de origen y como migrantes en la ciudad). 
- Existe una relación dialéctica entre el logro de condiciones materiales de existencia que posibiliten lo colectivo y lo comunitario y la actualización y recreación de la lengua.

- La neutralización del prejuicio y la subestimación desde la sociedad total hacia los grupos indígenas posibilita también la generación de espacios para la actualización y recreación de la lengua como expresión de lo colectivo y lo comunitario.

- Si el discurso -tal como lo plantea Sherzer (1987/1992)- es el locus donde se expresa y actualiza la relación entre lengua/ cultura-sociedad, en el análisis del mismo deberían aparecer indicadores respecto de la articulación grupo indígena/ sociedad total.

En síntesis, este estudio presenta los resultados de una profundización teórica y metodológica en torno al análisis de la lengua y el discurso en los procesos de socialización y construcción social de la identidad, en el contexto de las relaciones interétnicas, en un caso particular: indígenas tobas migrantes en la ciudad. Los resultados contribuyen al debate general planteado para la reglamentación del Art. 75, Inciso 17 de la Constitución Nacional y sus consecuencias sobre las políticas educativas nacionales y provinciales respecto a la cuestión indígena, en particular-comprendiendo las poblaciones que viven en sus lugares de origen como así también aquellas que hoy día se encuentran en los alrededores de las grandes ciudades, producto de la migración-. En tal sentido, entendemos que son los procesos migratorios los que explican la presencia, en los centros urbanos, de diversidades en los modos de hablar que se expresan en el contexto escolar. Diversidades que no se agotan en el habla misma, sino también en modos diferentes de sentir, comprender y actuar. Dadas las características de esta situación, en relación a los procesos de identificación étnica y discriminación social, las sociedades indígenas son vistas a través de estereotipos y estigmas por la sociedad global, negando su existencia o desconociéndolas; aspecto que se refleja en el ámbito de la escuela donde se suelen instrumentar algunas políticas educativas que no contemplan tal situación y no permiten entender el problema que subyace, generándose situaciones conflictivas que los maestros no están capacitados para resolver y que, a corto plazo, llevan a la repitencia o deserción de los niños indígenas. 


\section{- Organización de los Capítulos}

El presente estudio está organizado en cinco capítulos. En este Capítulo I, El pueblo toba en el camino de la migración: su distintividad y transformaciones, se señalan los objetivos generales y los aspectos centrales que guiaron el desarrollo de esta investigación. Asimismo, se presenta al pueblo Toba en general: pasado y presente, la vida en el Chaco y los cambios producidos como resultado de la migración a otras ciudades de las provincias de Santa Fe y Buenos Aires.

El Capítulo II, Aspectos metodológicos y teóricos de la investigación, está dividido en dos partes. En la Parte 1 se describen paso a paso los modos en que se desarrolló la investigación. Una investigación que se enmarca en el trabajo etnográfico, en el diálogo intercultural con las familias tobas y con la academia. Se detalla la manera en que se empezó a construir ese diálogo intercultural y cómo éste fue creciendo, construyendo el conocimiento conjuntamente con la gente Toba de la ciudad de La Plata. Se explicitan las distintas técnicas empleadas para la recolección de los datos: el análisis de redes, el aprendizaje de la lengua toba, las encuestas y censos para el relevamiento sociolingüístico, la obtención de discursos naturales, la aproximación interdisciplinaria. En la Parte 2 se presentan los principales postulados epistemológicos que guiaron y orientaron la investigación. De este modo, entender las vinculaciones entre lengua/ cultura y sociedad, y los procesos de construcción de la identidad y etnicidad, fueron aspectos claves para el presente estudio. Como así también lo fueron todas aquellas conceptualizaciones que fueron desarrollándose en el marco de las distintas disciplinas con las cuales hemos dialogado: antropología y antropología lingüística, sociolingüística, sociología del lenguaje, pragmática, etnografía de la comunicación. Un recorrido histórico por todas ellas nos permitió comprender los distintos intereses y paradigmas de análisis que nos posibilitan la comprensión de la/s realidad/es (Helberg 2007).

El Capítulo III, Una Aproximación Etnográfica a Los Tobas del Barrio "Las Malvinas", describe el proceso de construcción del Barrio Toba "Las Malvinas" desde una visión histórica y dinámica. Caracteriza al barrio identificando las principales actividades colectivas que se desarrollan en el mismo y que conforman el contexto de los discursos públicos y privados que en él circulan. La historia de la migración de las familias tobas, teniendo como eje principal la historia de vida de su principal líder, 
permite visualizar el uso de la lengua toba y del español en cada una de las instancias de la migración.

El Capítulo IV, Recursos y Estrategias Comunicativos y Metacomunicativos en la Comunidad Toba del Barrio "Las Malvinas", describe las principales características sociolingüísticas del Barrio Toba "Las Malvinas"; se identifican los roles sociales y lingüísticos de sus hablantes y los usos que tienen los dos códigos lingüísticos en cada uno de los dominios de uso: doméstico y de parentesco, vecinal, de aprovisionamiento, tránsito; se relevan los principales recursos comunicativos y metacomunicativos del Barrio Toba, como así también las estrategias comunicativas y metacomunicativas utilizadas por sus hablantes. Para ello, se identifican las principales situaciones o eventos comunicativos que caracterizan al barrio, como así también los eventos de habla. Y se analizan distintos discursos naturales registrados en diferentes eventos comunicativos tanto en el Barrio Toba "Las Malvinas" como fuera del mismo, en situaciones intra e interétnicas.

Finalmente, en el Capítulo V, Lengua/ Identidad/ Migración: Consideraciones Finales, se presentan las conclusiones a las que ha arribado este estudio. Nuestra aproximación antropológica y sociolingüística nos permite afirmar que la lengua toba está vigente a más de $1.000 \mathrm{~km}$ de distancia del lugar de origen del pueblo Toba. Que la lengua toba fue un importante elemento de cohesión para la conformación del Barrio Toba de La Plata y tuvo un papel significativo en cada una de las etapas de la migración del Chaco a la "gran ciudad". Y que, si bien los niños y jóvenes ya no se expresan en la lengua toba, la entienden y comparten también las normas sociolingüísticas. Estos dos aspectos nos posibilitan arribar a una de las principales conclusiones, en la que planteamos que el hecho de compartir las reglas y normas sociolingüísticas, las estrategias y recursos comunicativos y metacomunicativos, y tener conocimiento de parte del léxico de la lengua toba y entender una parte de la misma, los hace formar parte de la comunidad de habla toba del Barrio "Las Malvinas" en particular y del pueblo toba en general.

\section{I.2. La Cuestión Indígena Como Política de Estado}

Analizar la relación entre lengua e identidad nos llevó a comprender los modos en que el capital cultural -y, en especial, el lingüístico- de los grupos minoritarios y/o minorizados, como lo son las poblaciones indígenas en Argentina, se produce, distribuye y consume en el mundo "moderno". Argentina es un país que se ha pensado a 
sí mismo como "blanco" y "sin indios", como un país europeo y "descendido de los barcos", y esta imagen prevalece entre nosotros y se proyecta al exterior, condicionando el modo en que somos pensados como nación. La política indigenista en los procesos de conformación del Estado-nación consistió más bien en la negación de la diversidad, la búsqueda de la asimilación e integración de aquellos que eran diferentes. No obstante, desde las dos últimas décadas nos encontramos con un avance significativo en materia legislativa para tratar la cuestión indígena, en la cual se reconoce la preexistencia de los pueblos originarios y el derecho a la tierra, la salud y a una educación bilingüe e intercultural, entre otros aspectos. ${ }^{5}$ Este avance fue hecho tanto en el plano nacional como en el de aquellas provincias que hoy cuentan con una población aborigen importante. Un análisis del contexto y el proceso histórico y social de aparición de estas leyes (Ibáñez Caselli 2004) ${ }^{6}$ permite observar que las mismas surgieron más por influencia de las políticas indigenistas internacionales y la propia organización de los pueblos originarios que por un interés político genuino de las gestiones gubernamentales enmarcado en un proyecto de país que asuma su diversidad. La intención de realizar una "reparación histórica" estuvo signada por la sobreprotección, el asistencialismo y el paternalismo (Tamagno 1996); formas éstas que no permiten soluciones concretas, ni crecimiento autónomo y propio. Y, en varias ocasiones, el acercamiento que han tenido y tienen los partidos políticos hacia las comunidades aborígenes ha sido la búsqueda de posibles votantes, y no un interés por resolver cuestiones de fondo. Es así como muchos aspectos de dicha legislación vigente aún no están reglamentados. Este hecho expresa también una tendencia dentro de la política indigenista y la atención a las comunidades; es decir, la falta o demora en la reglamentación implica desinterés por atender los derechos de los pueblos indígenas y por resolver la situación que los aqueja; siendo, a la vez, una expresión de negación de la diversidad. Además, sigue predominando en los discursos legislativos una visión culturalista y estática de las poblaciones indígenas que oculta, al mismo tiempo, las desigualdades sociales. Se reconocen las pautas culturales propias y una lengua particular y, por lo tanto, el derecho de las comunidades a "conservarlas", al tiempo que está constantemente la idea de “integración” y “castellanización” (Ibáñez Caselli 2004).

\footnotetext{
${ }^{5}$ Ver Art. 75. Inc. 17 de la Constitución Nacional de 1994.

${ }^{6}$ Tesis de maestría: "Políticas Lingüísticas e Interculturalidad: Experiencias educativas para y con indígenas tobas en Argentina” CBC-FLACSO, 2004 (Aceptada para su publicación).
} 


\section{I.3. Los Tobas: Historia y Presente}

La literatura existente en torno al conocimiento de la cultura toba es amplia y diversa. Contamos tanto con crónicas de los primeros exploradores y misioneros de la región chaqueña del siglo XVI, como con información etnográfica y lingüística de investigadores nacionales y extranjeros que a lo largo de la historia fueron realizando distintos acercamientos en diferentes zonas y comunidades de la región. En los últimos tiempos, la situación de migración de las familias tobas -asentadas en lugares distantes de los territorios de origen-y el interés por los procesos sociales urbanos en los ámbitos académicos abrió el camino a la Línea de investigación sobre "Indígenas en la ciudad" dirigida por la Dra. Liliana Tamagno- que comenzara en 1986, dentro de la cual se inserta el presente estudio. ${ }^{7}$ A continuación, exponemos una síntesis de la historia y la dinámica del pueblo toba desde los tiempos de la conquista y colonización del Chaco hasta la actualidad, para luego, en los próximos capítulos, centrarnos en nuestro caso de estudio: la Comunidad Toba del Barrio "Las Malvinas" de la ciudad de La Plata.

\section{- En el tiempo de los abuelos, en el Chaco}

Hasta el siglo XIX, el territorio que habitó la gente toba fue principalmente la región ubicada entre los ríos Pilcomayo y Bermejo en el Chaco. ${ }^{8}$ Sin embargo, hacia fines del

\footnotetext{
${ }^{7}$ Destacamos los estudios antropológicos sobre el pueblo toba realizados en el Chaco por Cordeu (1967), Cordeu - Siffredi (1971), Miller (1971, 1979, 1980, 1996, 1999), Braunstein (1983, 1990, 1992, 1999), Arias (1996); en Formosa por Wright (1985, 1988, 1994, 1997, 1999), Gordillo (1994, 1997), Citro (2003); en la ciudad de Rosario por Bigot, Rodríguez y Vázquez (1991, 1992), Bigot y Vázquez (1999),
} Bigot (2004), Arias (2005, 2006); en Capital Federal y Provincia de Buenos Aires por Mendoza (1987, 1989, 1999), Tamagno (1988 y continúa); Messineo y otros (2002-2004 y continúa).

${ }^{8}$ Desde tiempos anteriores a la conquista y colonización el pueblo Toba o Qom habitó parte de la región del Gran Chaco - vasta llanura que tiene como límites al norte la meseta del Mato Grosso, al sur la cuenca del río Salado, al oeste las estribaciones de la Cordillera de los Andes y al este los ríos Paraná y Paraguay. La región se subdivide en tres subáreas: Chaco Boreal, al norte del río Pilcomayo; Chaco Central, entre los ríos Pilcomayo y Bermejo; y Chaco Austral, al sur del río Bermejo (Miller 1979). Las dos últimas corresponden a la región chaqueña argentina conformada por las actuales provincias de Chaco, Formosa, este de Salta y norte de Santa Fe (Ver Figura No 1). El Gran Chaco cuenta con numerosos pueblos cuyas lenguas pertenecen a seis familias lingüísticas distintas (Braunstein 1992). Hay coincidencia entre los estudiosos de la lengua toba en que ésta pertenece a la familia lingüística Guaycurú. Sin embargo, son varias las clasificaciones existentes de la misma ya sea por diferencias teórico-metodológicas en el momento de interpretar los datos o por la falta de información en lenguas que ya se han extinguido (Ver 
siglo XIX, algunas "bandas" -grupos localizados de familias extensas basadas en las relaciones de parentesco y de afinidad (Miller 1999)- rondaban por los alrededores de las Provincias de Santa Fe y Santiago del Estero, motivo por el cual ha sido muy frecuente que se haya colocado como límite sur al río Salado. Al final del siglo XVIII, algunas bandas tobas se dirigieron hacia el norte del Pilcomayo, llegando hasta el Chaco paraguayo y boliviano (Métraux 1946; Klein 1981).

Al igual que la mayoría de los pueblos que habitaron la región chaqueña, el pueblo Toba tuvo una economía caracterizada por la caza, la pesca y la recolección, practicando un estilo de vida nómada limitada y estacionaria. Las bandas constituían la unidad básica de la organización social. Un conjunto de bandas aliadas entre sí identificadas por una misma denominación y asociadas por lazos matrimoniales y de intercambio- o "tribus" (Braunstein 1983), se iban desplazando por un territorio determinado de manera cíclica, recorriendo los distintos espacios según los recursos que se pudieran obtener, acorde con las estaciones del año. ${ }^{9}$ De este modo, la movilidad dependía de la predisposición de mayor caza de un determinado animal, de la época de la pesca, de la recolección de la algarroba, etc. Distintos trabajos de antropólogos y lingüistas (Miller 1979; Braunstein y Wright 1990; Censabella 1999a, 1999b; Messineo 2000) concuerdan en pensar que las parcialidades que conformaban el pueblo toba presentaban distintas variaciones dialectales. Cada una de estas parcialidades tenía nombres de animales o de actividades o habilidades por las que se destacaban los miembros de esos grupos. Asimismo, estas apreciaciones coinciden con los relatos de nuestros interlocutores tobas al sostener que hay diferencias, por ejemplo, en las formas de hablar de los tobas del este con los del oeste:

“...dentro del pueblo toba había muchas regiones. Dentro de estas regiones estaban los la'añaxashecpi, los teguesanpi, los exaxaipi, los pioxotpi... ${ }^{10}$ eran grupos que hablaban el mismo idioma pero que cada uno le daba un final [sufijos] distinto... Entonces, de acuerdo a cada región que ellos vivían se daban los nombres. Los subgrupos dentro del mismo [lengua] toba, y dentro de cada subgrupo, le daban una terminología distinta o un final o un comienzo distinto a una cosa, iy se notaba a la legua! Porque los de Castelli

Tovar 1961; Loukotka 1968; Greenberg 1987a y 1987b; Tovar y Tovar 1984; Klein 1981; Kaufman 1990; Viegas Barros 1993; Censabella 1996; Messineo 2000; Bigot 2004).

9 Práctica que podemos interpretar relacionada con los conocimientos que los pueblos cazadores y recolectores poseían del medio ambiente lo que les permitía no sobre explotarlo (Guevara 2007).

${ }^{10}$ Cabe aclarar que la grafía utilizada en este testimonio es la ofrecida por la misma hablante. 
no hablan igual que los de Sáenz Peña y menos con los de Resistencia. Se notaba la diferencia." (Testimonio JG - 1993) ${ }^{11},{ }^{12}$.

Las actividades económicas consistían en trabajos particulares según el sexo. Así, los hombres (so ỹalepi), en grupo, se dedicaban a la caza de algunos sheguiacpi' (animales) tales como koz (chancho del monte), huaxaỹaxa' (zorro gris), soxona' (conejo), mañiq (ñandú), quishoq (puma), potaxanaxat (tortuga), tapineq (tatú mulita) y otros; a la pesca del nallen (tararira), sa'ashenaq (dorado), chelmeq (surubí), poxosoxoỹ (cascarudo), potai' (anguila), cote' (palometa), etc.

“...qalo'otá'. Qalo'ota' so qom. Era mucha la gente. So'oche qom qomla'a. La gente antigua. Ten qa'alota. Dicen que era mucha. Añaxaipi, ataxanaipi, epia'axanaipi. Eran hombres fuertes, muchachos valientes y que buscaban..., iban al monte a cazar, mariscadores eran..." [Testimonio JG - 1993]

Las mujeres (alole'pi) cuidaban de sus hijos (ñaqpiole'pi), realizaban las tareas domésticas y recolectaban frutos, raíces y animales más pequeños:

"En tiempo de algarroba todas las mujeres traen, se van al monte traen... cuando iban a mariscar, dicen que se iban bien temprano y se volvían a la tardecita, siempre en grupo, nunca de dos o tres, siempre cuatro o cinco o más; cuando buscaban esa frutita del bosque ca'llecte ${ }^{13}$ para hacer la qotaqui o yica ${ }^{14} . .$. y todas las mujeres van, juntas, en grupo siempre y van a buscar para sacar el hilo...Van las mujeres mayores, pero [éstas] les enseñan a la chicas jóvenes para que ellas aprendan, porque hay muchas mujeres que ya son, vamos a decir que viejas, y dicen que porque nosotros no vamos a estar, llegará el momento que termina nuestra vida y se quedan ustedes. Por eso es que ustedes tienen que aprender a hacer las cosas. Y asi fue. Entonces todas las chicas se van juntas cuando

${ }^{11}$ Messineo $(1989,2000)$ delimita cuatro áreas etnodialectales tobas: 1) Área noroccidental (NO) que coincide con la variedad hablada por quienes se adscriben como ra pigem l'ek; 2) Área centro-norte (CN) que correspondería al subgrupo de los no’olGaGanaq; 3) Área centro-sur (CS) que comprendería a los l'añagashek; y 4) Área sudoriental (SO), próximo a Las Palmas en el Chaco y se extiende a Formosa, donde se encontrarían los takshek. Sin embargo, postula para las lenguas guaycurúes la hipótesis de las cadenas dialectales; es decir, la existencia de un continuum de variedades en el que sucesivos eslabones, geográficamente contiguos, presentan distintos grados de inteligibilidad.

${ }^{12} \mathrm{Si}$ bien estas parcialidades hoy no se mantienen con la misma claridad que en el pasado, siguen siendo coordenadas de referencia cuando se habla de lazos matrimoniales y deberían tenerse en cuenta al momento de arbitrar políticas sociales y especialmente educativas.

${ }^{13}$ Se refiere a la planta del chaguar cuyas fibras son empleadas para la realización de pequeños bolsos, redes y, en la actualidad, vestimenta.

${ }^{14}$ Bolsa tejida de fibra de chaguar. 
se van las mujeres grandes así aprenden. Bueno, yo aprendí así cuando estaba..., cuando era joven, estaba mi mamá y mi abuelita, viejita también”. [Testimonio de CR - 1993]

La recolección de te'esaq (miel $)^{15}$-alimento y golosina principal de este pueblo- era tarea de hombres. Se practicó un tipo de agricultura incipiente en aquellas regiones que eran favorables para el cultivo; los principales fueron maíz, mandioca, calabaza, poroto, sandía, zapallo, tabaco, algodón y caña de azúcar, empleando como instrumento el palo de cavar o pala de madera (Métraux 1946).

Según estudios etnográficos había dos grandes valores que dominaban la vida de esta sociedad: el mantenimiento de un cierto equilibrio entre el hombre y la naturaleza, y el interés por el bienestar de los parientes. El primero estaba en manos de los pioxonaqpi, sujetos que cumplían con la función del chamanismo y que, en consecuencia, podían establecer comunicación constante con los seres y poderes espirituales; el segundo, relacionado con una serie de reglas o normas que los integrantes de esta sociedad debían cumplir para que ese equilibrio no se rompiera (Miller 1979). Tales reglas y normas estaban sustentadas por algunos tabúes alimenticios destinados a ser cumplidos por ambos sexos: no comer determinados animales antes de salir a cazar, o cuando la mujer estaba embarazada; restricciones para la mujer durante su período de menstruación, etc.

A diferencia de otras regiones del país, la conquista y colonización efectiva de la región chaqueña fue tardía. No obstante, el contacto de los tobas con la sociedad occidental fue constante desde el siglo XVI a través de la presencia de los primeros exploradores, soldados, colonos y misioneros que fueron llegando al Chaco con distintos intereses. A lo largo de los siglos XVI y XVII la incorporación del caballo traído por los españoles trajo como consecuencia importantes cambios en la organización social, política y económica de los pueblos autóctonos, y en particular de los tobas. Este hecho les posibilitaría dominar a grupos vecinos, adquiriendo estrategias de guerra efectivas y expansión de sus territorios. El malón constituyó una empresa colectiva, política y económica que desarrollaron estos pueblos, en especial, contra los poblados asentados en las fronteras. Las ciudadelas españolas fundadas en las cercanías de estas líneas fueron "atacadas" mediante los malones. ${ }^{16}$ De esta manera, la política

\footnotetext{
${ }^{15}$ En realidad, en la lengua toba no existe una palabra genérica que se refiera a miel como en español. Hay varias palabras para nombrarla de acuerdo con la abeja que la produce, la consistencia de la misma, etc. (Zacarías 1995).

16 Ver Métraux (1944); Kersten (1968); Cordeu-Siffredi (1971); Miller (1979); Fuscaldo (1987); Mandrini (1987).
} 
hacia los pueblos indígenas que predominó a lo largo de los siglos XVII, XVIII y, en especial, XIX, consistió en establecer pactos y alianzas con estas poblaciones nativas para "mantener en paz" las fronteras.

Hacia fines del siglo XIX y comienzos del XX, el pueblo Toba sufrió profundas alteraciones en sus condiciones materiales de existencia. Hasta 1870, la región chaqueña aún permanecía como territorio "libre", mientras se iban consolidando las fronteras nacionales mediante algunos enfrentamientos, acuerdos y tratados con los nativos, que permitieron la construcción de caminos y ciudades fortificadas. Sin embargo, al culminar la guerra sostenida con Paraguay, el gobierno nacional puso sus miras en esta región. Los ataques a los principales caciques se hicieron más constantes, organizándose verdaderas expediciones para tal fin, equivalentes al plan de desgaste preliminar llevado a cabo en Pampa y Patagonia (Martínez Sarasola 1992:300) que culminó en 1879 con la denominada "Campaña al Desierto" al mando del General Roca. En el Chaco, las acciones militares concluyeron con la expedición del General Victorica en 1884. Como resultado de estas operaciones, los pueblos nativos sufrieron dispersión y arrinconamiento, despojo, enfermedades, muertes; perdiendo por muerte o prisión a sus principales líderes. Por su parte, la nación incorporó esos territorios y por decreto subdividió la región en dos territorios nacionales: Formosa y Chaco. Los abuelos prácticamente no quieren hablar de esos tiempos de tanto sufrimiento y dolor. Muchas familias aborígenes se internaron en el monte huyendo de los soldados, varios murieron y otros fueron reducidos en colonias. Los territorios de caza, pesca y recolección fueron alambrados y restringidos.

Los enfrentamientos con la sociedad dominante no terminaron con esa campaña militar. La región chaqueña se fue poblando de colonos extranjeros que fueron tomando posesión de las tierras y el Estado comenzó a desarrollar una política agroganadera. Asimismo, se fueron instalando en la región el ferrocarril, los ingenios azucareros y las empresas forestales para la explotación del quebracho. Además, los obrajes, zafras e ingenios que se habían desarrollado en las provincias vecinas, junto con los que comenzaron a surgir en estos nuevos territorios nacionales, consideraron la incorporación compulsiva de los nativos a las nacientes actividades económicas de la región como mano de obra barata (Teruel 1999; Trinchero 2000; Tamagno 2001; Rodríguez Mir 2006). Entre 1906 y 1947 los tobas manifestaron fuertes muestras de 
rechazo a esta nueva situación siendo violentamente reprimidos ${ }^{17}$-acontecimientos que se mantienen muy vivos en la memoria de la gente indígena-. La población nativa perdió la posibilidad de usar libremente las tierras que ocupaban y se vio obligada a convertirse en peones rurales, trabajando en la carpida y cosecha del algodón, en la zafra y los trapiches, y como hacheros. ${ }^{18}$ Estos trabajos eran temporarios y poco seguros, puesto que un período de sequía o de mucha lluvia hacía peligrar la producción; $y$, además, la paga era poca.

Los pueblos originarios fueron sometidos a una situación de explotación, despojo y miseria en un contexto de fuertes actitudes discriminatorias por parte de los diferentes sectores de la sociedad en el ámbito laboral, comercial, político e, incluso, en el educativo. Muchos se convirtieron, en "trabajadores golondrinas" migrando estacionalmente por distintas regiones de la provincia del Chaco y por las otras provincias del norte argentino.

\section{- La migración a la gran ciudad}

Conforme se daba el avance de las fronteras: el alambrado, la tala del monte, la producción agrícola y el pastoreo privaron al pueblo Toba del uso de sus tierras y, por lo tanto, de su capacidad de desarrollarse en base a sus formas tradicionales. Muchas familias fueron arrinconadas y confinadas a otras poco productivas y de fácil inundación; y esto motivó, entre otras cosas, la búsqueda de mejores condiciones de vida en la ciudad. Primero hacia las ciudades o poblados principales de la región como J. José Castelli, Gral. San Martín, Roque Sáenz Peña y Resistencia, en la Provincia del Chaco, y la ciudad de Formosa en la Provincia homónima. Y, luego, hacia las ciudades

\footnotetext{
${ }^{17}$ Las matanzas fueron el resultado de importantes movilizaciones de familias tobas hacia diferentes localidades del Chaco (Napalpí 1924, El Zapallar 1933, Pampa del Indio 1935) y de Formosa (Las Lomitas 1947) -en un contexto de disconformidad ante las carencias y situación de explotación, entre otras cosas- y guiadas por líderes-chamanes a los que se les atribuían ciertos poderes y pregonaban la llegada de un cambio inminente, un nuevo orden social. Estos hechos fueron analizados por algunos especialistas, los cuales ofrecen distintas interpretaciones: "los últimos intentos chamánicos por restablecer la armonía" (Miller 1979) o "movimientos de tipo milenaristas y mesiánicos" (Bartolomé 1972; Cordeu 1969-70; Cordeu y Siffredi 1971; Fuscaldo 1982) o "respuestas socio-religiosas" (Tamagno 2000, 2001, 2004).

${ }^{18}$ En la memoria de la gente toba muchas de sus vivencias están vinculadas con algunos de estos sucesos históricos. Los mismos han sido analizados en los trabajos de Iñigo Carrera (1983); Pivetta (1999); y Tamagno (2001, 2003), entre otros.
} 
de Rosario (Provincia de Santa Fe) y el conurbano de la ciudad de Buenos Aires (Ver Figura $\mathrm{N}^{\mathrm{o}} 2$ ). Cabe aclarar que estas migraciones no fueron exclusivas de los Tobas. A partir de la segunda mitad del siglo XX, migrantes internos -pobres y empobrecidosllegaron a las grandes ciudades expulsados por la transformación de los modos de producción en el campo y por los requerimientos de mano de obra en la industria.

Con el tiempo, alrededor de las ciudades y poblados de la región chaqueña se fueron conformando distintos asentamientos o barrios indígenas. En la provincia del Chaco, los primeros barrios se empezaron a conformar hacia fines de la década de 1950 en ciudades como Roque Sáenz Peña, Castelli, Resistencia, Las Palmas (Wright 1999) (Ver Figura $\mathrm{N}^{\mathrm{o}}$ 3). En la ciudad de Resistencia, la presencia de familias tobas en las afueras de la ciudad, ubicadas en las vías del ferrocarril en desuso, llevó a las autoridades del municipio, junto con el apoyo de la Cruz Roja, a construir un plan de viviendas para aproximadamente 220 familias. Las viviendas fueron entregadas entre 1972 y 1973, dando origen al "Barrio Toba Cacique Taixoshí" (Comunicación personal J. Gómez 2000) (Ver Figura $N^{\circ}$ 4). El mismo hecho se registra hacia la década de 1970 en algunas ciudades de la provincia de Formosa como El Colorado, Clorinda y Formosa capital (Ver Figura $\mathrm{N}^{\mathrm{o}}$ 3). En esta última, el barrio toba se encuentra en el Lote 68 donde numerosas familias tobas han contado con un plan de viviendas del municipio. Cada uno de los barrios consta con la presencia de una escuela primaria a la que asisten, en su mayoría, niños tobas.

Más allá del lugar de origen, según los relatos de los propios protagonistas, hacia la década de los años ' 40 y '50 arribaron los primeros jefes de familias a la zona portuaria de Buenos Aires (Dock Sur y Talar de Pacheco). En tanto que la primera corriente migratoria de familias tobas a la ciudad de Rosario se registra hacia 1968 (Bigot, Rodríguez y Vázquez 1992; Garbulsky 1994; Pivetta 1999; Bigot 2004; Arias 2005). En ambos casos, las razones por las cuales se opta por esta acción son coincidentes: se migra por necesidad, por la falta de trabajo, por la búsqueda de una mejor capacitación para sus hijos. En definitiva, se decide emprender la marcha hacia la ciudad buscando mejores condiciones de vida. La migración ha sido constante incrementándose en los últimos años. ${ }^{19} \mathrm{Y}$ una vez instalados en la ciudad, una característica ha sido la de

\footnotetext{
${ }^{19}$ Las migraciones chaqueñas hacia las ciudades de Rosario y Buenos Aires aumentaron en las últimas décadas debido a la crisis de la industria algodonera de baja capacidad de capitalización y muy
} 
buscarse y tratar de vivir todos juntos, no perder los lazos de parentesco, vecindad y comunitarios:

“...hay que buscar la forma de sobrevivir, ¿no? entonces se van [del Chaco]. Y hay mucha gente que está conectada con gente que ya estuvieron, entonces por comentarios si le gusta... Ahora por más razones porque en el Chaco no hay nada, no hay ayuda ni para los colonos [no indígenas], no hay ni en la misma ciudad no hay trabajo entonces se van..."

“...Nosotros salíamos de Sáenz Peña y llegábamos en camión [a la cosecha de algodón], salíamos a las 5 de la mañana y hasta que llegábamos... pero termina ahí, y no hay nada... porque la necesidad es lo que hace pensar porque algunos no tienen 3 ó 4 hijos, sino 5 ó 6, 7 hijos y buscan la forma, se vienen solos tal vez y después cuando resuelven un poco el problema arranca toda la familia y se vienen..." (Testimonio LM, 2000)

En cuanto al tamaño de la población toba, las cifras con las que contamos son relativas. De acuerdo con el estudio realizado por ENDEPA (1987), se estima una población aproximada de 60.000 habitantes tobas, sin contar los que han migrado de su lugar de origen y que se encuentran dispersos por el territorio nacional. Según Pivetta (1999) en un primer momento la presencia de familias tobas en la ciudad de Rosario fue inadvertida para la mayoría de la población rosarina. Esta situación comenzaría a cambiar a partir de 1983, año en que llegan numerosas familias instalándose en la zona de Empalme Graneros (noroeste de la ciudad) sobre terrenos aledaños a las vías del ferrocarril, y en tierras públicas de Villa Banana y Cerrito al $4000{ }^{20}$ En 1991, la municipalidad rosarina elabora el "Proyecto de Relocalización Toba" y adjudica viviendas constituyéndose el barrio conocido con el nombre Barrio Toba de Rouillón, donde habitan 315 familias aproximadamente. Según estudios realizados, en 1998 la ciudad de Rosario albergaba 824 familias tobas repartidas en nueve asentamientos o barrios, estimándose una población de 5800 tobas (Censabella 1999:74-75). Tanto en el

dependiente del mercado externo, agravado por la inundación de los campos (Pivetta 1999:43). La migración interna hacia el Gran Buenos Aires es analizada por Tamagno (2001).

${ }^{20}$ Respecto del Barrio Empalme Graneros de Rosario, entre 2002 y 2003 los datos censales obtenidos por Arias (2005) arrojaron, sobre un total de 146 viviendas de los doce lotes en que fue dividido el sector emplazado entre las calles Juan José Paso, Travesía y Almafuerte, la cantidad de 186 familias, compuestas por 13 familias mononucleares, 103 nucleares y 30 extensas. La cantidad de personas censadas ascendió a 736. En cuanto al sexo de las personas, los varones superaban a las mujeres en apenas el $3.7 \%$. 
barrio de Rouillón como en ex Empalme Graneros, la comunidad logró con mucho esfuerzo la creación de una escuela para sus hijos (Ver Figura $\mathrm{N}^{\mathrm{o}} 5$ ).

En el conurbano bonaerense las familias tobas se fueron ubicando en distintas localidades tales como Ciudadela, General Pacheco, Villa IAPI, Lanús, Dock Sur nucleamientos más antiguos que ocupan tierras fiscales. Los más recientes se encuentran en la ciudad de La Plata (capital de la provincia de Buenos Aires) y en Derqui. Estos dos últimos casos son diferentes a los demás, puesto que las familias consiguieron tierras $\mathrm{y}$, por medio de planes de autoconstrucción de viviendas, se constituyeron en barrios organizados (Ver Figura $\mathrm{N}^{\mathrm{o}} 2$ ).

Otro elemento que caracteriza a estos nucleamientos es la organización de diferentes asociaciones civiles con personería jurídica, siendo el objetivo principal la lucha por la tierra, puesto que las tierras que ocupan son fiscales; las viviendas son precarias y se encuentran dispersas. Los casos de excepción son el Barrio Toba "Daviaxaiqui" de Derqui (partido de Pilar) y el Barrio Toba "Las Malvinas" de la ciudad de La Plata, este último organizado a través de la Asociación Civil Toba Ntaunaq Nam Qom. ${ }^{21}$

“...no es fácil, yo siempre digo tener primero el lugar, a donde tiene que estar la gente ... pero así como estamos viviendo ahora no se puede... Pero donde están ustedes [La Plata], están en lugar donde ya tienen su terreno, en su casita, entonces es más cómodo, es más cómodo trabajar así. En cambio nosotros no podemos trabajar así, porque todavía estamos todos divididos [separados], un poco allá, otro poco allá, entonces no podemos así..." (Testimonio RG - 2000)

“...Nosotros tenemos la ventaja que como grupo organizado la municipalidad nos donó las tierras, no pagamos impuestos, no pagamos nada por la tierra. Tenemos muchos beneficios. Tenemos un comedor donde comen 110 chicos, tenemos una huerta que estamos trabajando despacito...” (Testimonio JG - 2000)

Además, la ausencia de un trabajo seguro y permanente constituye una gran preocupación. Los hombres trabajan en la construcción, en la venta de artesanías y en algunas "changas" - trabajos temporarios-y algunas mujeres en trabajos domésticos, pero apenas alcanza para sobrevivir dada la situación económica de los últimos años del país. En La Plata llegaron a organizarse aportando su trabajo en un comedor infantil y

\footnotetext{
${ }^{21}$ La historia de este barrio se presenta en el capítulo III. En los últimos años se han conformado otros nucleamientos en los alrededores de la ciudad de La Plata que se encuentran cercanos al mismo, siendo aproximadamente 100 familias tobas las asentadas de manera precaria.
} 
en una huerta comunitaria que han sido subvencionados con el apoyo de los "Planes Trabajar" y la Municipalidad de La Plata, y a principios del año 2007 se ha logrado finalmente poner en marcha un proyecto de panadería que estaba planteado desde larga data.

Cada uno de estos nucleamientos cuenta con dos o tres escuelas en sus cercanías, a las que asisten los niños tobas y el resto de los niños no-tobas vecinos -hijos de familias también migrantes tanto internos como externos (principalmente, bolivianos, peruanos y paraguayos)-. En algunos casos, se dieron algunos esfuerzos por enviar a todos los niños de la comunidad a una misma escuela. ${ }^{22}$

\section{- Vivir en la ciudad}

A pesar de vivir lejos del lugar de origen, el "vivir en la ciudad" no significó olvidar los orígenes, la lengua, la historia, la cultura; "hubo que adaptarse, pero sin olvidar". Tradicionalmente eran los abuelos los encargados de transmitir el origen y la historia del pueblo toba. Ellos han difundido la lengua, los cuentos, los relatos; eran los guías; adoctrinaron el respeto hacia los mayores, hacia los demás, a ser solidarios, a vivir de modo comunitario, a trabajar todos juntos; enseñaron a respetar la naturaleza y a conocerla e interpretar sus señales; como así también las técnicas de caza y pesca y a cazar sólo lo necesario; trasmitieron conocimientos medicinales y prácticas de cura; hacían obedecer las reglas, vigilaban las prohibiciones y hacían respetar los tabúes y las formas de elegir a los caciques. Instruyeron también en el arte del trabajo con la cerámica y los tejidos de totora, palma y chaguar; en la música, la danza y los deportes. Para trasmitir todo este conocimiento, por un lado, los abuelos ofrecían por las noches, reunidos alrededor del fuego, largas charlas en la lengua toba a través de las cuales contaban los cuentos y daban consejos. Por otro, los niños aprendían jugando, imitando a sus mayores, observando y haciendo las cosas desde muy pequeños. Hoy, trasmitir y poner en práctica todas esas enseñanzas en la ciudad resulta difícil. En muchos casos ya no se cuenta con los abuelos, pero igual los padres tratan de conversar con sus hijos y contarles lo que les contaron sus mayores; les hablan del Chaco, del monte y del río, de cómo cazar y pescar; de cómo interpretar la naturaleza y estar en contacto con ella; de las cosas que se podían hacer y aquellas que estaban prohibidas; de la historia del pueblo toba y de los caciques; de la lucha actual. De manera tal que gran parte de los

\footnotetext{
${ }^{22}$ Sin embargo, las dificultades económicas y los problemas de matrícula no permitieron experiencias exitosas, al menos este fue el caso en el Barrio Toba "Las Malvinas".
} 
conocimientos y pautas culturales se siguen trasmitiendo en el proceso de enseñanzaaprendizaje:

“...[trato de enseñar el idioma] al menos eso intento, las artesanías también... Por ejemplo en mi caso particular, le participo a mi hija de la lucha, cuando hay una marcha le llevo, participa, es chiquita pero yo trato de que de alguna manera se vaya identificando, que sepa que es indigena...y seguir luchando por su pueblo en el día de mañana. Eso en mi caso particular. En el barrio también, a los jóvenes les enseñamos a ser líderes si hay alguien que se destaque..." (Testimonio JG - 2000)

La artesanía se continúa haciendo y los niños aprenden mirando a los padres. No obstante, el contexto urbano es muy diferente a la región chaqueña. Además, muchos niños han nacido ya en la Provincia de Buenos Aires y no conocen las Provincias de Chaco y Formosa; no conocen el monte ni el río. Es muy difícil obtener los materiales necesarios para elaborar la cerámica y los tejidos. No obstante, algunas de las prácticas tradicionales del pueblo toba se siguen reproduciendo en la ciudad, muchas de ellas han sido resignificadas y se han incorporado otras nuevas.

Vivir en esta gran ciudad implicó adaptarse a otros tiempos, otros ritmos, otras necesidades, otro trato con los vecinos, otra forma de hablar, otro vocabulario - diferente aun para los que vienen hablando español- y, en algunos casos, dejar de hablar la lengua y negar su identidad indígena.

“...cuando yo vine [a la ciudad] me sentí encarcelado, hay que adaptarse a una especie de encarcelamiento... a veces me siento invadido, como que uno no tiene aire... yo cuando llegué del Chaco pensaba que era todo igual y no es así. Yo pensaba que mi vecino era mi familia y no era así. A veces no es así. En el norte es como una gran familia, no quiere decir que va a hacer lo que quiere sino que es una confianza, y a veces la confianza no hay que pasar más allá. Para nosotros mantener la confianza, no pasar más allá. Ese es mi lema, mi modo de vivir, de ver la vida. Y en cuanto al trabajo también, para mí el trabajo es lo principal, pero hay que adaptarlo. Acá una vez me dijo, porque cuando empecé a trabajar me mandaban por todos lados. Entonces decía uno, yo decía a todos señores, así como respeto y uno me dice:- mirá, acá para andar bien, hay que atropellar a la gente - decía uno-claro, porque si vos sos bueno, u obediente, vos sos tonto. Entonces hay que adaptar a ello y ahi empieza la, una cultura totalmente cambiada. Pero no dejar de ser indígena sino que la cultura también, el modo de pensamiento..." (Testimonio EF - 2000). 
“...Encontramos dificultades en cuanto a vivir de acuerdo y con nuestra cultura, por las diferencias y las influencias. La cultura de los invasores reprime la cultura del pueblo toba..." (Testimonio TA - 2000)

En la ciudad se emplean otros códigos, otro vocabulario y otra forma de hablar. El español que se habla en Buenos Aires es diferente al que se emplea en el noreste del país. En este sentido, las familias tobas también se enfrentan con este otro desafío, manejar otros significados y encontrar los modos de expresión corrientes en el nuevo medio. Sin embargo, las influencias de la televisión y de los vecinos han hecho que los niños y los jóvenes adquieran, en algunos casos, este modismo, "el hablar aporteñado", o que suelan mal interpretar algunas palabras considerándolas como un insulto, lo que motiva enfrentamientos con los vecinos.

Son muchos los obstáculos que las familias tobas deben enfrentar día a día en la gran ciudad: discriminación, prejuicio, negación, vergüenza, estigmatización, falta de un espacio propio, dispersión, maltrato; tanto en lo laboral, como entre los vecinos y en la escuela. Sobre todo, en los asentamientos de Dock Sur y Villa IAPI donde las familias se encuentran más dispersas y donde la vida es más violenta. Se los discrimina por ser "indios", "cabecitas negras", por su apariencia y modo de hablar. Es por este motivo que muchos padres sienten temor de que sus hijos se identifiquen como toba, como aborigen, en la escuela, y no han querido enseñarles la lengua. Y ésta también es una gran carga que se ha traído de las provincias del noreste:

“...hay como 20, 30 niños que van a la misma escuela, pero nunca se identificaron como toba... muchas veces por temor de los padres, por el temor, por ahi... Lo que pasa es que a veces... pasa en el norte, que muchas veces mandan los chicos al colegio y por ser indigena no los reciben, dicen que no hay lugar. Siempre hay un argumento bien planteado, bien argumentado, bien pensado en contra del indígena y al escuchar el maestro dice: -no hay más lugar-, y no es así. Es bien argumentado... ¿Qué dirá el director [en Buenos Aires]? Ahi hay que ver...” (Testimonio EF - 2000)

Es un tanto diferente el caso de La Plata. El hecho de estar ya establecidos en un lugar, tener un terreno y una casa propios les ha permitido mantener un buen diálogo con los vecinos, hacerse respetar sin negar su identidad, e incluso tratar de acercar sus conocimientos, principios y modo de vida, brindando ayuda a quien la necesite:

“...en La Plata donde vivimos hay mucho respeto, ahora no sentimos esa discriminación. A todos lados donde fuimos nos han tratado muy bien, de hecho, nosotros también. Pero 
hay vecinos platenses que te dicen:-iay, indios! ¿pero en serio?-, -Si, yo vivo ahí, yo soy de la comunidad toba-. Siempre así, pero inclusive por los gubernamentales y todo eso, también mucho por la asociación se conoce gente, pero ahora, gracias a Dios, en ese sentido nos hemos manejado muy bien. Tanto en la escuela como la sociedad... Los vecinos, cuando quieren saber cómo hicimos para conseguir esto o lo otro, nos consultan" (Testimonio JG - 2000)

Atendiendo al hecho ya mostrado a lo largo de la línea de investigación no se debe pensar al pueblo Toba como un todo homogéneo. La migración y las transformaciones sufridas hacen que las familias que lo conforman presenten características particulares, de acuerdo con el lugar que habitan y sus distintas trayectorias sociohistóricas vividas. La situación sociolingüística, por lo tanto, también es diferente en cada localidad. En las localidades rurales del Chaco predomina el monolingüismo en lengua toba -donde la poca necesidad de hablar el castellano favorece la transmisión intergeneracional de la lengua vernácula; en tanto que, en la ciudad, el contacto con las fuentes de trabajo, la escuela y otros ámbitos la mayoría de los hablantes son bilingües. Además, si bien algunos niños y jóvenes no suelen hablar ya la lengua, muchos la entienden siendo semi-hablantes o presentan un bilingüismo casi pasivo ${ }^{23}$ (Ibáñez Caselli 1997, 2004; Messineo 2000). En cada región, la vitalidad de la lengua materna depende del tipo de articulación que las comunidades han tenido históricamente con la sociedad dominante. A lo largo de la historia, la explotación, el despojo y la miseria fueron legitimando estigmas y estereotipos en el contexto de la sociedad nacional que han originado situaciones de discriminación, negación y exclusión. En algunos casos, los mecanismos que ponen en funcionamiento tales estereotipos han obligado a negar su identidad ante la señalización negativa y no transmitir la lengua a sus hijos.

\footnotetext{
${ }^{23}$ Entendemos como semi-hablantes a aquellos hablantes cuyo español es fluido y hablan la lengua toba con dificultad, aunque la comprenden; en tanto que los bilingües casi pasivos son hablantes fluidos del español, que solamente entienden y conocen sólo parte del léxico toba, pero no pueden conversar en esta lengua.
} 


\section{Capítulo II}

\section{Aspectos Metodológicos y Teóricos Generales de la INVESTIGACIÓN}

En los últimos años, se han hecho frecuentes los debates metodológicos y políticos de la ciencia antropológica evidenciándose una tendencia hacia el análisis epistemológico de los textos antropológicos. Esta corriente, nacida en los Estados Unidos de América, pone en duda la producción etnográfica, cuestiona cuán fidedigna puede ser la información presentada por los etnógrafos y de quién es la voz que aparece en el relato etnográfico, y exalta las múltiples interferencias de la subjetividad del investigador en las descripciones. Es debido a estos señalamientos que algunos seguidores de esta corriente han orientado su trabajo a hacer "etnografías de la narrativa antropológica". ${ }^{24}$ Por el contrario, nuestra investigación parte de una reivindicación de la etnografía, entendida no sólo como "la actitud descriptiva de la ciencia del hombre" (Malinowski [1922] 1973; Nadel 1974; Conklin 1975), "el primer paso de una investigación antropológica" (Lévi-Strauss ([1961] 1984) o como el aspecto de la antropología que dio originalidad y valor científico a esta disciplina, sino como una parte constituyente y clave del quehacer antropológico. Una experiencia en donde, al recolectar datos, la teoría y la práctica dialogan y se retroalimentan. En este sentido, la investigación etnográfica concebida como un encuentro con el "otro" es constitutiva de la producción del conocimiento de la disciplina. Y es en el trabajo etnográfico donde esa retroalimentación entre teoría y práctica -que constituye el procedimiento básico del conocimiento científico en general- se hace explícita. Además, la investigación etnográfica resulta un medio de auto-reflexión puesto que el observador es parte

\footnotetext{
${ }^{24}$ Con respecto a un análisis reflexivo de la producción etnográfica podemos destacar el trabajo de Edward Bruner (1986), entre otros, cuyo propósito es entender la etnografía como discurso, como un género de la narrativa; y, aunque con estilos diferentes, el de Nigel Barley ([1983] 1989) y Paul Rabinow (1992) en los que se pretende plantear y comprender el propio proceso de investigación a través de una reflexión crítica de los modos y las condiciones en que se produce el saber en la disciplina.
} 
integrante del proceso de conocimiento y descubrimiento. Es por eso que se dice que en la antropología no existe el "hecho social", sino "hechos etnográficos". 25

En suma, consideramos que el trabajo de campo constituye la experiencia a partir de la cual se organiza la antropología. El mismo implica tanto el manejo de un conocimiento preciso - metodología, técnicas y teorías propias de la disciplina-, como el establecimiento de un tipo de relación especial con los interlocutores. De modo que "lo que un antropólogo declara haber hallado en el campo está condicionado por lo que se ha dicho o no previamente sobre ese lugar, por las relaciones que establece con el grupo que estudia y con diferentes sectores del mismo, por lo que quiere demostrar-sobre ese grupo y sobre sí mismo- a la comunidad académica para la cual escribe, por su posición (dominante o pretendiente) en el campo antropológico, por el manejo más o menos hábil de las tácticas discursivas con que puede lograr todo eso" (García Canclini 1991:59). Hacer explícitas las condiciones en que se desarrolló dicha experiencia ayuda a entender la relación etnográfica como una perspectiva doble, en donde la posición del investigador - personalidad, formación académica, principios, valores, estados de ánimo, prejuicios, etc.- influye sobre las posibles respuestas que obtenga de su interlocutor y viceversa (Panoff y Panoff 1975).

En este capítulo se presenta el perfil general de la investigación: el "antes" y el "durante" del proceso de investigación. En la primera parte, se explicitan los modos en que se fue recortando y construyendo el objeto de estudio y de qué manera se fue dialogando con nuestros interlocutores. Proceso éste orientado a la "producción de conocimiento conjunto" con la gente Toba del Barrio "Las Malvinas". De este modo, se deja en claro cuáles fueron los principios metodológicos y las técnicas empleadas durante el trabajo de recolección e interpretación de los datos, como así también los obstáculos epistemológicos encontrados y las estrategias utilizadas para superarlos. En la segunda parte, se realiza un recorrido por los principales conceptos y desarrollos teóricos que guiaron la investigación y que nos permitieron entender la dinámica de la lengua en la sociedad, los procesos sociales de construcción de la identidad y sus vinculaciones.

\footnotetext{
${ }^{25}$ Ver Peirano (1995).
} 


\section{Capítulo II}

\section{PARTE 1}

\section{Principios Metodológicos y Estrategias de CAMPo}

\section{II.1.1. Los Pasos en la Investigación y la Construcción del ObJeto de ESTUDIO}

Nuestro interés y preocupación por indagar en los temas de la lengua y la identidad en los procesos de contactos interétnicos nos llevaron, un día del año 1992, a conocer al grupo de familias tobas ubicado en las afueras de la ciudad de La Plata, provincia de Buenos Aires. ${ }^{26}$ Un barrio que se encontraba en plena construcción. Sólo se habían autoconstruido ocho viviendas de material; el resto de las familias tobas vivían en casillas prefabricadas a dos cuadras de las otras, con una disposición particular: las pequeñas habitaciones se hallaban alrededor de un patio central también pequeño, lo que daba una sensación de unidad y de que quienes allí vivían lo compartían todo. Este primer acercamiento se hizo con miembros del equipo de investigación de la Facultad de Ciencias Naturales y Museo, de la Universidad Nacional de La Plata ${ }^{27}$-al que me incorporé como integrante activa unos meses después- que se encontraba acompañando a las familias tobas, registrando el proceso de autoconstrucción de las viviendas y la historia del grupo y analizando los modos en que el mismo se articulaba con los distintos sectores de la sociedad nacional. A esta situación se sumaba el hecho de la

\footnotetext{
${ }^{26}$ Ya una investigación iniciada en 1986 (Tamagno 1986) daba cuenta de la vigencia de la lengua materna en las familias tobas de Villa Iapi -hoy vinculadas a las de La Plata por parentesco y/o vecindario en los lugares de origen.

${ }^{27}$ El equipo de investigación, integrado por docentes-investigadores de la Facultad de Ciencias Naturales y Museo- desarrolló el proyecto de investigación "Una comunidad toba en el Gran La Plata. Su articulación social”, que contó con el apoyo del programa de incentivos desde 1992 a 1998 y el proyecto de extensión universitaria “Los Tobas del Barrio Las Malvinas. Su proyección a nivel regional” (1993 1994), ambos dirigidos por la Dra. Liliana Tamagno y que tenían como objetivo realizar el seguimiento del proyecto de autoconstrucción de 36 viviendas que estaba en sus comienzos. Proyectos que a su vez se continuarían en la Línea de Investigación "Identidad, etnicidad, interculturalidad. Indígenas en ciudad” en el marco del Laboratorio de Investigaciones en Antropología Social de la Facultad de Ciencias Naturales y Museo del que fui miembro fundador en 1996, dirigido por la misma investigadora y en el marco del cual se desarrollaron y desarrollan investigaciones sobre educación (García, S. M. y otros 1994, 2002) etnomatemática (García, M. C. y otros 1998) e infancia (Colángelo 1995, 1996).
} 
migración. ${ }^{28}$ Las familias que se encontraban en la ciudad de La Plata provenían, en su mayoría, del Chaco -lugar de origen de la etnia Toba-, y las mismas habían migrado en diferentes momentos; no obstante, se habían reunido en función de un proyecto en común: "conseguir un pedacito de tierra donde vivir todos juntos".

En aquella primera oportunidad conocimos a quien en ese entonces era el líder del grupo y presidente de la Asociación Civil, junto con su familia. Y nuestra primera pregunta consistió en saber si la lengua toba aún se hablaba. Su respuesta fue que la lengua estaba vigente y que era preocupación en el grupo que "no se perdiera" y que anhelaban que "los niños la aprendieran”. Esto nos motivó mucho. ¿Qué hacía que una lengua indígena continuara siendo hablada después de 500 años de dominación/ subordinación? Y, lo que es más, ¿que fuera usada a más de $1.000 \mathrm{~km}$. de distancia de los lugares de origen y en la ciudad?

En 1993, con el apoyo económico de una beca de la Universidad Nacional de La Plata, pudimos comenzar la investigación con una orientación sociolingüística profundizando en la cuestión del bilingüismo y en aspectos relacionados con la lengua y la cultura. ${ }^{29}$ Las técnicas empleadas para el registro consistieron en entrevistas abiertas y semiabiertas, encuestas y observaciones ${ }^{30}$ de la vida cotidiana en distintos ámbitos de la comunidad, incluyendo situaciones comunicativas entre adultos, adultos-jóvenes/ niños, jóvenes y niños. La mayoría de las veces, los eventos comunicativos fueron grabados, en otros casos filmados y también registrados en notas de campo en el momento de la ejecución y posterior al evento según las circunstancias lo permitían.

Asimismo, si bien no se encontró ningún caso de monolingües en toba que nos impidiera la comunicación, decidimos aprender la lengua. Este aprendizaje se realizó

\footnotetext{
${ }^{28}$ La investigación que se venía desarrollando desde 1986 ya analizaba e interpretaba la doble condición de indígenas y de inmigrantes internos, algo novedoso y original en un contexto académico que no había problematizado hasta el momento la existencia de indígenas en la ciudad y que suponía que en el medio urbano se producía la pérdida de la identidad étnica.

${ }^{29}$ Beca de Iniciación a la Investigación Científica y Tecnológica de la Universidad Nacional de La Plata, "Bilingüismo en una comunidad toba de las afueras de la ciudad de La Plata: un enfoque antropológico" (Ibáñez Caselli, 1993-1995), dirigida por la Dra. Liliana Tamagno.

${ }^{30}$ Entendemos la observación y la observación participante, metodologías propias de la práctica antropológica, en términos de Bourdieu como objetivación participante donde el investigador ejecuta una observación controlada en el sentido de que la manera de tomar contacto con su objeto de estudio y problematizarlo está siempre guiado por ciertas preguntas y una tipología particular construidas para el fin de la investigación (Bourdieu y otros 1975).
} 
mediante una búsqueda de material bibliográfico sobre gramáticas y vocabularios existentes sobre la misma, como así también a través de clases sistemáticas dictadas por uno de los integrantes de la comunidad y conversaciones con los demás.

A medida que fuimos avanzando en la investigación y en los diálogos establecidos con la gente Toba en torno al tema de la lengua fueron apareciendo una serie de tópicos que condujeron a un abanico de subtemas. Aparecían no sólo aquellos relativos a los aspectos formales de la lengua y la comunicación, tales como el léxico y las características fonéticas y gramaticales, comparaciones entre el toba y el español, las normas y pautas de la comunicación en toba, sino también, referencias constantes a aspectos sociales y culturales de los hablantes: la historia familiar y del pueblo Toba en el Chaco y en la ciudad, las vivencias, las prácticas socioculturales, las relaciones y conflictos interétnicos, la geografía, fauna y flora del Chaco, las diferencias entre la vida en el campo y la ciudad. Así, el tema de la lengua se vinculaba con todos los aspectos de la vida social. Los avances en el campo y la adquisición de nuevos conocimientos teóricos que enriquecieron nuestra formación académica e interdisciplinaria nos condujeron a introducir la variable del discurso en el análisis de los procesos de socialización y construcción social de la identidad; y, de este modo, fuimos delineando la investigación cuyos resultados aquí se presentan. Esto fue realizado gracias a la obtención de financiamiento mediante tres becas de la Universidad Nacional de La Plata. $^{31}$

El trabajo de campo en el Barrio "Las Malvinas" fue sistemático, intensivo y continuo desde 1993 a 2003. Durante los primeros años (1993 a 1997) nuestras estancias en el barrio fueron más prolongadas, en tanto que en los últimos la estrategia tomada consistió en la realización de visitas periódicas; ${ }^{32}$ las tareas combinaron entre el

\footnotetext{
${ }^{31}$ La investigación fue desarrollada en el marco de los proyectos "Lengua y Discurso Qom en los procesos de socialización y construcción social de la identidad” (Ibáñez Caselli 1995-1997) -Beca de Perfeccionamiento a la Investigación Científica y Tecnológica de la Universidad Nacional de La Plata- y "Lengua e Identidad en el camino de la migración de indígenas tobas: una perspectiva interdisciplinaria” (Ibáñez Caselli 1997-2001) -Beca de Formación Superior a la Investigación Científica y Tecnológica (1998-1999) de la Universidad Nacional de La Plata; Beca FOMEC/ UNLP (1999-2001) dirigidos por la Dra. Liliana Tamagno y la Dra. Lucía Golluscio.

32 Cabe aclarar que, si bien comenzamos a tomar "distancia" con respecto a las tareas del trabajo de campo a partir de 2003 con fines de procesar los datos para entrar en la fase de redacción de la tesis, el contacto con las familias tobas nunca fue interrumpido.
} 
trabajo en equipo y el individual. Esto nos permitió seguir muy de cerca el proceso de configuración y crecimiento del propio grupo a medida que fueron tomando posición efectiva de las viviendas y observar y registrar los cambios sociales y, entre ellos, particularmente los lingüístico-comunicativos.

El hecho de que el conjunto no fuera muy numeroso posibilitó el trato y el conocimiento de todos sus integrantes. Al principio eran alrededor de quince grupos domésticos distribuidos de la siguiente manera: ocho se encontraban habitando las flamantes viviendas de material, en tanto que los restantes ocupaban las casillas de madera arriba descritas. Hubo también personas que no vivían todavía en La Plata, pero que venían con cierta frecuencia para aportar horas de trabajo. Con ellas también trabajamos. A partir del año 1996, la dinámica del barrio cambió significativamente. Las treinta y seis viviendas del plan estaban terminadas y comenzaron a ser ocupadas. Identificamos así para este período treinta grupos domésticos. Tanto para el primer período como para el segundo, realizamos un censo general donde uno de los ítems fue destinado especialmente para el tema de la lengua. Esto nos permitió conocer con mayor profundidad el perfil lingüístico y comunicativo de todas las familias y, en base a ello, seleccionar unos once grupos domésticos con el fin de efectuar un seguimiento particular construyendo sus historias de vida y observando y registrando sus características sociolingüísticas y comunicativas. Las variables que se tuvieron en cuenta para dicha selección fueron principalmente la edad, el lugar de nacimiento, el tiempo de migración, los lugares en los que el jefe/a de familia había estado antes de llegar a la ciudad de La Plata, las generaciones presentes, la asistencia o no a una escuela modalizada, ${ }^{33}$ las competencias lingüísticas, entre otras.

\section{II.1.2. Sobre El TrabaJo de CAMPo}

Con respecto al trabajo de campo en sí, cabe señalar que el mismo tuvo características particulares, diferentes - quizás- a lo planteado en un trabajo de campo clásico donde se espera, por parte del antropólogo, el "alejamiento del propio lugar de residencia y la convivencia permanente con el grupo estudiado por un período prolongado". Por empezar, las familias tobas eran nuestras vecinas. Desde nuestra casa

\footnotetext{
33 Denominamos "escuelas modalizadas" aquellas que, en el marco de una política educativa que contempla la educación indígena, presentan una enseñanza con una modalidad bilingüe y bicultural o intercultural.
} 
al barrio hay 30 minutos de distancia en ómnibus de línea. Por esta razón, podíamos llegar tan temprano como las familias nos lo permitieran, como regresar avanzado el atardecer. Como la mayoría de las familias se encontraban en plena tarea de autoconstruir sus viviendas, tanto hombres como mujeres, se trataba de no interrumpir su trabajo, ni perturbar su intimidad. Sumado a esto, si bien no había condiciones suficientes para que nos quedáramos a "vivir" en el lugar, tampoco lo consideramos necesario. Nuestra estrategia consistió entonces en visitas hechas todos los días y durante todo el día; otras a diferentes horas del día y en diferentes épocas del año; y también en días particulares de la semana en los que nos esperaban -previa solicitud de una entrevista- o se nos ${ }^{34}$ convocaba para el registro de alguna actividad específica.

El hecho de vivir cerca nos facilitó el contacto y la participación en la vida cotidiana $\mathrm{y}$ en todas las actividades especiales que se realizaban, tales como reuniones, asambleas, celebraciones, tanto dentro del barrio como fuera del mismo. Asimismo, en el equipo de investigación, llevamos a cabo algunas tareas como talleres y reuniones con integrantes de la asociación civil, con padres y madres, con jóvenes y niños; con alumnos y docentes de la escuela de adultos; y trabajamos, particularmente, con los niños, ofreciendo clases de apoyo en una actividad que denominamos Apoyo Escolar. ${ }^{35}$ Fuera de los límites del barrio realizamos talleres con docentes, alumnos y padres tobas en una escuela de la zona. En contadas ocasiones acompañamos también a algunos de los integrantes del grupo a una emisora radial y de televisión, y a conferencias y exposiciones. $\mathrm{Y}$ es importante señalar que, a menudo, recibimos llamadas telefónicas por parte de los mismos, con el propósito de alguna solicitud particular, brindar saludos y saber cómo nos encontrábamos -si es que nos ausentábamos algunos días-, como así también obtuvimos visitas en nuestro domicilio particular y en el Laboratorio de Investigaciones en Antropología Social (LIAS).

Todo ello significó el registro de incontables horas de observación e interacción durante diez años consecutivos; alrededor de 30 horas de grabación fílmica; más de sesenta cintas de audio; aproximadamente más de 700 fotografías, tomadas tanto como miembro del equipo de investigación como por ellos mismos, a quienes les dejábamos las cámaras fotográficas; y más de diez cuadernos utilizados como libreta de notas y diario de campo.

\footnotetext{
${ }^{34}$ Algunas de estas actividades se hacían en el contexto del trabajo en equipo del que soy miembro.

${ }^{35} \mathrm{El}$ mismo es descrito más adelante.
} 


\section{- De la ciudad de La Plata al Chaco}

Se expresó en párrafos anteriores que en los discursos que se producían en relación al tema de la lengua aparecía inevitablemente, entre otros aspectos, la referencia al lugar de origen: el Chaco. Además, en varias ocasiones nos encontrábamos en el barrio con la visita de familiares, amigos, pastores que provenían de la región chaqueña y muchos de ellos, hablando solamente la lengua toba. Con el tiempo, el contacto constante y el conocimiento de las familias tobas del Barrio "Las Malvinas" nos llevaron a viajar y conocer aquella región. Viajamos en dos oportunidades -en los años 1998 y 2000- y en ambas, acompañados por algunas mujeres del barrio y sus hijos pequeños. Nos hospedamos en la vivienda de uno de sus familiares en el Barrio Toba de la ciudad de Resistencia y, luego, realizamos viajes en conjunto por las comunidades del interior de la provincia visitando, principalmente, casas de algunos familiares de nuestros anfitriones y guías y localidades significativas en la historia del pueblo toba, su dinámica y organización.

En el viaje de estudio realizado en octubre de 1998 llegamos a la ciudad de Resistencia y registramos, especialmente, el desarrollo de la mesa "La Mujer Indígena", en la que participó el grupo de mujeres que nos acompañó en el viaje desde La Plata, en el contexto del "XXII Encuentro Nacional de Mujeres". En este evento también estuvieron las mujeres organizadas del Barrio Toba de Resistencia, ocurriendo así nuestro primer contacto con los habitantes de ese barrio. Terminado el encuentro, nos alojamos en la vivienda de una de nuestras acompañantes y al cabo de una semana realizamos un primer reconocimiento del lugar y una primera prospección mediante observaciones y entrevistas. Como segunda instancia, recorrimos, junto con algunos integrantes de los barrios de La Plata y Resistencia, las localidades de La Leonesa, Las Palmas y Pampa del Indio. (Ver Figura $\mathrm{N}^{\mathrm{o}}$ 3).

En marzo de 2000, efectuamos el segundo viaje de estudio conviviendo con una de las familias del Barrio Toba de Resistencia. En esta oportunidad, nuestro trabajo fue intensivo, participando y registrando el "Encuentro y Convención de Jóvenes de la Iglesia Evangélica Unida" 36 que se realiza anualmente en ese lugar y del $38^{\circ}$ Aniversario del establecimiento educativo UEP No 30 "Aída Z. de Florito" -escuela primaria ubicada en el corazón del barrio. Asimismo, trabajamos con los docentes indígenas de dicha institución; realizamos observaciones de clases en las aulas; y

\footnotetext{
${ }^{36}$ Mayores detalles de estos eventos se pueden ver en Tamagno (2001).
} 
profundizamos las tareas de relevamiento en torno a las relaciones de parentesco. También programamos un viaje al interior de la provincia, junto con algunos de nuestros anfitriones, visitando y reconociendo otros nucleamientos tobas en Colonia Aborigen, en las ciudades de Roque Sáenz Peña y Castelli, y en las localidades de El Bermejito y Olla Quebrada en las puertas del Impenetrable. ${ }^{37}$ (Ver Figura No 3).

\section{- De la ciudad de La Plata a otros nucleamientos tobas}

La relación con la gente toba de las afueras de la ciudad de La Plata también nos llevó a conocer y contactarnos con otros casos de migración de familias tobas que hoy conforman nucleamientos tanto en los alrededores del actual Barrio "Las Malvinas" y en el Gran Buenos Aires, como en la ciudad de Rosario (provincia de Santa Fe) y en el Lote 68 (provincia de Formosa).

En el caso de los nucleamientos del Gran La Plata realizamos varios acercamientos en distintas oportunidades. Al principio, los primeros asentamientos estaban conformados por algunas de las familias que habían estado anotadas en el Plan de Viviendas, pero que por distintos motivos habían perdido su lugar. Más tarde, fueron llegando otras familias provenientes del Chaco, de Rosario y del Gran Buenos Aires, muchas de ellas emparentadas con las del Barrio "Las Malvinas". Asimismo, efectuamos algunas aproximaciones en los nucleamientos del Gran Buenos Aires como Villa Iapi y Dock Sur. En noviembre del año 2000 coordinamos el “Taller de Reflexión para el mejoramiento de la Calidad Educativa con Comunidades Tobas de la provincia de Buenos Aires" que contó con la participación de representantes tobas de cada uno de los nucleamientos de la provincia, tales como Dock Sur, Gral. Pacheco, IAPI y La Plata, a excepción de Derqui. ${ }^{38}$ A lo largo de este taller, comparamos y analizamos conjuntamente las características de cada nucleamiento. (Ver Figura $\mathrm{N}^{\mathrm{o}} 2$ ).

En la ciudad de Rosario también existe una significativa población toba, que acusa un número de alrededor de $6.000 \mathrm{y}$ que en estos momentos es epicentro de importantes

\footnotetext{
${ }^{37}$ Se conoce como "El Impenetrable" a la extensión de monte xerófilo con un estrato denso de arbustos espinosos y ejemplares de quebracho blanco y colorado ubicado al oeste de la provincia.

${ }^{38}$ Este taller fue convocado a fines del año 2000 por el Área Escuelas Prioritarias del Ministerio de Educación de la Nación a través del "Área de Estudios Interdisciplinarios en Educación Aborigen" (AEIEA), del Departamento de Educación de la Universidad Nacional de Luján y contó con mi coordinación. La invitación fue hecha a todas las comunidades tobas del Gran Buenos Aires y La Plata y la decisión para participar fue tomada por las organizaciones correspondientes. (Ver Ibáñez Caselli y otros 2004).
} 
expresiones político-reivindicativas (Arias 2005). En esta ciudad realizamos algunas prospecciones, sólo en uno de los nucleamientos, ubicado en las cercanías de las calles Travesía y Almafuerte y Avenida J. J. Paso (ex Empalme Graneros); allí analizamos la situación social y educativa durante tres visitas realizadas a ese barrio en 1996, 1999 y 2000 (Ver Figura No 5).

En octubre de 1996, en ocasión de participar en el Taller de Reflexión: "Educación Bilingüe e Intercultural" -organizado por el Centro de Capacitación Zonal (CECAZO) y el Centro del Hombre Antiguo Chaqueño (CHACO), en Pozo del Tigre, Formosa-, nos contactamos con docentes indígenas y criollos de la Escuela $\mathrm{N}^{\circ} 335$ ubicada en el barrio toba Lote $68 \mathrm{Na}$ Qom, a unos 10km. aproximadamente de la ciudad de Formosa. Estos docentes nos invitaron a conocer la escuela y el barrio, de manera que también se pudo realizar un reconocimiento del lugar para los fines de la investigación.

\section{- Superando algunos obstáculos}

En términos de Briggs ([1986]1992), el investigador debe tener conocimiento de los rasgos metacomunicativos del grupo social con el que trabaja, con el fin de superar ciertos obstáculos sociolingüísticos que suelen surgir a la hora de interpretar los datos obtenidos en una interacción cara-a-cara, como lo puede ser una entrevista, una conversación informal, una encuesta. Por lo general, el investigador impone frente a su interlocutor sus propias pautas comunicativas y no percibe los rasgos pragmáticos, los recursos comunicativos y metacomunicativos nativos que caracterizan los eventos de habla en una situación social dada, que le dan fuerza y significado especial a lo que se dice.

Cabe advertir que las condiciones de nuestro trabajo de campo no fueron todas exitosas. Con frecuencia nos encontramos con algunos obstáculos y dificultades que nos hicieron poner a prueba nuestros conocimientos y personalidad con el fin de encontrar estrategias que nos permitieran cumplir con los objetivos fijados. Las dificultades más frecuentes consistieron, al principio, en entender la lógica de comunicación de las familias. Tuvimos que aprender a preguntar y saber esperar la respuesta. Comprender también que "los silencios" comunicaban. Luego, entrar en confianza, en especial con las mujeres, que hablaban poco, y que nos permitieran ingresar a su casa requirió de perseverancia. La solicitud muy anticipada de una "cita" no servía, cuando se llegaba a la hora dispuesta no estaban en su casa, o no estaban "preparados", esperándonos como nos hubiéramos imaginado o preferido que lo estuvieran-. Todo implicaba el 
manejo de "otros tiempos" que debimos aprender y respetar. Sumado a esto, están las numerosas interrupciones en los momentos más significativos -para nosotros- del evento comunicativo que nos encontrábamos registrando, ya sea por parte de la llegada de una visita inesperada o por los propios ruidos de la zona como los vendedores ambulantes, la música fuerte de un vecino, ladridos de perros, el llanto de un niño o la televisión que interferían la comunicación. Las inclemencias del tiempo que no permitían entrar y llegar al barrio con facilidad, como así también las vicisitudes propias de la vida cotidiana que enfrentaban a diario las familias se presentaban como obstáculos para el avance del estudio emprendido.

Los propios objetivos de nuestra investigación nos facilitaron encontrar los modos de superar gran parte de las dificultades halladas. Siendo esta una investigación sobre los usos de la lengua y la identidad, la cuestión del bilingüismo y la competencia sociolingüística del Barrio Toba "Las Malvinas", tuvimos como meta indagar las pautas y normas comunicativas y metacomunicativas del grupo. Esto implicó registrar y analizar los distintos eventos y situaciones comunicativas que se dan, tanto en el contexto barrial, en los niveles intra e interétnico, como fuera del mismo. Además, las visitas frecuentes al lugar fueron limando asperezas, desconfianzas y nos fuimos convirtiendo ya no sólo en "la investigadora" o "la antropóloga", sino que pasamos a interpretar otros roles tales como "la visita", "la amiga", "la confidente", "la alumna", entre otros. ${ }^{39} \mathrm{De}$ este modo, a medida que íbamos avanzando en nuestro conocimiento, se profundizaba la relación con los interlocutores.

\section{II.1.3. TeJiendo las Redes Sociales y de PaRentesco}

Los análisis de red y de parentesco fueron otras de las principales metodologías empleadas en esta investigación. Basándonos en algunos trabajos provenientes tanto de la antropología como de la sociolingüística fuimos configurando la red de relaciones sociales, lingüísticas y parentales, tanto del Barrio "Las Malvinas" como de éste con los otros nucleamientos tobas del Gran La Plata, Gran Buenos Aires, Rosario, Chaco y Formosa.

\footnotetext{
${ }^{39}$ La relación se profundizó a tal punto que ellos mismos acusando un grado importante de confianza me llegaron a decir: "ahora, lo único que le falta es que se venga a vivir acá, con nosotros". Incluso, en ciertas situaciones en las que no tenía a la vista mi grabadora o cuaderno, me alertaban que "no estaba grabando o tomando nota".
} 
El concepto de red alude a una matriz de vínculos sociales contenida en un ámbito social determinado; es decir, un campo social compuesto por relaciones entre personas (Mayer [1969]1980). Tales relaciones son definidas a través de ciertos criterios que subyacen en el grupo social. Estos pueden ser criterios de vecindad, amistad, parentesco, conexiones económicas, entre otros. Otra característica que tiene la red es la de ser "ilimitada": toda persona tiene relaciones con una serie de personas que, a su vez, están vinculadas a otras. Además, dentro de una red se pueden identificar conjuntos de personas vinculadas e interconectadas; el conjunto se diferencia de la red en que ésta se centra en torno de una sola persona $(e g o)$.

Siguiendo una perspectiva relacional, se puede sostener que, en una sociedad, los individuos están íntimamente conectados unos con otros y que, como resultado de esta interacción, cada uno desempeña un rol a través del cual participan en diferentes situaciones en busca de una gama de objetivos (Hannerz 1980). El rol que una persona pueda tener dependerá de ciertos atributos -características culturalmente definidas, aparte de la situación particular- que actuarán como discriminadores, tales como sexo, edad, religión, etnicidad, lengua, etc.

Gráficamente, se describe el concepto de red como un conjunto de puntos, algunos de ellos unidos por líneas, donde los puntos son personas o grupos de personas y las líneas indican qué persona interactúa con cada una de las otras.

Mediante entrevistas, historias de vida y las técnicas propias del análisis de parentesco fuimos reconstruyendo, principalmente, redes personales de los jefes/ jefas de los grupos domésticos del Barrio "Las Malvinas", y, a través de las mismas, se llegó a reconstruir la red de conformación del propio barrio. Luego, a medida que fuimos tomando contacto con los otros nucleamientos tobas, mencionados anteriormente, se amplió la red vinculando las familias tobas que viven en La Plata con las del Gran Buenos Aires, Rosario, Chaco y Formosa. Este análisis nos permitió distinguir, además, los usos y los roles sociales y lingüísticos de la lengua vernacular en el camino de la migración (Ver Capítulo IV).

\section{II.1.4. El APRENDIZAJE de la Lengua}

Desde los inicios de la investigación, como resultado de la interacción con nuestros interlocutores, se tomó la decisión de aprender la lengua toba. Consideramos que, de ese modo, se podría llegar a establecer un contacto más certero con el grupo, puesto que en varias conversaciones informales y entrevistas puntuales pudimos constatar cierta 
dificultad en expresar en castellano aspectos que en la lengua toba tenían un significado diferente cuya profundidad no podía expresarse en la otra lengua, sino bajo el riesgo de una simplificación. Otro de los propósitos estaba vinculado con la profundización en torno a la cuestión del bilingüismo y con el hecho de encontrarnos frente a discursos que presentaban casos de cambios de códigos y mezclas de códigos, para lo cual se consideró necesario adquirir conocimiento de la sintaxis de la lengua.

Si bien cualquiera de las personas del conjunto podía enseñar la lengua, se eligió como profesora a una mujer joven del grupo que había migrado del Chaco a la ciudad de La Plata hacía casi un año y que, en una de las oportunidades en que la entrevistamos, pudimos apreciar que poseía conocimiento sobre la grafía de la lengua y demostraba habilidades para reflexionar sobre su sintaxis. Se trataba de una persona que había completado sus estudios primarios y secundarios; tenía conocimiento de una tercera lengua: el inglés; había trabajado como secretaria del Instituto del Aborigen del Chaco (IDACH) -lo cual le había permitido conocer casi todas las comunidades aborígenes de esa provincia y sus realidades muy de cerca-; había ejercido la docencia en cursos de evangelización para niños; y, sobre todo, había participado en los primeros cursos de preparación de auxiliares docentes aborígenes dictados en la ciudad de R. Sáenz Peña, Chaco, por el Centro de Investigación y Formación para la Modalidad Aborigen (CIFMA). ${ }^{40}$ Estas características y, en especial, este último hecho, la hacía una persona singular y justificó la elección ante el resto de los integrantes del barrio que eran bilingües.

La situación de enseñanza-aprendizaje se convirtió no sólo en una herramienta para la investigación, sino que la misma, tomada como objeto de análisis, proporcionó en sí misma una significativa fuente de datos. Además, al cabo de unas semanas de haber comenzado a recibir clases sistemáticamente, previo acuerdo con nuestra profesora, percibimos que pasaba a ocupar un lugar distinto en el transcurso de la vida del barrio y a desempeñar un rol que sobresalía en el mismo: se pasó, de alguna manera, de ser "la investigadora..." o "la antropóloga" a ser "la alumna de...", y esto nos permitió una inserción particular en el grupo. De igual modo, se puede mencionar que se produjo un cambio de actitud, favorable, en la relación entrevistado-investigador al incorporar

\footnotetext{
${ }^{40}$ Para más información sobre la historia y el papel fundamental que desempeñó el Instituto de Nivel Terciario CIFMA en el desarrollo de un programa de capacitación y formación docente con una orientación bilingüe y bi/ intercultural en la Provincia del Chaco ver Ibáñez Caselli (2004).
} 
parte de ese conocimiento de la lengua en las entrevistas y conversaciones informales con otros integrantes del barrio. En ellas, cabe destacar la presencia de algunas risas manifestadas cuando escuchaban (y escuchan en la actualidad) que expresamos algo en la lengua toba ("la idioma" como dicen ellos), originando, al principio, cierta inquietud en nosotros, pero que fue mermando más tarde al comprender algunas de sus causas:

- “...da gracia que 'otro’ hable el idioma porque no es costumbre...”;

- “...no es lo común...”;

- “...porque la pronunciación es distinta, aunque suena lindo...”; o

- “...por el mismo asombro”.

El aprendizaje de la lengua toba comenzó en agosto de 1993 y consistió en uno o dos encuentros semanales, en horarios fijados de común acuerdo y con anterioridad. La mayoría de las clases fueron grabadas y se tomaron notas. Contamos también con un pizarrón con tizas, tanto en la casa de nuestra profesora como en la oficina de la asociación civil. Algunas veces, interrumpíamos la clase por la llegada de alguna visita -de niños, jóvenes o adultos- que, después de verificar lo que estábamos haciendo, se retiraba. En muchas ocasiones, algunas de estas visitas se incorporaron a la clase, según el tema del día. También dispusimos de recreos, donde la interacción verbal se hacía más distendida y discutíamos los temas de la vida cotidiana. ${ }^{41}$ Luego, al nacer su hija, la misma también se incorporó a las clases: al principio, de brazo en brazo; luego, jugando alrededor nuestro.

Esta práctica -considerada como un evento comunicativo- ha sido rica en intercambios por ambas partes. Por un lado, motivó una mayor reflexión, por parte de quien enseña, de su propia lengua, historia y cultura; y, por otro, se generó una actitud positiva hacia la lengua que se incrementaba en cada una de las clases, a la vez que la misma fue transmitida a otros integrantes del barrio, $y$, en particular, a los jóvenes. A medida que fueron pasando los meses y que la noticia de que "era la alumna de..." se había expandido, no sólo nuestra profesora nos comenzó a tomar exámenes de lo aprendido, sino también nuestros otros interlocutores. Esto para constatar que era verdad que estaba aprendiendo el idioma y, sobre todo, que "nos estaban enseñando correctamente".

\footnotetext{
${ }^{41} \mathrm{El}$ análisis de las clases de la lengua toba como evento comunicativo es presentado en el Capítulo IV con mayores detalles.
} 
Como explicaremos más adelante, el acto de enseñanza-aprendizaje no sólo permitió establecer una aproximación a los aspectos lingüísticos en el sentido de cómo hablar la lengua toba, sino también analizar algunas cuestiones acerca de los distintos aspectos socioculturales del grupo en cuestión; los valores y creencias que dominaron y dominan los modos de su existencia; la importancia del lugar de origen, el Chaco, como referente constante; y la propia historia del grupo toba. Apareciendo así, con claridad, la significación que tiene la lengua como medio de expresión y representación de la visión de mundo de una cultura. Esta experiencia favoreció, además, la relación con el grupo, permitiendo una buena inserción en el mismo y un buen rapport durante las entrevistas.

\section{II.1.5. LA LENGUA EN LA EDUCACIÓN}

El análisis de aquellos aspectos relacionados con el bilingüismo, la discriminación y la identidad nos llevaron a profundizar en la problemática de los niños y la lengua y, por ende, la educación formal. De este modo, comenzamos a trabajar muy de cerca el tema de la educación y, en especial, la Educación Bilingüe Bicultural/ Intercultural Bilingüe -programas particularmente destinados a las poblaciones originarias de Latinoamérica y desarrollados en los territorios indígenas-. ¿Qué sucedía con los niños tobas de la ciudad?; ¿cuáles eran sus dificultades en la escuela?; ¿sería posible implementar una política educativa especial para esta población? El trabajo en esta temática implicó relevar las experiencias educativas de los niños tobas del Barrio "Las Malvinas", como así también aquellas que se están dando en los lugares de origen. La sistematización nos llevó a distinguir entre experiencias que por su origen, participantes y desarrollo habían sido diseñadas para la gente toba, y otras que se desarrollaron con la misma, mediante su iniciativa, interés y necesidades. Una vez identificadas las experiencias se seleccionaron algunas de ellas y realizamos un seguimiento, reconstruyendo su gestación y describiendo las prácticas educativas actuales. ${ }^{42}$

Además, con el fin de profundizar en este tema, participamos en la construcción de dos experiencias de acción e investigación. La primera consistió en la realización de un apoyo escolar destinado a los niños tobas del Barrio "Las Malvinas", con el que se pretendió no sólo acompañar el proceso de aprendizaje de

\footnotetext{
${ }^{42}$ El desarrollo de esta investigación se presentó en Ibáñez Caselli, M. A. (2004), Tesis de Maestría: "Politicas Lingüísticas e Interculturalidad: Experiencias Educativas para y con Indígenas Tobas de Argentina", CBC/FLACSO-Ecuador (aceptado para su publicación).
} 
contenidos escolares, sino también producir conocimiento en conjunto con el fin de mejorar la relación escuela/ comunidad. Esto nos permitió efectuar una observación controlada en el marco de lo que se denomina la "lógica experimental"43 (García y otros 2002). El segundo, comprendió la coordinación del "Taller de Reflexión para mejorar la educación en las comunidades tobas de la provincia de Buenos Aires" mencionado en párrafos anteriores (Ibáñez Caselli y otros 2004).

\section{II.1.6. SOBRE EL RELEVAMIENTO SOCIOLINGÜÍSTICO}

Entendemos por aspectos sociolingüísticos aquellos elementos lingüísticos y sociales que permiten observar la relación existente entre la estructura de la lengua y la producción del habla, con la conducta y la estructura social del grupo, permitiendo, así, el análisis de la lengua en relación a la sociedad que la habla (Bolaño 1982). En el marco de estos principios, el estudio sociolingüístico puede dar cuenta de la naturaleza comunicativa de los procesos sociales, la forma en que los grupos sociales se delimitan, como, así también, de los mecanismos que operan en la hegemonía lingüística o el fenómeno de la dominación simbólica -en términos de Gramsci y Bourdieu- (en Gumperz 1996:47). Partimos de la idea de que existen pequeños grupos comunicativos, en el sentido antropológico de "grupos cara a cara", delimitados por estrategias discursivas compartidas. Esto significa que el hablante que comparte un conjunto de estrategias discursivas con otro ha pasado anteriormente por experiencias interactivas semejantes y ha crecido en contextos grupales similares. Entendiendo que cuando no se comparten estas estrategias comunicativas, se presentan problemas de comprensión y entendimiento (Gumperz 1996:46).

Sobre la base de las "Pautas para el relevamiento etnolingüístico", de Emma Gregores (s/f), ${ }^{44}$ y de la "Guía para el estudio etnográfico del uso del habla", de Joel Sherzer y Regna Darnell (1972), junto con una revisión crítica del material bibliográfico relacionado con este tema, elaboramos una Guía de pautas para el análisis sociolingüístico del Barrio Toba "Las Malvinas" [ver Anexo I]. La misma consta de tres partes:

\footnotetext{
${ }^{43}$ El tema de la "lógica de la experimentación" ha sido propuesto y desarrollado por Bourdieu y otros (1975); Mc Kinney (1968); Moll (1993).

${ }^{44}$ Para mayores referencias ver Golluscio (2002:22-28).
} 
1) Relevamiento a Nivel de los Individuos: Esta sección de la guía nos permitió obtener información de cada uno de los integrantes de los grupos domésticos, en función de aspectos individuales y de parentesco, lingüísticos, históricos y sociales.

A través de estos ítems se pudo acceder al conocimiento de la composición del grupo social. Esta guía sirvió de base para las preguntas formuladas en dos censos efectuados en el barrio, las entrevistas semi-estructuradas y libres, las historias de vida y las conversaciones casuales sostenidas con la gente toba. De esta manera, fuimos registrando datos en relación a las características de cada grupo doméstico; relaciones de parentesco entre las familias del barrio y de los otros lugares donde habita gente toba; edades y competencia lingüística; lugar de nacimiento y migración; roles sociales y lingüísticos en la estructura familiar y en la del barrio; la articulación social del grupo con los demás (vecinos, instituciones, etc.); nivel educativo adquirido; lengua materna; conocimiento de los códigos lingüísticos registrados en el barrio (toba/ español); actitudes y valores hacia las lenguas. Además, la exploración en estos temas tuvo como objetivo final observar cómo se fueron entretejiendo las redes sociales y, en especial, las lingüísticas -apoyada en el análisis de red y parentesco.

2) Relevamiento a Nivel Colectivo: los elementos diseñados en esta sección nos permitieron observar los usos de la lengua en su dinámica sociocultural. Se determinó, a través del registro de diferentes interacciones verbales, los usos de los dos códigos lingüísticos (español y toba) hablados en el barrio y en diferentes contextos situacionales que se dan en los siguientes dominios de uso: ${ }^{45}$ doméstico y de parentesco, abastecimiento, religioso, vecindad, tránsito. De este modo, se registraron diversas situaciones comunicativas, tales como sesiones de Culto, Asambleas, Reuniones Vecinales y Familiares, Visitas, entre otras, y se distinguieron los eventos de habla que en ellas ocurren; se analizaron los diferentes discursos, identificamos los componentes de los eventos de habla y los hechos de habla, y apelamos al análisis de la competencia comunicativa, de la conversación y del discurso (Hamel 1982; Sierra Camacho 1987; Schiffrin 1992, [1994] 1998; Chafe 1994).

Asimismo, prestamos especial atención a los temas que se hablan cotidianamente; entre quiénes y dónde se habla; en qué lengua se habla en los diferentes momentos del

\footnotetext{
${ }^{45}$ Denominamos dominios de uso a los contextos institucionales y conjunto de conductas similares que en ellos se pueden presentar (Fishman 1972).
} 
día; cuántas personas participan en la conversación; quiénes pueden participar de la conversación; con qué frecuencia se habla la lengua toba durante todo "un día"; si se usa la lengua toba para hablar solamente de determinados temas o no (Sherzer [1983] 1992, 1987; Tannen-Saville Troike 1985; Briggs [1986] 1992; Silverstein 1992). Todos estos elementos permiten identificar los posibles géneros discursivos que circulan en la comunidad, en este caso, en lengua materna y en español; como así también, los significados de los usos de las lenguas y las actitudes y valores que los hablantes poseen hacia las mismas.

Además, relevamos otros eventos de habla fuera del Barrio Toba "Las Malvinas". Eventos tales como charlas ofrecidas en distintos encuentros, jornadas, congresos, medios de comunicación de los que participaron algunos de los integrantes del barrio. Estos eventos comunicativos que se dieron a nivel interétnico, fuera del ámbito barrial y otros dentro del mismo- permitieron observar de qué manera se manifiesta la lengua de origen durante el evento de habla y comparar los recursos verbales en diferentes contextos y con distintos fines.

3) Socialización Lingüística: Los temas resaltados en esta sección tuvieron el propósito de permitir un seguimiento del proceso de socialización, en general, y de la socialización lingüística, en particular, con el fin de comprender la manera en que los individuos se vuelven miembros competentes del grupo social como, así también, el rol que desempeña la lengua en este proceso. En este sentido se indagó de qué manera el lenguaje es medio e instrumento del proceso de socialización y cómo se adquieren los usos apropiados del lenguaje como parte del conocimiento de la competencia social. Y esto nos posibilitó el estudio de la adquisición de la competencia comunicativa en la comunidad de habla (Schieffelin y Ochs 1986). Colocamos especial atención en los aspectos de la socialización en general; en la relación de los niños con los códigos lingüísticos; el grado de participación de los niños en los eventos comunicativos, entre otros. De igual modo, observamos la situación de los niños y la escuela y de los adolescentes y jóvenes en relación a los recursos verbales y las actitudes y valores hacia la lengua toba.

\section{II.1.7. LA APROXIMACIÓN INTERDISCIPLINARIA}

Nuestras primeras aproximaciones en el Barrio Toba "Las Malvinas" me permitieron observar que la lengua vernácula se encontraba vigente allí, tal como se había observado en el nucleamiento de Villa Iapi (Tamagno 1986). Esta lengua es hablada 
principalmente por las primeras generaciones de migrantes, llegadas tanto hace más de treinta años como en los últimos diez. La vigencia de la lengua toba en la ciudad, junto con el hecho de ser familias que han migrado, que se encuentran distantes de su lugar de origen y que hablan una lengua minoritaria y desprestigiada en el contexto nacional, nos llevó a plantear los primeros interrogantes:

- ¿Cuáles son los usos y funciones de esta lengua?

- ¿Quiénes poseen un mayor conocimiento de la misma?

- Ésta ¿es transmitida a las generaciones más recientes?

- Las nuevas generaciones ¿poseen interés por aprenderla y practicarla?

- ¿Cuáles son los significados sociales (actitudes, valores) de hablar la lengua toba en la ciudad?

Indagar sobre las posibles respuestas y sus fundamentos implicó realizar esta investigación con una aproximación interdisciplinaria que nos permitiera, desde nuestra formación y visión antropológica, estudiar el lenguaje y el discurso en su contexto y dinámica sociocultural. Dado que en Argentina no existe una tradición en la formación de antropólogos lingüistas como tal, sino sólo las carreras de Antropología con la orientación sociocultural por un lado, y de Letras y Literatura, con la orientación lingüística más bien como materia complementaria, por otro, ${ }^{46}$ esta investigación ha sido abordada incorporando al análisis antropológico categorías y modelos teóricos provenientes de otros campos de estudio cuyo interés es la lengua y el discurso, tales como la Etnografía del Habla o Etnografía de la Comunicación, la Sociolingüística, la Etnolingüística, la Sociología del Lenguaje y la Pragmática, al tiempo que hemos tomado elementos propios del Análisis del Discurso y el Análisis de la Conversación; todas ellas áreas que se han desarrollado dentro de un campo mayor que es el de la Antropología Lingüística y la Lingüística. En suma, la aproximación interdisciplinaria de esta investigación consistió en el diálogo de la antropología con y la utilización de herramientas teórico-metodológicas provenientes de distintas disciplinas que abarcan el estudio del uso del lenguaje en su contexto social. Disciplinas estas que son, a la vez, de

\footnotetext{
${ }^{46}$ Cabe señalar que, en la carrera de Antropología de la UNLP, la Lingüística es considerada una materia optativa y es cursada en la Facultad de Humanidades; en tanto que en la Universidad de Buenos Aires (UBA), esta materia es parte de los cursos de grado de la carrera y, además, desde el año 2002 aproximadamente, se tiene la posibilidad de cursar Sociolingüística y Etnolingüística como materias optativas.
} 
formación interdisciplinaria. Asimismo, se ha buscado la dirección de una antropóloga y una lingüista especializadas en estos temas que permitieron profundizar nuestros conocimientos en un continuo ejercicio interdisciplinario.

\section{II.1.8. EL TRABAJO DE INVESTIGACIÓN COMO DIÁLOGO INTERCULTURAL}

A medida que la investigación avanzó y fuimos conociéndonos con la gente toba -principales interlocutores- comenzamos a construir un diálogo intercultural (Bartolomé 2000; Helberg Chávez 2001). Es decir, un diálogo en el cual se podía dar "la capacidad de brindar aproximaciones valiosas, en la medida que se pueda ver lo que la cotidianeidad hace invisible y se sea capaz de dar cuenta de la alteridad sin 'cosificar' a sus protagonistas” (Bartolomé 2000). Lo que, es más, en el momento de observar, describir, analizar e interpretar los aspectos que hacen al bilingüismo y al uso de la lengua materna en gente toba en ciudad, comenzamos a destacar la necesidad de tener en cuenta no sólo las actitudes y valoraciones que los propios hablantes tenían de su propia lengua y cultura, sino también la valoración que "nosotros" -en el contexto de la sociedad total- damos a estos elementos. Apareció así, en el análisis de la relación lengua/ sociedad, la variable de la desigualdad y, por lo tanto, las del prejuicio y la discriminación. En este sentido, el concepto de interculturalidad junto con las nociones de tolerancia, respeto a la diferencia, equidad, entre otras, jugaron y juegan un papel importante como enfoque metodológico para nuestra investigación.

En la actualidad, el concepto de interculturalidad -fundamental como práctica pedagógica en los programas de educación bilingüe con poblaciones indígenas (Godenzzi 1996) - se asienta en el reconocimiento de la diversidad como un "recurso" enriquecedor para toda la sociedad. ${ }^{47}$ Es decir, una orientación en la que tanto la sociedad dominante como la indígena reconozcan, asuman y apoyen las diferencias étnicas y lingüísticas como factores de enriquecimiento sociocultural y como valiosos recursos para la sociedad en su conjunto (Hamel 1998).

Además, la interculturalidad no se trata de una dimensión que se limite sólo a uno de los campos de las relaciones humanas. Ésta se encuentra presente en todos los ámbitos posibles como alternativa frente al autoritarismo, el dogmatismo y el etnocentrismo (Heise, Tubino y Ardito 1994). Sumado a esto, siguiendo las reflexiones hechas por

\footnotetext{
${ }^{47}$ Tema trabajado en Ibáñez Caselli (1999, 2003, 2004, 2006).
} 
Xavier Albó (1999) pareciera que podemos hablar de alguna forma de interculturalidad dondequiera que ocurra cualquier relación entre dos culturas. Bajo esta circunstancia, se hace necesario diferenciar la interculturalidad como situación de hecho o concepto descriptivo, de la interculturalidad como principio normativo (Fuller 2002; Tubino 2002). En el primer caso, lo que se está expresando es el dato concreto de que en la mayoría de las naciones-Estado coexisten culturas diferentes. La relación entre estas culturas puede ser diversas, sin conflictos aparentes o puede haber discriminación y rechazo explícitos. En este sentido, definimos el contacto interétnico como todas aquellas situaciones donde se dan relaciones entre individuos o grupos de diversas procedencias (Cardoso de Oliveira 1992:19). En el segundo caso, la noción de interculturalidad va más allá. En la misma está implícita una propuesta ético-política que busca "perfeccionar el concepto de ciudadanía con el fin de añadir a los derechos ya consagrados de libertad e igualdad ante la ley, el del reconocimiento de los derechos culturales de los pueblos, culturas y grupos étnicos que conviven dentro de las fronteras de las naciones-Estado" (Fuller 2002:10). Es decir, lo intercultural abarca algo más que una simple relación entre individuos o grupos diferentes. El reconocimiento de lo diverso está acompañado por una actitud de mutuo entendimiento e intercambio, que estimula y propicia al enriquecimiento cultural de las partes. Por lo tanto, la verdadera meta de la interculturalidad busca la manera de relacionarse de un modo positivo y creativo, generando un enriquecimiento entre todos (Albó 1999:87), sin que por ello los interactuantes pierdan su identidad o distintividad. De esta forma, entendemos que la interculturalidad es una actitud de apertura, de diálogo horizontal y de enriquecimiento recíproco (Heise, Tubino y Ardito 1994); un deber-ser posible y una utopía realizable (Tubino 2002).

En síntesis, la propuesta intercultural busca generar espacios de liberación y acuerdo en el que no existan "minorías" excluidas de representación, opinión y capacidad de decisión en los ámbitos de administración del poder; supone el diálogo intercultural que busca colocarse en el lugar del otro, entenderlo desde su visión de mundo y su jerarquía de valoraciones y, especialmente, aceptar que los diferentes grupos y culturas están interrelacionados, se influencian mutuamente y pueden incluso compartir un proyecto conjunto (Fuller 2002:11). Estas posiciones coinciden de alguna manera con la línea de investigación del proyecto mayor que comenzó a delinearse en 1992 
"Interculturalidad. Etnicidad. Identidad. Indígenas en ciudad" 48 del cual formamos parte y que propone la construcción del conocimiento junto con la gente toba. En esta línea, reconocemos que los resultados obtenidos son parte de un trabajo conjunto donde aparecen las preocupaciones y las necesidades, las reflexiones y los saberes, los sueños y las utopías de nuestros interlocutores, al tiempo que dialogamos también con la academia (Tamagno 2001, 2006; Tamagno, García, Ibáñez y García 2005).

El diálogo con la academia implicó el intercambio teórico y de experiencias con colegas antropólogos y lingüistas, tanto nacionales como extranjeros, a través de lecturas y el contacto directo mediante la participación en distintos eventos académicos, tales como jornadas, congresos, seminarios, talleres, pasantías y reuniones de trabajo. Cabe señalar que en muchos de estos eventos la gente toba participó de una manera activa, conjuntamente con nuestro equipo de investigación, mediante exposiciones orales en mesas redondas o paneles que compartieron con profesionales y otros hermanos indígenas del país y de países vecinos; y, asimismo, presentaron vídeos del barrio y pósteres hechos junto con el equipo de investigación. ${ }^{49}$ Tan frecuente y "común" se convirtió esta práctica que, al cabo de un tiempo, no sólo éramos los antropólogos los que invitábamos a la gente toba a estos eventos de nuestra especialidad, sino que se empezó a dar el hecho contrario: eran ellos mismos los que nos invitaban a participar y a acompañarlos a jornadas y talleres organizados por las organizaciones indígenas o por alguna entidad gubernamental o no gubernamental en los que ellos eran los invitados principales.

La reflexión y el análisis de la interculturalidad se vieron enriquecidos cuando realizamos una pasantía de dos meses en una universidad mexicana -bajo la tutoría

\footnotetext{
${ }^{48}$ Proyecto del Programa de Incentivos de la Fac. de Ciencias Naturales y Museo, de la UNLP, dirigido por la Dra. L. Tamagno.

49 Entre algunos de los eventos en los que hemos participado conjuntamente podemos mencionar: Congreso Argentino de Antropología Social (1994), I Jornadas Indígenas en la Ciudad (1995), Jornadas de Extensión Universitaria (1995, 1997), Congreso Argentino de Antropología Social (1997), Jornadas de Construcción de la Identidad Étnica. Una Comparación Argentina/BrasilRosario (1997), XXII Encuentro de Mujeres (1998), Encuentro Latinoamericano de Estudiantes de Arquitectura - ELEA (1998), VIII Jornadas de Vídeo Antropológico (1998), Seminario Internacional: "Los pueblos indígenas en el siglo XXI. interculturalidad, derecho, justicia y desarrollo" (1999).
} 
de un antropólogo lingüista- profundizando aspectos teórico-metodológicos en el tratamiento de la problemática del bilingüismo y la educación indígena. ${ }^{50}$ Como consecuencia de este cometido, tuvimos la posibilidad de realizar trabajo de campo en una comunidad p'urhepecha, en el Estado de Michoacán. ${ }^{51}$ El conocimiento adquirido con la gente indígena de esa comunidad nos permitió comparar situaciones y ampliar aspectos de la problemática indígena latinoamericana en general. Experiencia y datos que fueron compartidos, luego, con la gente toba a través de charlas y exhibiciones del material obtenido en el propio Barrio Toba "Las Malvinas".

\footnotetext{
${ }^{50}$ La pasantía contó con el financiamiento del Fondo para el Mejoramiento de la Educación y la Ciencia (FOMEC), a través de la UNLP de septiembre a noviembre de 1998. Fue realizada en la Universidad Autónoma Metropolitana -UAM-Iztapalapa-, bajo la tutoría del Dr. R. Enrique Hamel.

${ }^{51}$ A raíz del trabajo realizado con el Dr. Enrique Hamel durante la pasantía, recibí una invitación para trabajar en el Proyecto "Comunidad Indígena y Educación Intercultural Bilingüe" como investigadora asociada. Realicé trabajo de campo con su equipo en una de las áreas indígenas de investigación, del 15 de febrero al 15 de abril de 1999. Esto me permitió un perfeccionamiento de las tareas propias de trabajo de campo centrando mi análisis particularmente en los principales indicadores etnolingüísticos (uso de las lenguas y vitalidad de la lengua indígena), estableciendo así comparaciones con lo observado en las comunidades tobas. Parte de los resultados de esta investigación fueron presentados en Hamel e Ibáñez Caselli (2000).
} 


\section{PARTE 2}

\section{Principales Postulados Epistemológicos de la InVESTIGaCión}

A continuación, se presentan algunos de los desarrollos teóricos más salientes que contribuyeron a la reflexión en torno a las relaciones entre lengua, cultura y sociedad; a la definición de etnia, identidad étnica y etnicidad; y a la comprensión de la dinámica de la lengua en la sociedad y las características de una comunidad de habla o discursiva. Todos estos lineamientos nos permiten manifestar y presentar las principales nociones y conceptualizaciones que guiaron esta investigación. Nociones y conceptos que serán definidos y redefinidos a lo largo de este capítulo y a los que volveremos en los próximos, según las necesidades lo requieran.

\section{II.2.1. Lengua, CUltura y Sociedad}

Indagar en torno a los usos y funciones que presenta una lengua dentro de un grupo sociocultural determinado, así como también las actitudes y valores que los hablantes poseen de su lengua materna implicó reflexionar sobre las relaciones existentes entre lenguaje, cultura y sociedad, y, con ello, poder realizar con esta investigación un aporte significativo a esta temática. Como veremos, las reflexiones en torno a esta problemática se han desarrollado desde los orígenes de la antropología siendo motivo también de análisis tanto de lingüistas como de especialistas de otras áreas de las ciencias sociales. Las vinculaciones entre estos tres conceptos no se ponen en duda; sin embargo, los diferentes especialistas han realizado abordajes particulares según su formación y época.

\section{- Algunos antecedentes}

En cuanto al concepto de cultura, éste ha sido motivo de grandes debates en el contexto de las teorías sociales por su complejidad y, en especial, en la ciencia antropológica. A lo largo de este debate fueron muchas y diversas las consideraciones sobre el rol particular que juega el lenguaje en la cultura; y este interés por la importancia del lenguaje lo encontramos desde los inicios y constitución de la antropología como ciencia. Un breve recorrido por las principales escuelas y corrientes antropológicas que tuvieron en consideración las vinculaciones entre lengua y cultura nos introducirá en el tema. 
En los albores de la disciplina, ubicamos las teorías que definieron la cultura como "todo lo aprendido", en oposición a "naturaleza", y que argumentaron que es a través de la socialización del lenguaje que adquirimos la cultura, incluida la lengua misma. Desde esta perspectiva, el lenguaje es una parte de la cultura y actúa como una forma de clasificar al mundo. En esta corriente teórica destacamos a los antropólogos sociales, fundadores de la escuela norteamericana -aunque de nacionalidad europea- como Franz Boas y su discípulo Edward Sapir. El primero de ellos se caracterizó por plantear que no se podría acceder al conocimiento de otra cultura si no se tenía un acceso directo a su lengua, en el sentido no sólo práctico, sino más bien como una necesidad teórica debido a las conexiones existentes entre lengua y cultura. Además, dio cuenta de la diversidad lingüística y la arbitrariedad de las lenguas en cuanto a su modo de clasificar el mundo importante aporte para el desarrollo del tema del relativismo cultural y lingüístico. Su interés por las lenguas indígenas de Norte América fue transmitido a sus discípulos. Uno de ellos, E. Sapir, reformuló el enfoque del rol de la lengua en la cultura, argumentando que los sistemas lingüísticos podrían ser estudiados como guías de los sistemas culturales, considerando así la lengua como un prerrequisito para el desarrollo de la cultura. Expuso la idea de que todas las lenguas poseen su propia lógica, consideraciones que permitieron desarrollar más tarde, junto con Benjamín L. Whorf la "hipótesis del relativismo lingüístico". Los estudios realizados por este último contribuyeron en el campo de la teoría lingüística centrándose en las relaciones entre lenguaje y visión de mundo. Según este autor, el análisis lingüístico debía basarse en la descripción de la visión de mundo de un grupo social, la cual debería ser inferida a partir de la sistematización de los patrones gramaticales $\mathrm{y}$, en especial, de las comparaciones entre lenguas radicalmente diferentes. Esta sistematización daría a conocer no sólo las categorías visibles o manifiestas (overt categories) -llamadas fenotipos-, sino también las ocultas o subyacentes (covert categories) - o criptotipos. ${ }^{52}$

Contemporáneamente a las teorías de Boas, en Gran Bretaña y en el marco del funcionalismo, destacamos la contribución de Bronislaw Malinowski al enfatizar la importancia del conocimiento de la lengua de una cultura o sociedad como técnica metodológica durante el trabajo de campo, por un lado, y la conceptualización de la

\footnotetext{
52 No es nuestra intención aquí desarrollar los aspectos teóricos de estos conceptos. Los mismos han sido debatidos y reformulados a lo largo del desarrollo de la disciplina. Para más información ver Bolaño (1982); Hudson ([1980] 1981); Duranti (1997); Golluscio (2002).
} 
lengua como un "modo de acción", por otro. En consideración con el primer aspecto, es a través del conocimiento de la lengua que el antropólogo puede traducir los valores y pensamientos propios de la cultura como un modo de evitar el etnocentrismo. De esta manera, el investigador alcanzaría una comprensión generalizada del contexto de la situación, en la que él también se encuentra inmerso, durante su trabajo de campo. Este concepto -luego desarrollado por J. R. Firth- se convertirá en esencial a la luz de los estudios posteriores, puesto que implica que el lenguaje sólo surge a la existencia cuando funciona en algún medio (Halliday [1978]1998). Es decir, dentro de este enfoque, se tiene la concepción de que los sentidos y usos de las formas lingüísticas, de las palabras y oraciones, son adquiridos y comprendidos a partir de su ocurrencia dentro del contexto de la situación (Robins 1976). Esto nos permite entender el segundo aspecto mencionado, donde Malinowski, en sus primeros trabajos, define a la lengua como un hábito corporal, comparable a cualquier otro tipo de costumbres y como parte integral de la cultura. En este sentido, la cultura es para este autor un todo organizado que se compone de dos partes: los artefactos y un sistema de costumbres - conjunto de elementos componentes relacionados entre sí. Lo importante de destacar en su pensamiento es la fuerza que le otorga a la lengua para accionar directa y consensuadamente sobre otros organismos y así lograr, indirectamente, la manipulación del medio ambiente. ${ }^{53}$

Volviendo a la antropología norteamericana, hacia fines de la década de 1950 y comienzos de 1960, toma predominio la concepción de la cultura como cuerpo de conocimiento. Los representantes de esta corriente teórica fueron principalmente W. Goodenough y Ch. Frake cuyos postulados permitieron el desarrollo de la etnociencia. En relación con lo lingüístico, se planteó que una forma de conocer la cultura era conocer su lengua. Se llegó a concebir la lengua como un conjunto de proposiciones acerca de lo que el hablante sabe o cree. Asimismo, en la misma época, pero en el marco del estructuralismo y en Francia, Claude Lévi-Strauss se destaca como el principal exponente de la consideración de la cultura como un sistema de signos, es decir, como comunicación. Dentro de este punto de vista, la cultura es representación

\footnotetext{
${ }^{53}$ Cabe aclarar que en un principio Malinowski entendió al lenguaje como un "modo de acción" y no "de reflexión" en relación a los "pueblos primitivos", para cuyo estudio se debía mantener unidos el habla y el contexto. Sin embargo, posteriormente reformuló su punto de vista y planteó la importancia de tener en cuenta el contexto para el estudio de cualquier lengua, incluso la escrita. Ver Kahn (1975).
} 
del mundo, un modo de darle sentido a la realidad que ha sido objetivada en historias, mitos, descripciones, teorías, proverbios, productos artísticos y actuaciones. Es importante mencionar que este autor resaltó la importancia de la lingüística como la única disciplina que por su metodología y técnicas alcanzadas podía ser considerada como una "verdadera ciencia". De manera tal que la antropología debía sacar provecho de los logros y progresos alcanzados por ésta. Es así como, por ejemplo, se realizaron estudios aplicando el análisis fonológico de la lingüística a los estudios de los sistemas de parentesco, entre otros. El mismo autor delimitó tres niveles de relación entre la Lingüística y la Antropología: un primer nivel de relación entre 'una' lengua y 'una' cultura; un segundo nivel de relación entre 'lenguaje' y 'cultura' en general; y, por último, una relación entre la lingüística y la antropología estudiadas como ciencias.

Hacia finales de la década de 1960 y comienzos de 1970 un conjunto de intelectuales -considerados postestructuralistas- concibieron la cultura como un sistema de prácticas (Lacan, Foucault, Derrida). En esta línea, para Pierre Bourdieu y Loïc Wacquant ([1982]1995), P. Bourdieu, J. C. Passeron y M. Saint Martín (1994) la lengua no sería un sistema autónomo, sino un sistema definido por los procesos sociopolíticos. Según Bourdieu ([1984] 1990), no podemos discutir sobre el lenguaje si no tomamos en consideración las condiciones sociales que permiten su existencia. El lenguaje existe solamente como habitus lingüístico, entendido como un sistema habitual y recurrente de disposiciones y expectativas.

\section{- La aproximación al lenguaje en su contexto social}

En cuanto al interés por las relaciones existentes entre lengua y sociedad en el contexto de la lingüística podemos decir que el estudio del lenguaje en su contexto social estuvo relegado debido a la atención que se le otorgó al análisis de tipo formal del sistema lingüístico. Es decir, desde los inicios de la lingüística prevaleció el interés por la fonología y la sintaxis, siguiendo la dicotomía planteada por Ferdinand de Saussure entre langue-parole, lengua-habla, y más tarde introducida por Noam Chomsky bajo las rúbricas de competencia-actuación lingüísticas, en la que el habla -aquel aspecto del lenguaje que, hasta entonces, había sido considerado imperfecto, diverso y asistemático- quedaba fuera del alcance de un estudio científico. Esto implicaba, por lo tanto, sostener estudios de la lengua disociados de la cultura o sociedad que la habla. Fue recién a mediados del siglo XX que C. Morris introdujo el término de pragmática 
para designar la "ciencia de los signos en relación con sus intérpretes". De modo tal que se daba inicio a la tricotomía en que se dividió y caracterizó la lingüística moderna: sintaxis - semántica - pragmática. La conformación de la pragmática significó un mayor interés por parte de los lingüistas por los aspectos que regulan el uso del lenguaje en la comunicación, destacándose los trabajos de J. Austin, J. Searle y H. Grice, entre otros. Se tomaron en consideración los factores extralingüísticos que determinan el uso del lenguaje, tales como el emisor, el destinatario, la intención comunicativa, el contexto verbal, la situación, etc. La contribución de sus trabajos permitió configurar una teoría general de las acciones comunicativas. En este sentido, se introdujo un desplazamiento de las categorías gramaticales hacia los "actos de habla" como unidades de análisis.

De aquí en adelante, influidos por los avances en las otras disciplinas sociales y el trabajo interdisciplinario, antropólogos, lingüistas y sociólogos fueron desarrollando diferentes enfoques teóricos que definieron áreas de interés en torno al habla, al estudio del lenguaje en su contexto social y a los cambios y la diversidad lingüísticos en sociedades multilingües, dando lugar al desarrollo de las perspectivas sociolingüísticas y antropológico lingüísticas.

El desarrollo de la etnolingüística, alrededor de 1940, comprendió pocos trabajos de escasa trascendencia en los Estados Unidos de AMÉRICA, aunque de mayor reconocimiento en Europa. ${ }^{54}$ Años más tarde, esta línea daría paso a otras disciplinas cuyas convergencias y divergencias interpretamos como similares a las que se dan entre la sociología y la antropología sociocultural, donde los límites absolutos no existen. Las características diferenciales entre estas dos disciplinas las debemos buscar en la historia del surgimiento y desarrollo de cada una. Mientras que la primera se ha caracterizado más bien por el estudio de las sociedades complejas, a gran escala, y ha tenido la tendencia de emplear métodos de tipo cuantitativos, la segunda se ha distinguido por el estudio a pequeña escala, en aquellas sociedades dominadas en el contexto de la situación colonial, consideradas "simples" o "primitivas", con el predominio del uso de métodos cualitativos. Así, la ciencia social creció, según Worsley (1966), como el reflejo de la división del mundo: los antropólogos estudiaron la no Europa, además de las tradiciones campesinas de la propia Europa; y los sociólogos estudiaron a los

\footnotetext{
${ }^{54}$ Según Duranti (1997) en Europa se habría conservado el nombre de etnolingüística como una forma de seguir la tradición de llamar etnología a la antropología sociocultural.
} 
"blancos". De la misma manera, creemos que el desarrollo de la antropología lingüística y la etnografía del habla representaron el interés conjunto de lingüistas y antropólogos por las lenguas indígenas, manifestando claramente la necesidad de incluir el estudio de los fenómenos culturales en la consideración de problemas lingüísticos y con un énfasis en una aproximación etnográfica y la utilización de métodos de tipo cualitativos. Luego, la atención puesta en los procesos sociales urbanos, ligada con el interés en los problemas del Tercer Mundo, dio un empuje al desarrollo de la sociolingüística sobrepasando los intereses de la etnolingüística de las décadas pasadas (Garvin y Lastra 1974); con una aproximación sociológica y la utilización de métodos de tipo cuantitativos.

Las orientaciones sociolingüísticas iniciadas por W. Labov en Norteamérica, por un lado, y por J. R. Firth y M. A. K. Halliday en Inglaterra, por otro, han aportado al desarrollo del análisis del lenguaje en su contexto social y a la perspectiva interaccional, respectivamente. Los trabajos sociolingüísticos se han caracterizado más bien por colocar un mayor énfasis en los estudios de variación y cambios lingüísticos; en tanto como veremos más adelante- los antropólogos lingüistas han abordado otras áreas de estudio tales como los registros del habla, lengua y género, los actos de habla y el discurso -lo que no quiere decir que los primeros no trabajen estas cuestiones y viceversa-. La Sociología del Lenguaje -así denominada especialmente por J. Fishmanes una de las áreas de investigación que se incluye en esta rama. Ésta trata básicamente del análisis de cómo interactúan los grandes factores sociales con los lenguajes y dialectos; aborda los problemas asociados al mantenimiento y desplazamiento de las lenguas minoritarias, el desarrollo de situaciones de bilingüismo, la estandarización de la lengua y la planificación lingüística de un país o región.

Es importante destacar en todo esto un caso de excepción en la historia del conocimiento de la lingüística. Se trata de los estudios tempranos desarrollados por V. Voloshinov hacia fines de 1920, aunque dados a conocer al "mundo científíco occidental" varias décadas más tarde. En su obra, este autor elabora una teoría social del lenguaje y el significado pionera de los estudios lingüísticos que incorporan lo social y lo ideológico.

A lo largo de la década de 1960, los trabajos realizados desde la antropología lingüística -cuyos principales representantes lo constituyen D. Hymes, J. Gumperz, R. Bauman, J. Sherzer y A. Duranti- centraron su foco de interés en el habla y la 
comunicación; alentaron la necesidad de analizar el lenguaje no ya como un sistema formal aislado de la cultura, sino como un componente constitutivo de la vida de las sociedades; y reconocieron que los hablantes no sólo poseen conocimiento de la gramática, sino, fundamentalmente, de las pautas y normas comunicativas que caracterizan a la comunidad de habla y de cómo hacer uso de su lengua apropiadamente. El análisis se centra en los patrones de la comunicación como partes constitutivas de la conducta y conocimiento cultural, puesto que la lengua es comportamiento y/ o conocimiento cultural, un sistema de uso cuyas reglas y normas componen una parte de la cultura. En este caso, el concepto de cultura es entendido como un sistema de ideas que delinea y da significado a toda conducta de la sociedad. De este modo, la antropología lingüística -también llamada lingüística antropológica- ${ }^{55}$ versa, en términos de Dell Hymes (1963:277), sobre "el estudio del habla y el lenguaje en el contexto de la antropología”. Sin embargo, la antropología lingüística no consiste sólo en el posible estudio que un antropólogo pudiera realizar de una lengua. No equivale a recopilar cuentos, leyendas, textos de otra cultura y que estos sean analizados por un especialista en las ciencias antropológicas. Su interés se centra básicamente en los usos del lenguaje; interés que puede ser compartido con las áreas de estudio a fines ya mencionadas arriba. En este sentido, la antropología lingüística se diferencia de estas otras disciplinas en que su foco está centrado en considerar al lenguaje como un conjunto de recursos simbólicos que construye lo social y representa tanto el mundo real como el posible. Este aspecto le permite contribuir al análisis de temas como, por ejemplo, el de la representación política, la constitución de la autoridad, la legitimación del poder, las bases culturales del racismo y los conflictos étnicos, el proceso de socialización, el contacto cultural y los cambios sociales, entre otros (Duranti 1997). La antropología lingüística se encuentra dentro del campo antropológico porque examina el lenguaje a través de los objetivos propios de esta disciplina. Es decir, coloca su mirada especialmente en cómo la cultura se transmite y reproduce, en las relaciones existentes entre los sistemas culturales y las diferentes formas de la organización social y en el rol que cumplen las condiciones materiales de existencia en la comprensión que la gente tiene del mundo (Duranti 1997:4). Para los antropólogos lingüistas el lenguaje es un recurso cultural y el habla una práctica sociocultural. Se considera a los hablantes como

\footnotetext{
${ }^{55}$ Ambos términos han sido utilizados indistintamente en la bibliografía (Ver Hymes 1963, 1964; Duranti 1997).
} 
actores sociales y al lenguaje como una fuente para y producto de la interacción social. $\mathrm{Su}$ principal proposición es que "hay dimensiones del habla que sólo pueden ser capturadas mediante el estudio de lo que la gente hace realmente con el lenguaje, colocando la atención en el énfasis que se colocan en las palabras, los silencios y los gestos en el propio contexto donde se producen esos signos" (Duranti 1997:9).

Como toda disciplina científica, la antropología lingüística, comparte elementos comunes con otras áreas de estudio; sus alcances teóricos $\mathrm{y}$ metodológicos se influencian y entrecruzan, compartiendo conceptos, técnicas y modelos de análisis. En este sentido, coincidimos con Colman (1978) en que el desarrollo de una disciplina se da mediante un doble juego: por un lado, en términos de su distinción; es decir, por una delimitación o recorte histórico de su objeto de estudio, se conforman campos particulares con formas propias de abordarlo, cuestionarlo y construirlo; cada uno con criterios metodológicos específicos. Se trata de un proceso en el que las diferentes disciplinas se van diferenciando unas de otras. Por otro lado, ese desarrollo es dialéctico y desigual; las disciplinas sufren una transformación histórica contradictoria según el tipo de relación que establecen con su objeto de estudio. Ante la hegemonía de una teoría o paradigma determinados y la presencia de ciertos obstáculos metodológicos que no pueden ser salteados por éstos, suelen aparecer otros que tratan de dar respuestas a los nuevos hechos; evaden las reglas del juego dominante, y se producen rupturas epistemológicas que consisten en acceder a ciertas leyes, métodos de organización de los datos que parten de otros supuestos teóricos que permiten interpretar y construir de un modo diferente el hecho científico ${ }^{56}$ Es así como la antropología lingüística ha ido modificando y desarrollando con el tiempo sus áreas teóricas. En las últimas décadas, ha ampliado su campo de interés incluyendo una serie de aspectos provenientes del estudio del folclore y la performance - traducido como "ejecución o actuación"-, ${ }^{57}$ la educación, la sociología cognitiva y la adquisición del lenguaje. Asimismo, la etnometodología, por un lado, y las teorías sociales que se interesan por los modos en que se construye la sociedad y cómo actúa la cultura, por otro, han enriquecido las investigaciones recientes.

\footnotetext{
${ }^{56}$ Para un desarrollo más profundo de esta temática ver Bourdieu (2000) donde el autor analiza la constitución de las disciplinas en relación a los campos de poder.

${ }^{57}$ Ver Golluscio (2002:36).
} 
Los aportes de las investigaciones provenientes de una nueva disciplina configurada a partir de la década de 1960, en el marco de la antropología lingüística, con intereses propios y bien definidos, y que contó inicialmente con los estudios de Dell Hymes (1962) y John Gumperz y D. Hymes (1964) son también importantes de destacar. Se trata de la Etnografía del Habla - o también llamada Etnografía de la Comunicaciónentendida como una aproximación al lenguaje y al habla en su contexto etnográfico (Sherzer 1983). Su desarrollo marcó un cambio de enfoque significativo entre los estudios lingüísticos, pasando del interés por el código -aspecto formal de la lengua-al de la lengua en uso. Una propuesta orientada al estudio interdisciplinario y centrada en el habla concebido como "los usos de la lengua en el desarrollo de la vida social" (Bauman y Sherzer 1975:96). Es más, el interés por el uso del lenguaje no es únicamente un compromiso metodológico para poder responder a la pregunta de qué es lo que realmente dicen los hablantes en diversos contextos, sino también una consecuencia del deseo de conocer lo que los hablantes hacen con el lenguaje, voluntaria o involuntariamente, consciente o inconscientemente, directa $o$ indirectamente. $\mathrm{Y}$ este interés por la labor realizada por y a través del lenguaje ha motivado a esta disciplina a indagar en los modos en que se recrea, cuestiona y establece la identidad y las relaciones sociales; a explicar por qué el mundo es como es y cómo se producen los cambios sociales; en cómo se estructuran los eventos comunicativos en un nivel tanto individual como social (Duranti 1992).

Con el propósito de desarrollar modos apropiados de descripción y clasificación, con el fin de responder a nuevas preguntas y dar a éstas un nuevo enfoque, Hymes construyó tres bloques de aproximación a la etnografía de la comunicación: 1) la perspectiva etnográfica; 2) el estudio de los eventos comunicativos que constituyen la vida social de la comunidad; y 3) un modelo de los diferentes componentes de los eventos. Entre las principales unidades de análisis lingüístico-comunicativas definidas por este autor para la etnografía del habla se encuentran: el acto de habla, el evento de habla, la situación de habla o situación comunicativa, como así también los componentes del habla. ${ }^{58} \mathrm{Al}$

\footnotetext{
${ }^{58}$ Estos componentes fueron elaborados por Hymes como una guía para los investigadores del tema y los denominó S-P-E-A-K-I-N-G -sigla que corresponde a la primera letra de cada uno de los componentes: Situation (situación), Participants (participantes), Ends (fines), Act Sequences (secuencias del acto comunicativo), Key (clave o tono), Instrumentalities (instrumentos), Norms (normas de interacción), Genre (género). Luego, algunos de estos fueron divididos en dos o más. Ver Hymes ([1972]1986).
} 
mismo tiempo, se incorporaron al análisis unidades tales como el concepto de comunidad de habla entendido como una entidad más de tipo social que lingüística. ${ }^{59}$

\section{- Los avances de los últimos años}

Tres conceptos, interconectados entre sí, serían los más sobresalientes de estas últimas décadas: la performance, la indexicalidad y la participación (Duranti 1997, Golluscio 2002). El primero de ellos refiere al dominio de la acción entre los hombres, en donde los antropólogos lingüistas colocan su mirada en los modos en que se ejecutan los actos comunicativos. Involucra las nociones de creatividad e improvisación. El segundo está relacionado con el concepto de índex o índice de Charles Pierce. Los índices son los signos que poseen algún tipo de relación con el objeto al cual refieren. Esta categoría se ha extendido a las expresiones lingüísticas tales como los pronombres demostrativos este, ese, aquel; los pronombres personales: yo y tú o $U d$.; las expresiones temporales ahora, ayer; y las expresiones espaciales: arriba, abajo, debajo, encima. La propiedad de estas expresiones se denomina indexicalidad y se ha ampliado su uso a la comunicación lingüística, puesto que en el uso del lenguaje muchas de las expresiones lingüísticas están conectadas o señalan aspectos del contexto sociocultural (Duranti 1997:17-18). A esto, podemos agregar que la indexicalidad es utilizada por el hablante para construir su identidad frente a los demás (Gumperz 1982). Finalmente, para definir el último concepto, se parte de la idea de que el hablante involucra en su actividad social algo más que expresiones lingüísticas; a la competencia lingüística le corresponde también las actitudes, valores y motivaciones concernientes al lenguaje, sus rasgos y sus usos (Hymes 1972). En este sentido, el punto central es el reconocimiento de que hablar una lengua significa ser miembro de una comunidad de habla y la participación es la categoría empleada en la actualidad por los antropólogos lingüistas para señalar que el hablante es parte de un conjunto de actividades culturalmente organizadas e interpretadas. Si bien el concepto de participación significó una dimensión de análisis importante en la aproximación etnográfica del habla desarrollada por Hymes, en la cual destacó tipos de participantes (hablante, emisor y remitente, por un lado, y oyente, receptor, audiencia y destinatario, por otro), fue Goffman $(1979,1981)$ quien desarrolló el tema con mayor profundidad mediante la teoría del posicionamiento (footing):

\footnotetext{
${ }^{59}$ El concepto de comunidad de habla ha resultado clave para nuestro análisis, destinando un apartado sólo para su tratamiento.
} 
posición o alineamiento que toma el individuo cuando realiza una expresión lingüística. ${ }^{60}$

Desde 1980 en adelante, los desarrollos teóricos se fueron enriqueciendo y confluyeron en nuevas orientaciones que permitieron aportes significativos a la reflexión de las vinculaciones entre lengua - cultura y sociedad. En relación a las teorías sociales, destacamos las contribuciones de P. Bourdieu al concebir al lenguaje como un conjunto de prácticas por sí mismo que implica tanto un sistema particular del mundo y reglas gramaticales, como -sobre la base de una pugna oculta del poder simbólico- un modo particular de comunicación, con un sistema distintivo de clasificación y formas de referencia. En este sentido, la noción de "cultura como práctica" se relaciona con la idea de "cultura como participación" que se basa en considerar que cualquier acción en el mundo, incluyendo la comunicación verbal, posee una inherente cualidad social, colectiva y participativa. Ésta sería, según Duranti (1997), una noción de cultura muy útil para los estudios sobre los modos en que el lenguaje es usado en el mundo, puesto que hablar una lengua implica estar capacitado para participar en interacciones con el mundo. Es a través del uso del lenguaje que somos miembros de la comunidad de ideas y prácticas. A esto, le debemos agregar las ideas en torno a que la lengua no es una entidad homogénea. En palabras de Bakhtin (1981), en la vida diaria el habla de una persona está llena de voces (voices) o heteroglosia.

Los nuevos enfoques en el campo de la antropología lingüística ya no sólo destacan la importancia del habla, sino que colocan su interés en el discurso, entendido éste tanto como práctica histórica y sociocultural, como el locus donde se expresa y actualiza la relación entre lengua, cultura y sociedad (Sherzer 1987, 1992). En este sentido, el discurso es constitutivo y constituyente de lo social y es creador de identidades y relaciones sociales (Urban 1991). Lo que ha permitido la configuración de una nueva propuesta teórico-metodológica: la aproximación a la lengua y la cultura centrada en el discurso (Sherzer 1987; Urban 1991). El análisis crítico del discurso enfatiza, por su parte, el estudio del discurso como práctica social (Fairclough 1992).

La aproximación etnográfica continúa siendo fundamental para el abordaje de esta temática, al tiempo que se realiza una revisión de los principales conceptos utilizados hasta entonces como el de comunidad de habla y contexto y se introducen otros claves

\footnotetext{
${ }^{60}$ Ver Duranti (1997).
} 
para el análisis como el de la competencia (meta)-comunicativa, la performance (o ejecución), la contextualización y la reflexividad de la lengua y la cultura.

Desde esta perspectiva, el habla es entendida como un proceso continuo de contextualización (Duranti 1997:211-212). La noción de contextualización es definida por Gumperz ([1991] 2000:32) como "el uso que hacen hablantes y oyentes de los signos verbales y no verbales que vinculan lo que se dice en un momento y lugar dado con el conocimiento adquirido a través de la experiencia pasada, con el fin de recuperar las presuposiciones sobre las que se apoyan para mantener el compromiso conversacional y evaluar cuál es el propósito”. En este sentido, la contextualización debe ser comprendida sobre la base de categorías, tales como el "marco de producción e interpretación" y las "pistas de contextualización". La primera refiere al conjunto de contextos posibles en la memoria de un hablante que le permiten dar sentido a una emisión o conversación; mientras que la segunda, consiste en todo aquello que le permite a un hablante y oyente en una conversación, interpretar de qué se trata la actividad, cómo se debe entender el contenido semántico y cómo cada una de las frases se relaciona con la que la antecede y la precede (Gumperz 1982:131). Esto lleva a este autor a redefinir otro de los conceptos claves, el de la competencia comunicativa: "el conocimiento de las convenciones lingüísticas y las convenciones comunicativas vinculadas a éstas que los hablantes deben poseer para iniciar y sostener el compromiso conversacional". El compromiso conversacional, dice Gumperz, es una precondición necesaria para la comprensión. La comunicación siempre supone compartir en alguna medida convenciones de señalización, pero esto no significa que los interlocutores deban hablar la misma lengua o dialecto en el sentido en que los lingüistas utilizan el término (Gumperz [1981] 2002:154). Todo esto ha permitido la configuración del desarrollo de las nociones y teorías sobre la indexicalidad, los roles de participación y la performance -ya expuestas- y que orientan las investigaciones en el campo de la antropología lingüística.

Tanto la lengua como la cultura tienen una propiedad en común que consiste en su capacidad "reflexiva". Lengua y cultura pueden funcionar al mismo tiempo como medio y objeto de la praxis social. Esto quiere decir que las prácticas culturales y, entre ellas las lingüísticas, al tiempo que se realizan, se monitorean reflexivamente. Sin embargo, este monitoreo se da tanto en las formas y los contenidos lingüísticos y culturales, como en los usos de esas formas y contenidos, posibilitando no sólo la enunciación sino 
también la generación de pistas en el destinatario de cómo lo dicho debe ser interpretado (Briones y Golluscio 1994). Así como la capacidad reflexiva del lenguaje (metalingüística) queda definida como "el usar la lengua para comunicar acerca de la actividad de usar la lengua" (Lucy 1993), la “metacomunicación” será la capacidad reflexiva que permite hablar de las relaciones entre hablante y oyente durante la comunicación y la "metacultura" la capacidad reflexiva de la cultura que habla sobre las pautas culturales mismas.

La lengua en uso, durante la interacción social, contextualiza y es, a la vez, contextualizada. Desde la aproximación interaccional, lengua, cultura y sociedad encuentran sus bases y se sostienen en la interacción. Cada uno de estos elementos están fundados en la relación reflexiva con el "yo", con "el otro" y entre el "yo" y "el otro", y es por fuera de estas mutuas relaciones constitutivas donde se crea el discurso.

De forma tal que las unidades de análisis en esta última corriente son de tipo lingüístico, comunicativas y también sociales, centrándose en las prácticas discursivas y los textos interaccionales. Esto ha permitido el desarrollo de teorías de la interacción del discurso y estudios del lenguaje orientados hacia la interacción y la conversación que incorporan las dimensiones de la pragmática y la metapragmática e integran categorías analíticas de las ciencias sociales (Bourdieu [1984] 1990; Hanks 1996; Silverstein 1992; Fairclough 1992; entre otros). Una aplicación de esta posición al discurso indígena es realizada por Golluscio (2006).

Asimismo, no debemos dejar de mencionar las perspectivas de abordajes vinculados al análisis del discurso y de la conversación. El primero, entendido como cualquier unidad lingüística de un nivel superior al de la oración, que incluye tanto formas dialógicas como monológicas, escritas como orales; y el segundo, como cualquier discurso producido por más de una persona, es decir, todo diálogo (Schiffrin 1992, [1994]1998). Ambos análisis, contemplan enfoques diferentes que son abordados desde las distintas áreas mencionadas en este apartado con una metodología específica, junto con otras disciplinas de las ciencias sociales como pueden ser la sociología, la psicología, la filosofía y la historia.

\section{II.2.2. IDENTIDAD, ETNICIDAD Y LOS USOS DE LA LENGUA}

De acuerdo con lo planteado en el punto anterior, podemos señalar que la lengua es un hecho social, por cuanto es elaborado socialmente. A la vez, posee una doble función 
social: como medio de comunicación y como modo de identificación de grupos sociales. Esto significa que es a través de la lengua que se expresan las distintas categorías del pensamiento que conforman la visión de mundo de un grupo particular. ${ }^{61}$ El lenguaje delimita los campos semánticos y elabora esquemas clasificadores, socialmente generados, que llevan a diferenciar los objetos, por ejemplo, según su "género" o "número", grado de intimidad social, etc. convirtiéndose en uno de los elementos por medio del cual el grupo se identifica a sí mismo y se distingue de los demás (Tamagno Ibáñez Caselli 1993). Este aspecto nos permite visualizar la profunda vinculación entre lengua - cultura - sociedad: el conocimiento y el uso de una lengua específica proporciona al hablante su propia identificación con un modo particular de vida y con modalidades de hablar propios del grupo de pertenencia. Incluso, en muchas situaciones, la lengua puede actuar como un signo diacrítico de la identidad (Bartolomé 1997). Pero ¿cómo se desarrolla, se expresa y se realiza este proceso? La bibliografía antropológica y lingüística que ha tratado esta temática es amplia y no es nuestro propósito hacer un recorrido exhaustivo. Sólo se señalarán las principales nociones que fueron significativas a los fines de esta investigación.

\section{- Los procesos de adquisición de la lengua y la socialización}

Biológicamente, se hereda la predisposición de un aparato fonador que permite la capacidad del lenguaje. Sin embargo, la lengua se adquiere desde el nacimiento en un proceso de interacción con los miembros del grupo de pertenencia. ¿Por qué se habla de la "adquisición" del lenguaje y no del "aprendizaje" del mismo?

En el transcurso de la socialización -que comprende una serie de mecanismos que se ponen en juego para integrar a los individuos dentro de su sociedad-, el niño comienza a internalizar el conjunto de conocimientos, valores, normas propios del grupo y la lengua misma, sus usos. Asimismo, cabe destacar que dicho proceso se lleva a cabo a través de ésta. Es decir, que los miembros de una sociedad utilizan el lenguaje para socializar, al tiempo que se adquiere la lengua y sus usos apropiados durante la competencia social a lo largo de la socialización (Schieffelin - Ochs 1986). Durante este proceso la madre, principal transmisora del lenguaje, no se empeña en enseñar la lengua a su hijo sistemáticamente -teniendo en cuenta, por ejemplo, las reglas sintácticas tal como su hijo la aprenderá luego en la escuela-, sino que sólo la transmite y el niño la va

\footnotetext{
${ }^{61}$ Entendemos el concepto de visión de mundo en términos de Kearney (1975) como los modos culturales que permiten la cognición, es decir "obtener conocimiento de".
} 
adquiriendo a través de la práctica cotidiana, en la interacción (Gumperz - Bennett 1981).

En el análisis sobre el modo en que el niño se socializa para ser parte de la sociedad P. Berger y T. Luckmann ([1968] 2001) destacan que "la sociedad existe como realidad tanto objetiva como subjetiva". Estos aspectos tienen su reconocimiento si se entiende la sociedad como el producto de un continuo proceso dialéctico compuesto por tres momentos: externalización, objetivación e internalización.

Siguiendo los planteamientos de este análisis, entendemos que el niño no nace miembro de una sociedad, sino que nace con una predisposición hacia la sociabilidad y es a través de un proceso que va siendo parte de la misma. El punto de partida de este proceso es la internalización: "la aprehensión o interpretación inmediata de un acontecimiento objetivo en cuanto que expresa significado; es decir, en cuanto manifestación de los procesos subjetivos de otros que, en consecuencia, se vuelven subjetivamente significativos para sí’. De esta manera, la internalización constituye la base, primero, para la comprensión de los propios semejantes $\mathrm{y}$, segundo, para la aprehensión del mundo en cuanto realidad significativa y social. Esta aprehensión comienza cuando el individuo "asume" el mundo en el que ya viven otros. Solamente cuando el mismo ha llegado a este grado de internalización puede ser considerado miembro de la sociedad.

El proceso ontogenético por el cual esto se realiza se denomina socialización: “inducción amplia y coherente de un individuo en el mundo objetivo de una sociedad o un sector de él".

Es importante destacar que la socialización comporta algo más que un aprendizaje puramente cognoscitivo, se efectúa en circunstancias de enorme carga emocional, aunque siempre la internalización se produce sólo cuando se da la identificación. El niño acepta los "roles" y actitudes de los otros significantes, o sea que los internaliza y se apropia de ellos. Y por esta identificación, el niño se identifica a sí mismo, adquiere una identidad subjetiva. En este proceso, se crea en la conciencia del niño una abstracción progresiva que va de los roles y actitudes de otros específicos, a los roles y actitudes en general, constituyéndose el "otro generalizado". Esto implica la internalización de la sociedad y la realidad objetiva en ella establecida y el establecimiento subjetivo de una identidad coherente y continua. De forma tal que, sociedad, identidad y realidad se cristalizan subjetivamente en el mismo proceso de 
internalización. Esto último se corresponde con la internalización del lenguaje, factor más importante, que objetiva las experiencias compartidas y las hace accesibles a todos los que pertenecen a la misma comunidad de habla convirtiéndose, de este modo, en base e instrumento del acopio colectivo de conocimiento. Además, el lenguaje aporta los medios que permiten objetivar nuevas experiencias, facilitando que éstas se incorporen al conocimiento ya existente (Berger y Luckmann [1968] 2001). Es así como, para estos autores, el lenguaje actúa como depositario de las sedimentaciones objetivas y objetivadas en la tradición de la colectividad de que se trate-experiencias que se han ido sedimentando como formas estereotipadas en la memoria del individuoy como el principal transmisor de los significados objetivados en las instituciones.

\section{- El habitus en las prácticas socioculturales}

Según lo planteado hasta aquí, el individuo se convierte en miembro de la sociedad mediante un complejo proceso de internalización y subjetivación de un mundo que se le presenta objetivado. $\mathrm{Y}$ en ese proceso, se adquiere el lenguaje al tiempo que éste es el vehículo de la socialización. Esto también implica la adquisición de las normas sociolingüísticas (pautas comunicativas y metacomunicativas) que imperan en la comunidad de habla que caracteriza al grupo social. Entonces, continuando con nuestro análisis... ¿cómo se construye ese mundo de lo social? Y... ¿cómo actúa el individuo a través de él?

En la construcción de ese ambiente social han participado una serie de "habituaciones" que finalmente se institucionalizaron en un proceso social e histórico dado, quedando así objetivadas para el individuo: “... las instituciones se experimentan como si poseyeran una realidad propia, que se presenta al individuo como un hecho externo y coercitivo" (Berger y Luckmann [1968] 2001:80). Cada institución posee un cuerpo de conocimiento que provee las reglas de comportamiento institucional apropiadas, el que, a su vez, se aprende en el curso de la socialización. Así, este cuerpo de conocimiento actúa como mediatizador de la internalización de las estructuras objetivadas del mundo social, dentro de la conciencia individual: "programa" los canales en los que la externalización produce un mundo objetivo y objetiva este mundo a través del lenguaje y del aparato cognoscitivo basado en el mismo. Es decir, lo ordena en objetos que han de aprehenderse como realidad, y se internaliza de nuevo como verdad objetivamente válida (Berger y Luckmann [1968] 2001). 
Profundizando en la comprensión de ello, P. Bourdieu (1980) trata de reconstruir en torno del concepto de habitus el proceso por el cual lo social se interioriza en los individuos y logra que las estructuras objetivas concuerden con las subjetivas. Si hay una homología entre el orden social y las prácticas de los sujetos es porque esas acciones se insertan en sistemas de hábitos, constituidos, en su mayoría, desde la infancia.

Siguiendo el análisis sobre cómo se interiorizan las estructuras sociales en los sujetos individuales y colectivos, según la "teoría del habitus" de P. Bourdieu, podemos entender que las prácticas sociales -y los objetos de conocimiento construidos en ellasestán orientadas por "el sistema de disposiciones estructuradas y estructurantes constituido en la práctica y dirigida hacia funciones prácticas" (Bourdieu 1980). Este sistema de disposiciones duraderas y transferibles a nuevas situaciones constituyen habitus: "esquemas básicos de percepción, pensamiento y acción", "principios generadores y organizadores de prácticas y representaciones” (Bourdieu 1991: 91-92).

El habitus es una capacidad infinita de engendrar en una libertad (controlada) productos - pensamientos, percepciones, expresiones, acciones- que tienen siempre como límites las condiciones de su producción, histórica y socialmente situadas. Esto quiere decir que el habitus es estructurado desde la sociedad y se le presenta objetivado al individuo; por otra parte, una vez que estas estructuras estructuradas han sido internalizadas por el individuo haciéndolas subjetivas, las mismas organizan las prácticas de éste determinando su actuar en la sociedad. De modo que los individuos que componen una sociedad van clasificando el mundo que los rodea de acuerdo con su sistema de habitus, el cual, a su vez, está relacionado con un sistema de clasificación social, es decir, una "clase social" determinada -clase en sentido etimológico(Bourdieu 1991: 98-100).

Según Bourdieu, el habitus, generado por las estructuras objetivas, genera a su vez las prácticas individuales, da a la conducta esquemas básicos de percepción, pensamiento y acción. Por ser sistemas de disposiciones durables y transponibles, estructuras predispuestas a funcionar como estructuras estructurantes, el habitus sistematiza el conjunto de las prácticas de cada persona y cada grupo, garantiza su coherencia con el desarrollo social. De esta forma, a través de la formación de habitus, las condiciones de existencia de cada clase van imponiendo inconscientemente un modo de clasificar y experimentar lo real. Cuando los sujetos seleccionan en rigor están 
representando los papeles que les fijó el sistema de clases. Sin embargo, para este autor, las prácticas no son meras ejecuciones del habitus producido por la educación familiar y escolar, por la interiorización de las reglas sociales. En las prácticas se actualizan, se vuelven acto, las disposiciones del habitus que han encontrado condiciones propicias para ejercerse. Es decir, si bien el habitus tiende a reproducir las condiciones objetivas que lo engendraron, un nuevo contexto, la apertura de posibilidades históricas diferentes, permiten reorganizar las disposiciones adquiridas y producir prácticas transformadoras.

La socialización, entonces, se realiza en la construcción e internalización del habitus. Todo individuo nace dentro de una estructura social objetiva en la cual encuentra a los otros significantes que están encargados de su socialización y que le son impuestos. Las definiciones que los otros significantes hacen de la situación del individuo le son presentadas a éste como realidad objetiva. Por lo tanto, él nace también dentro de un mundo social objetivo. Además, los otros significantes, que mediatizan el mundo para él, lo modifican en el curso de esa mediatización. Seleccionan aspectos del mundo según la situación que ocupan dentro de la estructura social y también en virtud de sus idiosincrasias individuales. El mundo social aparece filtrado para el individuo mediante esta doble selección (Berger y Luckmann [1968] 2001).

\section{- El habitus lingüístico en la dinámica de la sociedad}

Así como el individuo internaliza un mundo objetivado en y por la lengua -en relación a un conjunto de normas comunicativas y metacomuncativas-, en este mismo proceso se da también la aprehensión de signos lingüísticos y formas discursivas particulares generados según la clase social de pertenencia y en una época determinada. Cada clase social, en un momento histórico dado, al clasificar la realidad de un modo particular, le atribuye significados diferentes a las cosas que dice y hace, es decir, a las prácticas que realiza.

En este sentido, acordamos con los planteos desarrollados por V. Voloshinov ([1929] 1992) al decir que las formas del signo están determinadas ante todo tanto por la organización social de los hombres como por las condiciones más inmediatas de su interacción. Es decir, las relaciones de producción y la formación político-social condicionada directamente por aquellas determinan todos los posibles contactos de los hombres, todas las formas y modos de su comunicación verbal: en el trabajo, en la política, en la creación ideológica. A esto, el autor agrega que tanto las formas como los 
temas de las manifestaciones discursivas están determinados por las formas y los tipos de la comunicación discursiva. En cuanto cambian las formas cambia el signo. De modo tal que todo signo ideológico, incluyendo el verbal, al plasmarse en el proceso de comunicación social está determinado por el horizonte social de una época y de un grupo social dados. Así, cada una de las etapas por las que pasa la sociedad se encuentra caracterizada por un específico y limitado círculo de temas expuestos a la atención de la sociedad y en los que esta atención suele depositar un acento valorativo. Este grupo de temas se manifiesta como signos y para que esto ocurra sólo aquello que posea un valor social puede entrar en el mundo de la ideología, constituirse o consolidarse en él; por eso, todos los acentos ideológicos aparecen como acentos sociales que pretenden un reconocimiento social.

Sin embargo, Voloshinov destaca que el carácter del signo ideológico es multiacentuado: si bien las distintas clases sociales usan una misma lengua, la clase social no coincide con el colectivo semiótico, utilizando de manera diferente y "distintiva" los signos de la comunicación ideológica. Como consecuencia, en cada signo ideológico se cruzan los acentos de orientaciones diversas y cada signo llega a ser arena de las luchas de clases. En esta interacción, la clase dominante trata de volver a su signo ideológico monoacentual otorgándole un carácter eterno, por encima de las demás clases sociales.

De acuerdo con Bourdieu (1985), considerar al mundo social como un universo de intercambios simbólicos y reducir los mismos sólo al acto de comunicación que tiene por objeto ser descifrado por un código, lengua o cultura, no es suficiente para entender la dinámica de los intercambios lingüísticos. Agrega que es necesario mostrar que esas relaciones de comunicación por excelencia, que son los intercambios lingüísticos, son también relaciones de poder simbólico donde se actualizan las relaciones de fuerza entre los locutores y sus respectivos grupos. En este sentido, todo acto verbal es una coyuntura entre las disposiciones, socialmente modeladas, del habitus lingüístico -que implican una cierta propensión a hablar y decir determinadas cosas (interés expresivo) y una cierta capacidad de hablar definida a la vez como capacidad lingüística de infinita creación de discursos gramaticalmente semejantes y como capacidad social que permite utilizar adecuadamente esta competencia en una determinada situación- y las estructuras del mercado lingüístico, que se imponen como un sistema de sanciones y censuras específicas. De esta forma, la significación completa de los discursos se 
produce en la relación con un mercado, en el valor distintivo resultante de la relación actuada por los locutores, consciente o inconscientemente, entre el producto lingüístico ofrecido por un locutor social caracterizado y los productos simultáneamente propuestos en un determinado espacio social. A su vez, el producto lingüístico sólo se realiza completamente como mensaje cuando es descifrado. Por lo tanto, los esquemas de interpretación que los receptores ponen en práctica en su apropiación creadora del producto propuesto pueden estar más o menos alejados de los que han orientado la producción. A través de estos efectos, el mercado no sólo contribuye a crear el valor simbólico, sino también el sentido del discurso.

En este aspecto, Bourdieu define estilo lingüístico a la separación individual con respecto a la norma lingüística, esa elaboración particular que tiende a conferir al discurso propiedades distintivas, siendo percibido sólo en relación con sujetos percibientes, dotados de disposiciones diacríticas que permiten hacer distinciones entre formas de decir diferentes. Es decir, que el estilo en la dicción de una clase (social, sexual o de generación) comparada con otra, sólo existe en relación a agentes dotados de esquemas de percepción y de apreciación que permiten constituirlo como conjunto de diferencias sistemáticas. Por esta razón, señala que lo que circula en el mercado lingüístico no es "la lengua", sino discursos estilísticamente caracterizados; discursos que a la vez se colocan del lado de la producción, en la medida en que cada locutor se hace un idiolecto $^{62}$ con la lengua común, y del lado de la recepción, en la medida en que cada receptor contribuye a producir el mensaje que percibe introduciendo en él todo lo que constituye su experiencia singular y colectiva. De modo tal que este aspecto también se convierte en un elemento importante a tener en cuenta en el momento de definir una comunidad de habla.

Analizando la interacción verbal que se da en el seno de la sociedad, distinguimos una lengua oficial, la lengua, que es considerada legítima y es impuesta por medio de un proceso político de unificación lingüística a todos los hablantes considerados miembros de la comunidad lingüística. Los principales encargados de imponerla y realizar el control de su correcto uso son, principalmente, los docentes en las escuelas. Y, por otra parte, distintas lenguas, modalidades de habla o discursivas -caracterizadas por un estilo lingüístico particular- que se fueron y se van generando histórica y socialmente, de

${ }^{62}$ C. Hockett (1958:319) definió el idiolecto como "la totalidad de hábitos lingüisticos de una misma persona en una época dada". 
acuerdo con las características de género, edad, especificidades socioculturales, regionales, etc.

Durante el proceso de socialización -como ya hemos señalado- se internalizan submundos institucionales o basados sobre instituciones. Su alcance y su carácter se determina por la complejidad de la división del trabajo y la distribución social concomitante del conocimiento. Se adquiere el conocimiento especializado de "roles" y vocabularios específicos de acuerdo con ellos. Los procesos formales de la socialización presuponen un proceso de tratar con un "yo" formado con anterioridad y con "un mundo" ya internalizado. Frente a una sociedad diversa y desigual, como la nuestra pensando sobre todo en nuestro análisis del caso de los niños tobas en el contexto educativo, y en toda situación de contacto interétnico-, podemos entender la aparición de problemas de coherencia entre las internalizaciones originales y las nuevas. Establecer y mantener la coherencia presupone ciertos procedimientos conceptuales para integrar los diferentes cuerpos de conocimiento -y que también deberían ser tenidos en cuenta en toda política lingüística y educativa-. Y esto nos lleva a la problemática de la identidad en los procesos de contacto interétnicos.

\section{- Lengua y Discurso en el proceso de construcción social de la Identidad}

¿Qué entendemos por identidad? Una de las categorías explicativas centrales en la configuración de las reflexiones sobre identidad, según Bartolomé, es el concepto de “representación colectiva" de E. Durkheim (1903). Ésta es definida como las formas en que una sociedad representa los objetos de su experiencia; como contenidos de conciencia que reflejan la experiencia colectiva y añaden a la biografía individual el conocimiento generado por la sociedad. De esta manera, la representación colectiva sería el producto vivencial de la larga asociación espacial y temporal de un grupo humano que se manifiesta como formas de pensamiento no explícitas que incluso subyacen a las creencias. Más tarde, la concepción durkheimniana fue retomada y profundizada por psicólogos sociales, limitándose a complementarla al entenderla como formas socialmente construidas de percibir, pensar y actuar sobre la realidad dentro de un sistema cultural (Bartolomé 1997:43-44). De modo tal que la identidad implica un proceso complejo y dinámico de construcción social. Podemos hablar de dos niveles de identidad: el individual y el social. Sin embargo, el segundo es el principal puesto que la identidad individual se gesta en relación a una identidad social que se corresponde con la sociedad a la que el individuo pertenece y de la cual forma parte. 
Cuando se habla de un grupo social que habita en un determinado territorio, que comparte un conjunto de valores, normas y creencias y que habla una lengua determinada, entre otras cosas, existe una tendencia a identificarlo con una etnia. Este término deriva del vocablo griego ethnos y significa "pueblo". Tradicionalmente, se lo ha vinculado con factores culturales y con los conceptos de grupo y territorio; y en su definición ha predominado la idea tan discutida en el campo antropológico de "un territorio $=$ una lengua $=$ una sociedad $=$ una cultura". Esta idea aún continúa presente en algunos ámbitos académicos y predomina también en el sentido común de nuestra sociedad. En especial, es muy fuerte la noción de que si se pierden algunos de los elementos culturales que conforman esa etnia -particularmente la lengua- se "pierde la identidad". Esto se nos presentó como una afirmación muy marcada a la hora de acercarnos a analizar el Barrio Toba "Las Malvinas". Los funcionarios públicos, los docentes de las escuelas cercanas, los vecinos dudaban de que las familias tobas "conservaran su identidad"; 63 para ellos, el hecho de no vestir como indígenas y hablar la lengua toba, practicar el evangelio y compartir algunas características comunes de la vida en la ciudad, los llevaba a expresar que "los tobas habían perdido o estaban en vías de perder la identidad" (Tamagno 1991, Tamagno 1992a, 1992b, Tamagno e Ibáñez Caselli 1993, Tamagno 2001, Tamagno y otros 2005). Como veremos, se trata éste de un análisis culturalista, esencialista, atemporal y ahistórico que no permite visualizar la heterogeneidad, el dinamismo y las transformaciones que en todo grupo social se presenta y genera como resultado histórico y de contacto permanente con otros grupos. Este último aspecto es importante de destacar, ya que ningún grupo social se ha mantenido absolutamente aislado de otros. Las etnias son el resultado de la gestación y de los desarrollos históricos; es decir, se originaron sobre la base de los contactos interétnicos. Entendiendo por contacto interétnico las relaciones que se dan entre individuos y grupos de diversas procedencias "nacionales", "raciales" o "culturales" (Cardoso de Oliveira 1992:19). En relación a esto, como producto de las relaciones de contacto generalmente conflictivas, donde hay un grupo dominante y otro subordinado, donde se expresan las relaciones de poder, la identidad social se construye en un complejo proceso de aceptación/ rechazo de elementos y modelos (Tamagno 1988). Lo que es más, a nivel intraétnico, los grupos no son un todo homogéneo. No todos los miembros de una etnia comparten exactamente los mismos conocimientos como

\footnotetext{
${ }^{63}$ Igual situación ya había sido observada en Tamagno (1986) con los tobas de Villa IAPI.
} 
tampoco todos hablan de la misma manera la lengua. Existen diferencias etarias, de género, de clase -tal como lo expresáramos en párrafos anteriores en términos de Bourdieu.

Siguiendo los avances de la línea de investigación que desarrollamos en el Laboratorio de Investigaciones en Antropología Social (LIAS), acordamos con Bartolomé (1997:43) en que no debemos confundir cualquier forma de expresión identitaria con la identidad étnica, ya que ésta es una forma específica de la identidad social, que alude exclusivamente a la pertenencia a un grupo étnico. Como una forma de superar la visión culturalista del concepto de etnia, F. Barth (1976) definió los grupos étnicos como categorías de adscripción e identificación que son utilizadas por los actores mismos y tienen, por tanto, la característica de organizar la interacción entre los individuos. Según este autor, en la medida en que los actores utilizan las identidades étnicas para caracterizarse a sí mismos y a los otros, con fines de interacción, forman grupos étnicos en este sentido de organización (Barth 1976:15).

R. Cardoso de Oliveira (1976) retomó el carácter inconsciente y no sistemático de las representaciones colectivas para entender la identidad étnica como la forma ideológica que adoptan las representaciones colectivas de un grupo étnico. Así, para este autor, la identidad étnica se manifiesta como una construcción ideológica, que expresa y organiza la asunción grupal de las representaciones colectivas. Bartolomé señala que el mismo Cardoso de Oliveira siguiendo a Goodenough (1965) y Barth (1976) hizo hincapié en la noción de identidad contrastiva. Esto implica una relación entre nosotros y los otros, es decir, la existencia de dos o más identidades relacionadas que puedan ser confrontadas y con base en esas distinciones afirmar lo propio en oposición a lo alterno. Es decir, se trata de un concepto relacional, en la medida en que supone la definición de un grupo realizado en función del contraste con otro. De este modo, las identidades étnicas sólo se tornan comprensibles si las entendemos como expresiones de relaciones entre identidades diferenciadas. Por lo tanto, desde esta perspectiva, las categorías étnicas actuales pueden ser entendidas como construcciones ideológicas resultantes de las respectivas historias de articulación interétnica de cada grupo (Bartolomé 1997:4647).

Son varias las situaciones en las que se confunde identidad étnica con etnicidad. En este sentido, reflexiones sobre el tema (Tamagno 1988) permitieron deslindar estas conceptualizaciones. Dentro de las relaciones interétnicas -señala Bartolomé- es 
posible diferenciar la identidad o pertenencia al grupo étnico entendida como un fenómeno cognitivo que permite identificarnos e identificar a los miembros de nuestro propio grupo, de la etnicidad concebida como un fenómeno del comportamiento, ya que supone conductas en tanto miembro de ese mismo grupo. Es decir, la etnicidad es identidad en acción resultante de una definida "conciencia para sí". Por lo tanto, la identidad alude a los componentes históricos y estructurales de una ideología étnica, en tanto que la etnicidad constituye su expresión contextual (Bartolomé 1997:62-63). De esta manera, la etnicidad se manifiesta en forma exponencial a través de las rebeliones y movilizaciones tradicionales o de las nuevas organizaciones etnopolíticas. Se expresa como un estructurador de conductas políticas (Bartolomé 1997:64). Además, la etnicidad supone necesariamente una trayectoria -que es histórica y determinada por múltiples factores- y un origen -que es una experiencia primaria, individual, pero que también está traducida en saberes y narrativas a los que se acopla-. Lo que sería propio de las identidades étnicas es que, en ellas, la actualización histórica no anula el sentimiento de referencia al origen, sino que la refuerza; posibilitando la resolución simbólica y colectiva a esa contradicción que origina la fuerza política y emocional de la etnicidad (Pacheco de Oliveira 1999:30).

Cabe señalar que más allá de sus manifestaciones concretas, la identidad étnica se expresa también en forma explícita a través del discurso (Bartolomé 1997:66-67), definido en términos de N. Fairclough (1992) como "el uso de la lengua como una forma de práctica social". Esta idea tiene dos implicancias centrales. Primero, permite entender que el discurso es un modo de acción y una forma de representación, una forma por la cual la gente puede actuar sobre el mundo y sobre sí misma. Segundo, nos permite concebir al discurso en una relación dialéctica con la estructura social. Por un lado, el discurso es moldeado y constreñido por la estructura social en sentido amplio y en todos los niveles -la estructura de los discursos varía según las características del evento en el que se genera, en concordancia con el dominio social o institucional-. Y por otro, el discurso se construye socialmente. Las prácticas discursivas son prácticas sociales; sin embargo, para los fines del análisis el autor realiza una distinción. La práctica discursiva se constituye tanto de un modo convencional como creativo: contribuye a reproducir la sociedad (identidades sociales, relaciones sociales, sistemas de conocimiento y de creencias) y, al mismo tiempo, la transforma. En tanto que la práctica social tiene diversas orientaciones -económica, política, cultural, ideológica- y 
el discurso puede estar implicado en todas ellas sin que ninguna sea reducible al discurso mismo.

En este sentido, el autor señala tres aspectos que se relacionan con tres funciones del lenguaje que coexisten e interactúan en todo discurso:

a) El discurso contribuye a la construcción de identidades sociales y posición del sujeto. Este aspecto está vinculado con la función de identidad que se relaciona con los modos en que las identidades sociales se establecen en el discurso.

b) El discurso permite construir las relaciones sociales entre la gente. Este aspecto nos lleva a hablar de la función relacional que implica cómo se disponen y se negocian las relaciones sociales entre los discursos de los participantes.

c) El discurso contribuye en la construcción de los sistemas de creencias y conocimiento. Aspecto que se relaciona con la función ideacional del lenguaje que implica los modos en que los textos significan el mundo, sus procesos, entidades y relaciones.

Podemos agregar a esto una cuarta función del lenguaje: la textual que concierne los modos en que los bits de información se ubican en primer o segundo plano, se toman como algo dado o se presentan como algo nuevo, aparecen como temas o tópicos, y cómo una parte del texto se fusiona para preceder o continuar partes del texto (Halliday [1978] 1998).

Al entender los discursos como práctica social, Fairclough introduce dos conceptos claves para el análisis y que se relacionan con los lineamientos expuestos en los párrafos anteriores. El primero corresponde al de la ideología entendida como las significaciones/ construcciones de la realidad que se construyen en varias dimensiones de formas/ significados en la práctica discursiva y que contribuye a la producción, reproducción o transformación de las relaciones de dominación. Y el segundo, al de hegemonía referida a las relaciones de poder que se establecen en toda sociedad cuyo análisis permite entender los cambios en el discurso.

Complementando esta postura, el discurso se compone de ciertas unidades que están relacionadas con los focos de la conciencia. En este sentido, el modelo de análisis de W. Chafe (1994) se centra en los componentes de la prosodia tales como entonación, volumen, tiempo, acento, pausa, cualidad de la voz, alargamiento o acortamiento de la voz. Según este autor, hablar de unidades de entonación implica pensar que el habla no es un continuum. En él hay tanto sonidos como silencios (pausas) y estos últimos son 
tan significativos como los primeros. Si bien las pausas son propias de la forma de narrar, existen pausas que tienen que ver con los procesos cognitivos y pragmáticos. Es por esta razón que conviene diferenciarlas. Así, las unidades de entonación serían la expresión lingüística de la información de la conciencia. Por cada unidad de entonación habría expresada una sola idea.

En el análisis que realiza de una conversación observa que hay dos modos de brindar información: una inmediata y otra desplazada, tanto de tiempo como de persona y espacio. Ésta última se refiere a la información que resulta interesante ya que es sorpresiva e introduce algo nuevo. Son estos aspectos del habla desplazado los que resultan importantes analizar, puesto que constituyen estrategias que construye el hablante y que estarían marcando una determinada intención en el discurso.

\section{II.2.3. LA LENGUA, EL BILINGÜISMO Y LA COMUNIDAD}

Ya hemos señalado el doble rol de la lengua materna como medio de comunicación y transmisión de los aspectos culturales propios del grupo social que la habla y como emblema de identidad. Es más, en muchos casos, el no hablar la lengua es interpretado de inmediato como signo de haber "perdido la identidad". Incluso, cuando ya son pocos los hablantes que quedan en la comunidad y las generaciones más jóvenes no la practican, se diagnostica -utilizando una metáfora biologicista- "la muerte de la lengua" (Ibáñez Caselli y Tamagno 1999; Courtis y Vidal en prensa).

Los individuos no somos sólo portadores de cultura, sino que estamos constantemente generándola y transformándola (Barth 1984). En este sentido, la cultura se nos aparece como tradición, pero no debemos entenderla como "peso muerto", o "pasado cosificado", sino como algo que heredamos, practicamos, empleamos, transmutamos, acrecentamos, recreamos y transmitimos (Tamagno 2001:52). Como la cultura, la lengua es dinámica y se transforma con el tiempo ya sea por cambios internos en el desarrollo del propio uso de sus hablantes -transformaciones que implican el paso de muchos años-, o por influencias externas, como resultado del contacto entre los pueblos (intercambio de bienes, de mujeres, relaciones comerciales o fronterizas, guerras, migraciones, etc.). Esto último suele causar cambios más acelerados, aunque de forma gradual. Las variaciones pueden darse en ambos códigos lingüísticos que entran en contacto a través de préstamos en el léxico e interferencias de tipo fonológicas, sintácticas y semánticas, como así también dar lugar a la "creación" de una nueva 
lengua -como el caso de las lenguas pidgin y creoles-o la sustitución de una lengua por otra. Sin embargo, esta situación se vuelve mucho más compleja cuando incorporamos al análisis las causas y consecuencias sociales que dichas interferencias pueden llegar a tener. Que dos (o más) lenguas entren en contacto, significa que dos (o más) grupos sociales, o etnias establecen esa interacción. Muchos casos nos revelan que en esos procesos de contactos interétnicos subyacen relaciones de poder y que, por lo tanto, se generan conflictos. Esta situación debe analizarse teniendo en cuenta las variables de dominación/ subordinación, racismo, prejuicio, estigmatización, señalización negativa, desprestigio. Así, el grupo dominante impone también su lengua. Y ¿qué sucede con los hablantes y la/s lengua/s subordinada/s? En la mayoría de los Estados-nación, la lengua oficial suele ser sólo la del grupo dominante. Lo que es más, “el Estado aplica sobre las minorías étnicas la misma lógica que le hace concebir a la nación como una comunidad imaginada (Anderson [1983] 1993),64 pretendidamente homogénea... Por su reiteración, la identidad atribuida llega incluso a ser internalizada por sus destinatarios" (Bartolomé 1997:56-57). No obstante, las sociedades complejas presentan pluralismo y la reflexión en torno a esta pluralidad nos debe llevar a buscar qué cosas hay en común entre todas esas diversidades que las conforman.

El abordaje de las situaciones bilingües o multilingües abrió la posibilidad a una serie de estudios sobre "lenguas en contacto" cuyo principal pionero fue Uriel Weinreich (1953) quien colocó su atención especialmente en las teorías psicológicas del bilingüismo y en las características de aptitud verbal y desplazamiento lingüístico, selección de una lengua en cuanto a sus usos y función, motivaciones y asuntos de índole emocional. Además, examinó los problemas que se generaban en una situación de bilingüismo como fenómeno grupal en relación a cuestiones de tamaño del grupo

\footnotetext{
64 B. Anderson define a la nación como una "comunidad política imaginada, como inherentemente limitada y soberana". Es imaginada porque aun los miembros de la nación más pequeña no conocerán jamás a la mayoría de sus compatriotas, no los verán ni oirán siquiera hablar de ellos, pero en la mente de cada uno vive la imagen de su comunión. Se imagina limitada porque incluso la mayor de ellas, que alberga tal vez a mil millones de seres humanos vivos, tiene fronteras finitas, aunque elásticas, más allá de las cuales se encuentran otras naciones. Se imagina soberana porque el concepto nació en una época en que la Ilustración y la Revolución estaban destruyendo la legitimidad del reino dinástico jerárquico, divinamente ordenado. La garantía y el emblema de esta libertad es el Estado soberano. Y Se imagina como comunidad porque, independientemente de la desigualdad y la explotación que en efecto puedan prevalecer en cada caso, la nación se concibe siempre como un compañerismo profundo, horizontal.
} 
bilingüe y los rasgos socioculturales -la comunidad-; la existencia de bilingües con diferentes tipos de habla; y las actitudes lingüísticas de los bilingües; entre otros aspectos.65 Como veremos en los próximos capítulos, el Barrio Toba "Las Malvinas" constituye tanto para sus integrantes como para "nosotros" - los investigadores- una comunidad. Y en esta comunidad encontramos una situación de bilingüismo -el uso de dos códigos lingüísticos- donde los hablantes no sólo presentan una competencia lingüística diferencial, sino que los códigos son utilizados en determinados contextos y con un propósito particular. Por eso definimos esta comunidad como social y lingüísticamente heterogénea.

Para el tratamiento de esta situación consideramos el concepto de "comunidad lingüística", o "comunidad de habla" o "comunidad discursiva" -términos usados según la época y corriente teórica o autor que trató el tema- que constituye una unidad de análisis, de corte más social que lingüístico, significativa para el estudio del comportamiento lingüístico en un contexto social dado. Se parte del postulado de que toda interacción verbal es un proceso social en el que las expresiones se eligen de acuerdo con un conjunto de hábitos lingüísticos y normas sociales que son compartidas y reconocidas por todos los miembros de ese grupo. A los fines de nuestra investigación, en el proceso de analizar una situación de bilingüismo con diversas competencias lingüísticas -en el seno de una sociedad plural y compleja y de los contactos interétnicos- la consideración de la inclusión/ exclusión, la pertenencia o no a una determinada comunidad de habla/ discursiva de los integrantes del Barrio Toba "Las Malvinas" nos abrió algunos interrogantes: ¿Qué entendemos por comunidad, en general, y por comunidad de habla/ discursiva, en particular?; ¿quiénes integran o no la comunidad de habla?, ¿quién dispone la pertenencia o no a esa comunidad?; ¿cuáles son sus límites?; ¿esas fronteras son estáticas o flexibles?; ¿podemos entender la comunidad en términos de heterogeneidad?. Para tomar una posición clara y útil con respecto a este concepto que ha sido clave para esta investigación realizamos una revisión de la definición de comunidad, en general, para luego partir de la idea de "construcción simbólica de la comunidad" de Anthony Cohen y, así, redefinir la comunidad de habla/ discursiva a la luz de los últimos avances en el campo de la sociolingüística y la etnografía del habla.

${ }^{65}$ Ver Weinreich ([1953]1970). 


\section{- Comunidad: una construcción simbólica}

El vocablo "comunidad" deriva de la palabra latina communitate y alude a la calidad de lo común (a lo no privativo): de ideas, de origen, de vecinos; también puede ser sinónimo de pueblo, reunión de personas que viven juntas y bajo ciertas reglas. Y, desde el sentido común, es ésta la idea que predomina: "vivir en comunidad es vivir todos juntos en un mismo territorio y compartiendo las mismas cosas". Dentro de esta concepción hay varios elementos que podemos encontrar que hacen al concepto.

En primer lugar, la idea de compartir: todos los miembros de un determinado grupo que se asume como comunidad comparte una serie de rasgos, reglas, normas, tierra, costumbres, lengua, creencias e ideas. En segundo lugar, esos elementos que comparten en común los hacen distintos de otros grupos o comunidades. Es decir, la comunidad se reconoce en términos de similitudes y diferencias. En tercer lugar, hay en ella una noción relacional y de distinción: "la comunidad es en relación a". Esto quiere decir que los miembros que se reconocen como una comunidad, lo hacen en función de compartir una serie de características similares y diferentes a otros grupos con los cuales se relacionan. En cuarto lugar, está implícito un sentido de pertenencia. ${ }^{66}$ El sentido de pertenencia combina típicamente tanto componentes cognitivos como afectivos, un sentimiento de solidaridad como una compresión de la identidad compartida. Cualquier pauta de conducta que promueva la pertenencia a una comunidad se denomina “comunalización" y estos patrones, el conjunto de las relaciones comunales, están cultural e históricamente determinados (Brow 1990). En quinto lugar, la comunidad tiene fronteras que determinan quién está adentro o quien queda afuera.

Para nuestro análisis, el concepto de "frontera" o "zona fronteriza", en términos de U. Hannerz (1997), adquiere significativo interés ya que se refiere a una región en la cual las culturas se interpenetran dinámicamente a través de diversos esquemas de naturaleza política, ecológica, económica, de parentesco y también lingüística. En las fronteras se genera el espacio para la acción entre las culturas. ${ }^{67} \mathrm{Y}$, en ese proceso, las

\footnotetext{
${ }^{66}$ Ver Weber (1978:40).

${ }^{67}$ M. L. Pratt ([1992] 1997) refiere como "zona de contacto" al espacio de los encuentros coloniales, al espacio en que pueblos geográfica e históricamente separados entran en contacto y establecen relaciones duraderas, relaciones que usualmente implican condiciones de coerción, radical desigualdad e insuperable conflicto. Así, el uso del concepto "zona de contacto" constituye un intento de invocar la presencia conjunta, espacial y temporal, de sujetos cuyas trayectorias se interceptan.
} 
fronteras se constituyen como construcciones simbólicas que la propia gente realiza en la interacción (Cohen [1985] 1992). Esto permite comprender que las culturas no son visiblemente tan "limitadas", "puras", "homogéneas" y "atemporales" como la tradición antropológica muchas veces las retrata (Tamagno 2001:53). Comunidad no significa homogeneidad y tanto sus fronteras como los símbolos y representaciones que comparten sus miembros, pueden adquirir significados diferentes (Cohen [1985] 1992).

En este sentido, A. Cohen ([1985] 1992:15) nos dice que "no debemos construir la comunidad en términos de localidad, sino más bien en el sentido primario de "pertenecer a". Comunidad es aquella entidad a la que pertenecemos, más grande que el parentesco, pero más inmediata que la abstracción que llamamos 'sociedad" ". ${ }^{68}$ En la comunidad compartimos símbolos y representaciones, pero éstos no nos dicen qué significar, sino que nos dan la capacidad para producir significados. Que los miembros de una comunidad compartan los mismos símbolos -construidos social e históricamente-, no significa que compartan los mismos significados. Y es en la interacción social donde ponemos en práctica esos símbolos y entramos en el juego de la interpretación, produciéndose la transacción de significados.

La comunidad no es homogénea como tampoco es estática. A menudo, se relaciona el concepto de comunidad con "tradición", en oposición a "modernidad". Sin embargo, como nos dice Cohen, comunidad y modernidad no son fenómenos excluyentes. La comunidad posee una capacidad de creación y recreación simbólica infinita a través de sus mitos, rituales y tradiciones construidos. La gente mapea cognitivamente el pasado, el presente y el futuro. Y, en la lucha por interpretar, usamos nuestra experiencia pasada para rendir estímulos en una forma lo suficientemente familiar que podamos adjuntarles algún sentido. Nuestra experiencia funciona como un modelo de la realidad. De la misma manera, las colectividades acuden a su mapa cognitivo para orientarse en la interacción. Los mapas son parte del bagaje cultural acumulado por generaciones y asentado por el pasado. Se puede hablar con una lengua en común, podemos actuar con un comportamiento aparentemente similar, participar en los 'mismos' rituales, orar a un ‘mismo' dios, usar las mismas ropas y demás, sin estar subordinados a una tiranía ortodoxa. La individualidad y la comunalidad son entonces reconciliables. La comunalidad consiste en una comunalización de formas (tipos de comportamientos) cuyos contenidos (significados) pueden variar considerablemente entre sus miembros.

\footnotetext{
${ }^{68}$ La traducción es nuestra.
} 


\section{- El grupo social como comunidad de habla}

Si reconocemos la comunidad en la diversidad y en las transformaciones, como así también en la distintividad y aceptamos que sus límites son construidos simbólica, social e históricamente por sus integrantes, en la interacción: ¿cómo podemos caracterizar una comunidad en relación al habla y al discurso?

Adhiriendo al recorrido planteado con respecto a este tema en Golluscio (2002), en la historia de la lingüística, Leonard Bloomfield (1933) fue uno de los primeros que definió la comunidad lingüística como "un grupo de gente que se interrelaciona por medio de la lengua". En esta definición se coloca un mayor énfasis en el aspecto comunicativo y, según R. Hudson ([1980] 1981:36) deja abierta la posibilidad de que algunos se comuniquen por medio de una lengua y otros, por otra. Por su parte, Charles Hockett ([1958] 1979:17) definió comunidad lingüística como "el conjunto de todos los individuos que se comunican entre sí, directa o indirectamente, por medio de una lengua en común". Aquí también se pone la atención en la comunicación. No habría límites precisos entre las comunidades y, en el caso de que los individuos fueran bilingües o multilingües, éstos pertenecerían, desde esta perspectiva, principalmente a una comunidad lingüística -aquella cuya lengua dominan más.

A partir de la década de 1960, los estudiosos en el campo de la sociolingüística y la etnografía del habla, al poner su interés en los usos de las lenguas más que en el código, comienzan a formular definiciones de comunidad de habla enfatizando los aspectos de la interacción, los límites, las normas y reglas compartidas, las actitudes y valores respecto de las formas y usos de las lenguas.

Dentro de esta línea, John Gumperz (1962) definió la comunidad de habla como "un grupo social que puede ser monolingüe o multilingüe, que se mantiene unido por la frecuencia de patrones de interacción social y delimitado de las áreas circundantes por la escasez de líneas de comunicación”. Años más tarde, en 1968-71 modifica esta definición e introduce la necesidad de que deben darse diferencias específicamente lingüísticas entre los miembros de una comunidad y otra, diciendo que una comunidad de habla es "un conjunto de hombres que se caracteriza por poseer una interacción regular y frecuente llevada a cabo por medio de signos verbales que comparten sus miembros, y que, a la vez se encuentra separado de otros grupos similares debido a que entre ellos existen diferencias de significado en el uso de la lengua”. Está aquí presente la idea de que una comunidad debe tener límites que la diferencie de otra y que esas 
diferencias consisten en significados distintos atribuidos al uso de la lengua. Además, para este autor, los miembros de una misma comunidad lingüística no necesariamente deben hablar la misma lengua ni usar las mismas variantes lingüísticas en ocasiones similares, sino que, al menos, deben tener una lengua en común. Esto último implica que los hablantes compartan las reglas básicas que gobiernan la estrategia comunicativa, de manera que los hablantes puedan decodificar los contenidos -entendiendo los significados- sociales que se dan durante la comunicación.

En este sentido, William Labov (1972) plantea no definir la comunidad lingüística por un acuerdo sobre el uso de los elementos lingüísticos, sino más bien por la participación en el conjunto de las normas compartidas que pueden ser observadas a través del comportamiento. Este hecho, según Hudson ([1980] 1981:37), permite reconocer la comunidad lingüística como un grupo de gente que se siente una comunidad en algún sentido.

Siguiendo con esta idea, otras definiciones han hecho hincapié ya no tanto en la noción de uniformidad en el uso de los elementos del lenguaje, sino más bien en compartir un conjunto de actitudes sociales hacia la lengua. En 1972, Hymes definió la comunidad de habla como "una comunidad que comparte las reglas para el manejo y la interpretación del habla y las reglas para la interpretación de por lo menos una variedad lingüistica. Ambas condiciones son necesarias". De este modo, no basta con compartir las reglas gramaticales de una variedad lingüística (el campo de la lengua), sino también se deben conocer los usos (el campo del habla). La noción que este mismo autor introdujo en 1974 sobre "competencia comunicativa" -la competencia lingüística o gramatical más la competencia de las reglas sociales- aportó una nueva perspectiva al tema, debido a que ya no parecería tan importante conocer cómo se dice algo (la lengua), sino saber cómo decirlo apropiadamente. En este caso, el conocimiento de las pautas comunicativas y metacomunicativas permiten que el individuo realice un enunciado particular, según una situación dada y un tema singular.

Sumado a esto, las investigaciones realizadas por Nancy Dorian sobre el gaélico hablado en la costa sudeste de Escocia nos abren un nuevo camino y constituyen un valioso aporte para la definición de la comunidad de habla. El caso estudiado desde la perspectiva de esta autora reveló una situación sociolingüística mucho más compleja que pone en juicio también la noción de "muerte de lengua". La autora observó en una comunidad donde el gaélico se encuentra en retroceso con respecto al inglés, la 
existencia de diferentes habilidades lingüísticas que dan idea de un continuum de tipos de hablantes: a) en uno de los extremos, un grupo minoritario conformado por hablantes fluidos del gaélico; b) un grupo intermedio que es bilingüe de gaélico e inglés; y c) en el otro extremo, se encuentran los que hablan imperfectamente el gaélico pero que se sienten más cómodos hablando en inglés en sus hogares y que Dorian (1973) los denominó "semi-hablantes". En un trabajo posterior, la autora reconoció otro grupo de hablantes en este último extremo de la escala de habilidades lingüísticas, representado por los "bilingües casi pasivos": hablantes que se caracterizan por su receptividad de gran parte del gaélico, pero no pueden expresar oraciones completas en él. Ahora bien, si adoptamos la definición de Gumperz (1971) para analizar esta situación, los bilingües de gaélico e inglés pertenecerían a ambas comunidades de habla; sin embargo, ésta deja de ser operativa cuando tomamos en consideración el caso de los semi-hablantes y bilingües casi pasivos: si no hablan correctamente y con fluidez la lengua vernácula, pero tienen conocimiento de la misma porque pueden oficiar de traductores o pueden seguir una conversación en gaélico aunque respondan en inglés ¿a qué comunidad de habla pertenecen? Los semi-hablantes y bilingües casi pasivos no concuerdan con las normas de uso que prevalecen entre los hablantes fluidos del galés, teniendo en cuenta este criterio no parecen ser calificados como miembros de la comunidad de habla local de galés. Según Dorian (1982:27), interpretando la definición dada por Labov (1972) parecería plausible definir la comunidad de habla como "un grupo de hablantes que comparten un conjunto de actitudes sociales hacia la lengua". Asimismo, este grupo de hablantes que se encuentra en la escala menor de habilidades del galés se diferencia completamente de los monolingües ingleses quienes representan claramente al grupo que se excluye: "en primer lugar, sobresalen por su receptividad del galés y, en segundo lugar, tienen un conocimiento de las normas sociolingüísticas que operan en la comunidad de habla galesa”.

Para esta situación descripta, destaca la autora, parecerían más adecuadas las aproximaciones de comunidad de habla de Coder (1973) y Hymes (1974). El primero, plantea partir de la propia percepción que posee el grupo sobre la comunidad: "Una comunidad de habla está constituida por gente que se reconoce a sí misma como hablantes de una misma lengua; no se necesita otro atributo definitorio”. El segundo, propone tomar también como punto de partida "al grupo social más que la lengua y de este modo considerar la entera organización lingüística en relación con el mismo”. En ambos casos, la comunidad de habla galesa estaría incluyendo a los semi-hablantes y 
bilingües casi pasivos no sólo como participantes, sino como miembros porque comparten la misma competencia comunicativa: poseen una habilidad receptora y, sobre todo, un conocimiento de las normas sociolingüísticas del grupo lo que les permite emplear su limitada productividad de manera apropiada (Dorian 1982).

Esta nueva perspectiva de análisis es significativa puesto que permite reconocer la diversidad que toda comunidad puede contener, como así también su dinamismo y transformaciones. En este sentido, Suzanne Romaine (1982) plantea la necesidad de revisar las definiciones que se dieron en torno a comunidad de habla y destaca contemplar la heterogeneidad y la coexistencia de gramáticas existentes en la misma. En cada comunidad, los factores sociales y lingüísticos están ligados no sólo de diversas formas, sino también en diferentes grados. Por tanto, analizar la superposición de la estructura social y lingüística en una determinada comunidad de habla sería el objeto de estudio de cualquier investigación. En su análisis no recomienda abandonar el concepto de comunidad de habla como "un grupo de hablantes que comparten un conjunto de reglas y normas para el uso de la lengua"; sin embargo, reconoce que es necesario destacar que los miembros de una comunidad poseen un acceso diferencial a los usos disponibles de esa lengua.

Relacionar el concepto de comunidad de habla con los planteos de Bourdieu sobre estructura, habitus y prácticas nos permite explicar la existencia de las diversidades individuales en el contexto de las regularidades objetivas. ${ }^{69}$ Producto de la historia, el habitus (para nuestro caso, el habitus lingüístico) produce prácticas, individuales y colectivas, produce historia, asegura la presencia activa de las experiencias pasadas que, depositadas en cada organismo bajo la forma de principios tienden a garantizar la conformidad de las prácticas y su constancia a través del tiempo (Bourdieu 1991:94). Debido a que el habitus es una capacidad infinita de engendrar en total libertad (controlada) productos - pensamientos, percepciones, expresiones, acciones- que tienen siempre como límites las condiciones de su producción, histórica y socialmente situadas, la libertad condicionada y condicional que asegura está tan alejada de una creación de imprevisible novedad como de una simple reproducción mecánica de los

\footnotetext{
${ }^{69}$ Es decir, de todas las conductas posibles dentro de los límites de estas regularidades y sólo de estas; de todas las posibilidades factibles de ser sancionadas positivamente porque están objetivamente ajustadas a la lógica característica de un determinado campo y que tiende también a excluir sin violencia todas las "locuras" ("esto no es para nosotros"), o sea todas las conductas destinadas a ser negativamente sancionadas (Bourdieu 1991:96-97).
} 
condicionamientos iniciales (Bourdieu 1991:96). Este análisis nos permite, entonces, comprender la casi infinita posibilidad de variantes individuales (diversidad) en el marco de un campo determinado (la comunidad de habla como homogeneidad en la diferencia).

\section{- La comunidad discursiva: un nuevo concepto}

Por último, Golluscio (2002) destaca un nuevo giro en la historia del desarrollo de este concepto mediante la introducción de la noción de comunidad discursiva de G. Urban (1991). Incluido en la línea de científicos sociales que interpretan el lenguaje como práctica social e histórica y el discurso como constituyente y constitutivo de lo social, este autor señala la necesidad de estudiar los discursos vivos que circulan socialmente y que son producidos históricamente. Como nos dice Bourdieu (1991), las prácticas no se pueden deducir de las condiciones presentes que pueden parecer haberlas generado ni de las condiciones pasadas que han producido el habitus, principio duradero de su producción. Según este autor, sólo es posible explicarlas "si se relacionan las condiciones sociales en que se ha constituido el habitus que las ha engendrado y las condiciones sociales en las cuales se manifiestan", puesto que el habitus "es la presencia activa de todo el pasado del que es producto: es lo que proporciona a las prácticas su independencia relativa con relación a las determinaciones exteriores del presente inmediato". Bajo la creencia que el análisis de los discursos permite la aproximación a la cultura, Urban define comunidad discursiva como "aquella dentro de la cual una instancia de discurso surge sólo sobre la base de una historia continuada de tales instancias, en relación con las cuales puede ser situada. El 'situacionamiento' real se hace subjetivamente, pero se basa en un vasto rango de experiencia histórica con otras instancias, que son también parte de la circulación pública del discurso en la vida de una comunidad en marcha” (Urban 1991:9). Entonces, comunidad discursiva es aquella donde se constituyen y actualizan los discursos de la cultura (Golluscio 2002:33).

Sobre la base de estos principios, conceptos, definiciones y posturas se realizó el recorte del objeto de estudio. Los mismos guiaron las principales preguntas y problemas planteados a lo largo de la investigación; se recolectaron los datos empíricos y se procesó toda la información relevada tanto de fuentes de primera como de segunda mano. Al tiempo que esas mismas conceptualizaciones fueron reformuladas a medida que la investigación avanzaba en diálogo con los interlocutores. En el próximo capítulo 
se presenta al Barrio Toba "Las Malvinas" en su día a día para, luego, abordar las prácticas sociolingüísticas y discursivas identificadas en esta investigación. 


\title{
Capítulo III
}

\section{UNA AProximación EtNográfica a Los TOBAS del}

\section{BARRIO "LAS MALVINAS"}

\begin{abstract}
"Estamos aqui en La Plata porque no tenemos tierras en el Chaco, porque siguen todavía arrinconando a los indígenas...,...no tenemos propiedad...". "Sin organización, lo que yo veo en este momento, creo que no se puede hacer nada..." "Debemos organizarnos para ser escuchados... Sin leer, sin saber palabra en castellano, por eso ellos [los indígenas tobas] perdieron muchas cosas. Primer lugar tierras, porque ellos no saben hablar en castellano. No saben número alguno, eso dicen, esa la causa más grande de la comunidad toba....”. [Testimonio BLM 1994]
\end{abstract}

A lo lejos, entre casillas de chapas y maderas y calles polvorientas, se divisan las viviendas de techos rojos y paredes color ladrillo; una hilera de palmeras y otra de pinos bordean las casas y éstas envuelven un amplio espacio verde donde los niños juegan y crecen también algunos cultivos de hortalizas.

El barrio despierta muy temprano. Las mujeres comienzan con sus actividades domésticas: levantar de la cama a los chicos que asisten a la escuela en el turno mañana, preparar el desayuno -cuando se tiene con qué prepararlo- y despedir al marido que sale a ganarse la jornada de cada día. Generalmente, sólo se toma mate cebado o cocido con pan o galletitas. Los niños mayores cuidan de los menores y van todos juntos a la escuela. En algunas oportunidades, una mamá acompaña al grupo caminando hasta la misma escuela o sólo hasta la parada del ómnibus. Los hombres que cuentan con un trabajo de albañil o auxiliar de construcción o consiguieron alguna changuita dejan sus casas entre las 6 ó 7hs de la mañana a pie hasta la parada del ómnibus, en bicicleta o, en muy pocos casos, en auto, llevando algunos de sus vecinos. Quienes no tienen trabajo salen a buscarlo o a vender sus artesanías que, junto a la esposa e hijos, estuvieron modelando, pintando y armando días anteriores. Otro grupo se prepara para dar una charla en algún colegio en el centro de la ciudad que especialmente solicitó su presencia y también lleva artesanías para mostrar y vender, si se da la ocasión. Luego, todo parece volverse más tranquilo. Algunos vendedores ambulantes pasan por las calles polvorientas anunciando sus productos con fuertes altavoces que se dejan oír entre el ladrido de los perros y la música que sale de las 
casas. $^{70}$ Las mujeres asean sus hogares y, cuando el clima lo permite, lavan montañas de ropa afuera, en fuentones y baldes; en tanto que los niños que asisten a la escuela en el turno tarde comienzan a prepararse terminando alguna tarea escolar pendiente. Los que trabajan en la huerta o en el comedor, inician sus actividades tempranamente, en especial los primeros que, en el verano, aprovechan las horas en que el sol todavía no quema demasiado para trabajar la tierra. La encargada de hacer el pan comienza a amasar y armar los bollos mientras se enciende y calienta el horno. Algunos grupitos de chicos juegan y corren en las calles.

Hacia el mediodía, el barrio se puebla de guardapolvos blancos que regresan de las escuelas o que se dirigen hacia las mismas, acompañados por alguna mamá, hermano/a mayor o, aunque más raramente, solos. El pan ya está listo; las calles se llenan de niños que entran ansiosos y salen, al rato, del Comedor Comunitario Qom Llallacpi ya satisfechos. Al finalizar el horario del comedor, retorna la calma. Las calles se vacían y sólo quedan algunas personas trabajando en la huerta o cosiendo ropa en el obrador. Quienes terminaron con sus quehaceres se sientan a la sombra si el día está caluroso o al sol si hace frío, y toman mate cebado caliente o frío y observan...; otros, siguen lavando ropa afuera o se ponen a cocer o pintar la cerámica. Un grupito de mujeres jóvenes ayuda a la abuela a peinar la larga y grisácea cabellera. Algunos vecinos se visitan y son invitados a compartir el mate por un largo rato y la lengua toba se hace escuchar. Algún foráneo suele llegar a la hora de la siesta y solicita información; éste es atendido por uno de los integrantes de la comisión directiva de la asociación civil.

Alrededor de las 17:30hs, el barrio vuelve a recobrar el movimiento intenso cuando retornan los niños de la escuela con sus guardapolvos desprendidos y arrastrando sus mochilas y los hombres regresan de sus trabajos, cansados. Los primeros se van directo a jugar $y$, en algunos casos, se juntan en alguna casa que tiene televisión a ver los dibujos animados o algún otro programa apropiado para su edad; mientras que los segundos se dan un baño, se cambian y -cuando el tiempo lo permite- se sientan afuera a tomar mate y descansar mientras la familia comenta las novedades del día. Otros, se sientan afuera y leen la Biblia.

\footnotetext{
${ }^{70}$ En las viviendas de la gente no toba se escucha, generalmente, música de chamamé y cuarteto, mientras que en las de los tobas, predomina la música del culto evangélico a cargo de conjuntos de coros que han grabado y editado sus casetes.
} 
Al atardecer, la jornada no ha finalizado. La maestra de la Escuela de Adultos llega alrededor de las $18 \mathrm{hs}$ y sus alumnos se alistan para asistir. En tanto que, a las 19hs, la música del culto se escucha cada vez más fuerte y convoca a los fieles. Unas horas más tarde, las familias se reúnen en sus casas y los niños se van a dormir. Algunos matrimonios pueden quedarse despiertos modelando artesanías hasta bien entrada la noche. Cuando son días de mucho calor, las familias suelen sentarse en ronda afuera de sus casas, se conversa, y alguno de los mayores relata hechos o cuentos del pasado y del presente, y se recuerda al Chaco... Sin embargo, últimamente, grupos de jóvenes de los alrededores -entre los que también suelen haber algunos tobas- se reúnen en alguna esquina a beber... algunas veces, la noche ya no es tan tranquila como era años atrás cuando las casas comenzaron a levantarse en un terreno que era sólo campo, deshabitado. ${ }^{71}$

\section{III.1. EI Barrio y las Viviendas}

El Barrio "Las Malvinas" se encuentra en la localidad de Melchor Romero, en las afueras de la ciudad de La Plata (capital de la provincia de Buenos Aires), en dirección noroeste de la ciudad. Su nombre se debe a una antigua quinta que aún conserva su nombre y que abarcaba toda esa área. ${ }^{72}$ [Ver Figura $N^{\circ}$ 6: Plano de la ciudad de La Plata]

Hasta principios de la década de 1990, se caracterizó por ser una zona de quintas y casas de fin de semana. Desde entonces, el paisaje se fue transformando paulatinamente hasta urbanizarse, aunque predominan principalmente las casillas precarias, las calles de tierra, algunos descampados con acumulación de chatarras y basura y carros tirados por caballos con los que salen a recolectar cartones u otros deshechos. En los alrededores, se destacan unos criaderos de animales (ovejas, ñandúes, cerdos y caballos); talleres mecánicos para autos; y un complejo deportivo con canchas de paddle. Un campito con un salón multiuso

\footnotetext{
71 Hoy el barrio "Las Malvinas" está totalmente poblado por otros grupos sociales de escasos recursos provenientes de diferentes sectores de la sociedad y que fueron también adjudicatarios del Plan para las 540 viviendas del Gobierno de la Provincia de Buenos Aires. Aquejan sobremanera los problemas de desocupación y desempleo, conductas delictivas, droga y bebida, y el Barrio Toba no es una excepción. Por eso, una de las principales preocupaciones de la comisión directiva de la Asociación Civil Toba Ntaunaq Nam Qom tiene como prioridad diseñar las estrategias para mantener a los jóvenes y adolescentes ocupados con programas destinados a generar trabajo, inculcar valores e incentivar el estudio.

${ }^{72}$ Según consta en el Certificado Urbanístico emitido por el Programa Pro-tierra 10/11/88, antiguamente, se trataba de una chacra llamada "La Dominga" que pertenecía a los hermanos Causa y Bocca. Al morir uno de los hermanos, las tierras entraron en juicio de sucesión, fueron divididas y, un sector, donado al municipio. También llamada La Cumbre o Malvinas.
} 
que le pertenece a la Parroquia San Carlos, ubicada a más de 30 cuadras del lugar, y una Unidad Educativa Privada de Nivel Inicial que depende de ésta completan la zona. Una gran casa de fiestas con un lago con aves acuáticas dentro de su predio colinda en su parte posterior con el barrio.

Este predio se fue urbanizando mediante el Plan de Viviendas Pro-Tierra del gobierno de la provincia de Buenos Aires que tuvo como principal objetivo la construcción de 540 viviendas, ${ }^{73}$ de las cuales 36 fueron destinadas a la Asociación Civil Toba Ntaunaq Nam Qom. ${ }^{74}$ Estas 36 viviendas conformaron el "Barrio Toba", la "comunidad toba" o "los chalecitos de los tobas", como los conocen sus vecinos. ${ }^{75}$ Los chalecitos se extienden desde la avenida 35 a la calle 36 y desde la 151 a la 152 [ver Figura $N^{\circ}$ 7]. El Barrio Toba está conformado por viviendas de material que ocupan una manzana completa más dos cuadras de otra manzana enfrentada; un espacio verde interno con una huerta de 62 x $82 \mathrm{~m}^{2}$ y dos hileras de altos eucaliptos y otra de palmeras que dan una sensación agreste al lugar; una iglesia prefabricada de madera; un galpón multiusos de chapas; $\mathrm{y}$, recientemente, una panadería [ver Figura $\mathrm{N}^{\mathrm{o}} 8$ ] $^{76}$

Las viviendas son de ladrillos a la vista y techos de tejas a dos aguas. Por dentro, poseen dos habitaciones, un baño, un living-comedor y una cocina; y cuentan con instalaciones de luz y agua corriente. Por fuera, alrededor de las mismas, disponen de una pequeña extensión de tierra ${ }^{77}$ que se utiliza con múltiples funciones: para lavar y colgar la ropa; para el cuidado de diversas plantas y algunos árboles; como lugar de depósito de objetos; para el modelado y la cocción de la cerámica; como espacio de juego de los niños; y constituye el principal ámbito de recepción de visitas o punto de reunión y de descanso de los miembros de la unidad doméstica.

\footnotetext{
${ }^{73}$ El plan Pro-Tierra, es decir, el Plan Social y Familiar de Tierras, fue parte de una política pública dirigida a sectores carentes de tierra y vivienda urbanas que surgió durante el primer año del gobierno de Antonio Cafiero; en el marco de esta política se crea la Subsecretaría de Urbanismo y Vivienda de la Provincia de Buenos Aires (en Brunatti 1999).

${ }^{74}$ En idioma toba significa "todos juntos trabajando".

${ }^{75}$ Dentro de este plan de tierras y viviendas, los tobas tomaron un lugar destacado puesto que fueron los primeros en llegar, esto les dio la posibilidad de elegir los mejores terrenos y autoconstruir las viviendas. Sobre la historia del barrio toba ver Tamagno, Brunatti y Colángelo (1994); Tamagno (2001).

${ }^{76}$ A partir de principios del año 2007, se destinó un espacio detrás del salón multiusos donde se instaló una panadería.

${ }^{77}$ En 1996, las viviendas fueron cambiando su fisonomía cuando algunos dueños comenzaron a construir una cerca con alambre, rejas o maderas, delimitando los espacios.
} 
Las viviendas albergan aproximadamente 210 personas entre adultos y niños, aunque el número varía debido a que son frecuentes las "idas y venidas" - ya sea por temporadas cortas o largas - hacia y desde los otros puntos del país donde habitan más familias tobas tales como Derqui, Ciudadela, Talar de Pacheco, Dock Sud, Quilmes, en la provincia de Buenos Aires; Rosario en la provincia de Santa Fe; Resistencia y las diferentes localidades del interior de la provincia de Chaco y Formosa [Ver Figura $N^{o} 2$ ]. Los motivos y las características de estos desplazamientos pueden ser varios. En algunas ocasiones se traslada toda la familia y en otras sólo el hombre con el objetivo de buscar trabajo o porque "sintieron el llamado de algún familiar enfermo" desde el Chaco u otro lugar o "lo soñaron"; o bien viajan sólo las madres con sus hijos más pequeños para visitar a sus parientes o participar de las "Campañas" o "Movimientos" religiosos que se realizan cada vez que se hace presente un pastor reconocido en alguna localidad. En estos movimientos de renovación de la fe se realizan bautismos y sanaciones; se promueve la reconciliación de los fieles que se habían alejado de Jesús; y se consagran a los niños pequeños. Son también motivo de movilización de las familias las reuniones periódicas en localidades puntuales tales como el "Encuentro y Convención de Jóvenes" que se desarrolla en el Barrio Toba de Resistencia (Chaco) en el mes de marzo y la "Convención de Pastores de la Iglesia Evangélica Unida” que se lleva a cabo en la ciudad de R. Sáenz Peña en el mes de mayo (también en la provincia de Chaco), entre otros. Además, son frecuentes las asistencias a aniversarios de las iglesias, cumpleaños de 15, celebraciones por el Día del Indio o ferias que se organizan en algunas localidades de la zona o de las otras provincias.

Todas, excepto una de las treinta y seis viviendas, están adjudicadas a las familias. La vivienda restante fue destinada para ser la oficina de la Asociación Civil Toba Ntaunaq Nam Qom y lugar de recepción de visitas a nivel institucional. Cada unidad doméstica está habitada, generalmente, por una familia nuclear: la madre, el padre y los hijos -un promedio de cinco niños- si se trata de un matrimonio joven -adjudicatarios de la vivienda- que vinieron directamente del Chaco o vivían en alguna localidad del Gran Buenos Aires al momento de salir el Plan de Viviendas. En otros casos, encontramos tres generaciones en la unidad doméstica, tratándose de una familia extensa: los padres con sus hijos solteros, más los hijos casados y los nietos pequeños. También se da el hecho de que viva algún hermano/a soltero/a. En estas situaciones, se trata de familias que migraron hace más de veinte años del Chaco y que llegaron a la gran ciudad con sus primeros hijos cuando éstos eran pequeños. 
Sin embargo, a la ciudad de La Plata no vinieron solamente estas familias tobas. Unas seis más quedaron fuera del Plan de Autoconstrucción y, en la actualidad, viven dentro del predio de las 540 viviendas del Plan Social (en 150 y 35). ${ }^{78}$ A diferencia de los "chalecitos de los tobas", las casas que les fueron adjudicadas son de material prefabricado y mucho más modestas. Otras treinta, aproximadamente, llegaron más tarde $-\mathrm{a}$ fines de los años 1990- y se ubicaron en tierras fiscales o desocupadas -también por la zona, en 140 y 526en casillas de chapa, cartón y madera. Y, en los últimos años, unas veinte familias aproximadamente -algunas llegadas del Chaco y otras de 140 y 526-ocuparon un predio vacío en 36 entre 151 y 152, transformando la fisonomía del barrio toba y su "dinámica" según el parecer de la propia gente- y gestando a su vez sus propias formas de organización. Es de señalar que a pesar de las tensiones que esto genera al interior del conjunto formado por la totalidad de familias tobas residentes en el Barrio "Las Malvinas" de la ciudad de La Plata, las familias más antiguas en el lugar continúan siendo los referentes, siendo consultados permanentemente ante diferentes situaciones a resolver en la ciudad; al tiempo que las relaciones de parentesco y de vecindad en los lugares de origen, siguen ordenando la existencia cotidiana más allá de las organizaciones que coyunturalmente cada nucleamiento se da a sí mismo.

\section{III.2. Sobre la Organización SOCIAL}

"Bueno, yo me llamo R. C. Soy el presidente de la comunidad toba, eh... nuestro origen es el Chaco, llegamos en el '91. A pesar de ocho años de lucha para obtener la personería jurídica, después de ocho años recién que salió la personería jurídica tuvimos este pedazo de tierra que son 36 viviendas más un pedazo comunitario que son $60 \times 80$ aproximadamente. Eh... Después de obtener las tierras, construimos las viviendas. Se acabaron las casas y, bueno, luego se empezó el trabajo, siempre comunitario; algunos planes trabajar que nos dio el gobierno. Se está haciendo el pan casero y también está la costura, 'ropero comunitario' -le dicen-, y un comedor cedido por la comunidad. Tenemos la huerta que se está cultivando, que a veces, cuando hay beca se le da más fuerte y cuando no, baja, se descuida un poquito, pero se mantiene. Los papás están casi todos sin trabajo, así como las mamás, pero todos se ayudan en la comunidad, pero a veces salen a buscar changas"... "El trabajo comunitario es para nosotros... casi desde el origen se viene trabajando este método que es algo así como el trueque de hoy, que es el método que tenían los aborígenes.

\footnotetext{
${ }^{78}$ Los motivos se debieron a diferencias internas con respecto a los modos de proceder en la organización del grupo durante la construcción de las viviendas que no vienen al caso detallar.
} 
Porque en el Chaco se era cazador y también agricultor. Entonces, cuando iba una persona y no cazaba nada, bueno, se le ayudaba, un poquito cada uno. Así era el sistema de las comunidades aborigenes: el problema de uno era el problema de todos. Y esta es la realidad, esto nos llevó a construir los chalecitos..., pero nos llevó esfuerzo. Hoy tenemos la casa pero la cosa no termina ahí, sigue la lucha... porque ahora está la luz, el gas...”... “Bueno, a veces dicen: -si sos aborigen cómo vas a vender pan, si los aborígenes son de la selva-. Pero como nosotros estamos acá, en la gran ciudad, tenemos el derecho también de hacer el pan, tener una panadería... y competir también. "79

La Asociación Civil Toba Ntaunaq Nam Qom -para los fines de esta investigaciónapareció como la instancia principal de la organización de las familias que conforman la comunidad toba del Barrio "Las Malvinas", aunque no todos los que viven en las 36 viviendas son socios de la misma y algunos de estos no habitan en la actualidad en este barrio. Esta asociación se inició en la localidad de Ciudadela (conurbano bonaerense) hacia fines de la década de 1980 y obtuvo su Personería Jurídica en 1991, con domicilio en San Isidro Casanova. Contó como antecedentes con la constitución de otras asociaciones civiles indígenas de la cuales participaron sus socios fundadores. ${ }^{80}$

"Queríamos saber cómo se movía el hombre blanco para conseguir cosas en la ciudad, aprendimos y nos organizamos" [Testimonio BLM 1994]

La Comisión Directiva está conformada -según la exigencia del reglamento de Asociaciones Civiles sin Fines de Lucro- por un presidente ${ }^{81}$ y vicepresidente, un secretario y prosecretario, un tesorero y pro-tesorero, tres vocales titulares y tres suplentes, y una comisión de revisión, y se renueva por votación de sus socios cada dos años reglamentariamente. Los socios pagan una cuota mínima para mantenerse como miembros de la asociación y ayudar así con los gastos de mantenimiento de la misma. Esta estructura formal tiene sus requerimientos e impone ciertos modos de funcionamiento -según el reglamento- que tienen el compromiso de cumplir ante el órgano gubernamental que la otorga: reuniones de comisión directiva, asambleas generales, redacción de actas y órdenes

\footnotetext{
${ }^{79}$ Testimonio en Vídeo "Lo Onataq na qom llacpi. Trabajo de los hijos tobas", 2002. El énfasis es nuestro.

${ }^{80}$ Este aspecto es tratado en el punto II.7 de este capítulo.

${ }^{81}$ Es importante destacar que los presidentes electos han sido denominados por la sociedad no toba como "el cacique", aludiendo al imaginario colectivo y el estereotipo que ha construido la gente común sobre los indígenas y que ha sido reproducido en varias oportunidades por los medios de comunicación y en notas periodísticas del diario local.
} 
del día, balances, inventarios, elecciones de comisión directiva, etc. y cuenta con el asesoramiento de un contador público de origen no toba.

Al principio, la asociación cumplió con el papel principal de atender todas aquellas cuestiones relacionadas con la búsqueda y obtención de tierras. Una vez que se obtuvieron las tierras y entró en vigencia el plan de autoconstrucción de viviendas, la comisión directiva se encargó de llevar adelante este plan, siendo el vínculo entre el Instituto de Vivienda de la Provincia de Buenos Aires y las familias adjudicatarias.

Cuando las viviendas fueron terminadas, la ausencia de un trabajo seguro y permanente constituyó una gran preocupación. Las actividades laborales de los hombres consisten básicamente en la construcción, en la venta de artesanías y en algunas "changas" temporales; en tanto que son pocas las mujeres que salen a trabajar fuera del barrio. Las que lo hacen se dedican, básicamente, al trabajo doméstico. ${ }^{82}$ En los últimos tiempos se ha incrementado el cirujeo mediante la recolección de cartones, latas y vidrios y la modalidad de salir a pedir -aunque solamente en casos de necesidad extrema puesto que esta última no es una práctica bien considerada entre los miembros y sólo algunas familias lo practican.

Es por todo ello que la comisión directiva asumió el compromiso de buscar fuentes de trabajo y velar por el bien de la comunidad sumándose a los distintos planes sociales provenientes del Estado, tales como "Planes Nacionales Trabajar", "Plan Jefes y Jefas del Hogar"; además de vincularse a distintos organismos gubernamentales, tanto provinciales como nacionales -Municipalidad de La Plata, Ministerio de Acción Social, Secretaría de la Mujer y la Familia, Instituto Nacional de Asuntos Indígenas (INAI), Caritas, Universidad Nacional de La Plata (UNLP)- y no gubernamentales -Equipo Nacional de la Pastoral Aborigen (ENDEPA), Asociación "La Máquina de Hacer Sueños”, Asociación Vecinal Malvinense-, partidos políticos, con el fin de obtener fondos y subsidios.

“...uno se va adaptando a los trabajos que hay debido a que esto es una comunidad donde uno tiene que aprender de todo. Cualquier cosa que sea. Diferentes tipos de trabajos desde una huerta hasta cocinar, hasta hacer trabajo en la calle, un ropero, armar cosas. Bueno, eso hace que uno busque diferentes variedades de trabajos. Por ahi cosas que gusten más y, por ahi, otras que no tanto... "83

\footnotetext{
82 Es de resaltar la participación que tuvieron las mujeres durante la autoconstrucción de viviendas, capacitándose también a través de cursos de albañilería y electricidad.

${ }^{83}$ Ídem 10.
} 
Como resultado de tales estrategias se realizaron proyectos bajo una modalidad colectiva y comunitaria, ${ }^{84}$ algunos de los cuales se mantuvieron con cierta continuidad en el tiempo según el financiamiento que se pudo disponer. En todas estas actividades los coordinadores han sido fundamentalmente mujeres integrantes de la comisión directiva de la asociación civil.

\section{- La Huerta Comunitaria}

Desde el momento en que se planificaron las viviendas, se había pensado destinar parte del espacio comunitario para una huerta. Ésta comenzó a ser trabajada y cuidada a fines de 1993 por un grupo reducido de mujeres, que plantaron algunas hortalizas en tres pequeñas parcelas. Sin embargo, la Huerta Comunitaria creció en extensión $\left(62\right.$ x $\left.82 \mathrm{~m}^{2}\right)$ [ver Figura $\mathrm{N}^{\mathrm{o}} 8$ ] y tomó impulso al convertirse en uno de los primeros proyectos iniciado entre $1996 \mathrm{y}$ 1997 y que contó con el apoyo del Ministerio de Acción Social de la provincia de Buenos Aires, el Instituto Nacional de Tecnología Agropecuaria (INTA) y estudiantes de la carrera de agronomía de la UNLP. Estos últimos ofrecieron cursos de capacitación para el cuidado de la huerta y asesoramiento técnico para la puesta en práctica de la misma. El ministerio otorgó un subsidio para la compra de los materiales y semillas, y becas para doce personas, organizadas en dos turnos: el de la mañana y el de la tarde, con una coordinadora en cada uno de ellos que controlaba las horas de trabajo y las actividades. En sus inicios, estas becas fueron recibidas por seis hombres y seis mujeres que aportaban cuatro horas diarias de trabajo: desmalezar, limpiar, realizar los surcos, abonar, plantar, regar, fumigar, hacer los plantines, etc. Cuando alguno de los titulares no podía asistir, era sustituido por algún familiar, de modo que no se perdieran las horas de trabajo para lo cual se recibía la beca.

En un principio se pensó que la huerta podría ser dividida en parcelas y que cada familia cuidaría una de éstas. Sin embargo, esta idea no prosperó, puesto que organizando el trabajo de modo comunitario todos atenderían la parte de todos, habría más control en el cuidado y mantenimiento de la misma, y los productos se repartirían a todas las familias que los necesitaran y lo que sobrara podría ser vendido a los vecinos o a los alrededores. La coordinación de las tareas estuvo a cargo de algunos de los miembros de la dirección de la asociación civil.

\footnotetext{
${ }^{84}$ Hacemos una distinción entre lo que sería el trabajo colectivo y el comunitario según lo manifestado por la propia gente. El primero se refiere al trabajo conjunto, el sumar esfuerzos; mientras que lo comunitario va más allá, consiste en un modo de funcionar en base a valores e intereses comunes, implica modos particulares de resolver tensiones y conflictos (Tamagno 2001).
} 
La huerta no sólo fue un espacio de trabajo, sino de compartir y relacionarse. Un lugar donde el trabajo comunitario permitía y permite la recreación y resignificación de la lengua y la cultura tobas; ${ }^{85}$ el aprendizaje de los niños pequeños y la participación de los más grandecitos ayudando en las actividades propias de la huerta; el trabajar y estar cerca de sus hogares controlando los mismos. Entre las tareas también está la de preparar el mate cebado o cocido y, en todo momento, se acompaña con la charla amena y los chistes.

Las primeras cosechas colmaron todas las expectativas y limaron las asperezas que las inclemencias del clima, las plagas, y el trabajo duro de todos los días habían provocado. El trabajo no había sido fácil puesto que la tierra no era buena y hubo que trabajarla bastante; se tuvo que adaptar un tanque para el almacenamiento del agua y el riego; y el control sobre el cumplimiento del trabajo también fue muy riguroso. Se cosecharon lechugas, tomates, zapallitos, brócolis, perejil, zanahorias, cebollas, cebollas de verdeo, maíz. Y los tamaños fueron impresionantes. Más tarde, cuando se puso en marcha el comedor comunitario, las verduras y hortalizas proveyeron provisiones para su cocina.

Mientras hubo subvención del ministerio todo funcionó en orden; no obstante, cuando el subsidio se cortó se comenzó a hacer muy difícil su mantenimiento. Los conocimientos y la mano de obra estaban, pero ya no se contaba con la beca y no se recibía ninguna remuneración por las horas invertidas. De todos modos, se siguió trabajando con el aporte de aquellas personas que podían disponer de su tiempo para la atención de la huerta. Esto implicó muchos sacrificios porque tampoco se contaba con el subsidio para la compra de semillas y materiales. Luego, se consiguió entrar en los "Planes Trabajar" y, de ese modo, se obtuvo un pequeño estipendio para diez personas. Pero esto fue por una temporada nada más. Para fines del año 2002, lamentablemente, él área de cultivo se había reducido; y sólo quedaban algunos surcos con plantaciones, hasta que, finalmente, se abandonó al no poder sostener el trabajo con tan escasos recursos.

\section{- El Comedor Comunitario Qom Llalacpi: 'Los Hijos de los Tobas'}

"Bueno, nosotros empezamos a funcionar hace diez años aproximadamente. Primero con una copa de leche. Después, fue la necesidad lo que lo hizo funcionar y desde el

\footnotetext{
${ }^{85}$ Un hecho resaltado en varias oportunidades ha sido el cuidar de no romper con una regla de prohibición ancestral entre los tobas, la preocupación y el cuidado de que las mujeres menstruantes no toquen las herramientas de trabajo o de caza del cazador -en este caso, de la huerta- porque éste no tendría buena caza. Por esta razón, las mujeres menstruantes no trabajan la huerta durante esos días y se dedican a realizar otras actividades.
} 
'99 fue lo que es hoy este "Comedor Comunitario: Qom Llalacpi: Los Hijos de los Tobas»"

El obrador que había servido para guardar herramientas y materiales para la construcción de las viviendas y también para la huerta, fue cambiando su fisonomía poco a poco. Primero fue una "Copa de Leche". Se comenzó con una cocina pequeña a gas, una mesa y, luego, llegaron la heladera, el freezer, la cocina industrial, y todos los utensilios de cocina. El espacio de cocina también se amplió con una división de paredes de madera con una puerta de acceso desde el exterior y otra al interior del comedor, y una ventana tipo mostrador, también interna. Con el tiempo, se anexaron un cuartito de depósito de mercadería y un "horno ecológico". Este último, propuesto por la municipalidad en un plan de promover en los comedores comunitarios este tipo de equipamiento, en la moda de velar por la ecología y aprovechar los materiales de desecho para el funcionamiento del mismo, aunque -según la propia gente- "no es como el de barro que teníamos. Ahí sí que salían buenos panes...".

El trabajo fue coordinado, principalmente, por un grupo de mujeres que preparan la comida para alrededor de 100 niños tobas y algunos no tobas que viven en las cercanías, especialmente, menores de 5 años. ${ }^{86}$ El equipo está conformado por una cocinera principal, dos ó tres ayudantes de cocina y otras tres personas que sirven la comida a los niños. Estas personas cobran un sueldo por su trabajo y cumplen con un horario estricto. La Municipalidad de La Plata dio el apoyo financiero: mercadería, equipamiento y becas a través de un Plan Trabajar. Hubo el asesoramiento de personal de esa institución entre la que se encontraba una trabajadora social que insinuó un nombre para el comedor, pero que poco o nada de caso tuvo. El comedor llevó el nombre en la lengua toba "Qom Llalacpi" que significa "los hijos de los tobas" desde 1999.

Los niños comen en el mismo comedor, que dispone de dos grandes mesas hechas con tablones de madera sobre unos caballetes del mismo material, y otras dos de material aglomerado, acompañadas por banquetas de madera. Se dividen en dos turnos. El primero ingresa alrededor de las $11 \mathrm{hs}$ y el segundo cuando aquel termina. La mayoría de los niños asisten solos y los más pequeños acompañados por alguno de sus padres o hermanos mayores. En general, comen solos y de una manera ordenada y silenciosa, pero quienes

\footnotetext{
${ }^{86} \mathrm{Si}$ bien el comedor se inició como un comedor para niños entre 3 y 5 años, al mismo asisten niños que no entran dentro de esa escala. La situación económica obliga a muchos padres a depender de este comedor para la alimentación de sus hijos.
} 
sirven los platos están muy atentas al movimiento de los niños y los ayudan si es necesario, cuidando que no se queden sin comer.

La atención del comedor provocó que algunas de las personas que participan o participaron del mismo tomaran clases de cocina $y$, luego, enseñaran el conocimiento adquirido a los demás, poniendo en práctica diversos platillos con los nutrientes y proteínas necesarios que requieren los niños de esa edad -como así también según sus gustos-. Asimismo, la variedad de los platos del día ha dependido de los productos cosechados en la huerta, como así también de la mercadería que la municipalidad entrega semanal o mensualmente. En ciertas temporadas, la municipalidad ha entregado sólo los tickets de compra en aquellos comercios con los que ésta mantiene convenios. De modo tal que el trabajo en el comedor también implica el hacer las compras y la elección de los alimentos de primera necesidad. Otra de las tareas consiste en la limpieza del lugar cuando ya la jornada del día acaba y la preparación para el día siguiente. Cuando los niños terminan de comer, todo el personal de cocina comparte el almuerzo. Tanto durante la preparación de los alimentos como en la hora de degustarlos, el comedor se convierte en un espacio de socialización significativo para adultos, jóvenes y niños: la lengua toba, los temas de la actualidad como del pasado, todos los aspectos de la cultura toba se recrean y actualizan constantemente; hay esparcimiento y todo se comparte y se reafirman los lazos de solidaridad: ${ }^{87}$

"Muchas veces, una no está de buen ánimo, y esto se nota en la conducta, no hacés bien las cosas... entonces nos juntamos y hacemos como una terapia, [risas] empezamos a preguntar qué pasa, por qué estás así, -y, no, es que pasó esto en mi casa y...-y todas damos nuestra opinión y tratamos de desenchufarnos de nuestros problemas personales" (Testimonio BLM 1997)

El comedor atiende los días de semana (de lunes a viernes) y ofrece sólo el almuerzo; en tanto que los fines de semana las "cocineras" descansan o aprovechan para hacer las compras en el centro de la ciudad de La Plata.

Aun en los momentos en que los subsidios disminuyeron, el comedor se pudo sostener. Ha seguido con el apoyo de la municipalidad por ser uno de los pocos comedores subvencionados que ha cumplido con todo en regla y ha sabido administrar muy bien los

\footnotetext{
${ }^{87}$ En varias ocasiones tuve la oportunidad de compartir ese almuerzo cuando estaba en mis horas de 'trabajo de campo' sola o con mis compañeras del equipo de investigación, percibiendo el clima de camaradería, reciprocidad y solidaridad que se da durante el mismo; como así también saboreando los diferentes platillos.
} 
alimentos, dando un plato de comida a más de los niños registrados. Incluso, hasta ha realizado un intercambio o donaciones con otros comedores de la zona que estaban en peores condiciones cuando la crisis socio-económica de diciembre de 2001 afectó de manera particular.

\section{- El Ropero Comunitario}

Otro de los proyectos iniciados fue la organización de un ropero comunitario. Esto implicó el trabajo de un grupo de mujeres que recibieron un Plan Trabajar para capacitarse en la costura. Una profesional les ofreció clases sistemáticamente, dos veces por semana. Practicaron la elaboración de moldes, cortes, armado de las piezas, hilvanado y costura a máquina. Una coordinadora velaba por la participación de las becadas y el aporte de las horas de trabajo. Luego, pusieron en práctica sus conocimientos cortando y cosiendo telas, remendando otras. Contaron con dos máquinas de coser, una un poco más nueva que la otra. Algunos comercios donaron retazos de telas y, en otros casos, se fue juntando ropa usada, la que fue reciclada.

La incursión en la costura las llevó a elaborar "vestimenta o artículos en serie" destinados a todos los niños tobas. Un ejemplo fue la realización de los uniformes de gimnasia y bolsos y/o mochilas para los niños que asistieron a una colonia de vacaciones ofrecida por la municipalidad en una temporada de verano. También, se realizaron los delantales, repasadores, agarraderas y manteles para el comedor comunitario. Además, efectuaron trabajos a pedido que les acercaban las otras mujeres del lugar. Si bien el trabajo de costura puede parecer individual, hay que destacar el trabajo colectivo y comunitario que realizaron. Cada vez que se elaboraba una pieza, todas, de alguna u otra manera, participaban. Ya sea asesorando o ayudándose entre sí.

El clima siempre fue de una gran tranquilidad. La coordinadora abría el obrador en las tardes, y las mujeres iban llegando de a una o en grupitos. Cada una tomaba un lugar y una tarea -cuando no iba la profesora de costura- y siempre había conversación y risas, especialmente en el idioma toba. Una de las mujeres preparaba mate que acompañaba el trabajo y, ya al terminar las horas de trabajo, se preparaba el mate cocido o alguna otra bebida con galletitas, pan o pan dulce, compartiendo así la merienda. De vez en cuando, aparecía alguno de sus hijos para hacer alguna consulta a su mamá y las niñas curioseaban para aprender algo de costura. 


\section{- El Horno de Barro}

“...El horno funciona hace ya como tres años. Primero era más chico, ahora es más grande, y cada vez que se deteriora se vuelve a reparar..." 88

Uno de los últimos proyectos implementados fue el horno de barro para la elaboración de pan casero. Sin embargo, el horno de barro tiene toda $s u$ historia. Se comenzó con un pequeño hornito casi sin uso. Luego, en ocasión del Encuentro Latinoamericano de Estudiantes de Arquitectura ELEA/23-30 de octubre de 1998, realizado por la Facultad de Arquitectura de la Universidad Nacional de La Plata, los organizadores del evento decidieron realizar uno de sus talleres abiertos en el Barrio Toba con el tema «Indígenas Tobas en La Plata y el Plan de Autoconstrucción de Viviendas». Como una manera de devolver las atenciones que la gente toba había ofrecido para la realización de ese encuentro, los estudiantes de arquitectura tomaron el compromiso de ampliarles el horno de barro, mejorando su capacidad y calidad de uso. Las inclemencias del tiempo, el poco uso y los materiales con los que fue hecho, hicieron que el horno necesitara un mantenimiento permanente. Hasta que alrededor del año 2000, a través de un proyecto presentado a la municipalidad para obtener un plan de la misma, comenzó a funcionar de manera más sistemática:

"El pan casero no cualquiera lo puede hacer, porque todas las personas no amasan de la misma manera. Acá en el grupo tenemos dos personas que lo hacen y cuando no están ellos fallamos todos. Porque cualquiera lo puede hacer, pero hay quienes saben amasar mejor. La masa no te sale como ellos saben hacerlo. " 89

El horno funcionó articuladamente con el comedor comunitario. El pan era utilizado en el comedor y también se vendía en los alrededores; lo compraba la misma gente toba y sus vecinos como una manera de colaborar para juntar dinero y hacer las veredas -otro de los proyectos a ejecutarse prontamente- y también se vendía fuera del barrio. En los últimos años, como ya se comentó, por una iniciativa de la Municipalidad de La Plata, el horno de barro fue reemplazado por un "horno ecológico" hecho con un barril de metal inclaustrado en una de las chapas que sirven de pared al comedor. Se cortó la chapa en forma circular colocando la tapa del horno en el hueco y una parrillita en la cavidad del horno. Esto trajo como consecuencia una fea apariencia estética al lugar, ya que la chapa se quemó, dio más calor al ambiente y la comida, lamentablemente, la mayoría de las veces se quemaba.

\footnotetext{
${ }^{88}$ En LIAS/UNLP - Vídeo “Lo Onataq na qom...”.

${ }^{89}$ Ídem 19.
} 


\section{- Otras actividades, otros proyectos...}

Por una parte, hubo actividades que consistieron en la vinculación de algunos integrantes de la comisión directiva de la asociación civil con la Asociación Vecinal Malvinense -asociación conformada por representantes de los distintos grupos sociales que integraron el Plan de Viviendas para 540 familias del Barrio "Las Malvinas"-. Esta participación incentivó la organización de grupos de trabajos subvencionados por un Plan Trabajar para la limpieza de zanjas; la recolección y quema de basura; y el inicio de la construcción de las veredas y el mejoramiento del aspecto de las calles.

Por otra parte, existen otros proyectos soñados desde largo tiempo que fueron planificados para dar trabajo a la comunidad de un modo más estable, seguro e independiente: la construcción de una panadería; una fábrica de dulces y otra de premoldeados. La panadería ya casi es un sueño cumplido. A partir del año 2007, se condicionó un espacio detrás del salón multiuso y se recibió un subsidio para la compra de dos hornos industriales eléctricos y las mezcladoras de masa. La misma está a cargo de tres mujeres del barrio que empiezan sus labores muy temprano por las mañanas. Recibieron un entrenamiento a través del municipio y hoy elaboran pan y tartas dulces que salen a vender por el barrio a un precio módico, a la vez que aprovisionan el comedor comunitario. Para los otros proyectos: la fábrica de dulces y la de premoldeados, se sigue insistiendo en la obtención de un subsidio que permita la instalación de los mismos. También se tiene pensado asfaltar las cuadras de la calle 151 entre 35 y 36 y cerrarlas -haciéndolas peatonales- con el objetivo de montar un espacio de venta de sus artesanías y, asimismo, resguardar la seguridad de los niños que suelen jugar en la calle, cruzándose de un lado a otro y quedan al peligro de los automóviles que pasan por el lugar.

\section{II.3. La Práctica de "El Evangelio"}

"Nosotros no creemos mucho en la Virgen. Tampoco tenemos imágenes y la Iglesia Católica es más fría y siempre se repite lo mismo" (Testimonio BLM 1993).

La mayoría de las familias tobas del barrio son seguidoras de "El Evangelio", 90 el que domina en mayor o menor grado en su vida espiritual. Quienes son muy creyentes

\footnotetext{
${ }^{90}$ A partir de los primeros años de la década de 1940 se comenzó a gestar en el Chaco y en la cultura toba un movimiento religioso, según Miller, de tipo revitalizador, que incorporó al cuerpo de creencias y tradiciones tobas, elementos de tipo pentecostal basados en la curación por la fe, la glosolalia y la posesión del Espíritu Santo. Actualmente, todo asentamiento toba sostiene al menos un culto organizado (servicio religioso) que
} 
obedecen estrictamente las reglas y restricciones tales como: "no beber", "no fumar", "no bailar", "no recordar y vivir del pasado, sino pensar en el futuro". Algunos opinan que por esta razón muchos abuelos o fieles son muy reacios a contar o transmitir a los más jóvenes cuentos, leyendas y aspectos de la cosmogonía toba. Quienes aprenden a tocar algún instrumento musical tal como la guitarra, el acordeón o el bombo, sólo lo ejecutan en el contexto del servicio religioso.

La manifestación del Evangelio se da principalmente a través del culto. El culto consiste en la reunión de los fieles en un espacio cerrado y dirigido por un pastor (o más, según las circunstancias), un ayudante del pastor o secretario, un portero y un coro. Algunas veces, se recibe la visita de pastores y coristas que provienen de otras iglesias evangélicas de la zona o de alguna localidad de Buenos Aires o, incluso, de las provincias, en especial, de Santa Fe, Chaco y Formosa.

El culto se realiza en el Barrio Toba "Las Malvinas" durante dos o tres días fijos de la semana; sin embargo, éstos pueden variar dependiendo de "cuánta necesidad haya del Evangelio". En algunas ocasiones, puede practicarse a lo largo de toda la semana si es que se acerca algún fiel que se siente enfermo y necesita sanación.

Al principio, el culto funcionó en el obrador. Era un lugar pequeño y había que readaptar el lugar cada vez que se lo utilizaba corriendo las herramientas de la construcción, colocando sillas y una mesa como altar.

En 1996, una vez terminada la primera etapa de construcción de las viviendas y avanzada la segunda, el que fuera el primer presidente de la Asociación Civil Toba Ntaunaq Nam Qom, fundó la Iglesia Unida Templo de Fe. El trámite para su creación llevó su tiempo. Hubo la necesidad de vincularse con otra iglesia que cedió el fichero.91 La iglesia tiene una organización propia con sus autoridades: posee un presidente primero y un presidente segundo; un secretario y un prosecretario; seis vocales; y un primer, segundo y tercer revisor de cuentas.

Cuando se terminó con la segunda etapa y todas las viviendas fueron ocupadas, el obrador se convirtió en comedor y delante de éste, se colocaron las maderas de las casillas prefabricadas que habían servido de hogares mientras se construían las casas. Así quedó

proporciona los medios primarios de integración social (Miller 1979:11). (Ver también Miller 1971, 1999; Cordeau y Siffredi 1971; Fort 1989; Wright 1994; Tamagno 2001).

${ }^{91}$ Se refiere al permiso que las iglesias poseen de libre expresión de la fe. 
instaurado un espacio exclusivo para el culto, con banquetas de madera, un altar y un atril, un lugar para los coristas y algunos pósteres alusivos a pasajes bíblicos.

Alrededor de las 19 horas, al atardecer, comienzan los preparativos en el culto. Se colocan los manteles en una mesita que hace de altar, se lleva la Biblia, se acomodan las sillas y, a un costado del altar, se ubica un gran radio-grabador que sirve de amplificador de un micrófono que usa el pastor durante todo el servicio. Poco a poco van llegando el pastor y sus acompañantes, los coristas y los fieles; todos muy bien vestidos y peinados con una Biblia en sus manos, una hoja de papel donde hacer anotaciones y una lapicera. Llegan solos o en grupos de dos o tres. Generalmente, las mujeres ocupan el sector izquierdo y los hombres el derecho de frente al pastor, aunque pueden entremezclarse según la cantidad de fieles de cada sexo y el lugar que quede vacío si se llega tarde o si se perdió el lugar que se ocupaba. La entrada es libre; sin embargo, un "portero" se queda en la puerta o cerca de la misma recibiendo a los fieles que ingresan y egresan, e indica dónde sentarse. Algunos fieles pueden entrar o salir varias veces, al igual que los niños que acompañan a sus padres. Éstos suelen ir afuera a jugar y volver a entrar cuantas veces quieran. Los coristas hacen la apertura con algunas canciones como haciendo el llamado de los fieles. El culto puede durar sólo dos horas o toda la noche según las circunstancias.

Una vez al mes, se realiza la Santa Cena que consiste en el compartir el pan y el vino, siguiendo el episodio que indica la Biblia cuando Jesús, sabiendo que iba a morir, celebró con sus doce discípulos la última cena y transformó el pan en su cuerpo y el vino en su sangre. En el culto toba se bendice un pan mientras se lee el pasaje bíblico correspondiente a ese hecho y se lo corta en trocitos pequeños de modo tal que alcance para todos los presentes que han recibido el "bautismo de aguas". Luego, una persona pasa un platito entre los fieles y cada uno toma un trocito con la mano y lo tiene hasta que, habiéndose repartido todo, el pastor da la orden: "comamos todos juntos". A continuación, el pastor bendice el vino dispuesto en una jarra pequeña de mesa y otra persona se encarga de servir un poco en un vaso y va alcanzando éste a los fieles quienes beben un sorbito.

Las historias que explican el por qué eligieron seguir "el Evangelio" son diversas y muy personales. No obstante, es recurrente en los discursos la idea de haber estado "perdidos" o “enfermos” y que al acercarse al Evangelio encontraron la sanación:

"Mis hijos estaban muy enfermos, no encontraba cura. Me acerqué al Evangelio y comencé a asistir al culto porque creía en su curación, y eso fue lo que pasó" (Testimonio BLM 1994) 
"Yo tomaba mucho, y a través de El Evangelio dejé de tomar y de pegarle a mis hijos y a mi mujer" (Testimonio BLM 1996)

"De joven era creyente pero no iba a la iglesia. Fumaba mucho, trabajaba, hacia artesanías y todo lo que ganaba lo usaba para comprar cigarrillos. Era una chica muy rebelde... Un día mi hija se enfermó de meningitis siendo un bebé de 9 meses. Los médicos ya la daban por muerta hasta que un pastor la llevó al culto, le rezaron y se curó. Los médicos no lo podían creer... Ahi dejé de fumar y a ser más creyente" (Testimonio BLM 1995)

Cuando los niños son pequeños se les realiza su consagración o presentación a Dios. Luego, desde los 8 ó 10 años en adelante se realiza el bautismo de aguas que consiste en sumergir en el agua de un río (en el Chaco) o en una pileta (en La Plata) totalmente al bautizado -desde los pies a la cabeza- entre dos pastores, mientras otro ora y un grupo de coristas acompaña junto con el canto de los fieles. También, suele ocurrir que algunos fieles se alejen del Evangelio y, al cabo de un tiempo, decidan regresar. En estos casos, se realiza la conciliación o el arrepentimiento.

Durante un culto común pueden darse: el canto, la lectura de distintos pasajes bíblicos, la oratoria de uno o más pastores, la plegaria, la danza, la reconciliación y la imposición de manos.

Los cantos son, en general, largos -pueden durar entre 5 y 15 minutos- con estribillos que se suelen repetir reiteradas veces y de ritmos alegres, donde se pueden reconocer estilos musicales del folklore norteamericano y latinoamericano. Están acompañados por guitarras $\mathrm{y}$, algunas veces, por un acordeón y un bombo. Quienes guían el canto son hombres jóvenes que se ubican a un lado del pastor, mirando a los fieles. Algunos, acompañan el canto y el tocar de la guitarra con un paso que se asemeja a un pequeño saltito, o balanceo de un lado a otro, siguiendo el ritmo. Al otro lado, está el coro de las mujeres, especialmente niñas y adolescentes de voz muy aguda, que acompañan el canto con panderetas y palmas. En la ciudad de La Plata, pocas veces se ejecutaron canciones en lengua toba; sin embargo, el ritmo y la manera de vocalizar se asemeja a aquellos cantos tradicionales de este pueblo.

La lectura de algún pasaje bíblico suele hacerse antes y durante la oratoria o prédica del pastor. A ésta le sigue una explicación, consejos, enseñanzas que son motivo de la oratoria propiamente dicha. En cualquier momento de la misma también se puede recurrir a algún pasaje bíblico relacionado con el tema del discurso. La lectura se hace muy veloz y la 
realiza el mismo pastor, indicando previamente el evangelio y el versículo. Mientras esto ocurre, todos los fieles que tienen una Biblia en sus manos -incluidos los niños-, buscan la página correspondiente, la señalan y anotan en un papel para, luego, leerlo con más tranquilidad. Las miradas cómplices y las consultas entre sí, junto con los movimientos inquietos a un lado y a otro de niños y adolescentes parecen indicar que éstos no prestan demasiada atención directamente al contenido del versículo leído, y que sólo anotan su número y el de la página con mucho cuidado. Los temas de las oratorias son diversos y se suelen dar testimonios de las propias experiencias vividas por los pastores relacionadas con los hechos destacados en la Biblia.

En la plegaria participan todos. El pastor da el inicio y cada uno de los fieles comienza a rezar aumentando la intensidad al cabo de unos minutos. En los momentos de mayor tensión se produce lo que se conoce como glosolalia ${ }^{92}$ que consiste en invocar a la oración en voz alta -todos al unísono- llorar, gritar y recibir en ese momento el gozo. ${ }^{93}$ Este último también se da a través de la danza que consiste en dar pequeños saltitos en el lugar, levantando uno o dos brazos y con los ojos cerrados. En algunos casos hay desplazamientos suaves y circulares que se van haciendo cada vez más intensos hasta caer en el éxtasis, aunque sólo algunos fieles lo llegan a experimentar. La plegaria y la experiencia de la glosolalia también ocurren cuando hay imposición de manos y reconciliación. La primera se realiza cuando hay alguien que dice sentirse enfermo. Éste pasa adelante, se arrodilla, el pastor comienza a orar y coloca su mano en la cabeza del enfermo, al tiempo que todos los fieles también oran, con los ojos cerrados y un brazo levantado. Y la segunda, cuando una persona que se había alejado del culto, decide regresar. El pastor le pregunta cuál fue el motivo de su alejamiento, por cuánto tiempo se alejó y, luego, lo comenta en voz alta a los fieles. Todos juntos oran y al terminar, aplauden y saludan al arrepentido.

Cuando algún pastor llega de otro lugar se organizan los "Movimientos" o "Campañas Evangélicas". Éstos convocan mucha más gente y asiste también gente no toba. Consisten en reuniones diarias durante una o dos semanas completas, con actividades programadas. También suelen participar otros coros provenientes de otros lugares. Se dan los mismos

\footnotetext{
${ }^{92}$ Se designa con el nombre de glosolalia al don de hablar en lenguas y se refiere al episodio del Nuevo Testamento en que encontrándose la Virgen María con los doce discípulos, descendió sobre sus cabezas el Espíritu Santo y les dio el don de hablar en lenguas.

${ }^{93}$ Alcanzar el gozo equivale a recibir al Espíritu Santo (Miller 1979).
} 
elementos que aparecen en un culto común: canto, plegaria, lectura de la Biblia, oratoria, danza, imposición de manos y sanación. Además, se realizan consagraciones de niños pequeños, muchos reciben "el llamado de Jesús" por primera vez y se inician en "el Evangelio" o, si se habían alejado, se arrepienten y se acercan nuevamente. También es ocasión para el bautismo de aguas.

La gente que llega de otros lugares es alojada entre las familias del barrio y se prepara comida para todos, que luego comparten juntos en largas mesas dispuestas en la iglesia o al aire libre. En estos menesteres la mayoría ayuda, aún aquellos que no son creyentes. Se vive en el barrio una jornada con mucho fervor.

Dadas las características descriptas y la combinación de diferentes factores, podemos considerar al culto no sólo como un lugar de expresión de la fe, sino también un espacio de encuentros y reencuentros, cohesión y reafirmación de lazos de lealtad y compadrazgos, y un sitio donde aspectos de la cultura toba - entre los que se encuentra la lengua- también se recrean y revitalizan. ${ }^{94}$

\section{- Aniversario de La Iglesia Unida Templo de Fe}

Todos los 9 de Julio - coincidentemente con la fecha patria-, el barrio se prepara desde muy temprano para recibir a los invitados que participarán del aniversario de la iglesia. Las iglesias evangélicas vecinas y de distintas localidades del Gran Buenos Aires son convocadas y acuden ese día los pastores junto con un grupo de fieles, quienes llevan el saludo de toda la congregación, y presentan sus cánticos. También llegan parientes y amigos de IAPI y otros nucleamientos tobas de la provincia. Las mujeres del comedor hacen la torta $y$, aun las que no participan del culto, ayudan en la preparación del locro o las empanadas y las tortas fritas, platos con los que son agasajados los invitados a la hora del almuerzo. El festejo dura todo el día y se celebra en el culto. La iglesia se adorna con globos y guirnaldas y todos se visten de fiesta. Los niños entran y salen todo el tiempo. Un pastor del barrio dirige la ceremonia y una secretaria posee la lista de las presentaciones. A medida que se anuncian los pastores o coros pasan al frente y dan su mensaje, prédica o canto. También hay aplausos. En algunas ocasiones llega como invitado un pastor del Chaco y éste ejecuta su presentación en la lengua toba. Se observa mucho fervor entre la gente, incluso entre los no tobas que lo siguen con atención.

\section{- Cumpleaños de 15}

\footnotetext{
${ }^{94}$ Este aspecto es desarrollado con mayor profundidad en el Capítulo IV.
} 
Las niñas tobas festejan sus quince años también en el culto. Y en 1998 fuimos invitados especialmente para celebrar el cumpleaños de una de ellas. Con anticipación, comenzaron los preparativos. Se eligieron los padrinos que serían los principales encargados de los costos de la fiesta y acompañaría a la homenajeada durante toda la ceremonia. Se realizaron las invitaciones personalizadas y asistió gente de todos lados, tanto tobas como no tobas. La iglesia se adornó especialmente para la ocasión con globos de colores violeta, amarillo y rosado, guirnaldas y un cartel grande de color rosa brillante que decía: "Felices 15 años". A un lado del altar, se colocó la torta de tres pisos de la que colgaban cintitas que luego serían tiradas por otras niñas esperando sacar la sortija. La celebración se realizó en la noche. Alrededor de las 20 hs se convocó a los invitados, una mujer -familiar de la agasajada- hizo de "portera" y recibía y ubicaba a los mismos en el interior de la iglesia. Un coro de hombres conformado por unas quince guitarras se ubicó a la izquierda del altar, mirando al público; y otro de mujeres jóvenes y niñas, a la derecha, vestidas todas iguales, con falda azul y camisa blanca, quienes acompañaron sus cantos con panderetas. El pastor principal y los pastores invitados se sentaron detrás del altar, mirando al público y un ayudante del pastor condujo el evento. Se esperó a la homenajeada con cánticos de la iglesia y pequeñas oraciones. Los niños más pequeños se veían ansiosos e inquietos, entrando y saliendo a cada minuto, para no perderse la llegada de la agasajada. Mientras tanto, la cumpleañera estaba en su casa preparando su ajuar: un vestido acampanado de raso blanco y puntillas; zapatos blancos con taco y punta; y guantes blancos. El pelo recogido con trencitas y una coronita de pequeñas florcitas. Sus padrinos la esperaban en un auto y la trasladaron junto con sus padres hasta la iglesia. Allí, en la puerta, la recibió el pastor saludándola con un beso en cada mejilla, y la dirigió hacia el interior de la misma. Ella entró por el corredor central del brazo de su padrino y atrás, le seguían sus padres. Fue recibida con aplausos y caras muy alegres mientras los coros cantaban: "un feliz cumpleaños te deseamos a ti", aunque con ritmo de cántico de la iglesia. La homenajeada junto con sus padrinos y padres fueron ubicados en unas sillas que estaban dispuestas adelante, frente al altar, de espaldas al público, y se dio inicio al culto. Todos hicieron una oración y se les dio la palabra primero a los padres, los padrinos y, después, a la cumpleañera, quienes, muy emocionados, agradecieron a Dios, a todos los hermanos presentes y pidieron una oración o una canción. También hubo aplausos. Los pastores tomaron la palabra y, en un momento, se convocó a la sanación. Luego, se volvió a cantar: "que lo cumplas feliz y que Dios te bendiga y te guarde hasta el fin". Mientras tanto, los invitados formaron una fila y pasaron por adelante saludando a la homenajeada, a 
los padres y padrinos, y le entregaron sus regalos. Muchos de los presentes llevaron sus cámaras de fotos y se sacaron una foto con la agasajada de pie, al lado de la torta. Los coristas continuaron cantando y tocando, quedando como música de fondo. Se pidió a los invitados que salieran afuera y se preparó la iglesia con mesadas para compartir todos juntos una cena. Más tarde, las niñas se acercaron a la torta y se dispusieron a tirar de las cintas. Se aplaudió a la que sacó la sortija y se cortó la torta. Los globos fueron repartidos entre los más pequeños. En ningún momento se escuchó música que no fuera del culto y tampoco se bailó.

Tanto por los relatos recogidos como por las fotos observadas que son propiedad de las familias, los cumpleaños de 15 de las jovencitas responden al modelo descrito, convirtiéndose en un espacio de encuentros y reencuentros, puesto que los invitados suelen ser muchos y, algunos, vienen de lejos.

\section{III.4. Festejos Colectivos}

Así como observamos que la mayoría de las actividades se realizan de modo colectivo y comunitario, los festejos también tienen esta modalidad. Las fechas especiales tales como el 19 de abril "Día del Indio", el "Día del Niño", "Aniversario de La Iglesia Unida Templo de Fe", "Navidad y Año Nuevo", o el cumpleaños de algún niño que asiste al comedor, suelen festejarse todos juntos.

\section{- Día del Indio}

El 19 de abril de 1992 fue la primera celebración que se realizó en el barrio del "Día del Indio". Las primeras ocho viviendas estaban casi terminadas. Se invitó a familias del nucleamiento de Villa IAPI, hermanos de la congregación de los Vicentinos y jóvenes de una escuela de la ciudad de Buenos Aires que habían colaborado con la Asociación Civil. Se llegó a reunir un total de unas cincuenta personas aproximadamente. El festejo consistió en la preparación de un locro y tortas fritas, como así también la exposición y venta de artesanías (Tamagno 2001:169-170). Desde entonces, todos los años se celebra este día invitando a la gente en general, hermanos tobas de otros nucleamientos de la Provincia de Buenos Aires y a representantes de aquellas instituciones con las que la Asociación Civil mantiene una articulación social permanente.

Al año siguiente, los festejos del "Día del Indio" fueron especiales. En esa oportunidad, la paralización de la construcción y la escasez de fondos para continuar bajaron los ánimos de la gente. Fue así que algunos de los funcionarios que habían acompañado este proceso 
ofrecieron su colaboración para realizar una exposición abierta a los vecinos de la ciudad de La Plata para conmemorar ese día. Se montó una gran carpa en las cercanías de las viviendas en construcción donde se expusieron fotografías, material fílmico y los niños dibujaron lo que más les gustaba del barrio. Las mujeres prepararon el típico locro y las tortas fritas. Docentes de la zona, vecinos y agentes gubernamentales visitaron la exposición y el presidente de la asociación civil y una joven izaron la bandera argentina. ${ }^{95}$

En 1995 se volvió a vivir una jornada especial en conmemoración de ese día con la participación del equipo de investigación del proyecto "Los Tobas del Barrio Las Malvinas: su articulación social” de la Universidad Nacional de La Plata. El primer día se pasaron en el obrador los vídeos con las filmaciones efectuadas durante el proceso de autoconstrucción de las viviendas y otro del documentalista Mario Grasso con el tema "Indígenas en la ciudad" donde las familias del barrio habían participado; y también se colocó un pequeño puestito con exposición y venta de artesanías. El día finalizó con la presentación de un conjunto musical compuesto por un pilagá y un calchaquí que habían sido invitados a través del AIRA. ${ }^{96}$ Al día siguiente, hubo mucha más participación de gente de afuera. Las mujeres prepararon un gran locro y los hombres choripanes. Colocaron los puestos de artesanías afuera del obrador y las primeras lucieron sus sombreros de juncos y collares de barro y semillas. Se realizó una pequeña ceremonia con la bandera argentina donde un grupo de jóvenes tobas dijeron unas palabras. Los niños estuvieron todo el tiempo participando de las actividades y conversando y jugando entre los invitados.

Los festejos del año 1996 también fueron particulares. Las viviendas ya estaban casi terminadas. Todo el barrio participó cortando el pasto y sacando los yuyos del frente de las casas; se trajeron unos aparatos de música y se colocaron mesas con caballetes alrededor del obrador. Desde temprano, un grupo de mujeres comenzó a preparar dos grandes ollas con locro y otras hicieron la masa para las tortas fritas y prendieron el fuego con leña. Ese día pocos fueron a trabajar o a la escuela. Por la mañana hubo la visita del canal de televisión por cable de La Plata y de dos cursos de la escuela $\mathrm{N}^{\circ}$ 63. Se recibió la donación de algunos árboles y estos fueron plantados con la participación de los chicos de la escuela y del barrio. Al mediodía se sirvió el locro en dos grandes mesas. Las familias que no se

\footnotetext{
${ }^{95}$ Para más detalles del evento ver Tamagno (2001).

${ }^{96}$ Asociación de Indígenas de la República Argentina.
} 
sentaron a la misma junto con los invitados, también recibieron su ración y la llevaron a sus casas. En la tarde, llegaron más escuelas y un grupo mapuche cantó.

En otra oportunidad, se invitó a niños de nivel inicial y de Educación General Básica al barrio, se les ofreció chocolate, se expusieron artesanías y se dio una charla. En los últimos años sólo predominaron los almuerzos, invitando aquellas personas que colaboran más cercanamente con el barrio o la asociación civil. En tanto que se han incrementado las invitaciones de las escuelas de la ciudad de La Plata para que den charlas alusivas para ese día.

\section{- Día del Niño}

Los festejos del "Día del Niño" (primer domingo de agosto) también son motivo de actividades conjuntas. Quienes organizan la jornada son, principalmente, las mujeres que forman parte de la comisión directiva de la asociación civil, aunque participan todas las mamás. Desde que la gente toba llegó a La Plata distintas instituciones han estado vinculadas a su desarrollo. En este caso, para esta fecha, distintos organismos, funcionarios o vecinos suelen hacer donaciones de juguetes y/o golosinas.

"Era viernes y no teníamos nada más que una bolsita de caramelos y unos juguetitos.

Y al día siguiente nos llegó. Siempre algo nos llega” (Testimonio BLM 2003).

La modalidad de los festejos ha variado según las ocasiones y la ayuda recibida, pero siempre tratan de que todos lo chicos reciban su regalo y pasen un día feliz. En estas actividades también participan los adolescentes organizando o dirigiendo algunos juegos. Por ejemplo, en 1994 un grupo de mujeres se reunió y realizó algunos muñecos de trapo siguiendo los moldes y pasos de una conocida revista de manualidades. Como no pudieron hacer suficientes muñecos para todos, los juntaron y colocaron en una bolsa. Luego, ese día, organizaron una serie de juegos tales como: carreras de embolsados, llevar una papa con una cuchara en la boca, y fueron sacando de la bolsa los premios para los ganadores. En esa oportunidad una vecina de la "villa"97 se vistió de payaso y entretuvo a todos los niños. Hacia el año 1999, las vinculaciones del comedor comunitario con la Municipalidad de La Plata eran más estrechas y ésta envió para ese día un mago y un grupo de teatro que representó una obra vestidos de muñecos. Todos los niños tobas, y algunos vecinos también, participaron y festejaron su día, junto a las mamás que estuvieron más bien de

\footnotetext{
${ }^{97}$ De esta manera se refieren a los vecinos del barrio que no son tobas, que no poseen una vivienda de material y no están organizados como ellos.
} 
espectadoras porque, a pesar de ser alrededor de 50 niños, el comportamiento fue tranquilo y no hubo necesidad de alzar la voz. Los niños fueron colocados en una gran ronda, sentados en banquetas y en el pasto, cada uno trajo su jarrito, y fueron convidados con chocolatada, torta y galletitas. Luego, hicieron una fila de menor a mayor y se les repartió juguetes y golosinas. En otra ocasión, una profesora de gimnasia, enviada por la municipalidad, estuvo dando clases, organizando una colonia de vacaciones en un verano. La relación con esta profesora siguió durante el año y para el "Día del Niño" organizó, junto con las mamás, una serie de juegos al estilo de una kermés, tales como pasar una ratita de peluche por un tubo y tratar de pegarle con un palo cuando salía por el otro lado; el juego del "Tutti-Frutti" en un pizarrón; pescar unos pescaditos con imanes; tiro al blanco con unos plumones; encontrar un caramelo en un plato de harina; carrera de embolsados; fútbol y pelota al cesto. Por cada juego, los niños recibían caramelos como premio. Estos puestos estuvieron atendidos por adolescentes y mamás. También recibieron su vaso de chocolatada y porción de torta dispuestos en ronda; y, al finalizar, sus juguetes.

En la conmemoración del año 2003, a pesar de que las instituciones no brindaron su apoyo, igual se celebró ese día. Fueron las mamás que trabajan en el comedor las encargadas de organizar todo y generar un espacio para el festejo y alegría al día. Prepararon chocolate caliente y bizcochuelos. Los niños fueron dispuestos en una ronda en el pasto y se les sirvió en jarritos que cada uno de ellos había traído de sus casas y comieron alegremente. Luego, jugaron a la pilladita y a la pelota. Esta vez, no hubo ni música, ni nadie que los entretuviera. Algunas mamás se sentaron alrededor de éstos junto con sus hijos menores y nietos. Pasada una hora o más, a la orden de una mamá, los niños se dividieron en dos filas, una de mujeres y otra de varones, dispuestos de menor a mayor y estuvieron así un rato largo. Primero se les repartió un puñado de golosinas. Los que estaban primeros se volvieron a colocar en la fila, últimos. Al finalizar, fueron llevados en grupitos hacia el comedor acompañados por una mamá, donde unas mujeres los esperaban con los juguetes exhibidos en una mesa donde ellos mismos fueron eligiendo el que más les gustaba y se les volvió a dar golosinas. Estas mamás contabilizaron los chicos que no habían ido y les guardaron sus juguetes para entregárselos más tarde. En esa oportunidad conté treinta niñas y sesenta niños aproximadamente.

\section{III.5. Algunos Aspectos de la Socialización}

Los niños pequeños pasan la mayor parte del tiempo al cuidado de sus mamás, quienes los amamantan hasta el año y medio de vida aproximadamente. Durante ese lapso, aquellas 
madres que son toba hablantes, realizan la socialización del niño en y por la lengua qom; los niños encuentran en este idioma un medio armonioso, y suelen expresar su extrañamiento con llanto cuando escuchan hablar en "la castilla". En los casos donde las madres socializan a sus hijos en español, la lengua toba está presente a través de los abuelos, tíos, vecinos y visitas que llegan del Chaco.

Los niños en sus primeros años de vida son tranquilos y callados; sólo lloran cuando tienen hambre o alguna dolencia física los aqueja. En algunas oportunidades, cuando son más grandecitos, los padres tratan de hablar en la lengua a sus hijos:

"A mi me interesa que mis hijos aprendan la lengua. Por eso siempre le hablo al A., me siento y converso con él y hago que repita algunas palabras. Por ahi se me rie, pero yo sigo no más" (Testimonio BLM 1993).

Los hermanos mayores -sean varones o mujeres- tienen el deber de cuidar a sus hermanos menores. Esto se observa cuando un grupo de niños juega en la calle o cuando las mamás están trabajando en la huerta o en el comedor, éstos se quedan en la casa cuidando de los hermanitos más pequeños. ${ }^{98}$

Las puertas de las casas están, generalmente, abiertas por lo que los niños entran y salen con total libertad, y juegan y pasan la mayor parte de su tiempo libre en las calles, aunque vigilados siempre por la mirada de los mayores -sean sus parientes o no. ${ }^{99}$

Los niños aprenden fundamentalmente observando, imitando y jugando. Estas técnicas contrastan generalmente con las de la escuela, donde los niños son obligados a abstraer, memorizar y repetir. Asimismo, la escuela favorece las conductas individuales y competitivas, mientras que la modalidad aborigen privilegia la reciprocidad y las actitudes comunitarias-cooperativas (Ver Ibáñez Caselli 2004). Además, entre los tobas se dan técnicas particulares de transmisión del conocimiento, por ejemplo, existe la noción de “aprendizaje onírico", es decir, la posibilidad que el individuo reciba enseñanzas por parte de entidades no-humanas que lo instruye mientras duerme (Mendoza y Wright 1985).

\footnotetext{
${ }^{98}$ En algunas ocasiones, durante la experiencia de apoyo escolar que dábamos en el barrio, podíamos notar la presencia de algunos niños con sus cuadernos y su hermanito menor que había quedado a su cargo.

99 A este respecto, la investigación realizada por Colángelo (1995) demostró cómo en otros barrios periféricos el peligro se sitúa inmediatamente fuera de las viviendas. En este contexto, cuidar de los niños implica que no salgan afuera "donde está el peligro" y, con frecuencia, cuando los mayores salen y los tienen que dejar solos, los dejan con llave. En el caso del Barrio Toba, el espacio es comunitario y los límites por donde los niños circulan son más amplios y terminan donde acaba el barrio.
} 
Asimismo, la relación con la naturaleza siempre está presente, aun entre los tobas en la ciudad, lejos del Chaco. Los adultos están pendientes de todas las señales que ésta puede ofrecer y así saber si "va a hacer un buen día", "si lloverá", "hará mucho frío", "si alguien llegará de lejos", o "si habrá una mala noticia". Y esta vinculación con la naturaleza es trasmitida a los niños, quienes aprenden a estar atentos al canto de los pájaros, al movimiento de las nubes, a la puesta del sol y a los sueños. Asimismo, hay un conocimiento de hierbas y plantas que tienen acciones medicinales. Muchas de estas plantas son del Chaco, pero algunas mujeres han logrado cultivarlas en sus jardines.

Es frecuente que los niños participen en todas las actividades que realizan los adultos y en esta participación no tienen restricciones. Por ejemplo, los niños suelen ayudar en algunas tareas en la huerta o en la realización de la artesanía. Es común que un grupito de niños sea convocado por alguna artesana para enganchar las bolitas de barro que sirven para confeccionar los collares y pulseras típicas. Asimismo, se encuentran presentes en las reuniones, en las asambleas de la asociación y en las celebraciones del culto; lo mismo ocurre cuando llega algún foráneo y solicita una entrevista. Son transmisores de mensajes; realizan pequeños mandados y están atentos a todos los sucesos que acontecen en el barrio. En ningún momento se observa un reto fuerte o una prohibición tajante o se levanta mucho la voz. El control se hace más bien con la mirada.

Los niños son muy hábiles con los trabajos manuales, saben dibujar, pintar y modelar. Es común que jueguen con el barro haciendo bolitas para luego jugar con éstas al "juego de las bolitas" o como balines para tirar con hondas; algunos dejan volar su imaginación y modelan con el barro figuras mucho más complejas tales como dinosaurios y otros animales prehistóricos o algún personaje que han visto en la televisión; como así también "indios y militares a caballo" y juegan con estos a "la guerra". Los tipos de juegos son diversos y, en general, colectivos. Éstos difieren de los de "antes", los que se jugaban en el Chaco, en especial en los materiales que se utilizaban para hacer los juguetes. En el Chaco "las niñas hacen muñequitas con las patas del ñandú, vistiéndolas y todo. Los varones suelen hacer arcos y flechas y juegan a cazar”. En la ciudad de La Plata, las niñas juegan a la mamá y el papá con muñecos comerciales o con alguna mascota que tienen en la casa (perro, gato o conejo) o un hermanito menor (a estos juegos también se suelen integrar algunos varones); o andan en bicicleta o juegan a las visitas, a saltar con la soga, al elástico, a la ronda y juegos chocando las palmas de las manos acompañadas de canciones. Mientras que los juegos de los varones incluyen la pelota; las bolitas (de barro o vidrio); 
las figuritas; el llevar rodando, corriendo carreras, una rueda o neumático con una vara o con las manos; el subirse a los árboles; la lucha cuerpo a cuerpo o con espadas de madera o plástico y la red de las damajuanas como cascos. También exploran las zanjas y acequias intentando "cazar" peces o renacuajos o juntando cosas. Todos estos juegos son grupales. Al llegar uno al barrio se suelen ver estos grupitos conformados por niños y niñas de distintas edades. Entre estas edades ya no se escucha hablar la lengua qom. Cuando los niños tobas entran en contacto con otros niños del barrio o de la escuela, esta lengua se hace ausente. Sin embargo, ésta suele estar presente cuando llegan niños del Chaco que sólo se expresan en la misma. Aunque es el español el que domina en los juegos, en estos casos, los niños realizan un intercambio e incorporan algunos vocablos que se afianzan con los que internalizan en sus hogares. ${ }^{100}$

Cuando son adolescentes, las mujeres ayudan en los quehaceres domésticos, en tanto que algunos varones acompañan a sus padres y comienzan a realizar algunos trabajos remunerativos en la construcción, como ayudantes. A menudo, también acompañan a una exposición o feria de artesanía o charla. De esta forma, los adultos tratan de que se vayan animando a hablar en público y contar la historia del barrio.

En los últimos años, algunos jóvenes conformaron su propia familia tempranamente, entre los 14 y 16 años de edad. En estos casos, la nueva familia vive en la casa de los padres del varón, si ambos son tobas, o en el de la mujer si ella es toba y el otro cónyuge no lo es. En ambos casos, los abuelos participan de la crianza de los nietos.

\section{III.6. EL BARRIO Y LA EDUCACIÓN FORMAL}

"Eh, bueno, a la escuela 52 [asiste] un grupo, y después, por otro lado, a la escuela 63. Digamos, que en esta escuela 63, los maestros están más atentos, no faltan tanto, los alumnos rinden más inclusive. Digamos, los maestros son más estables porque todos los años hay una continuidad. Cuando no le andan cambiando a los maestros todos los años, ¿no?, siempre llaman a los mismos y eso ayuda también, creo, a los chicos. Son muy buenos. Eh, no asisten a la escuela 23 chiquitos, digamos, esto es por distintas razones. Algunos al no tener un trabajo seguro, no lo anotan en la escuela, porque no pueden comprarle la zapatilla, los útiles escolares. Por ahi nosotros por medio de la asociación tratamos de buscarles becas... pero lo único que conseguimos todos los años es guardapolvos y la ropa. Los calzados por ahi es imposible de

\footnotetext{
${ }^{100}$ Este aspecto es analizado en el Capítulo IV.
} 
encontrarlos, es un problema a veces. Y... la falta de trabajo es en todos lados" [Testimonio BLM 2000].

Los niños tobas no asisten todos a una misma escuela ni disponen de un establecimiento de Educación General Básica (EGB) en el propio barrio "Las Malvinas". Las entidades educativas se encuentran distantes, a excepción de un jardín de infantes (Nivel Inicial). La inscripción a las escuelas ha dependido más de la disponibilidad de bancos a la hora que los padres se han acercado a anotar a sus hijos que a una elección por una en particular. Los establecimientos a los que asisten son principalmente:

La Escuela N 52 "Islas Malvinas" -ubicada en 135 entre 33 y 34-, Las Quintas. Escuela pública a la que han asistido más niños durante los primeros años de haber llegado al barrio "Las Malvinas". Está alejada de éste si se quiere ir caminando y los niños llegan en ómnibus de línea.

La Escuela N 63 "República de Colombia" -ubicada en la Avenida 44 y 155-, El Retiro. Escuela pública a la que se accede sólo caminando, pero las calles son todas de barro y cuando llueve se hace muy difícil su tránsito.

La Escuela San Carlos -ubicada en 32 y 135- Se trata de una escuela privada y católica a la que asisten algunos niños tobas becados.

$>$ El Nivel Inicial "Josefina Bakhita" -ubicado en la esquina de 149 y 35-. Es la unidad escolar más cercana al barrio toba. Se trata de un Jardín de Infantes con dos salitas que depende de la Parroquia San Carlos, y que, según las autoridades de esa institución, "fue creada especialmente para los tobas" en 1995.

> La Escuela N 120 "Herminia Brumona" -ubicada en 17 entre 35 y 36, en la ciudad de La Plata-. La institución se encuentra bastante distante del barrio y los niños acceden a través de un ómnibus de línea que los deja en la puerta.

> Hogar "Pantalón Cortito" -en 139 y 40-. Es un hogar-escuela que alberga alrededor de 60 niños y ofrece guardería a unos 30. Por dos o tres años algunos niños tobas fueron trasladados por el ómnibus de este organismo a las escuelas y asistidos con el servicio de guardería por un par de horas.

Muy pocos niños han sido anotados en escuelas más lejanas y, en el caso de los que accedieron al nivel secundario, fueron a las escuelas del centro de la ciudad de La Plata 
debido a que no hay escuelas de nivel secundario o polimodal en la zona. De todos modos, desde que la gente toba llegó a esta ciudad, sólo dos adolescentes se encontraban en condiciones de asistir a la escuela secundaria. Lamentablemente, ninguno de ellos logró terminar sus estudios. Por otra parte, desde que todas las viviendas fueron habitadas -a mediados de 1996-, la demografía del barrio se incrementó aceleradamente, produciéndose muchos nacimientos. A estos casos, se les pudo realizar un seguimiento de su trayectoria escolar [Ver Gráficos $\mathrm{N}^{\circ} 1$ y 2].

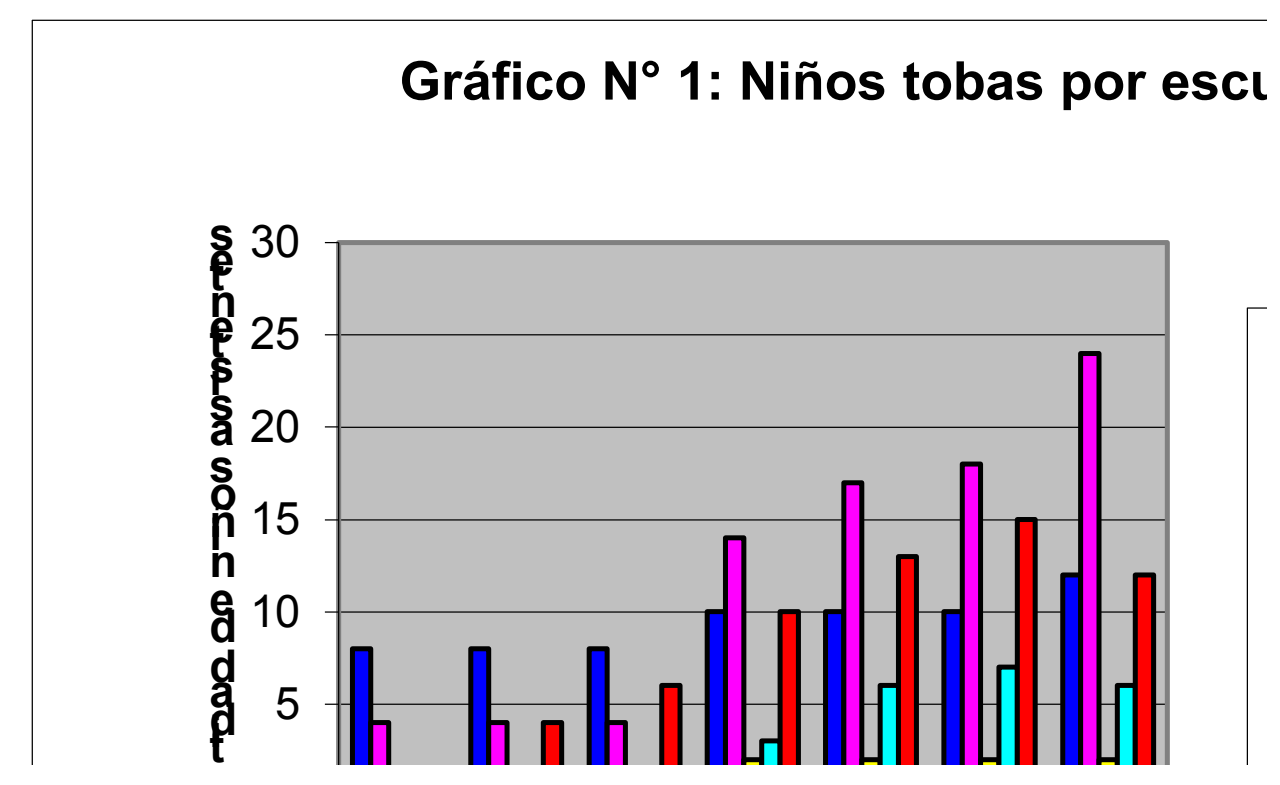

Cuando las primeras familias llegaron a la ciudad de La Plata sus hijos mayores se encontraban desfasados entre el grado escolar que le correspondía y la edad que tenían. Es decir, encontramos en muchos casos niños de 10 ú 11 años de edad que estaban asistiendo a un $2^{\circ}$ o $3^{\circ}$ grado. Las causas eran diversas. Se podía deber a que habían estado viviendo en diversos lugares antes de establecerse en esta ciudad y los niños habían perdido años lectivos o repetido por inasistencias, malas calificaciones o deserción. 


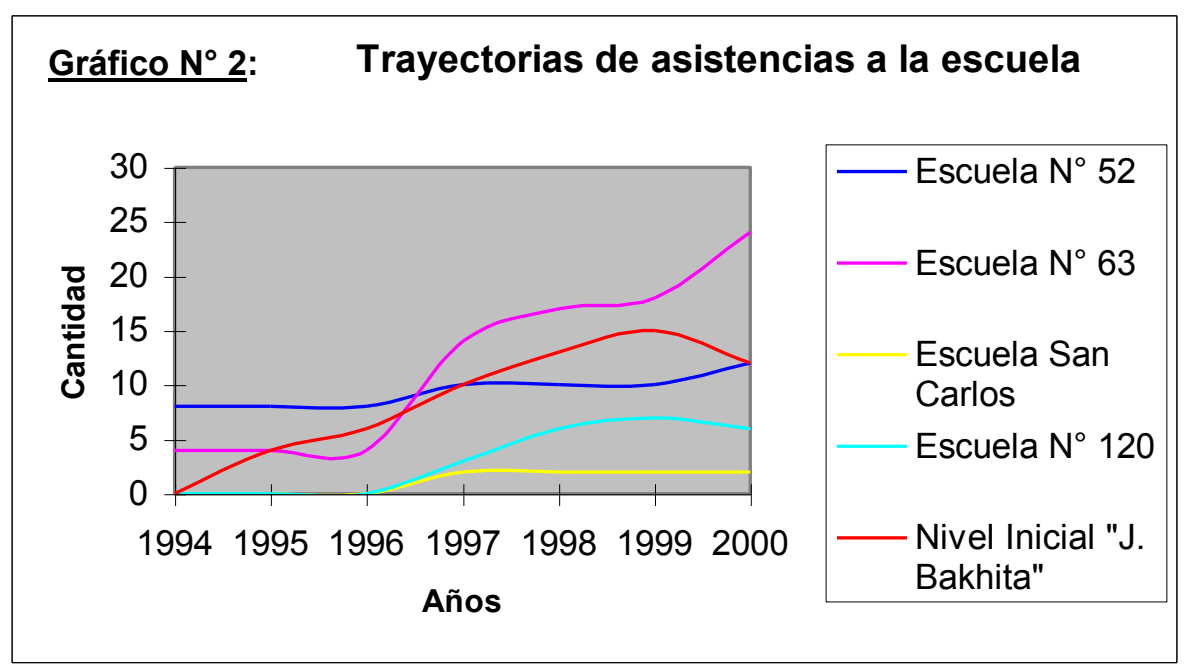

Por un lado, según los docentes de la Escuela $N^{\circ}$ 52, en 1993 los niños manifestaban falta de interés por realizar las tareas, mucha timidez, vergüenza y apenas hacían conocer sus voces -sobre todo entre los alumnos que asistían a los primeros grados-; parecían "vivir en otro mundo, y por eso no comprender bien"; y los más chicos deambulaban por las aulas visitando a sus hermanos mayores. También presentaban dificultades en la lectoescritura y, por esa razón, fueron colocados dentro del grupo de los "atrasados", formando parte del programa de recuperación que ejecutaba el gabinete pedagógico escolar. Por otro lado, el personal docente desconocía tanto la experiencia de autoconstrucción que las familias tobas estaban viviendo en el barrio y su propia historia, como así también que los padres hablaran otra lengua y que les hablaran a sus hijos en la misma.

"La otra vez escuché que uno de los niños le decía una palabra que, como no comprendí, lo reté pensando que estaba diciendo una mala palabra" [Testimonio E52 1994].

La deserción escolar, que había sido muy marcada entre 1993 y 1995, tuvo una tendencia a mermar a partir de 1996 y 1997 [Ver Gráfico № 1], años en que la segunda etapa de construcción finalizó, las familias se establecieron y todas las viviendas fueron ocupadas. Desde entonces, muchos niños pudieron tener una continuidad escolar, transcurriendo todo su ciclo lectivo desde el Nivel Inicial en el Jardín de Infantes "J. Bakhita" y el de la Educación General Básica (EGB) en un mismo establecimiento. En otros casos, hubo cambios de escuela debido a que las mamás no estaban atentas a las fechas de inscripción de los niños que se realizan antes de finalizar el año lectivo y, al empezar éste, ya no había bancos o por no estar conformes con la educación que recibían sus hijos. Por este motivo, ésta también fue una tarea de la secretaria de la asociación civil, 
quien poseía más conocimientos de los tiempos y los trámites que se debían hacer, aunque la inscripción siempre ha sido de forma individual. El descuido de las madres se daba en muchos casos por el hecho de no saber leer o no manejar "los tiempos de la ciudad" y poseer poco conocimiento del castellano. No obstante, las principales causas de no inscribir a los niños en las escuelas se deben, por un lado, al temor de no poder enviarlos "como corresponde"; es decir, con el guardapolvo, bien vestidos y calzados, con sus útiles escolares y la monedita para el pasaje de ómnibus $y$, por otro, por encontrarse indocumentados.

Las escuelas públicas de la zona están clasificadas como escuelas urbano-marginales y, hasta el año 2001, los docentes cobraban un plus por zona desfavorable o ruralidad, ${ }^{101}$ como una forma de compensar el viaje hasta la misma y las horas de trabajo dedicadas. Sin embargo, estos maestros tienen la particularidad de faltar mucho y suelen pedir licencias por un largo período, de modo que los niños siempre están con suplentes. Además, en los últimos años, los paros docentes han sido muy frecuentes y estos maestros se han adherido a todos ellos por un reclamo salarial y el mejoramiento del sistema educativo, en general. Sumado a esto, las condiciones edilicias son muy precarias, en especial, la de la Escuela $\mathrm{N}^{\circ}$ 52, y los elementos con los que cuentan no son suficientes. Ambas escuelas poseen un comedor y ofrecen una copa de leche y el almuerzo a todo el alumnado. Asimismo, las principales dificultades que presentan estas escuelas son la violencia familiar y la indisciplina de los niños. Las actividades del gabinete pedagógico han estado dirigidas a atender estas problemáticas. Los niños tobas son en general callados, de modo tal que no son considerados "un problema" por los docentes. Por el contrario, las impresiones que han tenido de ellos han sido entre otras que:

- son callados y tímidos;

- tienen buena conducta;

- vienen bien vestidos y calzados;

- son limpios y cariñosos;

- $\quad$ son más ordenados y respetuosos.

Esto ha provocado que no se hayan tomado las medidas necesarias para mejorar la calidad educativa de estos niños con políticas y estrategias metodológicas que atendieran sus problemáticas en el aprendizaje, dando la prioridad a los otros casos. Sin embargo, la

${ }^{101}$ Este plus fue quitado, conjuntamente con los beneficios de la antigüedad, a mediados del año 2001 por la Ley de Emergencia Económica de la Provincia de Buenos Aires. 
agresión, el maltrato, el insulto, la discriminación están presentes en la escuela y tocan muy de cerca a los niños tobas todos los días. Estas son razones por las cuales, en más de un caso, los niños no han querido ir más a la escuela.

Por un lado, a partir de 1997 la matrícula de los niños tobas en la Escuela $\mathrm{N}^{\circ} 63$ fue mayor. La estructura edilicia de esta escuela parece ser más nueva, con salones más amplios y ordenados, y los docentes no faltan tanto y son más estables. De todos modos, a esta escuela se accede caminando y las inclemencias del tiempo suelen ser un obstáculo para que los niños asistan con frecuencia. Los casos de repitencia por malas calificaciones o ausentismo siguen siendo marcados. Cuando los niños dejan de asistir, los maestros envían notas a los padres solicitando su presencia para conversar con ellos; si no acuden, una asistente social se presenta en sus hogares para indagar las causas. En otros casos, los padres son convocados para ofrecer charlas en la escuela, ${ }^{102}$ como así también la misma escuela fue invitada por la asociación civil al barrio para asistir a uno los festejos del 19 de abril, "Día del Indio". Estas actividades también se realizan en y con otros establecimientos escolares de la ciudad de La Plata, donde la fecha del 12 de octubre suele ser la preferida para su convocatoria.

Por otro lado, la concurrencia al nivel inicial también se incrementó desde 1997. En un principio, se dijo que el Jardín de Infantes "J. Bakhita” había sido "creado para los tobas" porque éstos habían sido los primeros en llegar al barrio "Las Malvinas" y construir sus viviendas; sin embargo, había preocupación entre los directivos de la misma, porque "los tobas no enviaban a sus hijos a esta escuela". No obstante, el relevamiento de los niños en edad escolar que realizamos en ese entonces, cuando se creó este Jardín de Infantes, nos mostró que la mayoría de los niños de 4 años estaban inscriptos en el mismo. Los casos de aquellos niños que no habían sido anotados se debían, principalmente, a que éstos se encontraban indocumentados o a que todavía no vivían definitivamente en el lugar. A medida que la concurrencia fue mayor, la comunidad toba estableció vínculos especiales con esta unidad escolar. Las madres tobas comenzaron a colaborar con la escuela ayudando en algunas tareas tales como: la realización de una pequeña huerta ecológica junto con los

\footnotetext{
102 Ocurrió el caso que quien era presidente de la asociación civil en ese entonces, fue invitado por la directora de la Escuela $\mathrm{N}^{\circ} 63$ a dar una charla a los chicos con motivo del 12 de octubre. Al ser anunciado por la maestra uno de sus hijos, que asistía a la misma, llegó todo exaltado contando a sus padres que: “زen mi escuela van a ir los indios con su cacique!", lo que causó mucha gracia ya que se trataba de ellos mismos y el cacique era su padre.
} 
docentes y niños; la enseñanza de cómo modelar la cerámica; y el contar cuentos de los tobas a todos los niños.

“...ahi, nosotros todos los años trabajamos, todos los 12 de octubre o 19 de abril... [continúa en el idioma] Y eso fue muy lindo, muy aceptado, yo les voy contando a través de cuentos, me han tomado tanto cariño que cada vez que me ven por la calle me saludan: ¡chau señora J.! [risas] pero es muy lindo. Siempre vamos con tres paisanas más y les contamos cosas, participamos de eso. [Testimonio BLM 2000]

Un seguimiento de las trayectorias escolares de los niños plasmadas en el Gráfico $\mathrm{N}^{\circ} 2$ nos permite realizar las siguientes observaciones:

Un incremento de la asistencia escolar de los niños tobas entre 1996 a 1997.

$>$ Este crecimiento continuó en el tiempo.

$>$ Una mayor concurrencia de los niños a la Unidad Educativa de Nivel Inicial "J. Bakhita" y a la Escuela $\mathrm{N}^{\circ} 63$.

$>$ En las otras escuelas donde asiste una menor cantidad de niños tobas, también hubo un aumento de asistencia entre 1997 y $1998 .{ }^{103}$

En general, las familias tobas valoran positivamente la escuela y expresan su importancia de cumplir con la misma a través de algunas de las siguientes expresiones:

- "Para aprender y poder trabajar";

- "Para hablar castellano y poder firmar";

- "Sirve para obtener un trabajo y defenderse mejor";

- "Para manejarse en esta sociedad";

- "Es importante en este siglo para dejar el trabajo bruto y encontrar trabajo mejor pago";

- "Para sacar cuentas, hacer cartas y notas para la asociación".

Por su parte, los niños suelen manifestar que no les gusta demasiado la escuela porque la maestra grita mucho y sus compañeros no tienen buena conducta. Contrariamente con lo

103 Es importante mencionar que a partir del año 2002 una escuela agrícola de la localidad de Melchor Romero se acercó al barrio toba con la propuesta de ofrecer bancos a todos los chicos con un régimen de doble escolaridad y una orientación en trabajos agrícolas. Ante esta propuesta, muchos niños, en especial los que se encontraban en los primeros grados, fueron inscriptos en dicho establecimiento escolar. La experiencia fue considerada como muy buena por las madres que acompañaban a los niños, pero la interrupción del servicio de transporte que les había sido asignado para trasladarse hasta la escuela impidió que esta experiencia continuara. 
que acostumbran a comunicar los niños en general, declaran que lo que menos les gusta son los recreos porque muchos compañeros les hacen bromas de mal gusto, los pelean o les pegan y no logran integrarse a los grupos. ${ }^{104}$ En cuanto a las materias, poseen un mayor interés por las matemáticas (-“hacer cuentas"-), que por lengua (-“leer y escribir”-).

Si bien observamos a partir de 1997 una mayor asistencia a la escuela y casos de éxito escolar, el bajo rendimiento que los niños tienen en la escuela es motivo de gran preocupación entre los padres.

Sumado a esto, existe otro elemento que inquieta a las familias: la información que brinda la mayoría de los docentes a sus alumnos acerca de la temática indígena. Aún se sigue hablando del "indio vestido con taparrabo y plumas, usando arco y flecha, de comportamiento salvaje y que vivió en el pasado".

“...Esa es otra realidad que vemos, la no actualización de los libros en cuanto al indigena, hacen que se representen esa imagen de los indios con pluma. El año pasado, nos habian invitado a una escuela y nos habian preparado una clase. Y bueno, cuando entramos todo el pizarrón estaba con dibujos de indígenas y todos con las plumas y taparrabo, y cuando llegamos con el abuelo y otras de las personas del barrio, y les pregunto a los chicos, que estaban jugando afuera, y les pregunto qué están haciendo ahi: -Y lo que pasa señora que estamos esperando a unos indigenas que enseguida están por llegar, que nos dijeron que ya iban a venir y nosotros estamos acá esperándolos-, y le digo: -los indígenas somos nosotros, estamos bajando nuestras artesanías. - iAh, señora, pero usted se viste igual que yo!-; -Si- le digo -lo que pasa es que esto es lo que está de moda-. Y... quedaron medio shoqueados porque esperaban ver algo que no es así..." (Testimonio BLM 2000)

La poca información y actualización que tienen los docentes y la sociedad toda acerca de los indígenas en la actualidad contribuyen a reproducir estereotipos. Esto motiva que los niños y jóvenes tobas pierdan la autoestima y renieguen de sus raíces, su historia, su lengua y su cultura. Las familias deben hacerles frente a todos estos factores día a día, manifestando, así, una gran preocupación, porque los principales elementos de la cultura toba no están siendo practicados por los niños y jóvenes en la ciudad. ${ }^{105}$

\section{- La Escuela de Adultos}

\footnotetext{
${ }^{104}$ Este aspecto lo hemos podido observar durante los recreos, en los que los niños juegan solos o con otros niños tobas; los hermanitos menores buscan a los mayores.

${ }^{105}$ Se volverá sobre este tema más adelante.
} 
"Y en cuanto a los grandes, la mayoría de los hermanos, de las 40 familias -el otro día aproveché una reunión que hubo en el barrio-, la mayoría de las familias, un $60 \%$, hicieron un $2^{\circ}$ ó $3^{\circ}$ grado, porque vinieron del campo y lo esencial para ellos era aprender a escribir su nombre y firmar nada más y... después algunos llegaron a $4^{o}$ ó $5^{\circ}$ grado, y terminaron $7^{\circ}$ grado 4 personas que yo conté. Y que terminamos el secundario sólo dos: otra chica y yo. Somos dos las que tenemos el secundario completo. Después los demás, cada una tiene su caso particular: se vivía en el campo y no habia, o se tenían que comprar los libros y no se podía... Eso es más o menos el nivel de todos en cuanto a educación me refiero". [Testimonio BLM 2000]

Desde que las primeras familias tobas llegaron al barrio, un maestro jubilado fundó una escuela para los adultos y la llamó: "Escuela de Afectos para Adultos". Ésta funcionaba bajo la sombra de un árbol y se enfrentó con varias dificultades para que desde el Ministerio de Educación o la Dirección de Escuelas de la provincia, enviaran maestros y mejoren las instalaciones del lugar. A partir de 1993, comenzó a funcionar en el barrio una Escuela de Adultos que contó con los planes de alfabetización del Ministerio de Educación de la provincia que destina a una docente a los barrios carenciados para que dicte clases a mayores de 15 años, para que puedan completar sus estudios primarios. La alfabetización es para todo el barrio "Las Malvinas"; sin embargo, desde un principio, las clases se dieron en la Comunidad Toba, por ser la más organizada y perseverante y la que contaba con una infraestructura mínima que le permitía a la docente realizar su tarea con más "comodidad". Al comienzo, las clases se dictaban en la casa terminada de una de las familias. Eran entre 6 ú 8 personas que se acercaban con una silla y un cuaderno en cada mano. Luego, se trasladaron a una vivienda en construcción y, finalmente, al comedor, donde cuentan con sillas, mesas y un pizarrón. Sin embargo, el espacio continúa siendo pequeño e incómodo para el dictado de las clases.

Desde entonces, mujeres y hombres, adultos y jóvenes, han estudiado en el turno nocturno. La docente llega alrededor de las 17:30hs de modo de comenzar alrededor de las $18 \mathrm{hs}$ y dicta clases hasta las $20 \mathrm{hs}$ aproximadamente. Algunos hombres llegan de trabajar, se bañan, descansan un poquito y asisten a esta escuela. Las mujeres son las primeras en llegar, siempre en grupitos y con ganas de aprender. Hay días en los que la docente primero realiza una recorrida por las casas, recordándoles que "ya es la hora de ir a la escuela"; no obstante, las deserciones o faltas son muchas durante el año lectivo:

"Tengo anotados once alumnos, pero sólo vienen ocho o menos. Conozco el motivo por el cual faltan y no puedo hacer otra cosa que entenderlos: porque es abuela y 
tiene que cuidar a los nietos porque la hija se va al conurbano a trabajar; porque está embarazada y tiene un chiquito de un año; porque le salió unas changas y tiene que aprovechar el trabajo; porque tiene cinco hijos varones..." (Testimonio BLM 1994)

Entre las expectativas y objetivos que la docente tiene para este trabajo aparecen muchas frustraciones:

$\diamond$ No tiene mucho espacio para trabajar.

$\diamond$ Hasta hay veces que hace de curandera: cura el empacho, pero le advierte a la gente que vaya al médico.

$\diamond$ Se limita a enseñar a leer y a escribir: -"para qué otra cosa, si enseño cuáles son sus derechos como ciudadanos después los echan del trabajo por reclamarlos y la culpa la tengo yo".

$\diamond$ Cómo hablar de otros temas si falta salud (-“ino tienen dientes!”-), trabajo; esta es una zona suburbana o rural.

$\diamond$ Cómo va a exigir para que vayan a la escuela cuando sabe que no tienen qué darle de comer a sus hijos.

$\diamond$ Tiene un gran currículo, pero de qué le sirve aplicar todo lo que sabe si no tiene con qué.

Por otra parte, las satisfacciones son muchas cuando alguien empieza a reconocer las letras, a leer las primeras frases y a escribir, y mucho más aún, y con gran orgullo, cuando terminan el año y alguien se recibe cumpliendo con el ciclo.

\section{III.7. Migración (LA LLEGADA) Y LAS REDES DE ARTICULACIÓN SOCIAL}

"El testimonio parece va a ser muy largo, porque... la llegada [a Buenos Aires]. Yo soy uno que me vine en el año '67, que vinimos los dos solos, por ejemplo, yo me vine con mi señora, en búsqueda de trabajo. Toda la gente allá, la gente conocida porque somos pequeños agricultores y no quería que viniera para acá. Y uno de mis hermanos mayor, me dijo que no, que no se vaya si no tengo ningún conocido. Que para ir a Bs. As. hay que tener un conocido y dirección exacta adónde tiene que ir. Porque si no, va a tener problema por ahi se va a extraviar, ese es el problema. Pero igual tuve que encarar, tuve que venir por una dirección...”. [Testimonio BLM 1994]

Desde la conformación de la Asociación Civil Toba Ntaunaq Nam Qom y la llegada de las familias tobas a la ciudad de La Plata las redes sociales establecidas con diferentes sectores de la sociedad platense, bonaerense y nacional, en general, fueron creciendo. Para dar cuenta de la red de relaciones actual del Barrio Toba "Las Malvinas", debemos partir 
del lugar de origen de las familias: el Chaco y las trayectorias trazadas por éstas a lo largo del camino de la migración a la ciudad. Asimismo, a través de este mecanismo, estaremos reconstruyendo la historia misma del barrio. A lo largo de esta historia, hemos distinguido distintas instancias o etapas diferenciadas según el tiempo y el espacio vividos y los tipos de relaciones instituidas (Ver Gráfico $N^{\circ}$ 3: Red de Relaciones Sociales en el Camino de la Migración). ${ }^{106}$

Cada punto de la red puede ser el inicio de la narración histórica; cada uno de los miembros del Barrio Toba "Las Malvinas" puede ser considerado ego. ${ }^{107}$ Sin embargo, a los fines de este análisis, y para una presentación más clara, partiremos de la trayectoria de quien fuera el líder principal del grupo, miembro fundador y primer presidente de la Asociación Civil Toba Ntaunaq Nam Qom, don Julio Ramírez (A). Esta elección no sólo se debe a los roles que éste ha cumplido y cumple en el barrio, sino también porque es una de las personas cuya trayectoria abarca todas las instancias de la red.

\section{- Instancia I: La vida en el Chaco}

(A) nació en Pampa del Indio (provincia del Chaco). Zona rural, al noreste de la provincia, donde la tierra fue dividida en lotes por los criollos, luego de la conquista y colonización definitiva del Chaco, a principios del siglo XX. El pueblo Toba, originario de ese lugar, recibió su parte: pequeñas parcelas donde crían unos pocos animales y cultivan algunas hortalizas, principalmente, para el consumo personal. Con el tiempo, la tierra se hizo más pobre e inundable $\mathrm{y}$, al crecer las familias, las extensiones se fueron reduciendo. Los hombres suelen buscar trabajo en la cosecha del algodón de los campos de mayor extensión que poseen los "gringos" o criollos de la zona o de otras localidades vecinas. Otros, se llegan hasta la ciudad más cercana o a Resistencia tratando de conseguir algunas changas o trabajos más seguros.

(A) fue al colegio, aunque sólo alcanzó hasta $2^{\circ}$ grado de la escuela primaria y tuvo que dejar por necesidad, "porque en el Chaco los niños aborígenes como no aborígenes a edad temprana comienzan a trabajar”. En esos años aprendió algo de castellano, pero éste lo aprendió más bien "de a oídas no más". Una vez tuvo un "sueño" en el que se le

\footnotetext{
${ }^{106}$ Cabe aclarar que el análisis de las redes de relaciones junto con el gráfico se trata de una versión revisada y ampliada de las publicadas en Ibáñez Caselli (1995), Ibáñez Caselli y Tamagno (1999), Ibáñez Caselli (2001).

${ }^{107}$ Referente principal, punto central de la red de la cual parten las líneas de relación con otros actores sociales: individuos o grupos de individuos, instituciones.
} 
aparecía un camino largo, que él mismo interpreta como el camino que lleva al barrio "Las Malvinas", a las casas autoconstruidas, viéndose como líder frente a ese objetivo. Al mismo tiempo, su destino como líder del grupo habría sido ya marcado, cuando, siendo él muy pequeño, una señora le dijo a su mamá que lo cuidara mucho porque: "ese chico tiene una misión muy importante que cumplir...". 
Gráfico $N^{0}$ 3: Red de Relaciones Sociales en el Camino de la Migración

Referencias:
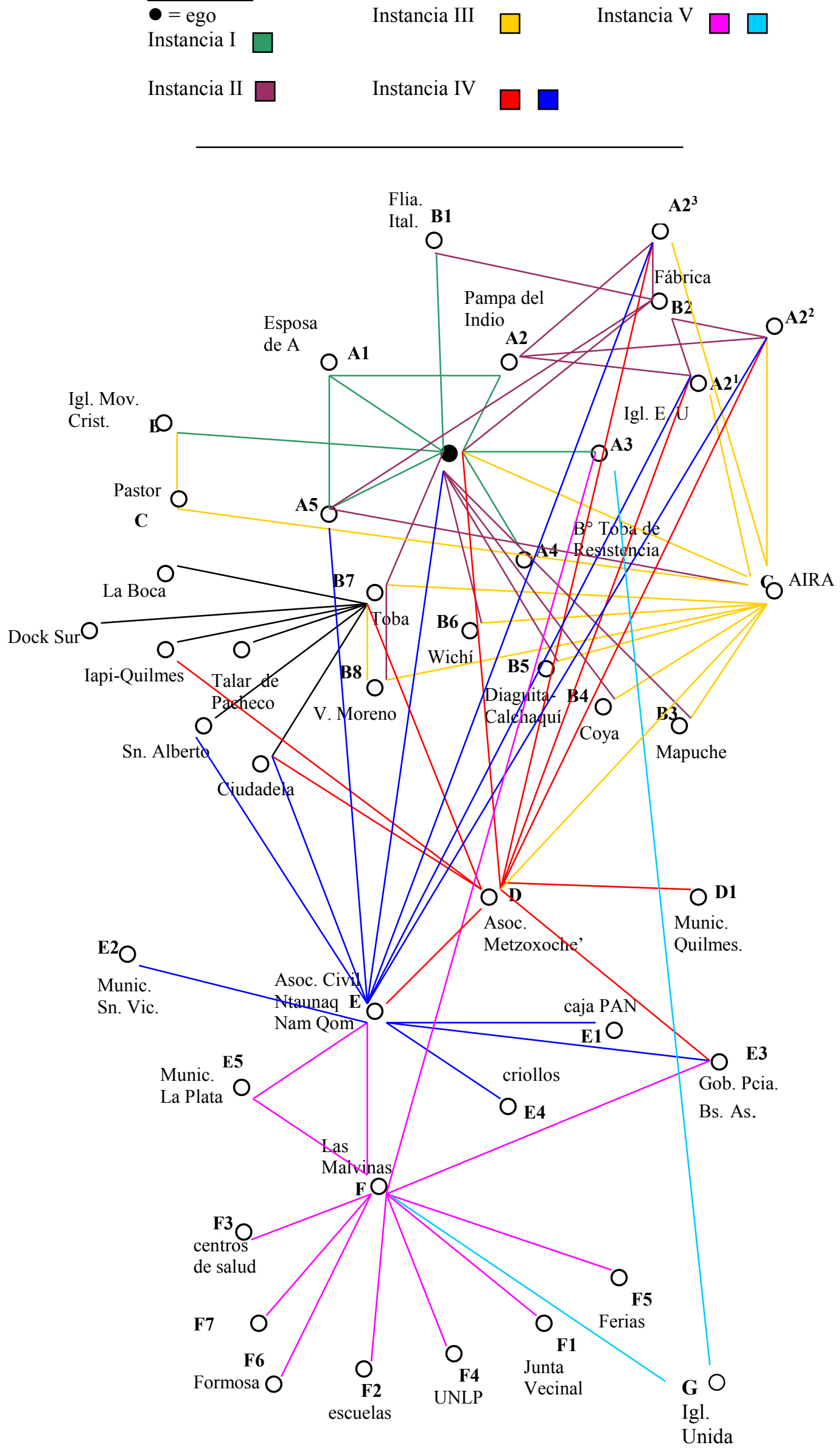
La falta de trabajo remunerado motivó que (A) se decidiera a migrar a la gran ciudad junto con su esposa (A1) cuya familia también es originaria de Pampa del Indio (A2). En la ciudad de Buenos Aires ya contaba con un familiar, un cuñado (A5); sin embargo, decidió contactar un matrimonio de origen italiano y evangélico (B1) que años atrás había conocido en una Campaña Evangélica que la Iglesia Movimiento Cristiano (B) de Buenos Aires había realizado en el Chaco -y ligada, de alguna manera, a la Iglesia Evangélica Unida (A3)-. Aunque no era muy creyente en ese entonces, era muy voluntarioso y conversador, y ayudó en la Campaña asistiendo a los foráneos. Se hizo amigo de este matrimonio y éste le dio su dirección en Buenos Aires.

En general, las otras familias que componen el barrio "Las Malvinas" provienen de zonas rurales o semi-rurales de la provincia del Chaco (Pampa del Indio, Quitilipi, Gral. San Martín, Las Palmas) y de la ciudad de Resistencia (A4). En esta última, los que provienen del interior de la provincia poseen parientes y para muchos esta ciudad fue como una posta antes de continuar el camino hacia Buenos Aires. ${ }^{108}$ En algunos casos, la ruta seguida fue la ciudad de Rosario, para luego continuar más al sur; en tanto que otros fueron directamente de Resistencia a Capital Federal (ver Figura $\mathrm{N}^{\circ}$ 2). Además, también migraron a la gran ciudad teniendo un contacto previo en ella: un pariente, vecino o amigo, que los recibió y albergó hasta que encontraron un lugar o un trabajo. Según las circunstancias, migró primero el jefe de familia y, luego, una vez establecido, llamó al resto de su familia; en otras situaciones, migraron todos juntos, con sus hijos pequeños; asimismo, se da el caso de jóvenes solteros que llegaron solos a Capital Federal o a la ciudad de La Plata y que viajaron en grupo, junto con otros jóvenes, para conocer y probar suerte. Muchos de estos jóvenes se quedaron y formaron sus familias. La primera migración se realizó a fines de la década de 1960 para algunos y de 1980 para otros. Algunas familias o jóvenes llegaron directamente del Chaco al barrio "Las Malvinas" en la década de 1990 y se quedaron allí; aunque las migraciones son constantes y aún continúan, y provienen tanto de la provincia de Chaco como de Formosa y Santa Fe.

\footnotetext{
${ }^{108}$ Particularmente, las relaciones de parentesco están dadas con las familias que viven en el Barrio Toba de Resistencia ubicado en las afueras de la ciudad: Calle Cruz Roja entre Juan XXIII y Ruta 11 (Ver Figura No 4).
} 


\section{- Instancia II: La llegada a Capital Federal y las primeras actividades}

(A) poseía un contacto, una dirección, y fue recibido solidariamente. Este matrimonio lo recomendó para un puesto como obrero de una fábrica metalúrgica (B2). Las diferencias se comenzaron a sentir puesto que no es lo mismo vivir en el campo que vivir en la ciudad:

“...eran ocho horas, y era poco, y me sobraba tiempo, porque allá trabajaba 14 horas, 16 horas por día, no teníamos reloj, nosotros fijábamos sólo desde la salida del sol hasta pisando la sombra largábamos, más o menos calculando la hora entre las doce o la una, y luego no nos vamos hasta la ida del sol. Bueno, cuando llegamos acá, el horario de entrada era a las 7 de la mañana, entrábamos hasta las tres de la tarde, hora corrido y para mí era.., bueno, me sobraba mucho tiempo." [Testimonio BLM 1994]

Allí trabajó duramente y "sin quejas" al punto de que su capataz le tuvo buena estima y le pidió que llevara a trabajar algunos amigos o familiares que fueran igual de trabajadores que él. De este modo, cuatro personas más tuvieron trabajo en la fábrica. Uno de ellos, fue su cuñado (A5) que ya vivía en Buenos Aires y, los otros, tres familiares ( $\mathrm{A} 2^{1}, \mathrm{~A} 2^{2}, \mathrm{~A} 2^{3}$ ) que hizo llamar del Chaco.

El hecho de quedarles tiempo en las tardes, a la salida del trabajo, posibilitó su participación en las reuniones que se realizaban en distintos locales de la Capital, junto con otros indígenas de otras etnias: mapuche (B3), coya (B4), diaguita-calchaquí (B5), wichí (B6) y también toba (B7) que habían migrado y se encontraban dispersos en esa ciudad. Uno de los objetivos principales fue "observar y conocer todo lo relacionado con la cuestión de tierras". Fue así que, como resultado de estas reuniones fundaron la Asociación de Indígenas de la República Argentina (AIRA) (C).

\section{- Instancia III: Los primeros pasos en la búsqueda de tierras}

De esta manera, el AIRA consistió en una agrupación conformada por indígenas que vivían en distintos puntos de la ciudad de Buenos Aires y donde estaban representadas la mayoría de las etnias del país. Se creó con la finalidad de reclamar por sus derechos y, en particular, por el derecho a la tierra. Para su creación, se eligió una comisión directiva donde uno de los hermanos de $(\mathrm{A}),\left(\mathrm{A} 2^{1}\right)$, fue nombrado junto con otro hermano toba que hoy está en la ciudad de Derqui (B8). Asimismo, más tarde, durante la conformación de la segunda comisión directiva, $\left(\mathrm{A} 2^{2}\right)$ tuvo el cargo de tesorero; de modo tal que (A) siguió muy de cerca las actividades desarrolladas por esta asociación. La misma recibió el apoyo 
económico de algunas iglesias evangélicas dependientes de la Iglesia Movimiento Cristiano. Con el dinero recibido compraron un local propio donde la asociación funcionó a pleno. Se armaron algunos proyectos que se enviaron al exterior para conseguir financiación. Los miembros del AIRA provenían de distintas ciudades: San Alberto, 3 de Febrero, Lomas de Zamora, y debieron afiliarse pagando una pequeña cuota. Las comunidades del interior de las provincias también se acercaron a esta asociación quien intercedió ante sus pedidos con el Estado y otras organizaciones. También hubo cursos de capacitación que algunos grupos fueron solicitando y realizando.

Uno de los proyectos que se logró fue la obtención de un predio de $800 \times 23 \mathrm{~m}^{2}$ en IAPI para 124 familias tobas. Diferencias internas en la organización de las propias etnias hicieron que un grupo de representantes tobas se separe del AIRA y se organice, así, la Asociación Toba Metzoxoche' (D).

\section{- Instancia IV: El pueblo Toba se organiza}

La Asociación Metzoxoche' estaba conformada principalmente por familias tobas que vivían en la ex-villa IAPI (partido de Quilmes) y por otras de San Alberto, Ciudadela, La Boca y Lomas de Zamora. Sin embargo, al crearse la comisión directiva (A) y quienes habían estado participando del AIRA desde los comienzos, quedaron afuera, no fueron elegidos. De todos modos, se afiliaron a la misma y viajaban de San Alberto a IAPI todas las veces que hiciera falta, después del trabajo e incluso hasta los fines de semana. Al parecer, el predio que se les iba a otorgar pertenecía a una fábrica y sus dueños dieron como excusa que estaba contaminado, con el fin de no ceder las tierras. Esto desmoronó un poco a la gente que se había entusiasmado y creído en la organización. No obstante, ante el primer reclamo hecho por la asociación, la Municipalidad de Quilmes (D1) otorgó un subsidio que fue destinado a la compra de insumos para un comedor infantil. Lamentablemente, la municipalidad creó lazos de clientelismo político y convocó al secretario de la asociación para un puesto en la municipalidad con el fin de que éste se ocupara de los asuntos de su gente. Se presentaron muchas dificultades y la asociación fracasó.

Ante esta situación, (A) junto con (A2 $\left.{ }^{1}, \mathrm{~A} 2^{2}, \mathrm{~A} 2^{3}\right)$ y la gente de Ciudadela insistieron en reorganizarse nuevamente. Ya contaban con la experiencia y conocimiento de cómo moverse en la ciudad y crearon a fines de la década de 1980 una nueva asociación que se llamó “Ntaunaq Nam Qom" (E) que significa "todos juntos trabajando"; después de ocho 
años de espera, lograron obtener el número de personería jurídica y se nombró una Comisión Directiva cuyo presidente fue (A).

Esta asociación se fue vinculando con distintas instituciones gubernamentales y no gubernamentales, y la relación con la iglesia siempre se mantuvo. En ese entonces, funcionaba la Caja $\operatorname{PAN}^{109}$ (E1), que ofreció una ayuda especial a las familias de Ciudadela. El empeño puesto por esa Comisión Directiva permitió su vinculación con autoridades del Gobierno de la Provincia de Buenos Aires (E3) y de la Municipalidad de San Vicente (E2). En dicho municipio hubo dos intentos de otorgamiento de tierras para el grupo. Intentos que fracasaron por cuestiones burocráticas, pero que no desanimaron del todo a la comisión. A esa altura, las vinculaciones con los criollos (E4) se habían incrementado y era mayor el conocimiento que se había adquirido de "cómo moverse en la gran ciudad”. Se siguió golpeando puertas hasta que a través de la presentación del pedido en el plan provincial Pro-Tierra, entran en un proyecto de Auto-Construcción de Viviendas en el Barrio "Las Malvinas" (F), en las afueras de la ciudad de La Plata. Se trató de un convenio hecho entre la gobernación de la Provincia de Buenos Aires y la Municipalidad de La Plata (E5).

\section{- Instancia V: La llegada a La Plata y la organización}

El predio establecido por la municipalidad contemplaba la construcción de 36 viviendas para los socios de la Asociación Civil Toba Ntaunaq Nam Qom. Algunas familias que habían participado desde el principio en esta iniciativa ya se habían desanimado y no creyeron que lo del barrio "Las Malvinas" pudiera ser posible. Cuando llegaron las primeras familias, el lugar era un gran despoblado y se instalaron en unas casillas de madera prefabricadas que la municipalidad había cedido. El plan funcionó en etapas y los adjudicatarios debían aportar horas de trabajo para la construcción. En este sentido, la participación en la misma fue tanto de hombres como de mujeres. A lo largo de la autoconstrucción el grupo inicial se fue completando con otras familias tobas provenientes del Gran Buenos Aires (Ciudadela, Quilmes, Lomas de Zamora) y otras que vinieron de las provincias de Chaco y Formosa. La vinculación del grupo con diferentes instituciones u organismos nacionales, provinciales y privados fueron creciendo, destacándose entre ellas la junta vecinal del barrio (F1), las escuelas de la zona (F2), los centros de salud (F3), la Universidad Nacional de La Plata (F4), las ferias de venta de artesanías (F5), las iglesias

\footnotetext{
${ }^{109}$ Plan Alimentario Nacional.
} 
cristianas (F6) y la Iglesia Evangélica Unida (A3). Al dejar el cargo de presidencia de la asociación, (A) funda la Iglesia Unida Templo de Fe (G) iniciando una nueva etapa como líder religioso.

\section{III.8. Las Relaciones de Parentesco, Amistad, Vecindad y Religiosidad}

Como ya se dijo, algunos socios fundadores de la Asociación Civil Toba Ntaunaq Nam Qom desistieron de la posibilidad de trasladarse a la ciudad de La Plata por el hecho de que proyectos anteriores habían fracasado. Aparte de perder la ilusión, era mucho el esfuerzo de trasladarse a un lugar totalmente desconocido y descampado, dejar lo poco que se había obtenido (trabajo, un lugar donde vivir, algunos objetos personales de valor, lazos sociales) para luego enterarse que esas tierras no iban a ser cedidas. Sin embargo, unos cuantos tuvieron fe, le creyeron a (A) e iniciaron el camino hacia el barrio "Las Malvinas". Al principio, fueron ocho unidades domésticas habitadas. Una vez finalizada la primera etapa de construcción, fueron llegando los dueños de las restantes viviendas. El plan estaba destinado para 36 viviendas y debían ser completados todos los adjudicatarios. Esta también fue una ardua tarea ya que en muchas ocasiones hubo que salir a buscar a quienes se habían anotado, pero que habían aportado pocas o casi ninguna hora de trabajo; como así también buscar gente nueva que quisiera y estuviera dispuesta a participar del proyecto y vivir en La Plata.

En primer lugar, un aspecto que los unía era el de reconocerse todos como pertenecientes a la etnia Toba. En segundo lugar, el estar afiliados a la asociación civil. Y, en tercer lugar, se trataba de gente toba que había migrado a la gran ciudad y tenía la necesidad de obtener tierras y una vivienda digna. Sin embargo, no todos los que presentaban estas características pudieron ingresar y permanecer en este proyecto. Hubo cierto criterio de selección por parte de (A): ser gente trabajadora y honesta, que compartiera la idea de "obtener un pedacito de tierra donde vivir, para recuperar la cultura y la lengua tobas".

Nuestra indagación en torno a los modos o por medio de quién se habían enterado del Plan de Autoconstrucción de Viviendas y cómo habían llegado a la ciudad de La Plata, nos permitió establecer la red de relaciones del propio Barrio Toba "Las Malvinas" (Ver Gráfico $\mathrm{N}^{\circ} 4$ - Red de Relaciones del BTLM)-. Para ello, partimos de (A) y las primeras ocho viviendas realizadas y habitadas durante la primera etapa de la construcción, para luego, ampliar la red con las familias restantes. El gráfico lleva la numeración de las 
viviendas y se ha completado, en caso de haberlos, con las relaciones de ambos jefes de cada unidad doméstica. Cabe destacar que la vivienda $\mathrm{N}^{\circ} 35$ corresponde a la de (A) y su esposa. La lectura de este gráfico nos permite observar que, aproximadamente, el 50\% de las unidades domésticas mantienen una relación de parentesco con la vivienda $\mathrm{N}^{\circ} 35$; en tanto que el resto, se trata de familias que conocieron a (A) en las reuniones mantenidas en el Gran Buenos Aires para la organización; fueron vecinos de la familia de (A) en Pampa del Indio o de algún otro familiar en el Barrio Toba de Resistencia; o conocieron a (A) a través del culto. Además, se da el caso de relaciones de parentesco entre algunos jefes de unidades domésticas que no están vinculados consanguíneamente con (A). Asimismo, los puntos más cercanos a la vivienda $\mathrm{N}^{\circ} 35$ corresponden a las familias que llegaron en las primeras etapas de la construcción y que, además, poseen una relación de parentesco entre sí; mientras que las más alejadas, arribaron tardíamente y, la mayoría, no mantiene vínculos sanguíneos. 
Gráfico $\mathbf{N}^{\circ}$ 4: Red de relaciones de parentesco, amistad, vecindad y religiosidad del Barrio Toba "Las Malvinas"

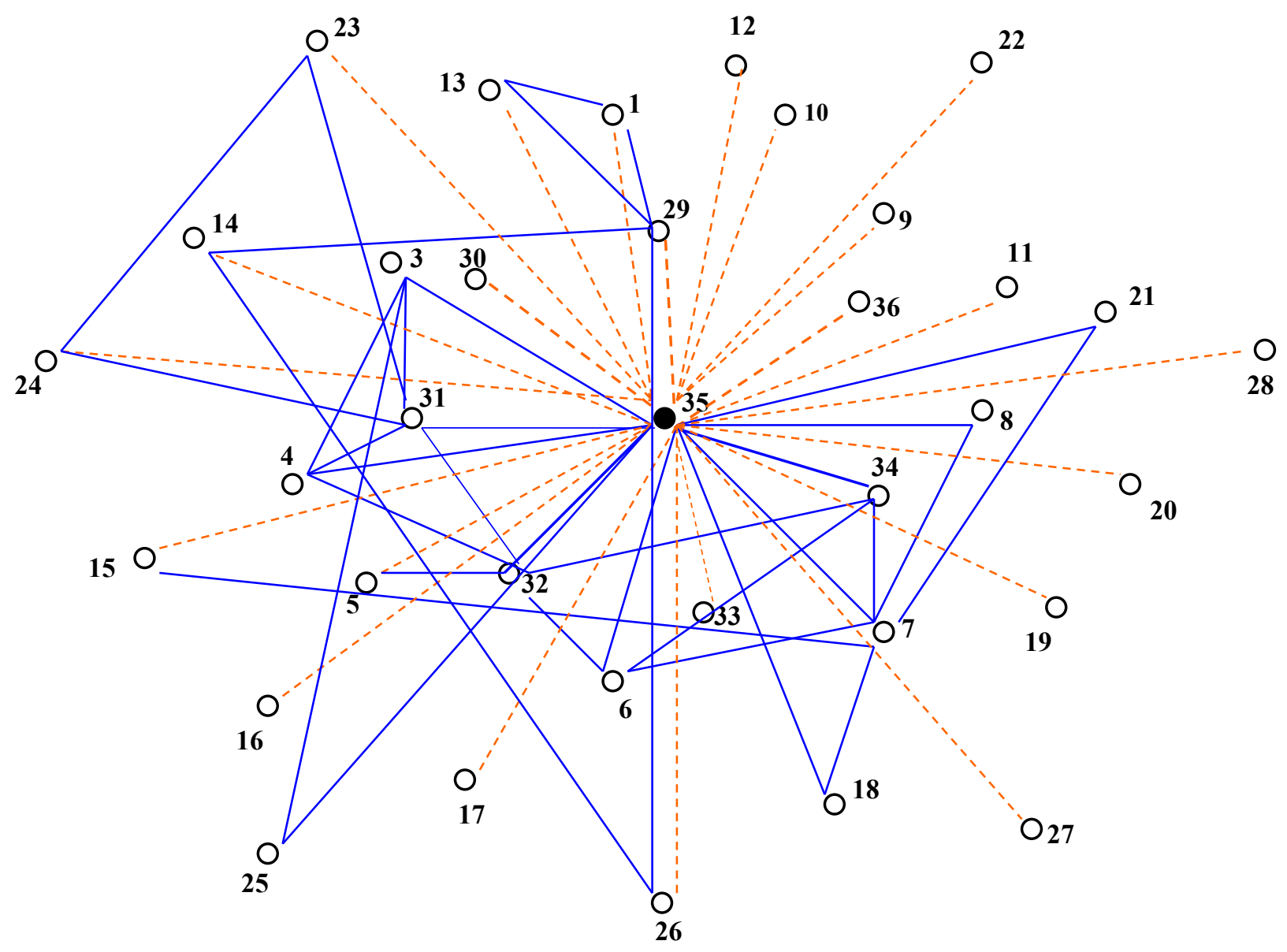

$\underline{\text { Referencias: }}$

1 a 36: Unidades Domésticas del Barrio Toba Las Malvinas Relaciones de Parentesco

: Relaciones de amistad, vecindad y religiosidad 
En este sentido, observamos que las familias que conforman el actual Barrio Toba "Las Malvinas" están relacionadas, por un lado, por lazos de parentesco y, por otro, por relaciones de amistad, vecindad o religiosidad. Es decir, todas las familias mantenían algún tipo de vinculación entre ellas antes de llegar al barrio "Las Malvinas", y esta vinculación hace que la red se extienda de La Plata hacia el Gran Buenos Aires; al Barrio Toba de Resistencia y el interior de la provincia del Chaco; a los nucleamientos tobas de la ciudad de Rosario; y la provincia de Formosa. Este aspecto puede ser visualizado con más claridad en los esquemas genealógicos colocados en el Anexo $\mathrm{N}^{\circ} 3$. En estos esquemas, se han enumerado del 1 al 278 a cada una de las relaciones encontradas y reconocidas.

El Esquema $\mathrm{N}^{\circ} 1$ es el que abarca las relaciones de parentesco de (A) y su esposa, (1) y (2) respectivamente -hasta donde pudimos acceder ${ }^{110}$. En el mismo no sólo se han volcado las vinculaciones consanguíneas y sus distancias temporales, sino que hemos agregado colores que nos ayudan a distinguir el espacio ocupado por éstas. Es decir, en este esquema es posible conocer si ese familiar se encuentra en otra vivienda del barrio "Las Malvinas"; o en otra localidad del Gran Buenos Aires o Gran La Plata; o en Rosario, Formosa o Chaco, y, de esta manera, pudimos extender la red.

La lectura del Esquema $\mathrm{N}^{\circ} 1$ nos indica que las relaciones consanguíneas provienen principalmente por parte de (2). Diez de las treinta y seis viviendas están ocupadas por sobrinos y sobrinos nietos; y cinco más por familiares de segundo orden -parientes políticos o por afinidad ${ }^{111}$. Todos ellos provienen de Pampa del Indio y Las Palmas, la segunda generación, y del Barrio Toba de Resistencia o Gran Buenos Aires, la tercera generación.

Resulta interesante también analizar las generaciones ascendentes de (2). Los relatos familiares nos hablan de la existencia de "familiones" que dominaban la región de Pampa del Indio, al que podemos considerar como un epicentro de la dinámica sociocultural del pueblo Toba; cada uno encabezado por un pioxonaq o chamán o jefe con fuertes poderes sobrenaturales. Según el poder económico, político y espiritual alcanzado, podían mantener a más de una mujer. Observando las líneas ascendentes encontramos la

${ }^{110}$ El esquema fue hecho mediante los datos obtenidos durante la investigación a través de dos censos, encuestas, entrevistas; y fue completado mediante la contrastación del mismo con algunos familiares que aceptaron el desafío.

${ }^{111}$ Es decir, nos referimos a que la relación consanguínea está dada por el esposo/a del sobrino/a o sobrino nieto/a de la esposa de (A). 
existencia de uno de estos pioxonaq como el abuelo de (2), (123), y un hermano de (2), (14). Por su parte, (2) posee sangre mestiza, puesto que (130) fue una blanca cautiva y que, según los cálculos generacionales que hemos hecho, este suceso habría ocurrido entre 1850-1860. De esta forma, la línea de ascendencia llegaría aproximadamente hasta mediados del siglo XIX.

El Esquema $\mathrm{N}^{\circ} 2$ refleja las unidades domésticas restantes que se acercaron al plan de viviendas por medio de relaciones de amistad, vecindad o religiosidad mantenidas con (A). Entre éstas no existe ninguna vinculación consanguínea entre sí, a excepción de cinco unidades domésticas (192-219). 


\section{CApítulo IV}

\section{RECURSOS Y ESTRATEGIAS COMUNICATIVOS Y METACOMUNICATIVOS en la Comunidad Toba del Barrio "Las Malvinas"}

\section{IV.1. EL RELEVAMIENTO SOCIOLINGÜÍSTICO}

\section{- Las primeras observaciones y registros en el campo}

Como ya se mencionó en el Capítulo II, nuestras primeras observaciones en torno a los usos y funciones de la lengua qom l'aqtaqa -así llaman los miembros de la comunidad a su lengua- en el Barrio Toba "Las Malvinas" coincidieron con el período de finalización de la primera etapa en la autoconstrucción de las viviendas (octubre de 1993). Para ese entonces, eran ocho las casas terminadas y habitadas y alrededor de nueve familias vivían en las casillas prefabricadas ubicadas a unos aproximadamente $250 \mathrm{~m}$. del lugar donde se estaba construyendo. Estas familias estaban aportando horas para la construcción y poder tener así derecho al techo propio. Otros jefes/as de familias venían los fines de semana desde distintos puntos del Gran Buenos Aires para aportar sus horas de trabajo, puesto que todavía no habían hecho la mudanza y/o tenían un puesto laboral que no querían abandonar. En tanto otros habían desistido y alejado del plan, por lo que el grupo todavía no se encontraba completo.

Durante nuestras primeras visitas al lugar, el código lingüístico que prevalecía "la castilla" -así se refieren los propios hablantes tobas al castellano o español-. La variedad del castellano usada por los tobas exhibe rasgos propios del hablar regional del nordeste argentino, especialmente el Chaco, el cual adopta rasgos propios del área guaraní. Así, se caracteriza por el uso de la consonante lateral palatal sonora, una marcada acentuación en la penúltima sílaba de las palabras y predominio de la práctica del leísmo, entre otros aspectos. ${ }^{112}$ Además, podemos señalar para esos primeros años

\footnotetext{
$112 \mathrm{Si}$ bien no ha sido nuestra intención y objetivo describir y analizar el español hablado por la gente toba, destacamos la falta de trabajos existentes en relación al habla regional de esa zona y la necesidad de estudiar este aspecto como elemento importante que se debería tomar en cuenta en el momento de pensar en una política y planificación lingüística para los programas educativos. El trabajo de Klein y Messineo (2003) nos ofrece una primera aproximación al análisis de las influencias de la lengua toba en el español.
} 
de estadía de las familias en la ciudad de La Plata el uso frecuente y espontáneo de un modo de saludo extendido en el área chaqueña, acompañado por dos besos (uno en cada mejilla) tanto en la bienvenida como la despedida, principalmente entre mujeres y entre hombres y mujeres -incluidos los niños-; en los niveles intra e interétnico. ${ }^{113}$ En cambio, el saludo entre los hombres consistía en estrecharse la mano derecha. Algunas veces, el que recibe coloca también su mano izquierda encima de las otras dos; este acto se acompaña con un breve gesto de bajar la cabeza y la vista. En algunas ocasiones, cuando existe mayor afinidad entre los actores, se agrega al saludo un fuerte abrazo atrayendo los cuerpos con las manos estrechadas y colocando el brazo izquierdo y el mentón por encima del hombro del contrario. ${ }^{114}$

En ese primer entonces, las familias parecían tímidas y reservadas; las mujeres hablaban muy poco $\mathrm{y}$, algunas, lo hacían nerviosamente y hablaban usando una corriente ingresiva de aire, ${ }^{115}$ resultando dificultoso escucharlas y entenderlas; los niños se asomaban, sonreían y se escondían. Sólo los hombres se expresaban con una mayor soltura y hablaban más, aunque en voz baja, pausado y como buscando -pensando- las palabras.

En esas primeras visitas al barrio no escuchamos hablar la lengua toba. ${ }^{116}$ Entonces, empezamos a preguntar si en el hogar, alguno de los integrantes del grupo doméstico hablaba esa lengua y, de serlo así, si los niños también lo hacían. Y en la mayoría de los hogares encontramos la siguiente respuesta:

\section{- “...nosotros con mi marido hablamos en lengua [toba] todo el tiempo”}

\footnotetext{
${ }^{113}$ Hemos observado que esta práctica extralingüística -típica de la región del nordeste argentino- se fue dejando con el paso de los años, en especial, en las vinculaciones interétnicas -quizás, cansados de quedarse con el saludo cortado esperando con la otra mejilla y/o como una estrategia de adaptación al nuevo ámbito de la ciudad en la que predomina el beso único.

114 Por su parte, no hemos observado que el saludo entre los hombres, en general, haya sufrido modificaciones con el paso del tiempo; aunque sí se debe aclarar que este saludo se destaca básicamente a nivel intraétnico, dado que en el plano interétnico se realiza sólo el estrechamiento de las manos y un breve gesto de bajar la cabeza.

${ }^{115}$ Este aspecto es descrito con mayores detalles más adelante.

${ }^{116}$ Cabe aclarar que durante la ceremonia de inauguración de las primeras ocho viviendas ( 19 de abril de 1992), el líder del grupo había iniciado su discurso en la lengua qom l'aqtaqa. De la misma manera, esta lengua fue utilizada durante el ritual de entrega de las llaves, pero sólo en relación a algunas familias.
} 
Mientras que, en relación a los niños, los padres y adultos manifestaban que poseían muy poco conocimiento del toba y que, en cambio, había un predominio del uso del español:

-“...nuestros hijos no hablan en lengua, ...pasan la mayor parte del tiempo con chicos que hablan la castilla...”

Con el fin de contar con un panorama más detallado y certero sobre los hablantes activos, y constatar la vigencia de la lengua vernácula dentro del grupo, se realizó un relevamiento sociolingüístico de las familias de la comunidad, que incluyó un cuestionario acompañado de observación y observación participante. Así, fuimos preguntando y observando en cada uno de los grupos domésticos, de manera sistemática, cuáles eran los miembros que hacían uso de la misma y quiénes no. Con respecto a los que hablaban la lengua toba, se les preguntó con quiénes y en qué momento lo hacían, con el propósito de ir determinando los dominios de uso, y cuándo habían aprendido a hablar el castellano, para determinar el grado de conocimiento de ambos códigos lingüísticos, en términos de competencia y actuación, ${ }^{117}$ y la relación entre ambos. A quienes sólo entendían la lengua, pero no podían expresarse en ésta, se les preguntó las razones de esta situación y si les gustaría poder hacerlo; de este modo, se podría tener una aproximación a cuestiones vinculadas con el prejuicio y la discriminación que se manifiestan en el contexto de la sociedad nacional y han constituido un importante obstáculo para el manejo y la transmisión de la lengua materna en comunidades indígenas de nuestro país (Gerzenstein y otros 1998, Golluscio 2006). Finalmente, otro aspecto importante que se indagó fue si había interés en que los chicos aprendieran la lengua y qué pensaban que se podía hacer para que el idioma no se perdiera -puesto que, a simple vista, era lo que parecía-. Se enfatizó este último punto, en función de lo manifestado por el presidente de la Asociación Civil en ese momento, quien destacaba - como ya se mencionó en el capítulo anterior- que "se había estado buscando un pedacito de tierra donde vivir todos juntos y donde poder recuperar y desarrollar la lengua, las costumbres y la cultura". Por lo tanto, la recuperación y revitalización de la lengua toba se habían convertido en una meta para el grupo y esto significaba que la misma era altamente valorada y contaba con un elevado prestigio.

117 En términos de Chomsky ([1965] 1973), la competencia lingüística refiere al conocimiento que el hablante-oyente tiene de su lengua; en tanto que la actuación lingüística, al uso real de la lengua en situaciones concretas. 
Durante las dos primeras etapas en el proceso de autoconstrucción de las viviendas (1991-1993 y 1993-1996), y como resultado de los primeros registros tomados durante nuestra primera aproximación al Barrio Toba "Las Malvinas", constatamos contrariamente a nuestras primeras impresiones- que los miembros de las familias, en particular aquellos de mayor edad y los que constituían la primera generación de migrantes, manifestaban competencia lingüística y habilidad en la producción en la lengua de origen, usándola en la vida cotidiana, especialmente en la interacción intramatrimonial y entre vecinos o miembros de la comunidad. Es decir, eran tobahablantes los hombres y mujeres mayores de 21 años y nacidos en el Chaco (principalmente, provenientes de Pampa del Indio y Resistencia, donde los más jóvenes habían asistido a la escuela bilingüe del Barrio Toba de Resistencia). ${ }^{118}$ El resto de los integrantes de cada uno de los grupos domésticos solamente entendía cuando "se le hablaba en lengua" o "escuchaba hablar en lengua", expresando muchos de ellos sentir vergüenza si lo hacían (Ver Anexo I). En su mayoría, este grupo de hablantes está constituido por jóvenes y niños venidos del Chaco de pequeños o adolescentes y otros nacidos en el Gran Buenos Aires y La Plata, y algunos que se dicen "criollos" - esposo/a no toba que, como consecuencia de la convivencia, entraron en contacto con esa lengua.

En cuanto a la pregunta: "entre quién o con quiénes se usa la lengua", manifestaron comunicarse en la misma:

$>$ con todos aquellos que tienen conocimiento de ella;

$>$ con los vecinos;

$>$ con su compañera o compañero y con los del barrio;

$>$ con los "mayores" del barrio;

$>$ con la familia (incluyendo los chicos) y los vecinos;

$>$ entre los mayores;

$>$ entre los paisanos. $^{119}$

\footnotetext{
${ }^{118}$ Advertimos, sin embargo, que haber cursado sus estudios primarios en la escuela UEP N 30 "Aída Z. de Florito" no es condición para que un individuo manifieste un grado alto de conocimiento gramatical y uso extendido y cotidiano de la lengua materna. Esta escuela, si bien posee maestros auxiliares bilingües que enseñan como materia especial lengua toba, no desarrolla todas las habilidades en esta lengua. Ver Messineo y Equipo Docente (1998) y Ibáñez Caselli (2004). Más bien, el conocimiento y uso de la lengua se encuentra en relación con un contexto familiar en el que la lengua tiene vigencia y significados.

${ }^{119}$ Modo de referirse a su propia gente de origen toba o proveniente del mismo lugar.
} 
Entre los toba-hablantes, el aprendizaje del castellano, generalmente, se había efectuado por razones de necesidad extrema y de manera poco sistemática:

$>\quad$ desde el momento que comenzaron a asistir a la escuela primaria;

$>$ para comunicarse con sus vecinos no tobas;

$>\quad$ cuando eran chicos, con la otra gente que no era toba;

$>$ en el contacto con los criollos;

$>$ trabajando para los criollos;

$>\quad$ cuando tuvieron que venirse a vivir a Buenos Aires, por obligación;

$>\quad$ en el tiempo que realizaron el Servicio Militar.

Por un lado, como ya se mencionó en el Capítulo III, la mayoría de los adultos había logrado alcanzar el $2^{\circ}$ o $3^{\circ}$ grado de la escuela primaria; por lo tanto, habría sido muy poco el conocimiento de la lengua hegemónica adquirido de manera formal, y mucho menos si consideramos que es recién a partir de fines de la década de 1980 que comienzan a pensarse en programas y escuelas especiales con enseñanza bilingüe en la Provincia del Chaco. ${ }^{120}$ Por otro lado, el aprendizaje a través del contacto con la gente no toba también habría traído un conocimiento parcial del castellano junto con particularidades consideradas "no canónicas" del propio uso, puesto que se habría adquirido el habla cotidiano y de contextos específicos: el vecinal y el laboral. Contextos que además, como sabemos, se encuentran impregnados de prejuicios y discriminación hacia la gente indígena. En estos casos, el aprendizaje del castellano se habría dado siendo jóvenes y/o adultos, resultando más dificultoso para estos últimos. Al llegar a Buenos Aires, ese conocimiento parcial del castellano se intensificó, lo cual significó también la adquisición de otro recurso lingüístico: "el hablar de la gran ciudad", "el porteño". En general, quienes tuvieron un mayor contacto con el campo laboral y adquirieron una mejor competencia lingüística fueron los hombres. Asimismo, aquellos jóvenes que llegaron a cumplir con el Servicio Militar obligatorio no sólo asimilaron la lengua oficial de un modo más sistemático, sino que también aprendieron a leer y a escribir, completando sus estudios primarios.

Por su parte, aunque los padres manifestaran que sus hijos ya no hablaban la lengua toba, se pudo observar que los niños y jóvenes nacidos no sólo en el Chaco, sino también en Buenos Aires y La Plata, tenían conocimiento de parte del léxico de la

\footnotetext{
${ }^{120}$ Hasta antes de esa fecha, las políticas educativas tendían a la homogeneización y castellanización, pero sin contemplar el castellano como segunda lengua. Para más información sobre el desarrollo de la Educación Indígena en el Chaco, ver Ibáñez Caselli (2004).
} 
lengua vernácula y entendían cuando los adultos les hablaban en lengua, porque ésta se hablaba en los hogares. Especialmente, tenían internalizadas palabras de uso cotidiano expresadas en el seno familiar y que están relacionadas con las acciones de "dar y recibir diferentes órdenes", "saludar", "nombrar la comida, la vestimenta, las cosas, los animales, los parientes, las partes del cuerpo". Un trabajo en conjunto -y de común acuerdo con ellos y sus padres- nos llevó a recolectar parte de ese vocabulario donde los niños escribieron las palabras que conocían y les preguntaban a sus padres o abuelos las que desconocían. Lamentablemente, sólo una adolescente accedió a escribir el material recolectado en un cuaderno. El resto no demostró demasiado interés y sólo mencionaron algunas palabras en forma oral. De todos modos, esa tarea fue complementada con observaciones realizadas en sus hogares. ${ }^{121}$

De manera tal que el qom l'aqtaqa se encontraba vigente en las afueras de la ciudad de La Plata, a más de $1.000 \mathrm{~km}$. del Chaco. Éste se hablaba en los hogares, en la intimidad de las familias, pero también comenzó a escucharse en las actividades de la construcción mientras se pasaban los ladrillos o preparaban la mezcla del cemento; en las horas de descanso, incluso con el maestro mayor de obras de origen no toba y representante del Instituto de la Vivienda. Aparecía entre chistes y comentarios jocosos, aun entre los jóvenes adultos que manifestaban vergüenza y ya no poder expresarse en ella, e intentaban explicarle y enseñarle a esta persona ajena al grupo lo que sabían. Durante la segunda etapa de la construcción (1993-1996) fueron muchas las reuniones realizadas para resolver y tomar decisiones en las tareas del trabajo, las jornadas, dar cuenta de lo avanzado y de las dificultades presentadas; y esto era necesario hacerlo entre todos, con todos los adjudicatarios. Estas reuniones eran iniciadas en español por alguno de los funcionarios del mencionado instituto; luego, encabezada por el presidente de la asociación, en ambos códigos lingüísticos. A las mujeres, presentes en todas las reuniones, sólo se las escuchaba hablar y comentar entre ellas y en la lengua toba. En muy pocas ocasiones participaban en voz alta de forma espontánea; generalmente, permanecían calladas y únicamente tomaban el turno de la palabra (en español) cuando había una pregunta dirigida hacia ellas particularmente.

\footnotetext{
${ }^{121} \mathrm{Al}$ inicio de esta tarea, eran sólo alrededor de ocho los niños en edad escolar que sabían ya escribir. La tarea consistió en brindarles cuadernos y lápices y hacer que anotaran las palabras en toba que conocían, su significado en español, e ir preguntando a sus padres y abuelos por el resto, y en el plazo de dos semanas. Sólo una joven de 14 años aceptó el desafío. Ver Anexo 4.
} 


\section{- Cumplida la autoconstrucción, el barrio alcanza una nueva dinámica}

A medida que la construcción de las viviendas avanzaba, el barrio fue cambiando su fisonomía y creció su población. Desde 1996 -época en que culminó la segunda etapa y se finalizaron y habitaron las 36 viviendas-, el barrio adquirió un mayor dinamismo no sólo porque llegaron nuevas familias al lugar, sino también porque se incrementó la tasa de nacimientos. Además, los alrededores se fueron poblando como parte del programa destinado a las 540 viviendas, entre las cuales las primeras habían sido las de los tobas. Los hombres empezaron a buscar empleo fuera del barrio y a estar más tiempo ausentes del mismo. Algunas mujeres consiguieron trabajo como empleadas domésticas por horas o cama adentro, o se ausentaban de sus hogares para vender las artesanías, acompañar a los niños al colegio, asistir a las reuniones escolares, dedicarse al cirujeo, o realizar trámites para la asociación. Por su parte, los niños comenzaron a tener mayor continuidad en la asistencia a la escuela y a jugar con otros niños vecinos no tobas cuando regresan de aquélla. Asimismo, la creación la Escuela de Nivel Inicial "Josefina Bakhita" en las cercanías del barrio permitió que los niños tobas iniciaran el ciclo educativo y se alejaran unas horas de sus hogares a edad más temprana. No obstante, a pesar de haberse dado las condiciones para completar todo el ciclo lectivo, algunos jóvenes adolescentes abandonaron sus estudios $y$, en cambio, formaron pareja $y$ tuvieron hijos - con personas tobas o no tobas- manteniendo la residencia en el propio barrio. $^{122}$

Todos estos aspectos nos llevaron a formular nuevos interrogantes en la investigación en torno a los usos y funciones de la lengua materna. Todo parecía indicar que la lengua toba ya no sería funcional y que dejaría de hablarse. Sin embargo, la situación era más compleja...

Al tiempo que fueron obtenidas las viviendas y el barrio se fue consolidando, la cuestión de la subsistencia pasó a ser prioritaria: había que sostener y sustentar las familias. La organización -liderada básicamente por la Asociación Civil Ntaunaq Nam Qom- fue clave para empezar este proceso.123 En este caso, fue a través de la misma

\footnotetext{
${ }^{122}$ Las causas del abandono escolar son diversas y fueron explicadas en el capítulo anterior: dificultades económicas, problemas de prejuicios, discriminación y violencia escolar, falta de atención adecuada a las necesidades de los educandos, entre otras.

${ }^{123}$ Este hecho se resaltó en el capítulo III, diciendo que para los efectos de esta investigación, la Asociación Civil Toba Ntaunaq Nam Qom, apareció como la principal instancia de organización.
} 
que se pusieron en marcha los proyectos tales como la Huerta Comunitaria, El Ropero Comunitario, el Comedor; actividades que dieron trabajo remunerado -por medio de becas y subsidios- y permitieron que muchos de los jefes y jefas de hogar permanecieran más tiempo en el barrio y cerca de sus hijos. Cada una de estas actividades se convirtió, además, en nuevos espacios de recreación y reproducción de la lengua toba. De modo tal que la misma adquirió nuevos usos, funcionalidad y significación.

El relevamiento sociolingüístico de los 34 grupos domésticos ${ }^{124}$ que conforman el barrio toba -mediante un segundo censo, entrevistas, observaciones y registros de situaciones comunicativas cotidianas- permitió aproximarnos, por un lado, a las características lingüísticas y sociales de cada uno de los integrantes de los grupos domésticos y, por otro, a la lengua en acción. La consideración de las categorías: edad, lugar de nacimiento, tiempo de migración, lugares que habían estado antes de llegar a la ciudad de La Plata, generación, asistencia o no a una escuela modalizada, etapa del ciclo de vida en que se aprendió el castellano, habilidades lingüísticas respecto del toba, tipo de hablante y actitudes hacia la lengua materna nos proporcionó los datos necesarios para caracterizar la comunidad toba del Barrio "Las Malvinas" como un grupo social y lingüísticamente diverso (ver Anexo 2).

La siguiente sistematización, volcada en el Cuadro $\mathrm{N}^{\circ} 1$ (ver página 145), nos permite visualizar la diversidad social y lingüística existente. ${ }^{125}$ En él distinguimos once grupos que representan a 11 tipos de hablantes de un modo general, puesto que, asimismo, podemos encontrar algunas variaciones dentro de cada uno de ellos. La distribución de hablantes propuesta es la siguiente:

A- Hombres y/o mujeres entre los 65-75 años de edad, nacidos en el Chaco, en zona rural, cuya lengua materna es el toba. Emplearon la misma como única o principal lengua hasta el momento de la migración a la gran ciudad, esta última ocurrida

\footnotetext{
${ }^{124} \mathrm{Si}$ bien se autoconstruyeron 36 viviendas, hablamos de 34 grupos domésticos ya que una de ellas, como ya se mencionó, fue destinada a la Asociación Civil Toba Ntaunaq Nam Qom y la otra no fue ocupada durante el tiempo que realizamos el período de trabajo de campo más intenso.

125 Cabe aclarar que lo expresado en este cuadro es el resultado de los modos en que se realizó esta investigación y los fines propuestos; se trata de una clasificación posible y, como toda tipología, una construcción. La misma fue elaborada entre los primeros años de iniciado el trabajo y reelaborada a medida que se fue avanzando, en la medida que fuera operativa como herramienta metodológica para el análisis e interpretación de los datos.
} 
hace aproximadamente cuarenta años. Adquirieron mayor competencia en el uso del castellano hacia la adultez.

B- Hombres y/o mujeres entre los 45-65 años de edad, nacidos en el Chaco, en zona rural, cuya lengua materna es el qom. Emplearon la lengua materna con mayor dominio en el Chaco, pero adquirieron el castellano en un contexto laboral y cuando migraron a la ciudad, hace aproximadamente treinta años, siendo jóvenes o adultos, $\mathrm{y}$, algunos, sobrinos del grupo A.

C- Hombres y/o mujeres entre los 45-65 años de edad, nacidos en el Chaco, en zona urbana. Con el toba como lengua materna y con algún conocimiento del castellano como segunda lengua en el lugar de origen, pero esta última lengua fue más afianzada luego de la migración a Buenos Aires, ocurrida hace aproximadamente treinta años.

D- Hombres y/o mujeres entre los 35-45 años de edad, nacidos en la provincia del Chaco, en zona rural, que emplearon la lengua materna hasta el momento de la migración, ocurrida hace aproximadamente entre cinco y diez años. Llegaron al Gran Buenos Aires o a La Plata directamente.

E- Hombres y/o mujeres entre los 25-35 años de edad, nacidos en el Chaco, en zona urbana. Tuvieron su socialización primaria en el Chaco y en lengua toba. Sin embargo, al comenzar la escuela primaria y migrar al conurbano bonaerense, priorizaron el castellano. En algunos de ellos la lengua toba sigue vigente en la actualidad porque sus padres y abuelos no han abandonado la lengua.

F- Hombres y/o mujeres entre los 25-35 años de edad, nacidos en el Barrio Toba de Resistencia. Asistieron a la escuela UEP $\mathrm{N}^{\circ} 30$ ubicada en ese barrio y cuyos abuelos fueron monolingües en toba. Llegaron a la ciudad de La Plata hace 10 años y hablan ambas lenguas fluidamente.

G- Jóvenes, menores de veinticinco años de edad, nacidos en el conurbano bonaerense, que han sido socializados en un contexto donde la lengua toba sólo se hablaba en la casa y entre los padres o abuelos. Adquirieron el castellano por contacto con chicos no tobas y la asistencia a la escuela. Sus padres reúnen las características presentadas en C. En la actualidad tan sólo poseen un conocimiento parcial de la lengua.

H- Niños menores de quince años de edad, nacidos en el conurbano bonaerense, que han sido socializados en lengua toba, pero incorporaron el castellano por contacto con chicos no tobas y la asistencia a la escuela, y cuyos padres reúnen las características presentadas en $\mathrm{B}$, teniendo en la actualidad tan sólo un conocimiento parcial de la lengua. 
I- Niños menores de quince años de edad, nacidos en el Chaco y en La Plata, que han recibido su socialización primaria en lengua toba, pero incorporado el castellano a través de hermanos mayores y por contacto con chicos no tobas y la asistencia a la escuela, y cuyos padres reúnen las características presentadas en D y F. Tienen en la actualidad tan sólo un conocimiento parcial de la lengua qom l'aqtaqa.

J- Niños menores de quince años de edad que nacieron en Buenos Aires y en la ciudad de La Plata. Hijos de padres que poseen poca fluidez de la lengua toba, segunda o tercera generación de migrantes (E), y nietos de C y B.

$\mathrm{K}$ - Adultos mayores de 25 años no tobas o criollos que han nacido en el Chaco y conformado pareja con un toba. Constituyen la primera generación de migrantes, su lengua materna es el castellano; sin embargo, comprenden en parte el toba porque su esposo/a le ha enseñado y por el hecho de vivir con las familias tobas y compartir algunas de las actividades en esa lengua. Sus hijos están incluidos en el grupo J. 


\section{Cuadro N 1: Diversidad Sociolingüística en el Barrio Toba Las Malvinas*}

\begin{tabular}{|c|c|c|c|c|c|c|c|c|c|c|c|c|}
\hline & $\mathbf{A}$ & B & $\mathrm{C}$ & D & $\mathbf{E}$ & $\mathbf{F}$ & G & H & \multirow{2}{*}{\multicolumn{2}{|c|}{$\frac{\text { I }}{<15 \text { años }}$}} & $\mathbf{J}$ & $\mathbf{K}$ \\
\hline Edad & $65-75$ años & 45-65 años & 45-65 años & $35-45$ años & $25-35$ años & 25-35 años & $<25$ años & $<25$ años & & & $<15$ años & $>25$ años \\
\hline Lugar de nacimiento & $\begin{array}{c}\text { Chaco } \\
\text { (zona rural) }\end{array}$ & $\begin{array}{c}\text { Chaco } \\
\text { (zona rural) }\end{array}$ & $\begin{array}{c}\text { Chaco } \\
\text { (zona urbana) }\end{array}$ & $\begin{array}{c}\text { Chaco } \\
\text { (zona rural) }\end{array}$ & $\begin{array}{c}\text { Chaco } \\
\text { (zona urbana) }\end{array}$ & $\begin{array}{c}\text { Chaco } \\
\text { (zona urbana) }\end{array}$ & $\begin{array}{l}\text { Buenos } \\
\text { Aires }\end{array}$ & Buenos Aires & $\begin{array}{c}\text { a) } \\
\text { Chaco }\end{array}$ & $\begin{array}{c}\text { b) } \\
\text { Buenos } \\
\text { Aires }\end{array}$ & Buenos Aires & Chaco \\
\hline Tiempo de migración & 40 años & 30 años & 30 años & 5 a 10 años & 25 años & 10 años & -- & -- & $\begin{array}{l}5 \text { a } 10 \\
\text { años }\end{array}$ & -- & -- & 10 años \\
\hline Generación & Primera & $\begin{array}{l}\text { Segunda en } \\
\text { relación a A }\end{array}$ & Primera & Primera & $\begin{array}{c}\text { Segunda/ } \\
\text { Tercera }\end{array}$ & Primera & $\begin{array}{c}\text { Segunda/ } \\
\text { Tercera }\end{array}$ & $\begin{array}{c}\text { Segunda/ } \\
\text { Tercera } \\
\end{array}$ & \multicolumn{2}{|c|}{ Segunda } & $\begin{array}{l}\text { Tercera/ } \\
\text { Segunda } \\
\end{array}$ & Primera \\
\hline $\begin{array}{l}\text { Habilidades verbales } \\
\text { respecto a la lengua Qom }\end{array}$ & $\begin{array}{l}\text { Hablante } \\
\text { fluido }\end{array}$ & $\begin{array}{l}\text { Hablante } \\
\text { fluido }\end{array}$ & Hablante fluido & $\begin{array}{l}\text { Hablante } \\
\text { fluido }\end{array}$ & Entiende & $\begin{array}{l}\text { Hablante } \\
\text { fluido }\end{array}$ & Entiende & $\begin{array}{l}\text { Entiende con } \\
\text { limitaciones }\end{array}$ & \multicolumn{2}{|c|}{ Entiende } & \begin{tabular}{|l|} 
Entiende con \\
limitaciones
\end{tabular} & $\begin{array}{l}\text { Entiende con } \\
\text { limitaciones }\end{array}$ \\
\hline Tipo de Hablante & Bilingüe & Bilingüe & Bilingüe & Bilingüe & $\begin{array}{c}\text { Semi- } \\
\text { hablante }\end{array}$ & Bilingüe & $\begin{array}{l}\text { Semiha- } \\
\text { blante }\end{array}$ & $\begin{array}{l}\text { Bilingüe casi- } \\
\text { pasivo }\end{array}$ & \multicolumn{2}{|c|}{ Semi-hablante } & $\begin{array}{c}\text { Bilingüe casi- } \\
\text { pasivo }\end{array}$ & $\begin{array}{l}\text { Bilingüe casi- } \\
\text { pasivo }\end{array}$ \\
\hline $\begin{array}{l}\text { Etapa de la vida en que } \\
\text { aprendió el castellano }\end{array}$ & $\begin{array}{c}\text { Adolescencia } \\
\text { o Adulta }\end{array}$ & $\begin{array}{c}\text { Adolescencia } \\
\text { o Adulta }\end{array}$ & $\begin{array}{l}\text { Adolescencia o } \\
\text { Adulta }\end{array}$ & Adulta & Niñez & Niñez & Niñez & Niñez & \multicolumn{2}{|c|}{ Niñez } & Niñez & Niñez \\
\hline $\begin{array}{c}\text { Asistencia a una escuela } \\
\text { modalizada }\end{array}$ & -- & -- & -- & -- & Sí & Sí & -- & -- & \multicolumn{2}{|c|}{--} & -- & -- \\
\hline OBSERVACIÓN & $\begin{array}{l}\text { Tíos de B } \\
\text { Tío-Abuelos } \\
\text { de H }\end{array}$ & $\begin{array}{c}\text { Sobrinos de A } \\
\text { Padres de E y } \\
\text { H Abuelos de } \\
\mathrm{J}\end{array}$ & $\begin{array}{l}\text { Padres de G, E } \\
\text { Abuelos de J }\end{array}$ & Padres de I & $\begin{array}{l}\text { Padres de J } \\
\text { Hijos de C y } \\
\text { B }\end{array}$ & Padres de $\mathrm{Ib}$ & $\begin{array}{c}\text { Hijos de C y } \\
\text { B }\end{array}$ & $\begin{array}{c}\text { Hijos de B y } \\
\text { C }\end{array}$ & \multicolumn{2}{|c|}{ Hijos de D } & $\begin{array}{c}\text { Hijos de E y F } \\
\text { Nietos de B y } \\
\text { C }\end{array}$ & Padres de $\mathrm{J}$ \\
\hline
\end{tabular}

* Este cuadro es una versión revisada y ampliada de la presentada en Ibáñez Caselli (2000). 
Del análisis de estos once grupos reconocemos tres grandes tipos de hablantes respecto de su competencia en toba: "hablante fluido del toba", "entiende toba", "entiende toba con limitaciones". Es decir, que la lengua toba no sólo es hablada por ciertos hablantes, sino que es importante rescatar que es entendida o comprendida, por completo o en parte, por otros. Y este último aspecto le otorga otra dimensión al análisis y que desarrollaremos con más profundidad más adelante. Es oportuno mencionar aquí que estas categorías fueron obtenidas a través de métodos cualitativos. En primer lugar, han sido mis propios interlocutores hablantes fluidos de la lengua toba quienes han medido y calificado el tipo de conocimiento que los otros hablantes poseen de esa lengua. En segundo lugar, estas consideraciones fueron contrastadas con nuestras propias observaciones en diferentes situaciones comunicativas mediante el registro riguroso de la variedad lingüística utilizada en los eventos comunicativos y el grado de participación y comprensión de los hablantes. ${ }^{126} \mathrm{Y}$, en tercer lugar, esta tarea se complementó con la realización de algunos talleres y actividades con los niños y jóvenes que fueron especificados en el Capítulo II, tales como apoyo escolar, visita a los colegios y trabajos en el aula y relevamiento de léxico toba con los niños, entre otros.

\section{IV.2. LOS ROLES SOCIALES Y LOS USOS DE LA LENGUA}

Según se desprende de las observaciones expresadas arriba, el Barrio Toba "Las Malvinas" presenta diversidad en los recursos lingüísticos utilizados. Podemos describirlo como un caso de bilingüismo, puesto que tanto la lengua toba como el español se utilizan cotidianamente. Según Coronado (1996) la continuidad del uso de una lengua indígena en una comunidad estaría más bien ligada a las necesidades internas de la misma: comunicación, transmisión cultural, cohesión social e identidad; mientras que el español se utilizaría como vehículo de contacto con el exterior. Esto es cierto para el caso que analizamos. El español es la lengua que se utiliza para comunicarse con los no tobas, fuera de los límites del barrio. Sin embargo, dentro del mismo, la lengua toba es hablada sólo en determinados contextos $\mathrm{y}$ en situaciones comunicativas particulares. Los hablantes bilingües con predominio de la lengua toba no siempre emplean esta lengua para la comunicación, aun en aquellas situaciones comunicativas donde la misma tendría mayor predisposición para ser utilizada. De manera tal que se da una diferenciación marcada en

\footnotetext{
${ }^{126}$ Se deja en claro también la necesidad de realizar un análisis minucioso y preciso, con métodos y tests de tipo cuantitativos que den cuenta del grado de conocimiento de la lengua toba que tienen los habitantes del barrio "Las Malvinas". Aspecto que no se propuso entre los objetivos de esta investigación.
} 
los usos y las funciones de la lengua toba. Por esta razón, describimos la situación de bilingüismo que encontramos en la comunidad toba del Barrio "Las Malvinas" como diglósica. Es decir, dadas las características sociolingüísticas de los grupos domésticos, hablar de bilingüismo no implica entender a éste como un modelo donde las dos lenguas conviven en igualdad de condiciones, sino que el mismo consiste en una situación de diglosia en el sentido que se da una diferenciación funcional en los usos de las dos variedades lingüísticas. ${ }^{127}$ Asimismo, coincidimos con el concepto de diglosia conflictiva propuesto por Hamel $(1983 ; 1988)$ en el sentido de que esta diferenciación sería el resultado de una relación conflictiva, no estable y asimétrica, entre una lengua dominante y una dominada; una tensión en la que, por un lado, se estaría dando una creciente expansión del español en la mayoría de los dominios de uso y, por otro, la manifestación latente de una resistencia lingüística y cultural del toba. Aspecto que intentaremos caracterizar a continuación.

Como es sabido, son varios los factores que pueden actuar como reguladores del uso de una lengua. ${ }^{128}$ Además, la selección de una lengua está relacionada con las normas socioculturales $\mathrm{y}$, sobre todo, con las expectativas que los integrantes de una comunidad de habla puedan tener. El interés por este hecho en particular nos llevó a realizar un seguimiento a algunos representantes de los once grupos de hablantes registrados. Entre los criterios utilizados para la selección de estos casos se consideraron las características sociolingüísticas de los miembros de la comunidad toba del Barrio "Las Malvinas"; además, el desempeño o no como líder del grupo, la participación en distintas situaciones comunicativas, el género (se tomaron en consideración tanto hombres como mujeres y su rol en la comunidad) en relación a los roles que cada uno de ellos cumplen en los eventos de habla y los usos de ambos códigos lingüísticos: la lengua toba y el español. A continuación, se describen algunos de los casos seleccionados para el análisis.

\footnotetext{
${ }^{127}$ Ferguson (1959) utilizó el término diglosia para referirse a una situación donde se daban dos formas de la misma lengua que se diferenciaban en su uso notablemente; identificando una variedad alta: empleada formalmente, en la iglesia, la política, etc., y otra baja: utilizada popularmente, en situaciones no oficiales y sin un desarrollo literario. Luego, Fishman (1971) amplía el concepto de diglosia refiriéndose a cualquier situación en la que se da una diferenciación funcional entre el uso de formas lingüísticas diferentes no necesariamente variantes de una misma lengua. (Ver Hudson [1980] 1981; Bolaño 1982).

${ }^{128}$ En situaciones de bilingüismo, Fishman (1972) destacó al tema (topic), la escena y el/los roles como posibles factores reguladores. El conjunto de estos reguladores hace a un concepto mayor que es el de dominio de uso (domains).
} 
Caso 1.: Tomamos como referencia ego a (JR) perteneciente al grupo A. (JR) es líder social y religioso, anciano, ex presidente de la asociación civil. El análisis de sus redes sociales y lingüísticas permite distinguir su repertorio de roles. ${ }^{129}$ Este repertorio está definido a partir de las diversas situaciones en que ego interactúa con los demás, refiriéndose tanto a su actuación dentro del barrio como con los distintos sectores de la sociedad global. Cada uno de los roles se circunscribe dentro de algún dominio de uso, como se muestra a continuación:

\section{Caso 1: Hablante del grupo A}

\begin{tabular}{|c|c|c|c|}
\hline Dominios de Uso & Repertorio de & \multicolumn{2}{|c|}{ Lengua } \\
\cline { 3 - 4 } & Roles & Toba & Castellano \\
\hline Doméstico & esposo & sí́ & sí- \\
Parentesco & padre & sí- & sí \\
& tío & sí & sí \\
& abuelo & sí- & sí \\
\hline Aprovisio- & presidente & sí & sí \\
namiento & líder & sí & sí \\
& intermediario & sí & sí \\
& vendedor & no & sí \\
\hline Religioso & Pastor & sí & sí \\
\hline Vecindad & buen vecino 130 & no & sí \\
& el "abuelo" & sí & sí \\
& consejero & sí & sí \\
& amigo/ vecino & sí & sí \\
\hline Tránsito & indígena & sí & sí \\
& vendedor & no & sí \\
& adjudicatario & no & sí \\
\hline
\end{tabular}

De acuerdo con el cuadro presentado, el uso de la lengua toba por parte de ego dependería de las personas con las que éste interactúa en las distintas situaciones y el tipo de relación que tiene ego con cada una de ellas (según su repertorio de roles). El uso de la lengua toba sería predominante en el dominio familiar y de parentesco, en las relaciones: esposo/ esposa, en tanto que en las de tío/ sobrino, abuelo/ nieto, el uso es menor; en el dominio de vecindad como "abuelo"-consejero/ oyente-discípulo; en el dominio de abastecimiento: presidente/ socio toba-hablante, líder/ seguidor. Mientras que el empleo del castellano se da en todos los dominios de uso, tanto en su relación con hablantes tobas fluidos -aunque en menor proporción-, como con los que sólo entienden o poseen

\footnotetext{
129 Según Bolaño (1982:53), la variedad de roles que una persona puede desempeñar en su comunidad lingüística la obliga al manejo de un repertorio verbal que le permita adaptarse a cada uno de ellos. Las comunidades de habla con mayor variedad de roles revelan un repertorio verbal más amplio.

${ }^{130}$ Se refiere a su relación vecinal fuera de los límites del Barrio Toba.
} 
limitaciones en comprender esa lengua. Solamente predomina el castellano en aquellas situaciones donde se interactúa con el sector de hablantes no tobas, dándose las relaciones de vendedor/ comprador, vecino/ vecino, ciudadano/ funcionario.

Caso 2: Tomamos el caso de (JG) que, según nuestra caracterización de los tipos de hablantes es representante del grupo F. Es mujer, joven-adulta, se ha desempeñado en la función de secretaria de la Asociación Civil y se ha destacado como líder especialmente, en los últimos años.

\section{Caso 2: Hablante del grupo $F$}

\begin{tabular}{|c|c|c|c|}
\hline Dominios de Uso & Repertorio de & \multicolumn{2}{|c|}{ Lengua } \\
\cline { 3 - 4 } & Roles & Toba & Castellano \\
\hline Doméstico & esposa & sí- & sí \\
y de & madre & sí- & sí \\
& tía & sí- & sí \\
& nuera & sí- & sí \\
\hline Aprovisio- & secretaria & sí + & sí \\
namiento & líder & sít & sí \\
& intermediaria & sít & sí \\
& docente & sít & sí \\
\hline Religioso & Participante del & sí & sí \\
& culto & & \\
\hline Vecindad & Buena vecina & sí & sí \\
& consejera & sít & sí \\
& amiga/ vecina & sít & sí \\
\hline Tránsito & indígena & sít & sí \\
& adjudicataria & sí & sí \\
& conferencista & sí & sí \\
\hline
\end{tabular}

En este caso, observamos el uso de la lengua toba en todos los dominios y, principalmente, fuera del familiar o doméstico. Se trata de uno de los hablantes jovenadulto de la lengua vernácula que más se destaca abiertamente y que se expresa en la misma públicamente. Sin embargo, en el ámbito doméstico sólo algunas veces se dirige a su esposo e hija en toba y cuando lo hace, lo realiza más en función de enseñanza o práctica (su pareja se ubica en el grupo E). Mientras que en los otros dominios tiene mayor frecuencia el uso de la lengua vernácula. Interpretamos esto como un mecanismo para reafirmar la identidad toba y, también, poder transmitir con la mayor claridad posible los deberes y obligaciones a los integrantes de la asociación civil y de la comunidad de habla toba.

Caso 3: (ER) es un hablante que representa al grupo E. Al igual que en el caso anterior es mujer, líder, joven-adulta, y se ha vinculado a los trabajos directivos de la asociación civil. 
Caso 3: Hablante del grupo E

\begin{tabular}{|c|c|c|c|}
\hline Dominios de Uso & Repertorio de & \multicolumn{2}{|c|}{ Lengua } \\
\cline { 3 - 4 } & Roles & Toba & Castellano \\
\hline Doméstico & esposa & no & sí \\
y de & madre & no & sí \\
Parentesco & tía & no & sí \\
& hermana & no & sí \\
\hline Aprovisio- & directiva & sí- & sí \\
namiento & líder & no & sí \\
& intermediaria & no & sí \\
& docente & no & sí \\
\hline Religioso & participante del & no & sí \\
& culto & & sí \\
\hline Vecindad & buena vecina & no & sí \\
& consejera & no & sí \\
\hline Tránsito & indígena & no & sí \\
& adjudicataria & no & sí \\
\hline
\end{tabular}

Como podemos observar aquí, ego posee un mayor predominio del castellano en todos los dominios de uso, aunque dice -y parece- entender todo cuando le hablan en lengua. Solamente en los momentos de mayor distensión y recreación y en reuniones con los jóvenes, jóvenes-adultos y adultos - momentos en que aparecen los chistes y las bromassuele expresar frases cortas y emplear parte del léxico toba.

Caso 4: (RC) es hombre, adulto y representante del grupo B. Ha ocupado el cargo de presidente de la asociación civil y se trata de una de las personas que sostiene más contactos de tipo interétnicos.

Caso 4: Hablante del grupo B

\begin{tabular}{|c|c|c|c|}
\hline Dominios de Uso & Repertorio de & \multicolumn{2}{|c|}{ Lengua } \\
\cline { 3 - 4 } & Roles & Toba & Castellano \\
\hline Doméstico & esposo & no & sí \\
y de & padre & no & sí \\
Parentesco & tío & no & sí \\
& abuelo & no & sí \\
& hermano & no & sí \\
\hline Aprovisio- & presidente & sí- & sí \\
namiento & líder & sí- & sí \\
& intermediario & no & sí \\
& albañil & no & sí \\
\hline
\end{tabular}




\begin{tabular}{|c|c|c|c|}
\hline Vecindad & $\begin{array}{c}\text { buen vecino } \\
\text { amigo/vecino }\end{array}$ & $\begin{array}{l}\text { no } \\
\text { no }\end{array}$ & sí \\
& sí \\
\hline Tránsito & indígena & sí- & sí \\
& adjudicatario & sí- & sí \\
& conferencista & sí- & sí \\
\hline
\end{tabular}

En este otro caso, a pesar de tener el toba como lengua materna, ésta es utilizada muy poco y en determinadas situaciones -especialmente en aquellas donde se resalta la identidad étnica-. No ha transmitido la lengua a sus hijos menores. Su actual esposa es no toba; aunque, por su vinculación con la gente toba desde pequeña le permite estar familiarizada con esa lengua.

Estos cuatro casos hacen referencia a los usos lingüísticos de personas que han tenido o tienen actualmente el rol de líderes de la comunidad, tanto hombres como mujeres, con características verbales, históricas y edades diferentes. Nos revelan que el uso de la lengua toba se hace más frecuente con relación a las situaciones en las cuales se pone en manifiesto la identidad étnica del grupo.

Por su parte, entre los hablantes fluidos de la lengua toba -representantes de los grupos A, B, C, D, F y que no se han destacado como líderes del grupo- la lengua toba tiene un mayor uso en los dominios familiar y de parentesco, religioso y vecindad. La hablan con sus esposos, hermanos, vecinos tobas del barrio y visitas que llegan del Chaco u otras localidades donde se habla esa lengua; en sus casas, en el culto, en la huerta, en el ropero comunitario, en el comedor; es decir, en todas aquellas situaciones en las que el trabajo es comunitario o son motivo de reunión y/o distracción. Los niños y jóvenes están presentes en todas estas actividades y escuchan la lengua todo el tiempo. Incluso, en algunas instancias estos últimos se molestan porque los adultos hablan en lengua todo el tiempo.

\section{IV.3. El CAMbio de Código como Estrategia Comunicativa}

En algunas oportunidades, se registraron en el Barrio Toba "Las Malvinas" ciertas situaciones comunicativas en las que se dio el cambio de código (code switching), fenómeno que interpretamos como una estrategia comunicativa de los hablantes. Por ejemplo:

La acción se desarrolla fuera de la vivienda -dominio de vecindad-, A (ego) y un grupo de vecinos toba-hablantes se encuentran reunidos recordando viejas anécdotas, experiencias pasadas. La conversación se realiza en toba. De pronto, se acerca un 
vecino no toba y los interrumpe. Lo invitan a adherirse a la reunión y todos los participantes pasan a utilizar el castellano -el tema de conversación también cambia.

Continúa la interlocución. De pronto, se retoman algunos de los temas que se estaban tratando antes de que llegara el vecino no toba. Se continúa hablando en castellano, pero por momentos aparece la alternancia hacia la lengua materna, hablando entre ellos y dejando fuera de la comunicación al vecino no toba.

Blom y Gumperz (1972) han sugerido que la alternancia entre dos variedades lingüísticas distintas sirve para simbolizar las diferentes identidades sociales que los individuos pueden asumir, puesto que factores sociales y lingüísticos estarían intrínsecamente relacionados en el proceso de comunicación. ${ }^{131}$ En ambos ejemplos mencionados arriba, el lugar situacional es el mismo, pero cambia el evento de habla. Es decir, en el primer ejemplo se da lo que los autores denominan cambio situacional. Aquí, la alternancia de la lengua toba al castellano está redefiniendo la situación: hay una persona ajena al grupo que no habla toba y que tampoco comparte las experiencias -tema de conversación anterior a su llegada. ${ }^{132}$

En el segundo ejemplo, se daría lo que los mismos autores llaman un cambio metafórico: el uso de la lengua cambia debido a problemas de tipo temático, el tema "requiere" que se lo trate en lengua, evidenciando que la conversación ha adquirido un significado social especial que implica un cierto grado de confiabilidad, privacidad y/o emotividad.

Tales cambios fueron detectados en los distintos dominios, incluso en el religioso. El culto se oficia en una u otra lengua, según las características lingüísticas de quienes estén

131 Con el propósito de analizar los significados que tiene el cambio entre códigos en una determinada interacción estos autores plantearon la necesidad de conocer el contexto en que se desarrolla la acción. Éste estaría delimitado por el lugar situacional, es decir, el ámbito físico en que se desarrolla la acción; la situación social: todas las actividades realizadas por un conjunto particular de personas, reunidas en un lugar situacional particular, en un determinado tiempo de duración; es decir, el tipo de relaciones que mantienen las personas; y el evento social: la selección de temas que distinguen a la situación.

${ }^{132} \mathrm{Si}$ analizamos el momento de la migración y el impacto que este proceso produce en los hablantes, se puede afirmar que dicho cambio implicó también un cambio situacional importante respecto del uso de la lengua materna. Si tomamos el caso de A (JR), su trayectoria migratoria, podemos observar que la lengua qom l'aqtaqa tenía un uso frecuente en la mayoría de los dominios que se pudieron delinear durante el transcurso de su vida en el Chaco, mientras que en Buenos Aires su empleo aparece más restringido, limitándose solamente a algunos dominios y al contacto con ciertas personas. 
participando en ese momento. Sin embargo, en el caso de hacerse en castellano, durante ciertas ocasiones el pastor toba utiliza la alternancia de códigos para captar la atención de los presentes, quienes en algunas oportunidades también le contestan en esa lengua. Volveremos sobre este tema más adelante.

Destacamos también la importancia que adquiere la alternancia de la lengua toba en situaciones que poseen una alta carga emotiva. Por ejemplo, fue altamente significativo el cambio de código que se dio en el acto de inauguración de las primeras ocho viviendas. En esta ocasión, (JR) - (ego) - en calidad de presidente de la asociación civil, inició su discurso en castellano ante un público diverso: futuros adjudicatarios - hablantes fluidos y no fluidos del toba- autoridades gubernamentales, representantes de la UNLP, vecinos y amigos invitados, y a los pocos minutos, continuó en toba, para luego, volver al castellano y dirigirse a todos los presentes. A continuación, reproducimos parte de su acto verbal:

“...Hemos llegado a los seis años de lucha para conseguir estas tierras, para conseguir la vivienda; muchas veces no tiene qué comer mis hijos, estuve trabajando con mucho sacrificio, pero cuando supe que salió este terreno, tuve que renunciar al trabajo pero seguimos luchando y seguiremos luchando... [continúa hablando en lengua toba]

El día cuando termina $R$. pero hay que seguir luchando y trabajando, hay que enseñar a los chicos, los nietos y los hijos, después lo que viene atrás de nosotros.

Gracias a Dios que ha tocado los corazones de los hermanos criollos blancos, por eso ellos están presentes en este día. Gracias..."

En este caso, la carga emotiva era muy fuerte; se trataba de un sueño hecho realidad, el logro de algo sumamente valorado que había costado tanto tiempo y sudor conseguir. Y a esta gran emoción acompañó la lengua materna, expresando sentimientos muy íntimos de las familias protagonistas. En este contexto, y dentro de la misma situación comunicativa, se desarrolló otro evento comunicativo también significativo: la entrega de las llaves a los adjudicatarios. Ésta se realizó frente a la puerta de la vivienda que le correspondía a cada uno. El presidente de la asociación inició la ceremonia con una pequeña presentación que consistió en la emisión de un discurso mayoritariamente en lengua toba. El rito, que consistió en levantar las llaves al tiempo que se efectuaba la acción verbal ofreciendo la llave a cada uno de los jefes domésticos, y seguido de un abrazo, estuvo a cargo de otro de los adultos de la comunidad -líder religioso y perteneciente al grupo lingüístico (A)-. Las palabras ofrecidas fueron hechas principalmente en lengua toba. Para el caso de aquellos no hablantes activos de esta lengua, otra persona - un familiar cercano- les fue traduciendo 
al español. El contenido del mensaje dirigido en cada uno de los casos fue prácticamente el mismo, aunque con algunas variaciones. Seguidamente, reproducimos el acto verbal ejecutado en la Vivienda $\mathrm{N}^{\mathrm{o}} 34$, donde el adjudicatario de esta vivienda era un joven soltero y representante del grupo E. Su padre fue quien se acercó y tradujo las palabras del que entregaba las llaves.

\begin{tabular}{|l|l|}
\hline \multicolumn{2}{|c|}{$\begin{array}{c}\text { Palabras de ceremonia de entrega de } \\
\text { llaves }\end{array}$} \\
\hline $\begin{array}{l}\text { El que entrega las } \\
\text { Ilaves }\end{array}$ & El que traduce \\
\hline - adem, adogue & - "cuidala bien" \\
\hline - aduapi & $\begin{array}{l}\text { - "Estás dentro del } \\
\text { sufrimiento" }\end{array}$ \\
\hline - atalpi & $\begin{array}{l}\text { - "Que tengas la } \\
\text { proyección de } \\
\text { cultura" }\end{array}$ \\
\hline & - "Dios te bendiga” \\
\hline
\end{tabular}

Otro ejemplo de destacar es la visita que realizó el Coro Toba Ch'elalapi, del Barrio Toba de Resistencia, al barrio de La Plata en el contexto de un evento académico organizado por la Facultad de Arquitectura de la UNLP. El coro, cuyas canciones son interpretadas en su mayoría en lengua toba, presentó su repertorio en el Auditorio del Bosque de la ciudad. Un grupo de niños, jóvenes y adultos del Barrio Toba "Las Malvinas" asistió al concierto. Al día siguiente, el coro fue al barrio y volvió a actuar esta vez en el galpón. Bajo estas circunstancias, el evento fue mucho más íntimo y participó principalmente la gente toba del barrio. Las canciones interpretadas fueron en lengua qom l'aqtaqa, y lo interesante fue que luego de cada interpretación, hubo actos de habla entre los miembros del coro y su auditorio sólo en esta lengua. Fue un momento en el que la lengua vernácula fluyó todo el tiempo, en medio de risas, aplausos y silbidos (por parte de los chicos), distensión entre los participantes y mucha alegría. Aun entre los niños, que no se perdieron ningún canto y acompañaron las canciones con sus palmas. Acto seguido, los principales líderes del Barrio Toba "Las Malvinas", visitantes presentes del Chaco y representantes del coro se reunieron en la oficina de la asociación civil con el fin de intercambiar las experiencias vividas en relación a la obtención de títulos de las tierras y la necesidad de que los proyectos a realizarse estén dirigidos por los propios tobas. En esta oportunidad, ego -adulto, presidente de la asociación civil, miembro del grupo lingüístico 
B- que "desde que migró a Buenos Aires nunca más había podido expresarse en toba" según sus propias palabras-, inició la reunión sólo en esta lengua. En esta ocasión, marcó muy bien los roles y actitudes del "nam qom" (el pueblo toba) y el "docshepi" (los hombres blancos). ${ }^{133}$ La reunión duró aproximadamente 45 minutos. El discurso de ego fue sólo en lengua toba, alternando con el castellano en algunos momentos, en especial hacia el final de la reunión, cuando llegaron y se adhirieron a la misma estudiantes de arquitectura. No obstante, aunque en castellano, ego siguió empleando léxico toba en su discurso. Podemos interpretar que el tema principal fue dejar muy en claro que, de acuerdo con la experiencia, todos los proyectos a elaborarse de aquí en más deben estar en manos de los propios indígenas; que los políticos y los “docshepi" ayudan, pero son más promesas que hechos y que, por eso, "el indio debe ser protagonista de sus propios hechos". Esto posibilitó también el uso de la lengua materna; es decir, el uso de la propia lengua dio aún más peso y valor a la reunión y lo discutido en la misma, como un ejemplo a seguir.

Se hace necesario destacar que, además, registramos casos de cambio de código entre los hablantes pertenecientes a los grupos E, G y D, quienes en muchas situaciones comunicativas utilizan alguna palabra o frase en toba con un alto contenido de significación social, tales como "malas palabras", chistes. Aspectos que sólo tienen mayor comprensión y cercanía en lengua toba.

\section{IV.4. Las Redes de Relación Social y Los Usos de la Lengua a lo LaRgo de la MigRACIÓn}

Poder comprender la dinámica lingüística en el Barrio Toba "Las Malvinas", implicó entender el proceso vivido a lo largo de la migración y los usos que la lengua materna había tenido en el lugar de origen, como así también en cada uno de los espacios ocupados en el trayecto hasta llegar a la ciudad de La Plata. Para ello, a partir del análisis de la red de relaciones de (JR) (A en nuestro ejemplo), partiendo desde su salida del Chaco (ver Gráfico $\mathrm{N}^{\circ} 3$ del Capítulo III) junto con la reconstrucción de otras historias de vida registradas en el barrio, pudimos determinar las actitudes que los hablantes tobas han tenido hacia la lengua de origen durante el trayecto de su migración -tomando principalmente en consideración la frecuencia de su uso en cada una de las instancias o etapas distinguidas-. Asimismo, partimos de la premisa de que "los cambios en el uso del

\footnotetext{
133 Apareciendo también la mezcla de códigos (code mixing) en su discurso (Blom and Gumperz 1972; Scotton and Ury 1977; Poplack 1980), situación que es muy común entre los tobas de hoy.
} 
lenguaje se relacionan con procesos sociales y culturales" (Fairclough 1992). La elaboración del Gráfico $\mathrm{N}^{\circ} 4$-también en el Capítulo III- permitió observar las múltiples formas en que los integrantes del barrio se fueron interconectando entre sí, diferenciando también sus roles sociales y lingüísticos. La sistematización de estos roles determinó la importancia de la lengua materna en los diferentes dominios de uso y su función.

De esta forma $-\mathrm{y}$ siguiendo el Gráfico $\mathrm{N}^{\circ} 3$ del Capítulo III- observamos que en la Instancia I la lengua qom l'aqtaqa tenía en la región del Chaco un uso frecuente y predominante en la mayoría de los dominios $-\mathrm{y}$, especialmente, en la zona rural-. El aprendizaje del castellano se realizó más por una situación de necesidad: el conseguir y mantener un trabajo remunerado. Sin embargo, el conocimiento adquirido de esta lengua fue limitado, puesto que no hubo un aprendizaje formal y sistemático. En algunos casos, el primer paso de la migración fue hacia las ciudades cercanas a la zona de residencia: Castelli, Roque Sáenz Peña, Resistencia (ver Figura No 3); en otros, se migró directamente a la Capital Federal. Cuando se llega al Gran Buenos Aires -Instancias II y III- se incorpora el castellano con mayor fluidez; sin embargo, la lengua materna fue un factor de unión con algunos de los parientes que, más tarde, también migraron y con otros "paisanos" que estaban dispersos por distintas localidades del Gran Buenos Aires. Aquí, el uso del castellano fue necesario no sólo para trabajar, sino también para la organización. Ésta se inició con representantes indígenas de distintas etnias; por lo tanto, el castellano actuó como lengua franca. En la Instancia III, la organización los llevó a vincularse con diferentes agentes sociales del "mundo de los blancos": abogados, autoridades gubernamentales y no gubernamentales, eclesiásticos. De forma tal que la lengua materna se restringió a los dominios doméstico y de parentesco y vecindad. Durante la Instancia IV, la organización se vuelve particularmente hacia el pueblo Toba. En este caso, la lengua de origen habría tenido mayor protagonismo, convirtiéndose en la lengua utilizada para la organización y cohesión del grupo. Sin embargo, el uso del castellano tuvo igual importancia ya que el mismo fue necesario para comunicarse con los distintos sectores de la sociedad nacional con los que se necesitó vincularse para la organización y concreción de proyectos colectivos.

Desde los inicios del Plan de Autoconstrucción (Instancia V), la lengua de origen es empleada habitualmente, aunque -como hemos visto- en determinados dominios de uso: doméstico y de parentesco, vecinal, religioso, organizativo, laboral-barrial. En la misma, distinguimos tres etapas que se corresponden con aquellas del proyecto de construcción de 
las viviendas. Durante la primera, la construcción de las primeras ocho viviendas, el uso del castellano se destacó, puesto que fue la lengua que ayudó a realizar los trámites y los contactos con el ministerio y la secretaría de la vivienda; a la elaboración de los planos y a la asesoría con el arquitecto y el maestro mayor de obras; a la compra de los materiales; también se recibieron algunos cursos cortos sobre construcción e instalación de la electricidad, entre otros. No obstante, el uso de la lengua toba fue significativo entre las actividades cotidianas del grupo y ayudó en la cohesión del mismo. ${ }^{134} \mathrm{Al}$ entrar en la segunda etapa, la construcción de las 28 viviendas restantes, llegaron nuevas familias y la lengua qom l'aqtaqa fluyó con mayor frecuencia en los dominios de uso doméstico y de parentesco, vecindad, religioso. Algunas de estas familias habían llegado directa o recientemente del Chaco y traían consigo una mayor vitalidad de la lengua. Al concluir las viviendas y cumplir con el sueño de la casa propia, se dieron las condiciones para que la lengua vernácula se continuara recreando al tiempo que el castellano constituyó la lengua franca utilizada con el "afuera" y para las actividades laborales. Las condiciones que han permitido la recreación de la lengua toba son: la convivencia cercana; el trabajo colectivo y comunitario; las visitas provenientes del Chaco y de otras localidades donde también habita gente toba; los encuentros e intercambios que generan las campañas evangélicas como así también los festejos de los aniversarios de la Iglesia Unida Templo de Fe; el reconocimiento de ser "gente indígena viviendo en La Plata" por parte de vecinos, escuelas, profesionales, funcionarios; la identificación de esta experiencia como "un ejemplo a seguir" para otros grupos indígenas. Es decir, esta experiencia de autoconstrucción -en vista de su desarrollo como un proceso de "construcción social del espacio y de la identidad"- habría permitido crear un ámbito favorable para que la lengua materna se actualice y recree. Y esta actualización y revitalización han dependido, especialmente, de una articulación positiva del grupo con el entorno -en el sentido de ausencia de discriminación, negación, subestimación-, de una actitud abierta, de reconocimiento y de apoyo hacia el grupo y de la posibilidad de expresar libremente la propia identidad. Cabe aclarar que tal reconocimiento ha ido acompañado de un contexto mayor de interés y preocupación por la cuestión indígena, tanto en los niveles nacional como internacional. No obstante, esta articulación positiva que destacamos con el entorno se ha dado especialmente en el aspecto colectivo, cuando se toma al Barrio Toba como un

\footnotetext{
${ }^{134}$ Muestra de ello fue el discurso hecho en toba durante la ceremonia de inauguración de las primeras ocho viviendas y la entrega de llaves.
} 
todo, y donde se reconoce la identidad étnica; en cambio, no sucede lo mismo cuando se coloca la mirada en los individuos. En estos casos han aparecido algunas situaciones de discriminación tanto en el ámbito escolar como en el laboral y hasta vecinal. Aspectos que serán analizados más tarde.

Asimismo, cabe señalar que esta descripción que hemos hecho de los usos de la lengua en el camino de la migración representa más cercanamente al caso de los hombres puesto que han sido éstos los que han tenido mayor contacto con la "sociedad blanca" a través del trabajo remunerado y la organización. Las mujeres, al quedar en el barrio al cuidado de los hijos y de los quehaceres cotidianos, se vieron menos expuestas a la imposición del castellano. Muy pocas mujeres han trabajado fuera de sus hogares y las que lo han hecho, han realizado sólo trabajos domésticos. Es en esta situación que aprendieron el castellano y éste se comenzó a utilizar con mayor frecuencia a partir de la migración.

No obstante, es importante indicar que desde que se conformó el Barrio Toba "Las Malvinas", el rol de la mujer ha sido protagónico y esencial para el mantenimiento de lo comunitario, asumiendo un sinnúmero de tareas cuando los hombres debían procurar changas para lograr el sustento de los que quedaban en casa. Las mujeres han participado en la construcción de las viviendas y se han hecho cargo de los emprendimientos proyectados a través de los planes sociales. Trabajos todos estos realizados en el propio barrio, lo cual ha favorecido la presencia y el uso de la lengua toba durante estas tareas, tales como la huerta, el comedor comunitario, el taller de costura y otras. Sin embargo, debemos distinguir dos tipos de grupos de mujeres. El primero, conformado por mujeres líderes que se han hecho cargo de la conducción de los programas y que son las que salen del barrio para realizar los trámites pertinentes con la Municipalidad de La Plata y otras dependencias o instituciones. Este grupo posee un manejo fluido del castellano, aunque está integrado por representantes de los grupos E, F y K. También son las encargadas de recibir las visitas de los "docshepi" que se presentan frecuentemente en el barrio (periodistas, estudiantes, asistentes sociales, funcionarios, etc.). En tanto que el segundo grupo de mujeres sólo realizan las tareas que les corresponde según el plan vigente; están presentes en algunas de las reuniones que se realizan cuando llegan los "docshepi" al barrio, pero permanecen más calladas y tímidas; utilizan un español menos fluido y acompañan con la lengua qom l'aqtaqa la mayoría de sus actividades (representantes de los grupos A, B, C, D).

\section{IV.5. RECURSOS VERBALES Y ESTRATEGIAS COMUNICATIVAS Y METACOMUNICATIVAS}


Como hemos señalado en el Capítulo II, partimos de la consideración del discurso como el locus de la expresión concreta y actual de la relación entre lengua, cultura y sociedad: "el discurso crea, recrea, focaliza, modifica y transmite tanto la cultura como la lengua y su intersección" (Sherzer 1987:296). En el mismo marco, el discurso es, a la vez, un modo de acción y una forma de representación; una manera por la cual la gente puede actuar sobre el mundo y sobre sí misma. Al tiempo, mantiene una relación dialéctica con la estructura social. Es decir, por un lado, el discurso es moldeado por la estructura social -la constitución de los discursos varía según las características del evento en el que se generen, en concordancia con el dominio social o institucional-; y, por otro, se construye socialmente. ${ }^{135}$ Además, tanto el uso frecuente de categorías gramaticales como los recursos de la prosodia permiten al hablante, consciente o inconscientemente, expresar distintos significados, actualizándolos en el discurso. Los rasgos prosódicos tales como entonación, volumen, tiempo, acento, pausa, cualidad de la voz, alargamiento o acortamiento de la voz constituyen unidades relacionadas a la conciencia; cada unidad de entonación estaría expresando una idea. ${ }^{136}$ La detección de estos aspectos en los discursos nos posibilita el descubrimiento de las estrategias utilizadas por los hablantes para expresar sus intenciones, deseos y su propia identidad, al tiempo que la construyen.

Con el propósito de entender los modos en que los miembros de la comunidad toba del Barrio "Las Malvinas" construyen su identidad y aproximarnos a las estrategias comunicativas y metacomunicativas que utilizan consciente e inconscientemente para construirla, es que se procedió a la recolección de discursos en sus contextos naturales de uso. Entendemos por contexto tanto la escena social y cultural, las reglas de uso del lenguaje; como lo inmediato, lo emergente y lo que se actualiza en el evento de habla. ${ }^{137}$

Presentamos a continuación algunos discursos obtenidos en diferentes situaciones comunicativas registradas tanto en el Barrio Toba "Las Malvinas", como fuera del mismo. En cada caso, destacamos las características contextuales en que los mismos se desarrollaron y las condiciones en que fueron registradas; se describen los participantes, el escenario, y se ofrece el análisis correspondiente.

\section{- Discursos privados obtenidos en situación de entrevista}

\footnotetext{
135 Ver Fairclough (1992).

${ }^{136}$ Ver Chafe (1994).

${ }^{137}$ Ver Sherzer (1987, 1989).
} 
En esta sección abordamos dos fragmentos de dos entrevistas obtenidas en el Barrio Toba "Las Malvinas", aunque en distintas circunstancias. La primera, corresponde a una situación interétnica entre dos investigadoras del Laboratorio de Investigaciones en Antropología Social (LIAS) de la UNLP y una mujer adulta, identificada con el grupo de hablantes D. La segunda, de manera inversa, una investigadora del LIAS y dos mujeres tobas - una identificada con el grupo de hablantes A y la otra con el grupo F-. En este último caso, también se da una relación intraétnica entre las dos interlocutoras y, a su vez, interviene el factor generacional.

\section{- Entrevista a (JF), hablante del grupo D}

\section{Participantes y escenario:}

La entrevista fue llevada a cabo por dos integrantes del equipo de investigación -(I1) y (I2) - a una mujer toba (JF) identificada con el grupo de hablantes D, que había migrado del Chaco - de la zona de Pampa del Indio- hacía aproximadamente siete años (según el momento en que se realizó la entrevista) y que había aprendido el castellano siendo adolescente ante la necesidad de trabajar en el ámbito doméstico. Por lo tanto, se trataba de una mujer con poca competencia lingüística en español. Al llegar a su vivienda, (JF) se encontraba con "visitas", reunidas afuera de su casa, mientras que sus, por entonces, cinco hijos correteaban y jugaban en las cercanías junto a otros niños tobas del barrio. Cuando nos acercamos, se produjo un cambio de código: estaban hablando en la lengua y se dirigieron a nosotras en castellano, irrumpiendo con algunas risas. Al cabo de unos minutos, las visitas se fueron, dejando a (JF) sola para la entrevista. Ésta se realizó afuera de la vivienda, sentadas en el pasto; con su bebé en brazos y sus otros hijos jugando alrededor nuestro. Tuvo una duración aproximada de 45 minutos de grabación.

Nuestra entrevista guardaba dos propósitos. Por un lado, teníamos la intención de indagar en los temas relacionados con la socialización en el Chaco, las pautas de crianza y la lengua toba. Por otro, observar y registrar el uso del lenguaje en su contexto natural. Si bien (JF) no nos esperaba, nos conocía de visitas previas y sabía, por otras oportunidades, que queríamos conversar con ella con más tiempo y disposición.

A lo largo de toda la interacción verbal se desarrollaron distintos eventos de habla distinguiéndose: 
$>$ La entrevista en sí, con participaciones de tipo pregunta-respuesta entre (JF) y las entrevistadoras -donde la comunicación entre estas últimas fue de manera extralingüística (gestos y miradas).

$>$ Entrevista con participaciones de tipo pregunta-respuesta entre los niños y las entrevistadoras.

Diálogos cortos y relación lúdica entre los niños y entre éstos y las entrevistadoras.

$>$ Relación madre/ hijos donde se dieron distintos actos de habla: reto, orden, preguntas; y comunicación extralingüística a través de miradas, risas, gestos.

\section{Fragmento de la entrevista: ${ }^{138}$}

1. I1: ¿¿Qué nos podés contar de cuando eras chica?/

2. JF : /cuando era . chica../ eh../

3. I2: /de cuando eras chica,/ allá en el Chaco,/ ¿qué hacían,/ trabajaban?/

4. JF: /y../ la ayudaba a mi mamá, a mi tía.../

5. I1:/¿Tenés más hermanos?/

6. JF : /¿eh?../ sí, tengo/

7. I1: /Más grandes o más chicos que vos?/

8. JF : ¡¡No!,/ son grandes ya,/ tienen chicos ya,../ y .../ \{no, /después cuando vivía en el $\underline{\text { Chaco }}$ yo vivía con mi mamá,/ y ../ yo la ayudaba,/ y../ ellos siembran zapallos, batata, mandioca, todo eso,/ después lo otro..(NO SE ENTIENDE), y comíamo' todo eso..( NO SE ENTIENDE)/ y../ después cuando lavábamo' la ropa,/ lavábamo’ la ropa pero en una zanja,/ viste,/ en un charco../

9. I1: ¿y vivían en Pampa del Indio con vecinos,/ gente que estaba cercana/ o tenían un campo grande?/

10. JF : /sí,/ ellos tienen../ tienen chacra así.../ y.../ están lejos lo' vecinos, / no tan cerquita así como ahora, / son lejo' por acá, por allá están / así/

11. I2: /y del pueblo ¿vivían cerca?/

12. JF : ¡„No! Lejo’./ Casi una legua (NO SE ENTIENDE)

13. I1: /ahora vos/ ¿desde chiquita hablaste en la lengua, te enseñaron la lengua? /

14. JF : /sí, sí/ ahora que.. soy grande/ \{recién aprendí el castellano $\} /$ porque yo . entré . a

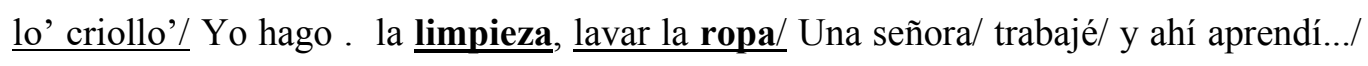

\footnotetext{
${ }^{138}$ Ver en Referencias de Trascripción al inicio del documento en la página .
} 
y cuando . yo . veo a lo' criollo/ cuando vienen/ yo . tengo miedo/ por . que . yo no hablo casi [SE RÍE]

15. I1: /¿pero miedo por qué?/

16. JF : /y sí,/ porque no sé hablar,/ no entiendo/ pero./

17. I1: /y cuando vos empezaste a trabajar con esta señora?

[LOS CHICOS SE ACERCAN Y SE TIRAN ENCIMA NUESTRO]

18. JF :/ah!,/ sí/ ¡No Loncho,/ que’ate quieto!/

19. I1: /no hablabas nada de castellano, empezaste a hablar.../

20. JF : /eh. Sí, nada/ [EL BEBÉ EMPIEZA A LLORAR] /NNo Pelo!/ Quiere dormir este chic'. ¡idormí! [DESPACITO LE HABLA EN LA LENGUA]

$[\ldots]$

\section{EI análisis:}

Se trata de un género discursivo particular: la entrevista. Sin embargo, la misma se realiza en el marco de una situación comunicativa usual entre la gente toba que es "la visita" ( a a advidaGaq). Como ya hemos mencionado en el Capítulo III, las visitas son muy frecuentes y significativas; se dan entre ellos mismos, de casa en casa, o bien recibiendo gente que viene de afuera -tanto tobas que viven en el Gran Buenos Aires como en el resto del país, como, así también, de no tobas-. Es común encontrar a la gente reunida, en la puerta de sus viviendas, conversando y tomando mate por las tardes, cuando, en general, ya han acabado las tareas domésticas o llegan los hombres de trabajar. Es en este contexto donde se suman las visitas. Este hecho es una característica que también la hemos observado en el Chaco; es manifestado por la gente en sus relatos; y lo consideramos significativo, puesto que constituye un espacio importante de socialización. Durante la situación de visita se comenta lo acontecido en el día, se cuentan cosas, se dan consejos, al tiempo que mantiene la cohesión del grupo.

Volviendo a nuestro ejemplo, podemos decir que nuestra entrevista tuvo características fuera de lo común que le hicieron perder toda cuota de formalidad que podría llegar a tener. Además, los hechos y acciones acontecidos minimizaron el poder que nosotras, como investigadoras, podríamos manejar. Por empezar, se desarrolló fuera de la casa, y sentadas en el pasto; esta modalidad le dio más informalidad a la situación comunicativa, al tiempo que también produjo un efecto de curiosidad en especial en los chicos -partícipes activos del evento. 
En la línea (1.), la entrevistadora (I1) introduce el primer tópico: la niñez en el Chaco. Se puede observar en (2.) que, ante la pregunta, la entrevistada repite la última parte información dada-, pero de un modo pausado, y enfatizando el sustantivo "chica". Esto puede interpretarse como que (JF) se toma un tiempo para pensar en una respuesta sobre esta información, o bien que, por su poca competencia lingüística en español, necesita realizar el ejercicio de "traducir" lo dicho y lo que va a decir.

A continuación, en (3.), la entrevistadora (I2) especifica el tópico (la niñez en el Chaco) y lo amplía pasando los verbos a tercera persona del plural: “¿qué hacían/ trabajaban?”. Ya no se está preguntando sobre la vida de la entrevistada en el Chaco sino también de la gente que vivía allá, al tiempo que se condiciona la pregunta. Este recurso empleado por (I2) da a entender que, en ese momento, el hecho de que (JF) haya demorado en contestar fue interpretado como que ésta no había comprendido la pregunta y se opta por ampliarla como estrategia comunicativa.

Ante la introducción en (3.) del subtópico: 'lo que se hacía', 'el trabajo', (JF) en (4.) utiliza como recurso lingüístico el conector " $y$ ” con una pausa larga y responde usando el verbo ayudar como sinónimo de trabajar; sin embargo, no cambia la persona y el número, sino que contesta en primera persona. Este hecho, nos permite suponer que: a) (JF) sí entendió la primera pregunta planteada al principio, y b) el uso del silencio en su discurso es significativo.

El silencio en la interacción comunicativa con los miembros de la comunidad se define como una estrategia discursiva. La misma ha sido observada en otras oportunidades, especialmente entre las mujeres mayores del barrio; pero también constituye un recurso discursivo que se da en todo el grupo en general. En este caso, el silencio adquiere un valor metapragmático. Indexa el discurso señalando la brecha que existe entre entrevistada y entrevistadoras respecto de la concepción de tiempo y el manejo de tiempos diferentes en la comunicación.

Asimismo, es importante destacar el significado que tiene para (JF) el lexema 'trabajo', en el contexto de su infancia en el Chaco: -“(yo cuando era chica) /la ayudaba a mi mamá, a mi tía/"-, es decir, su trabajo consistía en ayudar en las tareas de sus mayores de su mismo sexo (mamá, tía, abuela): característica de la socialización de las niñas en ese contexto. Cabe destacar que, además de cambiar la velocidad del discurso en (4.), acentúa con mayor énfasis los lexemas mamá y tía -agentes significativos de la socialización-. Por otra parte, la utilización del 'la' como objeto directo y del pronombre posesivo 'mi', 
refuerza la función destacada que tuvieron estos agentes socializadores en su vida. Es frecuente en las entrevistas que las mujeres resalten este hecho. Entre las mujeres jóvenes son comunes las expresiones: "-yo no tengo aquí a mi mamá para que me aconseje o que me enseñe cómo criar a mi hijo-"; en tanto que las mujeres de más edad siempre introducen el tópico de la mamá, la tía o la abuela que les aconsejaba o les enseñaba "cómo hacer las tareas".

Siguiendo con el análisis de la entrevista, se observa que la segunda pausa más larga, introducida por (JF) en (4.) vuelve a ser interpretada por la investigadora, en ese momento, como manifestación de posibles dificultades de la entrevistada para continuar hablando y se introduce en (5.) un nuevo tópico: 'los hermanos' acompañado de un cambio del tiempo verbal, ya que se refiere a un acercamiento hacia el presente. Esto actúa como una interrupción en la cohesión del discurso y un obstáculo para la comprensión, hecho que se manifiesta en la interjección: ‘¿eh?’ que expresa (JF) junto con la pausa larga introducida y la contestación rápida. Al insistir en (5.) sobre el tópico de los hermanos, vemos que (JF) vuelve a acelerar la velocidad del discurso y, al mismo tiempo, toma posesión del turno en la conversación. Así, analizando (8.) (JF) comienza su discurso con un acto de habla que es una exclamación y, al mismo tiempo una negación. Se refiere a los hermanos en tiempo presente y desdobla la información nueva -la situación generacional de sus hermanos con respecto a ella- en dos unidades de entonación que brindan dos nuevas informaciones: los hermanos no son ni más grandes ni más chicos que ella, son grandes (adultos) y tienen chicos (hijos). Esto nos permite plantear tres hipótesis: a) La poca competencia de (JF) en español no le permitió entender la pregunta; b) la introducción de un nuevo tópico y el manejo distinto de la velocidad en el discurso entre entrevistadora/ entrevistado actuó como una interferencia en la comunicación y no permitió que (JF) tomara su tiempo para pensar en una respuesta; y c) sí entendió la pregunta, pero para ella tiene otro significado: no importa que los hermanos sean mayores o menores que ella, sino que tienen hijos y por eso son adultos. Esta última hipótesis se refuerza en el hecho que (JF) quien, a continuación, introduce un conector con una pausa larga y vuelve al primer tópico planteado al principio de la entrevista: la vida en el Chaco. En este caso, cabe destacar que (JF) retoma una información dada pero baja el volumen de la voz, como acomodando su pensamiento y, quizás, buscando las palabras en español. Parte de ella y amplía la información: “/yo vivía con mi mamá/ y .. /yo la ayudaba/ y..”. Esto lo hace en primera persona, en un tiempo pasado y en un pretérito imperfecto que refuerza la idea de duración. A su vez, divide las unidades de entonación con un conectivo y una pausa larga. De pronto, 
cambia el número y persona y el tiempo verbal: "/ellos siembran zapallos, batata, mandioca, todo eso,/ después lo otro..( )," y vuelve a cambiar la persona y el número y el tiempo verbal: “/y comíamo’ todo eso..( )/ y.. /después cuando lavábamo' la ropa, lavábamo' la ropa pero en una zanja, / viste,/ en un charco...". Es decir, pasa de un 'yo' a un 'ellos' para terminar en un 'nosotros'; de un pretérito imperfecto que da la idea de duración a un presente que asegura, atestigua y, nuevamente, se vuelve al pretérito imperfecto.

Estos desplazamientos -en términos de Chafe (1994)- son interesantes de analizar. Pueden ser interpretados como que:

a) se habla de un hecho en el pasado, pero este hecho también se da en la actualidad: la familia que quedó en el Chaco sigue viviendo en el campo, siembra esos alimentos que son los mismos que comía ella cuando era niña;

b) esto mismo pudo haber sido dicho utilizando el verbo en pasado, lo que nos permite suponer que la razón haya sido la poca competencia lingüística en español.

Sin embargo, el uso del 'yo', 'ellos' y 'nosotros' resulta significativo. Por una parte, este último puede ser interpretado como un nosotros inclusivo para el primer caso “comíamos”- puede incluir a un 'yo' (mujer) y 'ellos' (varones y mujeres), en tanto que, en el segundo -“lavábamos”- sería un nosotros exclusivo 'yo' (mujer) y ella/s (mujeres) quienes tenían la tarea de lavar la ropa. Por otra parte, (JF) introduce una nueva información sobre 'ellos', sus hermanos, tópico que la entrevistadora había presentado en presente. Éste estaría actuando como un índice metapragmático que configura una identidad. Podría tratarse, entonces, de una estrategia discursiva de convergencia de (JF) con el propósito de cumplir con las expectativas de las entrevistadoras.

Es notable también diferenciar que, cuando (JF) se refiere al Chaco, la velocidad del discurso es más lenta al tiempo que baja el volumen de la voz; mientras que, cuando habla de la actualidad, aumenta el volumen de la voz y acelera la velocidad del discurso. Sin embargo, cabe destacar que hay una diferencia notoria en la velocidad del discurso cuando éste se realiza en la lengua materna con respecto al español. Estos aspectos constituyen una característica de todo el grupo.

Al respecto, otro hecho importante de destacar, analizando (8.), son los momentos en que el volumen de la voz baja a tal punto que no se entiende lo que se dice. Se invierte la corriente de aire egresiva normal en el habla por una corriente de aire ingresiva. Este es un hecho que no es sólo característico de (JF), sino que ha sido observado en todas las 
mujeres tobas del barrio y también de otras localidades, tanto mayores como jóvenes. Además, seguido por un conectivo y una pausa larga, vuelve nuevamente al sub-tópico del trabajo, agrega información y realiza una comparación marcada por otro conectivo: 'pero'. Asimismo, vemos en (8.) que introduce el marcador fático 'viste'. El uso del viste puede ser interpretado como un recurso a la vez metacultural (Briones y Golluscio 1994) y metacomunicativo (Bateson 1972). Por un lado, se trata de una marca de reflexividad sobre las actividades culturales propias del Chaco, del campo, y que son distintas de las de La Plata, la ciudad: 'allá se lavaba en el río, en un charco'; 'aquí es distinto, y tuve que aprender'. Por otro lado, desplaza el discurso hacia el acto comunicativo mismo, involucrando, comprometiendo al oyente.

En (10.) vuelven a aparecer afirmaciones con fuerte significado metacultural, donde se compara cómo se vive en el Chaco y cómo viven ahora en La Plata. Esto está marcado por el contraste en la velocidad del habla y el uso de dos adverbios que manifiestan oposición y diferencia: disminución en la velocidad del habla y énfasis en el adverbio "lejos", cuando se refiere al Chaco; y un aumento en la velocidad del habla y énfasis en el adverbio "cerca", cuando se refiere al lugar donde vive ahora.

En (13.) una de las entrevistadoras introduce un nuevo tópico: la lengua toba, su aprendizaje. (JF) contesta con una doble afirmación, lo que da la idea de que es algo significativo para ella 'hablar la lengua', y, sola, desplaza la información hacia el subtópico del aprendizaje del español, su trabajo entre los criollos de 'hacer la limpieza, lavar la ropa'. En este sentido, se evidencia una intencionalidad por parte de (JF) de dejar claro que 'aprender el español' - la lengua del criollo- fue una obligación ante la necesidad de tener que trabajar para el criollo. Al mismo tiempo, es también su intención manifestar que este aprendizaje ha sido reciente: "ahora que... soy grande, \{recién aprendí el castellano\}"; sin embargo, si bien enfatiza el lexema "grande", a continuación, cambia el volumen de la voz. En este caso, interpretamos este cambio como una expresión de "vergüenza". Esta idea se ve, a continuación, reforzada al manifestar tener, en el presente, un sentimiento de miedo cuando ve llegar a los criollos, dado que no habla bien el castellano. Al mismo tiempo, hay un fenómeno extralingüístico: la risa. Una risa que se nos aparece como nerviosa o vergonzosa, pero que es, a su vez, picaresca puesto que relativiza lo dicho y compromete al oyente llevándolo a preguntar la razón de su miedo. Así, con esta estrategia, refuerza la idea de "no saber hablar el español”, "no entender la lengua del criollo", puesto que su lengua materna es otra y es aquella en la cual le habla a su bebé, en 
la intimidad, para que se duerma (20.). Es decir, en el medio del barullo, del griterío de los chicos, -según nuestra interpretación-, y de las hostigadoras preguntas de sus visitantes (las investigadoras), (JF) toma el dominio de la interacción a través del cambio de código y de su interrelación con su bebé, y deja a los demás afuera de la misma.

Dado el contexto general en el que se desarrolló la entrevista, una primera interpretación de esa situación nos dejó la sensación que los objetivos y expectativas planteados previamente no se habían cumplido, siendo pocos los resultados obtenidos: por momentos, el diálogo parecía confuso; intentamos superar los silencios con preguntas; sentíamos que los chicos interrumpían y la información obtenida pareció escasa. Sin embargo, la aplicación del análisis del discurso, el tener en cuenta los modelos de análisis aquí utilizados y la aplicación de éstos a la totalidad del contexto en el que la entrevista se enmarcó nos permiten una segunda lectura y acceder a una información mucho más rica. Esta perspectiva de análisis nos ofrece elementos para interpretar los modos en que nuestra interlocutora se posiciona (Goffman 1979) estratégicamente, expresando y construyendo su propia identidad a través del discurso. Una identidad que se construye a partir de la experiencia individual, pero de un individuo que pertenece a un grupo determinado y que comparte con éste un horizonte histórico y social (Voloshinov 1992) en común.

El énfasis puesto en las estrategias discursivas utilizadas a lo largo de este discurso permite observar, en primer lugar, cómo el discurso va construyendo la identidad social y, por lo tanto, la posición del sujeto. ${ }^{139}$ Precisamente, (JF) se presentó como madre, hija, hermana, trabajadora doméstica, en una actitud reflexiva de dos mundos: "el de los criollos" y "el de los tobas". En segundo lugar, el discurso construye las relaciones sociales entre la gente. ${ }^{140} \mathrm{~A}$ lo largo de la entrevista, (JF) -que habla poco español, que tiene miedo de hablar en esta lengua- se convirtió en quien guió el evento de habla volviendo siempre al tópico inicial, sin que la presencia de los niños se convirtiera en una interferencia, sino que en cierto sentido le daba "poder": ella podía hablar tranquilamente, de algo que le era significativo y cumplir su rol de madre y entrevistada.

\footnotetext{
139 Función de identidad del lenguaje que se relaciona con los modos en que las identidades sociales se establecen en el discurso (Fairclough 1992: 64).

${ }^{140}$ Función relacional del lenguaje que implica cómo se disponen y se negocian las relaciones sociales entre los discursos de los participantes (Fairclough 1992:64).
} 
Coincidimos entonces con Fairclough (1992) en que el discurso contribuye a la construcción de los sistemas de creencias y conocimiento, ${ }^{141}$ al tiempo que los reproduce y recrea. ${ }^{142}$ El hecho de que, ante la pregunta por sus hermanos, (JF) haya contestado: "son grandes ya, tienen chicos ya,..”, con tan pocas palabras, está diciendo mucho: en ello está implícita una cierta concepción de la vida y del ciclo vital donde el hecho de tener hijos implica tener un grado de madurez y es considerado significativo en el contexto sociocultural del grupo, y que es diferente a otros. Veamos otros casos.

\section{- Entrevista a (DC) y (JG) representantes del grupo A y F}

\section{Participantes y escenario:}

La entrevista fue realizada a dos mujeres tobas del barrio "Las Malvinas" de la ciudad de La Plata identificadas una con el grupo de hablantes A y la otra con el F. A continuación, se presenta un fragmento de la entrevista que tuvo una duración de una hora y media.

En el momento de ejecutada la interacción verbal, (DC) poseía unos 70 años de edad y había llegado del Chaco hacía más de 25 años; (JG) de unos 25 años de edad, había migrado del Chaco tan sólo 5 años. Es decir, se trató de una entrevista hecha a dos mujeres que representaban dos generaciones diferentes. En esa oportunidad, (JG) se encontraba de visita en la casa de (DC). Ambas son vecinas y las une una relación de parentesco por afinidad. Asimismo, (DC) es considerada por todo el barrio como "la abuela" por su edad, experiencia y sabiduría.

Cabe destacar que la entrevista no tuvo la característica tradicional de preguntasrespuestas, sino más bien la misma se inició como una conversación con las entrevistadas donde hubo instancias de narración, diálogos y complementación entre las mismas tanto en español como en toba y español. El tópico que dio inicio a la entrevista fue la lengua toba: los usos y el significado de algunas palabras, las formas del saludo, los términos de parentesco, el sistema de numeración, entre otros aspectos.

\section{Fragmento de la entrevista:}

\footnotetext{
141 Función ideacional del lenguaje que implica los modos en que los textos significan el mundo, sus procesos, entidades y relaciones (Fairclough 1992:64).

${ }^{142}$ Función textual que se refiere a los modos en que los bits de información se ubican en primer o segundo plano, se toman como algo dado o se presentan como algo nuevo, aparecen como temas o tópicos, y cómo una parte del texto se fusiona para preceder o continuar las otras partes (Fairclough 1992:64).
} 
1. I: ... /y números?/

2. JG: /números,/ no tenían números.../ Nunca se.../ ¿a ver?/ dosolká’ era poco../

3. DC: ono'olec/, dosolká'../, cómo si diría.../

4. JG: /deriva de la raíz castellana./

5. DC: /sí/

6. JG: /ono'olec viene de uno./ Uno,/ ono'olec es uno.../ dosolká,' dos,.../ y/ por ahí.../ cuando era.. poco número/ decían sala'a mé.../ no hay una escala de números definida.../ Y/ si eran muucho: la'apa'/

7. DC: mm...,/qalo'otá'/

8. JG: /qalo'otá'/. IQalo'ota' so qom/ era mucha la gente... /So'oche qom qomla'a/ la gente antigua.. Iten qa'alota' dicen que era mucha... /Añaxaipi../ lataxanaipi../ lepia'axanaipi...,/ eran hombres fuertes../ muchos valientes.../ y que buscaban./ eh./ lepiaraipi/ son los que iban al monte a cazar../ mariscadores eran./

9. DC : /epiaxaipi/mariscar /

10. JG: ..(SONRISAS MUY SUAVES)...

11. I: / ¿y las mujeres?/ (SONRISAS SUAVES)

12. JG: /alopi../ /alolenataq/ ahí es su trabajo/

13. DC: (HABLA EN TOBA, NO SE ENTIENDE) /...En tiempo de algarroba./ todas las mujeres. traen./ se van al monte./ traen lo que.../

14. JG: /también, eran como mariscadoras de...

15. DC: /también /

16. JG: /de las frutas de la algarroba/

17. DC: todas/ cuestión de eso /alpi/ muchas mujeres se juntan/ y se van a la mañana/ bien temprano/ al monte/ se van a buscar/ y pescan /alpi/

18. JG: /taqaen e pe cheguene tom, taqaen/

19. DC; mm.../ marisca también/

20. JG: /negueton che gue ...../

21. DC: /.../ (CONTESTA EN TOBA)

22. JG: /... cuando iban a mariscar/ dice que../ se iban bien temprano/ y/ se volvían a la tardecita./ siempre en grupo./ nunca de dos o tres/ siempre cuatro o cinco o más/ cuando buscaban esa frutita del bosque callaxanaiguil

23. DC: sí/ todo eso/ hasta eso se van a buscar/ 
24. JG: /cañaipi/

25. DC: /para hacer la yica/ esa/ y toodas las mujeres se van./ juntas./ siempre en grupo./ y van a buscar para sacar el hilo...

26. JG: /la planta del chaguar/

27. DC: /ah./ La planta del chaguar/ ese cardo./ en el monte/ se van muchas/y de ahí ya.../

28. JG: /las mujeres mayores/ jóvenes/

29. DC: /las mujeres mayores./ pero le enseñan a la chicas jóvenes./ para que ella aprende../ porque/ hay muchas mujeres que ya son./ \{vamos a decir que viejas. $\} /$ y dicen que/ porque nosotros no vamos a estar../ llegará el momento que termina nuestra vida/ y se quedan ustedes./ Por eso es que/ ustedes tienen que aprender a hacer las cosas.../ Y así fue.../ Entonces/ todas las chicas se van a juntar cuando se van las mujeres grandes../ así aprenden./ Bueno./ yo aprendí así/ \{cuando estaba./ cuando era joven. $\} /$ estaba mi mamá/ y/ mi abuelita/ viejiiita también./ $\underline{\text { Y no alcancé bien/ ¿viste?/_porque../ cuando }}$ me hice grande/ ya murió mi mamá/ y/ murió mi abuelita../ Ella sabe hacer los telares/ y todo eso./ Nada más que para hilar/ sí. Alcancé/ me enseñó ella./ la abuelita./ para hilar algodón/ o/ eso./ chaguar/ \{“la chaguar”\}/ y/ para sacar la fibra./ eso.../ \{Pero/ lo demás/ "lo que ya sabe"/ ya no alcancé más $\}$./

30. JG: claro/ las enseñanzas se iban pasando de generación en generación/ de forma verbal/ (DC VA ASINTIENDO CON LA CABEZA Y LA MIRADA). No había nada escrito/ todo era práctica/: aprendías/ o/ aprendías./ Ahí.. /Y./ yo me acuerdo/ una vez que estaba en Pampa del Indio me había ido con dos de mis abuelitas/ bah!/ una era mi bisabuela/ vendría a ser./ Sí/ era mi bisabuela/ y/ estaba reviejiita también.../ Y habíamos ido/ también/ para buscar/ pero/ yuyos/ así/ eran para un remedio./ Y ella sabía mucho/ y...

31. DC: / hasta de esos remedios te enseñan../ todo../ los antiguos../ de yuyos../ sino/ de grasas/ así/ de mariscas/ todo eso../ remedios./ Por ejemplo/: la grasa del avestruz../ cuando hay../ icómo es eso que tenemos?../ hay esa sarna../ cuando/ hay esos granos grandes/y/ la gente ese no más es el remedio/

32. I: /con grasa de avestruz/

33. JG: /y/ con eso la gente se cura/

34. DC: /sí./ Y../ ¿cómo es?./ la grasa de yacaré/ que se dice../ con eso también/ y../ cuando hay../ ¿cómo se llama?/ griipe./ así./ Fuerte./ toodos los chicos le ponen acá./ la grasa del avestruz/ o/ del../

35. JG: /así/ en las axilas/ o/ de yacaré/

36. DC; /entonces../ cuando hay peste./ parece/ entonces/ que no les agarra../ Le agarra../ \{"pero.. no muy fuerte"\}./ 
37. JG: /era como una manera de protegerse./ era como para prevenir../ Esas grasas./

38. DC: /Después/ le matan al lagarto/ ¿cómo es que le dicen/ la iguana?/ Eso/ cuando mariscan la gente,/ la hiel esa/ la hiel/ lo sacan la hiel/y/ le llaman los chicos/: -ivengan/ vengan/ vengan!/- Y/ lo revientan/ así/ en los ojitos./ Y/ cuando hay ese mal de vista. no le agarra a los chicos.../ Sí./

39. JG: /¡ah!/ ¡los ojitos!./ Bueno/ ese era otro de los medicamentos que teníamos/ no había hospitales./

40. DC: /sí/ sí/ no había../ por eso/ parece que los antiguos eran fuertes/ nunca conoce los hospitales/ nada./ Así no más se curan./ Sí./ Los chicos./

41. JG: $y$ / hasta inclusive tenían buena vista../ porque./ siendo ancianos/ no necesitaban anteojos../ sin embargo/ ahora los nuevos sí../

$[\ldots]$

\section{El análisis:}

Si bien, en términos de Foucault (1972), la modalidad discursiva en que se contextualiza este texto consiste en una entrevista -que comenzó a través de una interacción de preguntas-respuestas-, la misma se convierte principalmente en relato donde se ausenta el rol del investigador, convirtiéndose sólo en audiencia y/o destinatario de esa narración. Desde el punto de vista del plano de la enunciación, ambas interlocutoras son enunciadoras y sus intervenciones se complementan, sin superponerse: (DC) es quien ejerce cierto poder o autoridad "vigilando" o supervisando la información dada por su condición de mujer mayor, poseedora de los conocimientos de los antiguos; en tanto que (JG) se desenvuelve en el rol de intérprete no sólo de la lengua sino también de los dos mundos: el pasado/ el presente; el "antes"/ el "ahora"; los tobas "antiguos"/ los tobas "modernos". Es decir, mientras (DC) construye su discurso como un relato de cómo vivían los antiguos y cómo ella se socializó; (JG) elige la explicación y justificación de ese pasado reciente a través de una comparación con el presente y algunos episodios de su infancia en los que alcanzó a compartir algunas de aquellas vivencias. Así, a lo largo del relato, la una agrega información nueva al enunciado de la otra. En algunas ocasiones se produce un cambio de código, estableciéndose un diálogo entre ellas en qom l'aqtaqa como un modo de consulta o ampliación de la información que se está dando; luego, (JG) traduce, en parte, y explica a su destinatario.

Para el análisis de este fragmento, es necesario contextualizar todo el evento de habla puesto que presenta varias instancias significativas: 
a) Al comienzo, después haber invitado a la investigadora a pasar y habernos sentado en el living de su casa, y al cabo de unos minutos de silencio, (DC) pregunta a (JG) por otra persona ajena al barrio; ésta responde y, luego, se dirige a la investigadora y le explica de quién estaban hablando. Este acto le da cierta importancia al evento y es una forma de "alertar" y decir: "otras personas han venido a preguntar y luego no regresan". Se trata de una manera de posicionarse en el evento de habla donde las emisoras o entrevistadas generan y manifiestan tener el poder de la palabra frente al investigador o destinatario.

b) Se produce otro silencio largo e, inmediatamente, la investigadora introduce el deseo que "le relaten algo", un cuento, una leyenda puesto que en ese momento se encontraba realizando un relevamiento de ese tipo. A este pedido, responden con risas picarescas -y miradas cómplices- diciendo que no se les ocurre nada, y la dejan afuera de la interacción verbal mediante un diálogo en lengua. Este diálogo no es traducido, por lo que la investigadora introduce el tema de lo poco que había aprendido del idioma.

c) Allí se produce el inicio de la entrevista propiamente dicha. Ambas entrevistadas aceptan, por fin, la propuesta (aceptan a la investigadora), se distienden y empiezan a responder y a narrar. El fragmento aquí presentado y que analizaremos a continuación corresponde a esta instancia.

d) Pasada, aproximadamente, una hora y media la conversación se interrumpe con la llegada del esposo de DC.

Si centramos la atención en la instancia c) observamos que, luego de conversar en torno a los saludos y las formas de dirigirse a hombres y mujeres, y sobre los términos de parentesco, se produce un silencio largo que es interceptado por la investigadora al introducir el tópico sobre "el sistema de numeración toba". Esto crea una situación de alto significado metacultural, puesto que (JG) realiza un ejercicio discursivo de reflexividad aún mayor para contrastar el sistema actual con el que debe haber existido antes, ya que el sistema numeral toba original sería muy diferente al occidental. En esta reflexión (DC) la ayuda, guiándola (ver líneas de 2-7). En (7.) (DC) corrige e introduce un nuevo lexema en toba: qalo'otá' ("mucho"). Éste es retomado por (JG) y es contextualizado en un relato que da inicio a la performance o ejecución de la narración sobre "el tiempo de los antiguos". La misma presenta varias pausas y es ejecutada en una velocidad lenta y un tono de voz suave. Las pausas introducidas aludirían al acto de "re-contar" (Sherzer 1983), recordar un 
relato narrado por sus mayores y que habría escuchado en su niñez, como así también al esfuerzo de traducir unidad por unidad de significado. En este relato (JG) configura un "ellos": "era mucha la gente"; "gente antigua"; "hombres fuertes"; "muchos valientes"; "mariscadores". Al tiempo que pone distancia en ese relato a través del "dicen" -ella no lo vio, se lo contaron-. Se trata de un discurso ajeno, narrado en un estilo indirecto, aquel que la gente mayor suele contar por las tardecitas cuando se reunían alrededor del fuego para relatar viejas historias. ${ }^{143}$ Este relato se interrumpe al introducir un lexema que le es un poco dificultoso traducir; (JG) trata de reflexionar sobre su significado y es apoyada por (DC) mediante una corrección en su pronunciación - ver en (9.)- y, a la vez, coloca el acento en el lexema "mariscar". Se produce una pausa larga y (JG) acompaña esa pausa con suaves, tímidas y emotivas sonrisas. Este silencio -significativo en el contexto de la narración, que llevó a las enunciadoras al mundo de los antiguos, al recuerdo y la admiración- es interrumpido por la entrevistadora al introducir la referencia de cómo eran las mujeres tobas. Esto causa risas -esta vez de mayor intensidad-, en especial en (JG) y ésta responde en toba y continúa en español, efectuando un cambio de código sin traducción. Le sigue (DC) también en lengua y con una voz muy baja al punto de no llegar a escucharse muy bien y, luego, prosigue en español (13.). Esta continuidad resulta un intento por parte de (DC) de traducir su propio discurso. En esta oportunidad, (DC) configura un "ellas" destacando el "tiempo de la algarroba" y "el monte". Sin embargo, el discurso hecho en español es muy cortado, con pausas donde (DC) no termina de cerrar las ideas. En (14.), (JG), que había perdido el turno de la conversación, lo retoma ayudando a (DC) a cerrar esas ideas con información nueva e introduce el lexema "mariscar" que también puede significar el trabajo realizado por las mujeres. (DC) encuentra en (JG) el apoyo suficiente, asiente positivamente en la respuesta que dio su intérprete utilizando un adverbio de modo "también" y agrega un adjetivo: "todas", seguido de: "cuestión de eso / alpi". En este caso, utiliza como estrategia discursiva un pronombre demostrativo: "eso" para referirse al vocablo algarroba que no es traducido; se trata de una manera de sintetizar lo que (JG) viene reflexionando, de manera indexical, para rápidamente continuar con su relato. Cabe notar al final de (17.) la traducción errónea que hace (DC) al decir "pescar alpi", por querer explicar que "las mujeres recolectaban la algarroba". No obstante, (JG) obliga a (DC) a proseguir con el relato en lengua toba (21.), se produce un diálogo entre ellas en esta lengua y, finalmente, (JG) traduce (22.). En esta ocasión, (JG) utiliza un estilo

\footnotetext{
${ }^{143}$ Según otras fuentes de información, incluso de la misma interlocutora dada en otra oportunidad.
} 
indirecto dando a entender que está traduciendo lo dicho por (DC). Seguidamente, el relato de (DC) vuelve a ser en español, agregando información nueva a lo traducido por (JG). En las líneas (23.) y (25.), (DC) vuelve a utilizar como recurso el pronombre demostrativo "eso", "sí, todo eso", "esa", como una forma de sintetizar y asentir lo dicho por (JG), aunque, sobre todo, como una estrategia de no traducir con fluidez y riqueza la expresión ejecutada. Se trataría de un recurso discursivo característico de un hablante poco fluido en español.

En (27.), se puede observar que (DC) vuelve a utilizar este recurso; esta vez, resaltando la estrategia de no formar una oración completa en español, sino entrecortándola; y termina su idea con un: "y ahí ya". (JG) complementa la información dada "se van muchas", aclarando que son tanto las mujeres jóvenes como las mayores quienes se van juntas al monte a juntar la fibra de la planta del chaguar. A esto, (DC) retoma lo dicho por su interlocutora, pero aclara y agrega otra información: van tanto las mujeres jóvenes como las mayores, pero estas últimas tienen la misión de enseñar a las más jóvenes para que aprendan a realizar las tareas propias de su género.

Es interesante el análisis de la línea (29.). Se trata de una de las intervenciones de mayor duración realizada por (DC). La misma se ejecuta mayoritariamente en un tono de voz más suave y en una velocidad más lenta, con algunas aceleraciones. En especial, al finalizar las frases donde se produce el cambio en la corriente de aire egresiva normal del habla por una corriente de aire ingresiva. Al inicio de su relato utiliza un estilo indirecto: "dicen que", aunque en presente. De modo tal que pone en ella las palabras de sus abuelitas como si se lo estuvieran diciendo en ese momento: "porque nosotros no vamos a estar"; así, revive esa pauta cultural y la trae al presente y a la ciudad. Utiliza varios conectores: "por eso es que”, “y así fue”, “entonces”. Las oraciones son más largas que las anteriores pero, de igual forma, no están hechas o dichas de modo completo; los conectores le sirven para unir las ideas escasamente formuladas. El relato de sus mayores termina con un: "así aprenden", aquí la enunciadora toma distancia del relato, ya no se incluye, y realiza un cierre con valor metacomunicativo y metacultural. A continuación, agrega: "bueno, yo aprendí así". Lo cual convierte ese relato en un testimonio. (DC) refuerza ese testimonio contando su experiencia y aclarando que no alcanzó a aprender todo lo que sus abuelitas sabían porque eran muy mayores y sólo aprendió algunas cosas.

(JG), que había permanecido muy atenta al relato, lo refuerza retomando el turno de la conversación y realizando una reflexión metacultural: "las enseñanzas se iban pasando de 
generación en generación, de forma verbal"; compara la pauta de socialización de los tobas con la del mundo moderno. A su vez, se hace partícipe de esa pauta recordando su vivencia, con lo que aprendió con su abuelita. (DC) vuelve a tomar el turno de la conversación -(31.) - agregando y especificando una nueva información: "hasta de esos remedios te enseñan". Y otra vez se vuelve a incluir en el relato. Este aspecto es interesante si pensamos que (DC) es una persona mayor que estaría en el rol de instruir a las más jóvenes. Sin embargo, el hecho de incluirse en el relato y no tomar distancia, deja ver de manera clara que ella, como persona mayor, no puede transmitir esas enseñanzas a las más jóvenes puesto que ya no está en el monte, la vida en la ciudad es muy diferente, y aquello quedó en el pasado. Introduce un ejemplo de cómo se curaban antes y de ahí en más, ambas interlocutoras comienzan a comparar la manera de curar que tenían los tobas antiguos y los de ahora.

El fragmento que hemos seleccionado para el análisis es muy rico en información y recursos discursivos. Es importante señalar que ese pasado del cual hablan ambas interlocutoras está ubicado en el Chaco, en el monte, en Pampa del Indio. Es notorio cómo, con frecuencia, ese pasado es relatado en tiempo presente por (DC) remitiéndose a un pasado reciente, el de su niñez y juventud. En ese contexto, por momentos, introduce un discurso ajeno: lo que la mamá o abuela le decía a ella. En cambio, la enunciación que hace (JG) está hecha en un tiempo pasado, en un pretérito imperfecto. La diferencia en los usos de los tiempos verbales puede deberse a un empleo más fluido del castellano en (JG) que en (DC), teniendo en cuenta que esta última no recibió una educación formal y aprendió el castellano tardíamente, luego de su migración, dominando más la lengua toba. Resulta elemental diferenciar, en este caso, los discursos ajenos empleados en una y otra de las enunciadoras. En el caso de (DC), ella se hace partícipe del mismo, se incluye dentro del relato, se coloca dentro de la situación, como reproduciendo ese momento en el que la mamá le daba la enseñanza.

Asimismo, a lo largo de la interacción, hay una complementariedad entre las interlocutoras producto del uso de la lengua de origen. (DC) corrige a (JG) alguna palabra mal empleada o mal pronunciada; asiente y confirma sobre la información sociocultural que ofrece (JG): "sí, todo eso", "también"; agrega información: "para hacer la yica", "hasta esas cosas te enseñan”. En tanto que (JG) explica a partir de su conocimiento, producto de sus vivencias y, sobre todo, el contacto con la sociedad no toba: "claro, las enseñanzas se iban pasando de generación en generación”, "no había nada escrito", "era 
como una manera de protegerse...". A la vez, que esa explicación está dada a través de una comparación con el mundo actual: "no había hospitales", "no necesitaban anteojos” como ahora.

En términos de Hanks (1989), la enunciación de (JG) estaría actuando, en este fragmento de la entrevista, como meta-texto del discurso de (DC). El con-texto lo constituye la entrevista completa, donde este texto (fragmento) se pone en situación. El inicio de la entrevista configura el pre-texto hasta que aparece el lexema qalota' ("mucho"), que es lo que marca el comienzo del tema central de la entrevista donde la socialización de las mujeres y la vida de un pasado reciente adquieren importancia (cotexto). Finalmente, consideramos como post-texto el resultado de la entrevista, la obtención de información.

A lo largo de este tramo de la entrevista donde el tema central es el relato de cómo eran socializadas las mujeres recibiendo sus enseñanzas y a través del análisis del discurso de (JG) se puede apreciar cómo aparecen formas que cumplen la función explicativa, por medio de pares de oposición:

- las enseñanzas se iban pasando de generación en generación de forma verbal/ no había nada escrito;

- ése era otro de los medicamentos que teníamos / no había hospitales;

- tenían buena vista / no necesitaban anteojos.

En esta interacción discursiva, si bien ambas interlocutoras comparten un colectivo lingüístico y la misma sociedad y están reunidas en una situación concreta, cada una de ellas pertenece a generaciones diferentes y trae consigo una historia particular. Esto hace que, por un lado, (JG) por haber recibido una formación formal (terminó la escuela secundaria) y haber adquirido los conocimientos de la sociedad nacional de una manera más sistemática, ponga cierta distancia respecto del discurso de (DC), analizando lo que ésta dice, dando las razones, explicando los por qué y comparando los conocimientos y acciones del mundo toba con los de la sociedad occidental: "deriva de la raíz castellana” y los otros ejemplos antes mencionados. Por otro, (DC) sigue atenta el discurso de (JG) como una especie de agente metadiscursivo de control-, haciéndole algunas correcciones en cuanto a algunos términos en la lengua y el uso de los mismos, controlando también las explicaciones que ésta da.

A lo largo del discurso se suceden distintos actos de habla: afirmaciones: "sí, todo eso"; preguntas cerradas (que no se espera una respuesta del otro): “cuando hay ¿cómo es eso 
que tenemos?...”; y “¿cómo es?...”. Asimismo, es frecuente el uso de estilo indirecto introducido por la expresión "dice que", índice metadiscursivo del carácter de "re-contado" del discurso: "cuando iban a mariscar dice que se iban bien temprano y se volvían a la tardecita".

De modo tal que la entrevista, que comenzó de un modo "tímido" y desinteresado, ${ }^{144}$ se convirtió en un espacio de recreación y reflexión de los aspectos que hacen al mundo toba; en él se fue configurando al mismo tiempo un pasado: un "antes" representado por "los antiguos" y un presente: el "ahora" marcado por el "nosotros", "los tobas modernos". Asimismo, se construyó un discurso en torno a las diferencias de género describiendo y reflexionando sobre las tareas realizadas por las mujeres y las pautas de socialización de las mismas. Por último, el análisis de esta interacción dialógica permite identificar y definir los roles sociales en juego y distinguir las relaciones de edad y de uso de las variantes lingüísticas que manifiestan las interlocutoras.

\section{- Discurso público en contexto académico}

\section{Participante y Escenario:}

El siguiente es el discurso completo dado por (JR) -identificado con el grupo de hablantes A- como integrante de una mesa redonda en el IV Congreso Nacional de Antropología celebrado en la ciudad de Olavarría en julio de 1994. Esta mesa fue compartida con antropólogos y otros dirigentes indígenas de Argentina; (JR) fue el cuarto expositor después de tres antropólogas nacionales.

Se decidió colocar el discurso completo debido a la riqueza de su contenido y los recursos verbales que podemos encontrar en él.

1. Buenas tarde..// Yo soy de la comunidad tobas// quee estoy viviendos acá en.. La Platas,// en la calle ciento cincuenta y uno y treinta y cinco.// Ehh, //somo' treinta y seis familia'.// Eh,// bueno,// en primer lugar,// estee,// no voy a entender mucho// porquee este encuentro creo que// esto para los antropólogo/ía social.// Yo no soy antropólogo, $/ /$ nada más soy indígena dirigentes, $/ /$ como presidente de nuestra asociación civil\}. //

7. Pero..// comos estee encuentros creo que hay otros hermanos que vienen de otros países..// entonces, // me alegro muchos de encontrarles// y //verlos el rostro de ello.../

\footnotetext{
${ }^{144}$ Cuando llegué a la casa de DC, lo hice con la intención de entrevistar a su esposo, pero el mismo no se encontraba. No obstante, me invitaron a quedarme y esperar a que llegara. En ese contexto es que comencé a preguntar y me dijeron que "ellas no sabían nada", "que no tenían nada para contar". Sin embargo, la interacción duró más de una hora y la misma finalizó cuando llegó el esposo quien tomó la palabra a continuación y las mujeres ya no intervinieron.
} 
Yo sé que// ellos están luchando también a causa de nuestros pueblos indígenas.//

10. Somo' treinta y seis familia'// quee.. hemos. migrados aquí en La Plata,..// por causa de..// voy a comentar nada más un poquito de nuestra historias de por qué estamo' viviendo aquí en La Plata. // Primer lugar quee no tenemo' tierras en el Chaco.. //porque siguen todavía, //por ejemplo,// arrinconándos a los indígenas.// Yo sé que hay varias familias también en Rosario, en Santa Fe, en Gran Buenos Aire' //más o

15. menos hay tres mil familia' que se están expandido. // Entonce,// ehh// la lucha,// y vamo' a seguir luchando// como han mencionado para los quinientos años.// Y este momento,// por ejemplo,// de..// siempre de pedir colaboración;// es la esperanza de todos ustedes// estudiantes jóvenes, adultos, aquellos doctores también quee. no son indio.// Pero siempre he pedido colaboración,// por ello.// En primer lugar de los

20. toba,// por ejemplo. $/ /$ Nosotros, // yo soy uno que no tengo estudio...// pero. estoy luchando... // para el bien de nuestros hijos,// como bien dice,// para los presentes,// los porvenir..// estamos pensando siempre. siempre// porque así fueron las ideas de nuestros héroes pasados...// Sin leer,// sin saber palabra en castellanos,// por esos // sig.., este..// por eso ellos perdieron.// ehh.// muchas cosas.// Primer lugar tierras.//

25. porque ellos no saben hablar en castellano.// No saber. número alguno.// eso dicen ese la causa más grande de la comunidad toba..// Los hermanos wichí por lo menos están organizados // y //yo sé que ellos.// por ejemplo.// tienen maestros.// Tal vez tienen algún profesor.// tal vez tienes algún doctor.// algún abogado.// Pero los toba no..// No tenemos nada, //de nada.// Los hermanos Coyas// yo sé, // conozco// tanto

30. como lo' hermanos mapuche,// conozco.// que ellos están formando.// por ejemplo.// tienen esos argumentos.. para defender// y esperemos los hermanos que defiendan su pueblo.// Porquee.// es un poco muy doloroso en este momento. yo les voy a plantear un poquito si nosotro'//. por ejemplo.// nos vamo' a organizar..// creo que no tenemos salida...// Pero en este momentos tenemos

35. que organizarnos para que puedan escuchar los pueblos indio. // Sin organización// lo que yo veo en este momento// creo que// no se puede hacer nada// tanto como en el Chaco//. En el Chaco// hasta el día de hoy// no tiene tal vez salida//. Los hermanos están acorralados// esperando //hay veces//. los compañeros políticos//.. Pero nunca hacen nada//.. Que me perdone algún. partidario político//. Yo no soy//.. no estoy en

40. contra de las política//, de los partidarios políticos//, sino que siempre yo pido a ellos// para que ellos colaboren.. por nuestra necesidad// para que nosotros seamos hijos de esta nación//. Porque si nosotros no trabajamos todos conjunto// \{no somos nada $\} / /$. En una palabra//.. Hace pocos días// no es cierto// pasó un caso//.. aquí en nuestro país//.. Entonces// pienso yo que// si nosotros reconocemos como humanos//.. tenemos que

45. pensarnos un poco lo que estamos viviendo aquí// en nuestras Argentinas//. Yo sé que hay muchos hijos de extranjeros.. Nosotros no somos extranjeros//.. Desde el principio// no es cierto// porque ustedes saben muy bien la historia// qque los primeros pobladores son los indígenas $\} / /$ los pueblos indios//. los pueblos aborígenes//. los pueblo toba//. los pueblo pilagá//. lo mocoví//. los wichí//. Pero// ninguno de nosotros

50. tenemos propiedad// no tenemos nada de tierra//.. Posiblemente//. si aprueban el terreno que estamos viviendo en estos momentos// vamos a ser propietarios//. para treinta y seis familias// nada más//... por entre medio de alguna organización//. $\underline{\underline{\text { Hemos }}}$ puesto// la organización se llama "Asociación Civil Ntaunaq Nam Qom//.. Muchos me preguntan//. qué es el Ntaunaq Nam Qom// qué es lo que significa// el trabajar todos

55. juntos unidos// con un sólo pensamiento// un sólo sentir// para que vayamos adelante//. \{Porque así he vivido\}// la vida de nuestros héroes pasados $/ /$. siempre.. \{han trabajado todos juntos $\}$. Aquel que lo tiene// la tranza//. Acá le llaman como comunista// ¿no es cierto?// por lo que tenemos en forma común//. Por eso// aquí estamos trabajando en este momento//. Nada más//. 
En primer término, debemos señalar que (JR) se ha destacado desde su migración a la gran ciudad por realizar discursos frente a un público en general: vecinos y paisanos tobas, representantes de otras organizaciones indígenas, estudiantes, funcionarios públicos, como así también miembros de la iglesia toba. Por lo tanto, estamos ante un hablante hábil en la construcción de discursos tanto en lengua vernácula como en español. Su manejo del español es el de un hablante no nativo, con interferencias de su propia lengua. Por ejemplo, en su discurso no hay concordancia de género entre artículos, sustantivos y adjetivos; hay hipercorrección en el uso de las "eses" al final de sílabas, como así también éstas están ausentes en algunos sustantivos, artículos y verbos. Sin embargo, un uso estratégico de conectores produce cohesión en el discurso expresando consecuencia lógica ("por eso", “por lo que”, “entonces”), adición (“también”), orden (“primer lugar”, “nada más”). Asimismo, la reiteración de la expresión "por ejemplo" adquiere una finalidad retórica.

Analizando la estructura general del discurso, podemos distinguir tres partes principales que conforman un discurso con estructura lógica y coherente. La primera parte está conformada por las primeras doce líneas. En ella, (JR) se identifica a nivel personal como toba, migrante, indígena, dirigente, presidente de la asociación civil y como "no antropólogo". Además, justifica su participación en un evento que no le corresponde a través de la presencia de otros representantes indígenas de Argentina y otras regiones de América Latina con quienes comparte elementos en común, en especial, "la lucha": tópico principal de su discurso. Este aspecto lo deja muy bien señalado si tenemos en cuenta los cambios en la velocidad del habla. Inicia con un saludo calmo, toma su tiempo para comprometer a la audiencia, se identifica y ubica espacialmente su lugar de procedencia de manera entrecortada con pausas llenadas con interjecciones a modo de dubitación y alargamiento de vocales como buscando las palabras o configurando las ideas. Y, de pronto, aumenta la velocidad del habla y tímida, aunque picarescamente -porque baja el volumen de su voz y lo complementa con una acción extralingüística que consiste en bajar la cabeza y entreguiñar un ojo- advierte a la audiencia que él no va a entender mucho porque no es especialista, no es antropólogo, esto lo expresa con mayor seguridad, sin pausas ni silencios. Luego, disminuye la velocidad del habla, y se coloca en posición de expositor: no va a entender mucho porque no es antropólogo -aclara-; sin embargo, están 
presentes otros indígenas hermanos y a ellos se va a dirigir, los saluda cordialmente y deja insinuar lo que va a ser el tópico de su discurso: la lucha. ${ }^{145}$

(JR) crea su posicionamiento (footing) en el discurso propiamente dicho a través de la expresión: (líneas 11. - 12.) "voy a comentar nada más un poquito de por qué estamos viviendo aquí en La Plata". Este nuevo “disclaimer" -mediante el uso del restrictivo "nada más" en conjunción con el diminutivo para reforzar el significado del objeto "un poco"constituye una estrategia discursiva mediante la cual el hablante, mitigando su propia imagen para evitar cualquier posible rechazo de la audiencia, sintetiza y pone en foco el contenido central de su discurso. Con esta expresión compromete a la audiencia para que le preste atención y los coloca en situación, se posiciona y los posiciona y legitima como audiencia. A partir de aquí, se dirige alternando entre la $1^{a}$ persona del plural y la $1^{\text {a }}$ del singular, introduciendo la problemática de la comunidad toba: la no tenencia de la tierra, de la propiedad, las causas de la migración y la necesidad de organizarse para continuar con la lucha. Este tópico es mencionado explícitamente cinco veces en el discurso y, a su vez, está vinculado a otros sub-tópicos: tierra, organización y trabajo comunitario. A través de un conector que indica orden en (12.), plantea el tema de la migración colocando el acento en la "no tenencia de la tierra", y "el arrinconamiento" que se les sigue realizando a los indígenas; razones por las cuales, los tobas migraron a la ciudad de La Plata. Sin embargo, (JR) no se refiere sólo al caso de los tobas de La Plata, son más las familias que han tenido que migrar y que se han ubicado en otras ciudades del país. Con esto, plantea una identificación y una problemática étnica: los tobas en general. Es decir, la lucha es de todos (16.). Seguidamente, en (17.) una primera lectura da la impresión de que el hablante realiza un corte en el desarrollo de su discurso, saltando a otro tema. No obstante, si nos detenemos con mayor precisión podemos observar que, en realidad, (JR) introduce el tema de la colaboración: razón por la cual aceptó estar en un espacio y en un rol que, a primera vista, no le correspondería por tratarse de un evento para antropólogos. Esto está focalizado mediante la expresión temporal: "Y este momento". Está ahí, con un fin: pedir la colaboración -no sólo económica, sino el asesoramiento, el apoyo en la lucha para la obtención, principalmente, de la tierra- de jóvenes, estudiantes, profesionales, políticos, funcionarios, en definitiva, de los no indígenas. Plantea que ése es el trabajo que realiza

\footnotetext{
${ }^{145}$ Esta forma de comunicar que asume (JR) para comenzar su performance, por la cual el enunciador niega o pone en duda su habilidad o conocimiento sobre un tema o una conducta para luego mostrarla, es definida por Richard Bauman (1993) como disclaimer en la ejecución.
} 
siempre y que es para el bien del futuro de los tobas. Entre las líneas (20.) y (34.), (JR) acentúa varios lexemas y alterna entre una velocidad normal y otra más lenta para configurar las condiciones en que se realiza la lucha. Se coloca como ejemplo: "yo soy uno que no tengo estudio", sin embargo, se mueve y lucha por su ideal; y se compara con los tobas antiguos -"héroes"- que, sin saber leer y contar, hablar el castellano, también lucharon. Sin embargo, éstos perdieron. Y la lucha actual consiste en conocer del mundo de "los blancos" y organizarse. En este caso, utiliza un estilo indirecto para hacer referencia a esta reflexión junto con el recurso de la anáfora donde enfatiza el adjetivo demostrativo "eso" y "ese": "eso dicen ese la causa más grande de la comunidad toba". Tanto "eso" como "ese" refieren a los hechos de no saber ni de números ni de palabras en español -creando indexicalidad-. Introduce el lexema "organización" ejemplificando el caso de los wichí. Da fe de conocer los avances de otros pueblos indígenas cuyos miembros han accedido al estudio, para ello utiliza actos de habla que atestiguan y testifican lo dicho: "conozco", "yo sé”. Y compara estos avances con los tobas: "Pero los toba no..// No tenemos nada, //de nada.//".

Entre (35.) y (36.), (JR) vuelve a focalizar su discurso esta vez en el sub-tópico de la organización repitiendo la construcción “en este momento" que por extensión está indexicando también el espacio compartido en esa situación comunicativa: "pero en este momento yo les voy a plantear..."; es decir, aquí y ahora. Además, este aspecto está marcado por un aumento en la velocidad del habla. El cambio de velocidad del habla en el discurso junto con el cambio en la entonación al final de las frases y las pausas largas están actuando como modos de introducir a la audiencia en el texto, captarla, crear interés y que ésta lo siga, lo escuche. Seguidamente, en la línea (45.) llega al punto culminante (el clímax) retórico. Éste es señalado con una opinión personal: "si nosotros no trabajamos todos conjunto// \{no somos nada $\}$ " expresado en una velocidad menor y una disminución del volumen de la voz al finalizar la frase. Es decir, (JR) plantea aquí la idea principal que quiere transmitir a su audiencia y lo resalta dándole relevancia sintetizando dicha frase con la expresión: "en una palabra". Sin embargo, luego de una pausa larga se abre del tema haciendo referencia a un hecho reciente -que no es mencionado-, planteando el caso de que los indígenas no son extranjeros y la necesidad de pensarse y ser pensados como "hijos" (ciudadanos) del país. De esta manera va hilvanando las ideas que luego van a tener su desenlace final. Con un acto metacomunicativo y metacultural: "porque ustedes saben muy bien la historia" abre el tramo final del discurso, en el que enfatiza y deja en claro cuál es la problemática del indígena: la no tenencia de la tierra ni de títulos de propiedad. 
Estrategia ésta que le sirve para llegar al foco de su discurso, el ejemplo de las familias tobas de La Plata, la conformación de la Asociación Civil Ntaunaq Nam Qom, la organización de estas familias y la posibilidad de que a través de la misma obtengan un terreno, la casa y el título de propiedad. En (50.) se dirige a la audiencia con un par pregunta-respuesta que le permite en un estilo directo definir la Asociación.

Concluye así con una reflexión y enseñanza que surgen a colación de lo que significa "Ntaunaq nam qom": el trabajar todos juntos por un mismo objetivo. Esta reflexión y, a la vez, enseñanza está señalada por un acto de habla que lo lleva a atestiguar: "porque así he vivido", a la vez que transmite emoción a la audiencia al disminuir el volumen de su voz y cambiar su entonación, y hace alusión a los héroes pasados: así han vivido ellos y eso fue lo que les enseñaron. Sigue el ejemplo de los antepasados de vivir de un modo comunitario. Prosigue con un comentario interesante, dicho en un lenguaje más informal y en una velocidad en el habla menor: "aquel que lo tiene// la transa//. Resulta difícil entender el significado de esta expresión, puesto que hace uso de una anáfora a través de un objeto directo que no se sabe a qué hace referencia, omite la idea. Seguidamente, se dirige a la audiencia en un estilo directo, como entablando un diálogo con la misma y marcando la diferencia entre un nosotros y un ustedes, el mundo de los indígenas y el mundo de los blancos y realiza una reflexión metacultural: "Acá le llaman como comunista// ¿no es cierto?// por lo que tenemos en forma común”. Con un adverbio de lugar marca el mundo de los blancos, al cual él no pertenece y establece la relación del trabajo comunitario con la concepción occidental de comunista; realiza una pregunta cerrada y una justificación que enfatiza el lexema común. Finalmente, utiliza como recurso verbal un conector de consecuencia "por eso" -que a su vez refiere a lo dicho anteriormente-, para desencadenar en el hecho que ésa es la tarea que las familias tobas de La Plata están emprendiendo: siguiendo las enseñanzas de los antiguos, están trabajando todos juntos con un mismo objetivo. Y acaba con un "nada más", fórmula de cierre que expresa que lo ha dicho todo y deja sobrentender que tiene la autoridad suficiente para expresar lo dicho.

Durante los quince minutos que duró su intervención, y en pocas palabras, (JR) planteó la problemática, la desarrolló y le dio una consecuencia lógica. Se posicionó planteando las diferencias con su audiencia y compañeros del panel: no es un profesional de la antropología y no es "blanco". Configuró un nosotros que incluyó a los otros grupos indígenas, no sólo a los tobas en general y a los de La Plata en particular. Por último, 
manifestó un manejo muy competente del español. Como hablante no nativo del español (JR) hizo uso de los recursos verbales necesarios, comprometió al oyente para que lo escuchara y demostró su autoridad en la temática expresada. Más adelante veremos el uso de estos mismos recursos en relación a la prédica de tipo religiosa.

\section{IV.6. Eventos y Situaciones Comunicativas donde SE ExPReSa la Significación DEL HECHO DE HABLA}

Nos interesa en este apartado aproximarnos a los diferentes aspectos que hacen a la dinámica sociocultural de la comunidad toba del Barrio "Las Malvinas" a través de la lengua en acción, en uso y función. Para ello, distinguimos y analizamos las situaciones comunicativas y los eventos de habla que en ellas ocurren. Se tiene en cuenta para la caracterización de los mismos el conjunto de los componentes que acompañan y permiten identificar un evento de habla de otro, ${ }^{146}$ como así también las actitudes que los hablantes expresan hacia los dos códigos lingüísticos y los roles sociales y lingüísticos que se ejecutan. Todos éstos, aspectos que nos permiten entender cómo el grupo construye su propia identidad y cómo éste distingue e interpreta a los demás; y poder así aproximarnos a las reglas y normas que rigen las conductas sociolingüísticas de la comunidad. Asimismo, en algunos casos, se tuvo en cuenta para el análisis aquellos elementos ya utilizados en los apartados anteriores tales como la prosodia y los turnos en la conversación.

De este modo, hemos identificado en la comunidad toba del Barrio "Las Malvinas" una serie situaciones comunicativas que se señalan en el Cuadro $\mathrm{N}^{0} 2$ y que serán analizadas a continuación. En cada una de ellas, podemos distinguir distintos eventos de habla que sobresalen por su frecuencia, su repetición en diferentes situaciones comunicativas, el lugar destacado que ocupan y la presencia de ciertas reglas formales que los hace diferenciales. Messineo (2000) reconoció para el habla toba particularmente tres estilos ${ }^{147}$ elementales: el conversacional, el de la oratoria y el narrativo. Estos estilos combinados con ciertos recursos morfosintácticos y con las características de los contextos de

\footnotetext{
146 Ver Capítulo II (Parte II).

${ }^{147}$ Urban (1984:312) define estilo de habla como "un tipo reconocible de uso del habla que se distingue de otros tipos por sus rasgos formales. Unos años más tarde, este mismo autor junto con J. Sherzer (1988:285) interpretaron los estilos como "vehículos de significado que proveen el modelo emblemático del orden social y que pueden ser utilizados por los hablantes para establecer y transformar las relaciones sociales”.
} 
producción y recepción de los discursos estarían conformando géneros particulares del habla toba. ${ }^{148}$

\begin{tabular}{|l|l|}
\hline \multicolumn{2}{|c|}{$\begin{array}{c}\text { Cuadro } \mathbf{N}^{\mathbf{2}} \text { 2 } \\
\text { Principales Situaciones Comunicativas identificadas en } \\
\text { Barrio toba "Las Malvinas" }\end{array}$} \\
\hline Situaciones Comunicativas & Variantes \\
\hline 1.Asambleas & $\begin{array}{l}\text { a. Generales } \\
\text { b. De la Asociación Civil } \\
\text { c. De la iglesia }\end{array}$ \\
\hline 2. Sesiones de Culto & --- \\
\hline 3. Celebraciones & $\begin{array}{l}\text { a. De la iglesia } \\
\text { b. Cívico-comunitarias }\end{array}$ \\
\hline 4. Reuniones Comunales & --- \\
\hline 5. Visitas & --- \\
\hline $\begin{array}{l}\text { 6. Reuniones y Talleres } \\
\text { interétnicos }\end{array}$ & --- \\
\hline 7. Charlas y Conferencias & $\begin{array}{l}\text { a. En el barrio } \\
\text { b. Fuera del barrio }\end{array}$ \\
\hline 8. Actividades educativas & ---- \\
\hline
\end{tabular}

A lo largo de nuestra investigación en torno a los usos de la lengua toba y del español en el Barrio "Las Malvinas", hemos identificado eventos de habla significativos que se vinculan con algunos de los géneros citados por la mencionada autora y que se sintetizan en el Cuadro $\mathrm{N}^{\mathrm{o}} 3$. Estos son:

\begin{tabular}{|r|l|}
\hline \multicolumn{2}{|c|}{ Cuadro $\mathbf{N}^{\circ} \mathbf{3}$} \\
Eventos de Habla identificados en la comunidad toba del Barrio “Las Malvinas" \\
\hline Prédica (discurso religioso) \\
\hline En qué ocasión se hace: & En el culto \\
\hline Quién la hace: & El pastor primero y segundo \\
\hline En qué lengua: & $\begin{array}{l}\text { En castellano la mayor parte del evento, } \\
\text { y en toba en momentos claves de la } \\
\text { ceremonia }\end{array}$ \\
\hline Oratoria (discurso político) \\
\hline En qué ocasión se hace: & En reuniones, asambleas \\
\hline
\end{tabular}

\footnotetext{
${ }^{148}$ Esta autora considera a los géneros del habla toba como "los modos prototípicos de habla que han sido transmitidos históricamente y que responden a patrones temáticos, estructurales y estilísticos relativamente regulares. Son tipos de discursos colectivamente reconocidos, forman parte de una taxonomía vernácula propia y, aunque no en todos los casos, reciben una denominación en lengua toba. Ocurren en contextos sociales determinados y se caracterizan por poseer un valor en sí mismos, otorgado por la propia comunidad de hablantes y que se manifiesta en el propósito o finalidad de cada género (pedagógico, para obtener resultados concretos, para entretener, etc.)" (Mesineo 2000:261).
} 


\begin{tabular}{|c|c|}
\hline Quién la hace: & $\begin{array}{l}\text { Presidente y algún miembro de la } \\
\text { comisión directiva de la Asociación Civil } \\
\text { Ntaunaq Nam Qom. }\end{array}$ \\
\hline En qué lengua: & $\begin{array}{l}\text { En castellano y en toba (en momentos } \\
\text { significativos de la reunión, para reforzar } \\
\text { o aclarar lo dicho en castellano) }\end{array}$ \\
\hline \multicolumn{2}{|l|}{ - Narración de cuentos/mitos/ leyendas/ } \\
\hline Cuándo se hace: & $\begin{array}{l}\text { Durante las visitas, cuando se reúne la } \\
\text { familia, en la escuela* }\end{array}$ \\
\hline Quién sabe: & Los adultos de más de 30 años \\
\hline Quién lo cuenta: & El adulto, el abuelo \\
\hline Quiénes escuchan: & Niños, jóvenes y adultos \\
\hline En qué momento del día se cuenta: & Preferentemente al atardecer \\
\hline Dónde se cuenta: & Reunidos fuera de la casa \\
\hline Temas: & $\begin{array}{l}\text { Varios (animales - astros - experiencias } \\
\text { personales) }\end{array}$ \\
\hline Duración: & Dos a tres horas \\
\hline Lengua utilizada: & Castellano y toba \\
\hline \multicolumn{2}{|l|}{ - Chismes/ chistes } \\
\hline Cuándo se hace: & $\begin{array}{l}\text { Especialmente en las visitas, entre } \\
\text { vecinos, durante las jornadas de trabajo, } \\
\text { reuniones }\end{array}$ \\
\hline Entre quienes: & $\begin{array}{l}\text { Entre mujeres solas u hombres solos; y } \\
\text { también entre hombres y mujeres. }\end{array}$ \\
\hline Quién lo hace: & $\begin{array}{l}\text { Cualquiera, pero hay gente reconocida } \\
\text { por el grupo como especialista }\end{array}$ \\
\hline Temas: & Varios \\
\hline En qué lengua: & $\begin{array}{l}\text { La mayoría de las veces en toba; algunas } \\
\text { veces en castellano y toba. }\end{array}$ \\
\hline \multicolumn{2}{|l|}{ - Conversación } \\
\hline Cuándo se hace: & $\begin{array}{l}\text { Cotidianamente en el contexto familiar; } \\
\text { durante las visitas; en las jornadas de } \\
\text { trabajo: cocina, huerta, etc. }\end{array}$ \\
\hline Entre quienes: & $\begin{array}{l}\text { Entre esposos, padres/ hijos; abuelo/ } \\
\text { nieto; entre visitas; entre vecinos; entre } \\
\text { compañeros de trabajo. }\end{array}$ \\
\hline Quién lo hace: & Todos \\
\hline Temas: & Varios \\
\hline En qué lengua: & $\begin{array}{l}\text { La mayoría de las veces en toba entre } \\
\text { esposos, visitas de gente toba al barrio y } \\
\text { entre compañeros de trabajo } \\
\text { (especialmente las mujeres); algunas }\end{array}$ \\
\hline
\end{tabular}




\begin{tabular}{|c|c|}
\hline & $\begin{array}{l}\text { veces en castellano y toba. En castellano } \\
\text { con los hijos y con hablantes no tobas. }\end{array}$ \\
\hline \multicolumn{2}{|c|}{ - Enseñanzas/transmisión de conocimientos en general } \\
\hline En qué ocasión se hace: & $\begin{array}{l}\text { Escuela de Adultos, Apoyo Escolar, } \\
\text { Talleres de Costura, Huerta. }\end{array}$ \\
\hline Quién la hace: & $\begin{array}{l}\text { - Maestros "criollos": ajenos al grupo } \\
\text { toba } \\
\text { - Adultos, jóvenes, niños }\end{array}$ \\
\hline En qué lengua: & Sólo en castellano \\
\hline Duración: & De una dos horas \\
\hline \multicolumn{2}{|c|}{ - Enseñanzas/transmisión de conocimientos tobas } \\
\hline En qué ocasión se hace: & Clases de lengua toba \\
\hline Quién la hace: & $\begin{array}{l}\text { - Un miembro de la comunidad } \\
\text { - Niños de la comunidad/ investigadora }\end{array}$ \\
\hline En qué lengua: & En lengua toba y español \\
\hline Duración: & Una hora, una o dos veces a la semana \\
\hline \multicolumn{2}{|l|}{ - $\underline{\text { Consejos, Advertencias }}$} \\
\hline En qué ocasión se hace: & $\begin{array}{l}\text { En las reuniones, conversaciones } \\
\text { personales }\end{array}$ \\
\hline Quién la hace: & $\begin{array}{l}\text { - El abuelo, el padre, el pastor, el } \\
\text { directivo (líder) }\end{array}$ \\
\hline En qué lengua: & En lengua toba y español \\
\hline En qué ocasión: & En cualquier momento del día \\
\hline
\end{tabular}

Entre los eventos de habla identificados en el Barrio Toba "Las Malvinas" destacamos, en primer lugar, la prédica y la oratoria. Ambos eventos refieren a la habilidad de dirigirse a una audiencia con gran elocuencia; el primero en el campo de lo religioso, durante el culto y ejecutado principalmente por los pastores; y el segundo, en situaciones tales como reuniones, ceremonias y asambleas referentes a la propia organización y realizado, generalmente, por el presidente de la asociación civil. Los mismos se producen tanto en toba como en español, aunque el uso de la lengua materna es más frecuente durante la oratoria. $^{149}$

Otros tipos de eventos de habla identificados son los consejos y advertencias, encabezados por un “yo siempre les digo...”, e incluso chistes. Los consejos y advertencias

149 Messineo (2000:265) reconoce dentro del estilo de la oratoria -para el caso del habla toba- diferentes géneros discursivos entre los que se encontrarían, entre otros, la prédica religiosa y el discurso político. Para nuestro análisis, identificamos con el nombre de oratoria a un tipo de discurso político con fin retórico que busca convencer al oyente o audiencia y tomar decisiones. 
son realizados principalmente por los adultos y abuelos en cualquier momento del día. ${ }^{150}$ En tanto que los chistes son ejecutados por todos los hablantes, en especial, cuando se comparte una conversación o charla entre vecinos, familiares y durante el trabajo. Entre mujeres jóvenes y adultas, éstos son interpretados preferentemente en lengua toba.

Las conversaciones son otro tipo de evento de habla que se ejecutan en todo momento, por cualquier tipo de hablante y en todos los dominios de uso, tanto en lengua materna como en español. ${ }^{151}$

Además, destacamos la narración de cuentos, mitos o leyendas. ${ }^{152} \mathrm{Si}$ bien son pocos los hablantes que se identifican como narradores, son los abuelos y adultos quienes tienen mayor conocimiento. En algunas ocasiones, cuando están reunidos por las tardes un abuelo suele narrar algún relato toba tal como "se hacía en el Chaco alrededor de una fogata". Sin embargo, en la ciudad -y en la ciudad de La Plata- y en estos tiempos, es más frecuente escuchar en una conversación un relato bíblico y preferentemente en español. También se ejecutan relatos de mitos o leyendas durante el culto. En este caso, se da un sincretismo entre un pasaje bíblico -que es producido para explicar o fundamentar algún hecho al cual se está haciendo referencia- y un relato del Chaco. Es decir, los relatos bíblicos son llevados y contextualizados en el Chaco: por ejemplo "Jesús caminando por Pampa del Indio o bautizando en el Río Bermejo". Fuera del barrio también se cuentan y se narran relatos tobas. Esto ocurre en el Jardín de Infantes "Josefina Bakhita” donde algunas mamás

150 Según Messineo (2000), los consejos en lengua toba -nqataGako'-constituyen uno de los géneros más destacados por sus características formales e importancia social. Cumplen un papel pedagógico significativo durante la socialización puesto que transmiten contenidos culturales tradicionales, reglas y normas sociales y valores.

${ }^{151} \mathrm{Al}$ analizar el discurso en toba, Messineo (2000) señala que no existirían restricciones de lugar y tiempo como así tampoco actividades específicas en las que la conversación -na’aqtaGayaGaq en lengua tobapudiera estar prohibida. Este género discursivo constituye el evento principal de las "visitas" -que hemos ya descrito- y está presente en todas las reuniones comunitarias y religiosas. Además, y conforme lo hemos comprobado, la autora destaca que las conversaciones cotidianas tienden a estructurarse en forma de diálogo, de modo que - dadas las reglas formales en el uso de la lengua en diferentes contextos- no habría lugar a las superposiciones, sino que se respetarían los turnos de habla de una sola persona a la vez. Aspecto último que también ocurre en los discursos en español.

152 En relación a las narraciones, Messineo (2000) realiza un interesante análisis estilístico del discurso toba diferenciando distintos estilos y géneros particulares según determinados rasgos a saber: la evidencialidad y la cita directa, el uso de verbos de movimiento y traslado, los nombres propios que aluden a entidades sobrenaturales, el uso del marcador pragmático de foco $/ \mathrm{m} /$. Las narraciones refieren tanto al "tiempo de los antiguos", como a "un pasado reciente". 
suelen participar todos los años, a pedido de las maestras, enseñando a los niños cómo elaborar artesanías y, en este contexto, les narran algunos cuentos, mitos, leyendas tobas. Estos son relatados en español, pero introducen el vocabulario toba.

Las enseñanzas y transmisiones de conocimientos también son frecuentes como eventos de habla. En este caso, diferenciamos dos tipos. Por un lado, aquellas que fueron transmitidas por personas ajenas a la comunidad toba: maestra de adultos, investigadoras que ofrecieron un apoyo escolar, funcionarios y profesionales de distintas instituciones que dictaron cursos de albañilería, electricidad, huerta, costura, todo este conocimiento transmitido y aprendido en castellano. Y, por otro, aquellas que fueron dadas por algunos integrantes de la comunidad toba del Barrio "Las Malvinas", tanto en toba como en español. Entre estas últimas, destacamos las enseñanzas de la lengua toba por parte de una hablante de la comunidad, transmitidas tanto a los niños tobas del barrio como a mi persona.

\section{- Las Asambleas}

Las reuniones comunales -identificadas con el apelativo de "asambleas"- constituyeron una de las situaciones comunicativas más frecuente y característica que acompañaron a lo largo del proceso de configuración de la asociación civil y de construcción de las viviendas del Barrio Toba "Las Malvinas". Se entiende por asamblea un conjunto de personas reunidas con un fin y que mantiene una estructura formal (reglas) singular y regular. Ya se ha destacado en apartados anteriores relativos a la historia de conformación del Barrio "Las Malvinas" que los miembros fundadores de la Asociación Civil Toba "Ntaunaq Nam Qom” participaron de muchas reuniones en diferentes entidades, tanto tobas como no tobas, indígenas y no indígenas, con el fin de iniciar la organización. Desde el momento que llegan a la ciudad de La Plata, la propia interacción entre los socios activos, por un lado, y adjudicatarios de las viviendas, por el otro, hizo que las asambleas se convirtieran en la situación comunicativa más destacada en torno de la constitución del barrio. Luego, en cuanto éste tomó forma y dinámica, las reuniones comunales fueron necesarias para mantener el orden y las decisiones basadas en los deseos y beneficios de toda la comunidad. En base a sus objetivos, fines y el tipo de integrantes que participan, destacamos tres modalidades: las asambleas generales, las asambleas de la asociación civil y las asambleas religiosas.

a) Asambleas Generales 
Se trata de reuniones ejecutadas en el contexto de la construcción de las viviendas. A lo largo del proceso de construcción hubo numerosas reuniones hechas con funcionarios públicos de la Provincia de Buenos Aires y representantes de las entidades que financiaron y desarrollaron el programa Pro-Tierra y el Plan de 540 Viviendas; también diferentes profesionales (arquitectos, ingenieros, maestro de obras) que guiaron la obra misma y otros que apoyaron en la concreción y organización del plan (asistentes sociales, técnicos de la construcción que dictaron talleres, entre otros). Muchas de estas reuniones se desarrollaron en el centro de la ciudad de La Plata, en edificios como Obras Públicas, Secretaría de la Vivienda o dependencias de la Casa de Gobierno de la Provincia de Buenos Aires y en ellas sólo participaron el presidente de la asociación civil acompañado por el secretario o alguno de los vocales. Luego, el resultado de estos encuentros era volcado en reuniones comunales donde participaban los adjudicatarios, tanto hombres como mujeres, y se diagramaban y planificaban las tareas a realizar. Sin embargo, estas reuniones tomaron más cuerpo durante la segunda etapa de la construcción, ${ }^{153}$ cuando se iniciaron las veintiocho casas restantes y se había incrementado el número de los adjudicatarios presentes en las cercanías del barrio. Éstas adquirieron la categoría de asambleas generales puesto que ya no sólo se informaba, se distribuían las tareas y se programaban los pasos a seguir, sino que también se discutían las dificultades que iban apareciendo y se tomaban decisiones. Además, fueron tomando una estructura formal: eran dirigidas por el mismo presidente de la asociación civil y contaron con la presencia de un secretario (que, generalmente, era quien ejercía esa función en la asociación o algún otro joven que supiera leer y escribir). Este último tomaba nota de todo lo ocurrido elevando un acta de cada asamblea modalidad que fue tomada de la propia organización como asociación civil juntamente con las experiencias tenidas con anterioridad a la llegada a la ciudad de La Plata. Participaban de las mismas los miembros socios y los futuros adjudicatarios de las viviendas, como también representantes de las entidades públicas antes mencionadas que intervinieron en la marcha del programa. De manera tal que las podemos caracterizar como de carácter privado, interétnico y formal, y desarrolladas en el dominio vecinal. A continuación, analizamos una de las asambleas llevada a cabo en marzo de 1996.

\begin{tabular}{|l|l|}
\hline \multicolumn{2}{|c|}{ (a)- Asamblea General } \\
\hline Dominio: & Vecinal \\
\hline
\end{tabular}

${ }^{153}$ Ver Capítulo III.1 


\begin{tabular}{|l|l|}
\hline $\begin{array}{l}\text { Variedad Lingüística } \\
\text { Usada: }\end{array}$ & Castellano/ Toba \\
\hline Contextos: & Formal \\
\hline & Privado \\
\hline & Interétnico* \\
\hline
\end{tabular}

\begin{tabular}{|c|c|}
\hline - $\underline{\text { Acto: }}$ & Asamblea Gral. de la Obra 9/3/96 \\
\hline Hora del Día: & 12-13:30 hs. \\
\hline Duración del Evento: & 1 hora y 30 minutos \\
\hline Dónde se hace: & $\begin{array}{l}\text { En el barrio, en una de las casas sin } \\
\text { terminar }\end{array}$ \\
\hline Motivo: & $\begin{array}{l}\text { Resolver la continuación de la obra y } \\
\text { convenir la finalización de la misma el } 19 \\
\text { de abril de } 1996\end{array}$ \\
\hline Participantes: & $\begin{array}{l}22 \text { personas aproximadamente: } \\
\text { - dos hombres no tobas, del Instituto de la } \\
\text { Vivienda } \\
-10 \text { hombres tobas } \\
-10 \text { mujeres tobas } \\
\text { - niños que entran y salen }\end{array}$ \\
\hline $\begin{array}{r}\text { Relación entre los } \\
\text { participantes: }\end{array}$ & $\begin{array}{l}\text { Beneficiarios de las viviendas a terminar } \\
\text { y que están aportando horas }\end{array}$ \\
\hline $\begin{array}{r}\text { Quiénes no pueden } \\
\text { participar: }\end{array}$ & $\begin{array}{l}\text { Las } 8 \text { familias poseedoras de las casas y } \\
\text { nuevos que no hayan aportado horas }\end{array}$ \\
\hline $\begin{array}{l}\text { Frecuencia en que se } \\
\text { realiza el evento: }\end{array}$ & Todos los sábados \\
\hline $\begin{array}{r}\text { Observaciones del uso } \\
\text { de las lenguas: }\end{array}$ & $\begin{array}{l}\text { La lengua toba: se habló en el grupo de } \\
\text { las mujeres, entre ellas, desde que } \\
\text { llegaron hasta el inicio de la reunión y a } \\
\text { la llegada de A (presidente de la } \\
\text { Asociación Civil). } \\
\text { La reunión la inició el maestro mayor de } \\
\text { obras (en castellano); hubo mayor } \\
\text { participación de los hombres; muy pocas } \\
\text { mujeres participaron salvo preguntas } \\
\text { dirigidas hacia ellas. } \\
\text { Cuando tomó la palabra A, inició su } \\
\text { discurso en toba. }\end{array}$ \\
\hline
\end{tabular}

\section{El contexto:}

Esta asamblea tuvo una duración de una hora y media aproximadamente. Participaron veintidós personas, distinguiéndose doce mujeres y diez hombres tobas. Sumado a ello, se encontraban el arquitecto y el maestro mayor de obras (no tobas). La asamblea fue 
convocada para el mediodía. Poco a poco fueron llegando los participantes: los hombres solos o en grupos pequeños de dos o tres personas, algunos con sus herramientas de trabajo a cuestas, y se fueron ubicando - parados la mayoría- alrededor de una pequeña mesa colocada a la entrada de una de las habitaciones de una casa a medio construir. Las mujeres, en cambio, fueron llegando en grupos de cuatro o cinco y se sentaron al fondo de la habitación, todas juntas ocupando dos filas, incluida la secretaria con un cuaderno y una lapicera en la mano; dos de ellas quedaron paradas cerca y otras tres -que llegaron más tarde- asomaban por la ventana. Alrededor de la mesa central, el presidente de la asociación civil, el arquitecto y el maestro mayor de obras. Debemos mencionar también la presencia de algunos niños que entraban y salían del recinto buscando o constatando que sus mamás u otro pariente se encontraban en el lugar; jugaban un poco, se reían, lloraban y escuchaban. A la espera de los asambleístas, el presidente de la asociación -y presidente de la asamblea- comenzó a intercambiar algunas palabras en toba con los presentes, de una manera jocosa y distendida, que generó romper un poco con la tensión que se percibía. Hubo risas como respuesta, en especial por parte de las mujeres, que eran las únicas que dialogaban entre ellas en voz baja y "en lengua".

Este tipo de asamblea se realizaba, generalmente, todos los sábados y de ella participaban los beneficiarios de las veintiocho viviendas que se estaban construyendo y aquellos que se encontraban aportando horas de trabajo. No participaban los dueños y ocupantes de las ocho viviendas ya finalizadas - a excepción del presidente de la asociación-. En esta ocasión, el motivo principal de la reunión consistió en ponerse de acuerdo en resolver la continuación de la obra y convenir la finalización de la misma para el 19 de abril de ese año. La obra había estado un tiempo paralizada, algunos no estaban aportando horas, otros se habían ido del plan y habían ingresado nuevos. La situación estaba tensa porque no se había cobrado a tiempo un cheque, lo cual había retrasado todo, y el ingreso de nuevos adjudicatarios había traído algunos disgustos entre quienes llevaban más tiempo en el plan por la cantidad de horas de trabajo aportadas, entre otros aspectos.

\section{Desarrollo de la asamblea:}

Antes de dar inicio a la sesión, el presidente (PA) trató de reducir la tensión existente con un comentario hecho en lengua toba. Todos rieron hasta que, seguidamente, tomaron la palabra el maestro mayor de obras (MO) y el arquitecto, planteando directamente la propuesta de "trabajar duro" y finalizar la obra en la fecha prevista. Además, (MO) señaló que no era mucho lo que faltaba y que, por eso, creía que, de ahora en más, no importaba la 
cantidad de horas que se había aportado, sino el trabajo concreto que se pudiera realizar; indicó también que veía muy importante en este tramo "el aporte que pudieran hacer las mujeres ya que ellas son las que más interés tienen en terminar las casas y ultimar los detalles, porque son las que están en las casas todo el dia; mientras que el hombre está afuera trabajando y sólo la usa para comer y dormir"; por ese motivo "el hombre no ve las necesidades que tiene la casa, en tanto que las mujeres, sí”. Y agregó: "esto ya lo apliqué en otros planes y dio buenos resultados". Finalizada la intervención se pidió la opinión de todos en cuanto si tomaban el compromiso. El primero en tomar la palabra fue uno de los nuevos adjudicatarios quien manifestó estar de acuerdo y que había que "darle duro no más y terminar de una vez”. La situación alcanzó la tensión máxima en la segunda intervención que correspondió a uno de los adjudicatarios (AG) con más tiempo en el lugar. Éste se enfrentó oponiéndose a muchas de los aspectos planteados por (MO) y este último lo refutó. Abajo reproducimos un fragmento de esa intervención.

$(\ldots)^{154}$

AG: - ...Las mujeres no tienen nada que decir, ni hacer aquí, ellas nos siguen a nosotros, es el hombre quien lleva la manija... ¿Qué pasa si el 19 no se terminan las casas, se entregan igual?; ...yo ya no trabajo; ... hace cinco años que estoy en esto, tengo más derecho junto con X, X2, X3. ... Tenemos desconfianza de (MO) porque la obra no se termina y él sigue cobrando... Además, está el problema de la gente que no está trabajando, quiero un capataz que vigile a la gente, Ud. no conoce nuestra etnia, no conoce nuestra raza, no sabe cómo son...

MO: - Me parece que lo que dice (AG) es negativo, ;no lo escuchen! \{Y SE DIRIGE A LAS MUJERES\}. Las mujeres son importantes para la finalización de las casas, son quienes están todo el día y miran los detalles...

(...)

Luego, siguieron otras intervenciones. Una de ellas manifestó disgusto en torno al cómputo de horas trabajadas por alguien. Esta inquietud fue subsanada inmediatamente por el arquitecto, aclarando los motivos por los cuales se había actuado de esa manera. No obstante, hubo otra intervención señalando una condición a esa situación. Seguidamente, se manifestó otra inquietud, pero de menor grado de tensión, que tuvo que ver con otra cuestión más urgente: la coordinación de un comedor que atendiera las necesidades de los hijos de los que se encontraban aportando horas de trabajo. En esta ocasión hubo un

${ }^{154}$ Cabe aclarar que, en este caso, el registro de esta asamblea no se realizó mediante la grabación, sino que se tomó nota literal. Por tal razón, no incorporamos aspectos de la prosodia. 
acuerdo generalizado, se propuso y se nombró rápidamente a una de las personas que se haría cargo de conseguir las verduras en forma gratuita y de custodiar la mercadería para tal fin, por su honradez, honestidad y ser un "hermano" (miembro de la iglesia). Hasta ese momento, (PA) no había intervenido en el debate hasta que se le preguntó qué opinaba sobre el tema. Su discurso fue en español y de manera muy pausada. Éste comenzó realizando una síntesis de lo que se había discutido hasta ese momento y opinó a través del ejemplo, en forma de enseñanza, de cómo habían hecho las primeras ocho familias para construir sus viviendas; de todo el esfuerzo que les había demandado; de cómo se cuidaban y alertaban los unos a los otros cuando alguien haraganeaba o estaba enfermo; y de cómo se organizaron para despertarse todos a una misma hora. Terminado este relato, tomó la dirección de la reunión y pidió que se pusieran de acuerdo en cómo iba a funcionar el comedor, quién se encargaría de la cocina, si sería con voluntarios o sólo con miembros del grupo de los veintiocho; y qué clase de comida se haría. En esta oportunidad sí se pidió la opinión de las mujeres, quienes se animaron a hablar un poco, aunque con frases muy cortas y también en español. Después, (MO) tomó nota de quiénes trabajarían en la semana como "cucharines" e interrogó a las mujeres acerca de sus esposos. Finalmente, se cerró la asamblea y fueron despejando el lugar uno por uno. La secretaria también tomó nota.

El análisis:

El primer aspecto que podemos señalar es que, a pesar de haber habido tensión durante la reunión, los hombres tomaron la palabra de una manera ordenada y calmada, con grandes silencios entre turno y turno y tomándolos sólo a través de las miradas. Sus discursos no se superpusieron y dispusieron de un tono de voz moderado. Quienes se encontraban sentados se levantaron al hablar y los que estaban parados erguían su cuerpo dando un paso adelante. Sólo los foráneos irrumpían sobre los discursos -aunque se notaba que hacían todo el esfuerzo por no hacerlo- y se mantuvieron sentados. Por ese motivo, las propuestas e inquietudes planteadas fueron respondidas al instante por estos últimos. En total, siete hombres tobas tomaron la palabra. Entre ellos, sólo (PA) se expresó en lengua toba en voz alta dentro del recinto, aunque lo realizó únicamente antes de dar inicio a la reunión. Esto, sumado al registro y análisis de otras asambleas de este tipo, nos permite afirmar que el español ha sido la lengua de uso predominante. Por su parte, las mujeres no pidieron la palabra y sólo dos de ellas intervinieron para responder una pregunta puntual que se le había hecho y con frases muy cortas también en español. Sin embargo, estuvieron atentas a cada uno de los discursos y respondían extra-lingüísticamente con agudas 
observaciones a todo el recinto, miradas entre ellas, tímidas risas agachando la cabeza y tapándose la boca con las manos, o con pequeños diálogos "en lengua", al tiempo que hablaban con algunos de los niños presentes, y otra amamantaba a su bebé.

El análisis del fragmento de la interacción verbal arriba citado permite distinguir tres tópicos que sintetizan el conflicto y expresan oposición a la propuesta de los foráneos: la participación de las mujeres en la obra; la aparición de nuevos adjudicatarios que aportaron poco trabajo y la desconfianza hacia el maestro mayor de obras. Podemos caracterizar estos tres elementos de orden interétnico e intercultural. En primer lugar, la obra estaba siendo dirigida por no tobas y el hecho de haberse atrasado creó desconfianza sobre un mal manejo del dinero y el aprovechamiento de esa situación para "cobrar sin trabajar lo debido". Este es un tema recurrente en algunos discursos de algunos hombres tobas: la traición del "blanco" en la no redistribución de los recursos y la idea de superioridad y de "sacar ventaja sobre el indio". Segundo, habían sido los no tobas quienes habían tomado la decisión de computar las horas aportadas de los nuevos, aspecto que escapaba a la dinámica de tomar decisiones en forma comunitaria. Y, por último, el tratar de imponer en el grupo un lugar diferente del ocupado tradicionalmente por la mujer. ${ }^{155}$ No obstante, (MO) siguió sosteniendo su posición respondiendo con un juicio de valor y un acto de habla de negación y una orden. Ante esta situación, el rol de (PA) fue de mediador. Su estilo fue indirecto y tomó la actitud de relatar su experiencia y la de los anteriores que lo acompañaron en la misma tarea, dando el ejemplo. No tomó partido por ninguna de las dos posiciones y, luego, instó a avanzar realizando propuestas concretas. Fue la última palabra en ese sentido, ya que las intervenciones que siguieron tuvieron que ver con dicha proposición. ${ }^{156}$

\section{b) Asambleas de la Asociación Civil}

Las asambleas en torno a los aspectos administrativos, directivos y organizativos de la Asociación Civil Toba "Ntaunaq Nam Qom” son de carácter obligatorio y se realizan al menos una vez al año. Las mismas disponen de una estructura formal que es requerida por

\footnotetext{
${ }^{155} \mathrm{Al}$ respecto, cabe aclarar que, si bien la mujer toba alcanzó un rol protagónico durante la construcción de las viviendas y, especialmente, al finalizar la misma, éstas siempre se han mantenido con un perfil bajo, participando, pero hablando sólo lo necesario en las reuniones y asesorando a sus parejas en el contexto de sus hogares.

${ }^{156}$ Cabe mencionar que, aunque se colocó todo el empeño posible, la obra no se terminó para tal fecha y la entrega de las mismas no tuvieron una ceremonia especial como ocurrió en la primera etapa.
} 
el reglamento otorgado por la entidad gubernamental nacional. En estas reuniones sólo participan los miembros socios de la asociación. Para ser un miembro activo se debe mantener al día el pago de una cuota mínima. Para que una sesión tenga lugar debe contar con un número mínimo de asistentes. Como ya se describió en el Capítulo III.2, la asociación está dirigida por una comisión directiva que se renueva cada dos años y es elegida por mayoría en el marco de una asamblea. Con motivo de tener que presentar, por reglamento, ante el ente regulador, un balance de los ingresos y egresos de dinero, el inventario de bienes materiales y una memoria anual, la asociación requiere también de los servicios de un contador.

Como ya se adelantó, la asociación cumplió un rol muy importante en la organización del grupo y la conformación del barrio "Las Malvinas". Durante los primeros años, fue a través de la misma que se logró entrar en el Plan de Viviendas; se ocupó de dirigir y supervisar cada uno de los pasos seguidos a lo largo de la autoconstrucción; luego, coordinó los ingresos a los Planes Trabajar, Jefes y Jefas; realizó las gestiones pertinentes para la creación del comedor de los niños, la huerta, el horno de pan y el taller de costura, entre otras tareas. También incentivó y dirigió las actividades en torno a los festejos especiales celebrados en el barrio, tales como "El Día del Indio”, "El Día de la Madre”, "El Día del Niño". Se presenta a continuación la descripción y análisis de una de las asambleas donde se desarrolló uno de los actos eleccionarios, en enero de 1994.

\begin{tabular}{|c|c|}
\hline \multicolumn{2}{|c|}{ (b)- Asamblea } \\
\hline Dominio: & Vecinal \\
\hline $\begin{array}{r}\text { Variedad Lingüística } \\
\text { Usada: }\end{array}$ & Castellano/ Toba \\
\hline Contextos: & Formal \\
\hline & Privado \\
\hline & Intraétnico \\
\hline
\end{tabular}

\begin{tabular}{|r|l|}
\hline$\bullet \underline{\text { Acto: }}$ & $\begin{array}{l}\text { Asamblea Gral. de la Asociación Civil } \\
\text { Toba “Ntaunaq Nam Qom” 2/1/94 }\end{array}$ \\
\hline Hora del Día: & $11: 30-13: 00 \mathrm{hs}$ \\
\hline Duración del Evento: & $2 \mathrm{hs}$ \\
\hline Dónde se hace: & en el barrio, en el obrador \\
\hline Motivos principales: & $\begin{array}{l}\text { Poner a consideración el Balance e } \\
\text { Inventario de la asociación de 1991. } \\
\text { Elección de Autoridades de la asociación. }\end{array}$ \\
\hline
\end{tabular}




\begin{tabular}{|r|l|}
\hline Participantes: & $\begin{array}{l}\text { 30 personas aproximadamente: } \\
-29 \text { hombres y mujeres tobas } \\
\text { - el contador (no toba) } \\
\text { - niños que entran y salen }\end{array}$ \\
\hline $\begin{array}{r}\text { Relación entre los } \\
\text { participantes: }\end{array}$ & $\begin{array}{l}\text { Miembros socios de la asociación, } \\
\text { algunos no residentes en La Plata }\end{array}$ \\
\hline $\begin{array}{r}\text { Quiénes no pueden } \\
\text { participar: }\end{array}$ & Quienes no son socios \\
\hline $\begin{array}{r}\text { Frecuencia en que se } \\
\text { realiza el evento: }\end{array}$ & Cada 2 años aproximadamente \\
\hline $\begin{array}{r}\text { Observaciones del uso de } \\
\text { las lenguas: }\end{array}$ & $\begin{array}{l}\text { La reunión se inició en castellano, } \\
\text { presidida por el presidente de la } \\
\text { asociación y ayudado con el secretario, } \\
\text { tesorero y el contador (no toba). Las } \\
\text { lecturas de las actas se realizaron en } \\
\text { castellano. La lengua toba predominó en } \\
\text { todas las instancias de discusión, } \\
\text { explicación de lo leído, aclaraciones de lo } \\
\text { hecho. }\end{array}$ \\
\hline
\end{tabular}

\section{El contexto:}

La reunión se llevó a cabo un día domingo en el obrador del barrio, a las 11:30hs de la mañana y tuvo una duración de dos horas. De los cincuenta y ocho socios registrados en la asociación, estuvieron presentes ese día aproximadamente treinta, ${ }^{157}$ por lo que se contó con el quórum mínimo para su desarrollo. Además, estuvo presente el contador (no toba). Algunos de los socios que asistieron no residían en La Plata, vinieron desde el Gran Buenos Aires y también del Chaco. La reunión se realizó un día no laborable a los fines de facilitar a todos los socios la asistencia.

A un lado del recinto, presidiendo la reunión, se ubicaron: el contador y los miembros de la comisión directiva saliente, frente a unas mesas dispuestas como escritorio. Atrás, un pizarrón donde figuraba la fecha, se anunciaba la asamblea y el principal objetivo del orden del día: "Poner a consideración el Balance de 1991 y Elegir nueva Comisión Directiva" y, en el rincón derecho, una bandera argentina con una cinta bordada que decía: “Ntaunaq Nam Qom”. El resto de los presentes se ubicaron sentados mirando hacia la comisión directiva, a un metro y medio de distancia, y en forma de semicírculo. También debemos destacar la participación de los niños que entraban y salían del recinto cuantas veces querían, lloraban, escuchaban y miraban.

\footnotetext{
${ }^{157}$ Nuevamente observamos en este caso la presencia mayoritaria de las mujeres en las reuniones comunales, aunque su participación activa en las mismas sea menor.
} 


\section{LA AGENDA DE LA ASAMBLEA YA ESTABA PREESTABLECIDA AL MOMENTO DE INICIAR LA REUNIÓN} Y FUE LA SIGUIENTE:

$>$ Lectura y consideración del acta anterior

$>$ Motivos por los cuales se llamaba fuera de término

$>$ Consideración del inventario, balance general, etc.

$>$ Elección de nueve miembros titulares y tres suplentes de la comisión directiva

$>$ Elección de dos socios para firmar el acta

\section{Desarrollo de la asamblea:}

Una vez que ingresaron los socios al recinto, el contador se dispuso a tomar lista y el presidente (PR) saliente firmó el acta y dio por iniciada la asamblea con las siguientes palabras en español: “Vamos a empezar la asamblea...” y, después, comenzó a leer el acta, aunque con mucha dificultad, escrita en un lenguaje técnico; el contador le brindaba algo de ayuda corrigiéndole algunas palabras. Un integrante de la comisión directiva saliente (R) pidió que se nombrara a un voluntario para que leyera las actas e hiciera de secretario; posteriormente, $(\mathrm{PR})$ continuó su discurso en lengua toba.

La persona que desempeñó el rol de secretaria (S) de la asamblea prosiguió con la lectura del acta finalizando con la siguiente frase: "Puestos en consideración de los artículos tanto en lengua castellana como en la de la comunidad toba... resultan aprobados". Luego de un largo silencio, el contador ordenó: "Tienen que aprobar el acta" y uno de los presentes (PO) preguntó: “¿cómo va a hacer?”. Seguidamente, (S) pasó a explicar algunos de los puntos tratados en el acta, en español, y, especialmente, el motivo de haber hecho el cambio de domicilio de la asociación. Los presentes demostraron confusión, nadie decía nada y, de pronto, uno de ellos hizo una pregunta en lengua toba y respondió el $(\mathrm{PR})$ en esa misma lengua. Seguidamente, otra intervención en esta última lengua y (PR) volvió a responder. Finalmente, (R) propuso: "Ya que está hecha la aclaración que los que están por lo afirmativo que levanten la mano" y todos levantaron la mano. Y agregó: "Puesto a consideración en idioma castellano y de la comunidad". De esa manera, se dio por aprobada el acta anterior.

Prosiguió (PR). Inició su discurso en español y lo continuó en toba planteando los motivos por los cuales no se habían hecho los balances anteriores. (R) tomó el turno de la palabra y se unió al debate planteado por (PR) de un modo muy pausado y en español y terminó diciendo: "hay que poner en orden los papeles". A continuación, el contador pidió 
la palabra para explicar lo que se había estado hablando hasta ese momento. Su intervención fue hecha en un lenguaje muy técnico y, a continuación, le solicitó a (S) que prosiguiera con la lectura de la Memoria del Balance 91-92. Al finalizar la lectura, el contador volvió a tomar la palabra explicando la parte contable del mismo. El (PR) intervino en lengua toba y, al culminar su discurso, cambió de código y preguntó: “¿quién quiere firmar?". Hubo silencio. (R) también aclaró los puntos del balance intercambiando entre español y toba y, al finalizar, todos levantaron sus manos votando por la aprobación del balance.

Una vez terminada la votación, (S) leyó en castellano el cuarto punto del orden del día y lo explicó en castellano, aunque con un lenguaje mucho más simple y preguntó: “¿hay alguna lista que tengan para presentar?".

En ese momento, los participantes intercambiaron algunas palabras entre ellos en voz baja, pero nadie intervino.

Pasaron unos minutos y, como nadie decía nada, (R) propuso: "Bueno, hermanos, están escuchando la nómina más o menos propuesta, si no hay una objeción, si no están de acuerdo, se vota. Tienen la palabra”.

Hubo unos minutos de silencio y uno de los presentes (FG) intervino en castellano: "Yo pido la palabra. Yo quiero saber ¿los nombres qué fueron elegidos por la comisión o entre ellos"?.

A lo que el contador respondió: “¡no!, ellos son los nombres nada más, después se les da el cargo. Son representantes".

Otro de los presentes que ya había intervenido, (PO) preguntó: “¿no se había hecho ya eso?

Y (S) le responde: "eso internamente”.

Ante este malentendido, (R) propuso: "Por qué no hacemos más práctico. Se dice el primero. Para el cargo de presidente, ¿están de acuerdo el hermano JR?”. Y todos levantaron las manos. Y así siguió, nombrando a cada uno de los candidatos propuestos hasta armarse la comisión directiva completa. Al terminar, pidió un aplauso.

Luego que (S) leyó lo acordado, el flamante presidente tomó la palabra. Comenzó su discurso en castellano y lo continuó en toba; su intervención duró aproximadamente veinte minutos y en ella realizó una síntesis de toda la lucha, la organización, y aconsejó sobre lo que se debía hacer de ahora en más. Además, introdujo aspectos bíblicos haciendo 
referencia a la creación del hombre y la mujer. Al acabar, lo aplaudieron y (R) agregó: "Esto es lo que eligieron ustedes. La comisión no va a tomar la decisión, sino que la decisión la van a tomar ustedes”, y también lo aplaudieron. El contador elaboró el acta correspondiente del día y los elegidos la firmaron con mucho cuidado. Al retirarse el contador se pidió un fuerte aplauso para él y éste saludó a toda la comisión directiva saliente. Este acto marcó la culminación del acto eleccionario, pero la reunión continuó dirigida por la nueva comisión directiva de una manera más informal. El principal planteo fue de carácter comunicativo ya que se preguntó directamente si había algún problema en las informaciones que realizaba la comisión, si no se entendía lo que se decía.

El análisis:

Si bien (PR) presidió la asamblea, quien la dirigió realmente fue el contador manifestando y coordinado en todo momento los pasos que se debían seguir -según el reglamento-. Hubo una mayor participación de los hombres. Se generaron muchos silencios entre las intervenciones donde los participantes se quedaban mirándose los unos a los otros, como desconcertados, en especial, luego de la lectura de los documentos. Se observó en esta oportunidad, como en otras reuniones de este tipo, cierta dificultad para avanzar sobre los aspectos planteados. La estructura de la asamblea responde a las características que se piden en el reglamento: se toma lista de los presentes, se elabora un acta, se da lectura a la orden del día; se plantean y debaten los puntos y se vota su aprobación. El lenguaje utilizado en las actas, balances, memorias e inventarios están hechos en un registro técnico y en muchas ocasiones no llegan al entendimiento de los presentes. Es por esta razón que se opta por tomar como estrategia un elemento propio de la comunidad: se recurre al uso de la lengua toba para explicar y ampliar estos aspectos que no quedan claros. Muestra de ello es la consigna introducida en el documento leído: "puestos en consideración en lengua castellana como en la de la comunidad toba". Esto evidencia que, si bien este tipo de actos requiere la lengua dominante (el español) por norma, la lengua materna ocupa un rol muy importante y se recurre a ella en todo momento, actuando en los momentos más destacados y decisivos; la lengua vernácula sirve para aclarar, explicar, ampliar y ayudar a decidir. No obstante, se produce la mezcla de códigos empleando préstamos del español para los vocablos del léxico contable que no tienen traducción, como "balance" e "inventario", entre otros. Por su parte, el español domina en cada una de las instancias propias de la asamblea: lectura, orden del día, preguntas sobre la aprobación o no de los documentos, etc. El contador respeta esta 
estrategia y lo hace constar en las actas. También, sabe que, aunque se trate de una situación formal, los participantes tienen sus propias características y formas de decidir; pide permiso para intervenir, manifiesta paciencia, pide que se le traduzca lo que se dijo en la otra lengua; pero, luego, acelera el proceso ordenando las lecturas. El ritmo de la gente toba es distinto del contador. Toman las decisiones con más calma. En estas circunstancias, observamos el papel de (R) como broker o articulador. Se trata de una persona muy respetada y miembro fundador de la asociación. Vivió un tiempo en el Gran Buenos Aires, pero tomó la decisión de regresar al Chaco con parte de su familia luego de haberse formado la asociación. Algunos hijos integraron el plan de viviendas. Se trata de un bilingüe con predominio del español. Su trayectoria a lo largo del proceso de conformación de la asociación civil, lo hace una persona con gran experiencia en el manejo de reuniones. Es por ello por lo que, en todo momento, fue quien introdujo dinamismo en la asamblea y propuso opciones para acelerar el proceso de votación. También tuvo una actitud de alertar a la gente en las decisiones que se tomaban: "esto es lo que eligieron ustedes".

(PR) fue quien utilizó como recurso lingüístico la lengua materna con el objetivo de llegar más a la comprensión de la gente y también se emocionó cuando fue reelegido como presidente de la asociación. Cabe destacar los cambios de código realizados durante su rol de conductor de la asamblea, llegando a la gente en lengua materna pero, sobre todo, respetando las formas características de una situación comunicativa como esta.

\section{c) Asambleas Religiosas}

En el ámbito religioso, hemos destacado la práctica del pentecostalismo y la constitución de una Iglesia Evangélica Toba. ${ }^{158}$ Aparte de las sesiones de culto ejecutadas al menos dos veces a la semana y la celebración de la Santa Cena, una vez al mes, en el desarrollo del culto están implicadas ciertas reuniones periódicas que tienen que ver con aspectos organizativos y administrativos de la iglesia. Éstas tienen el carácter de asambleas donde participan los miembros de la junta directiva y los fieles-socios de la Iglesia Unida Templo de Fe. Podríamos caracterizar dichas reuniones como vecinales e interétnicas ya que asisten también vecinos no tobas, algunos de los cuales han integrado la junta directiva. A continuación, describimos y analizamos uno de esos eventos.

\begin{tabular}{|c|l|}
\hline \multicolumn{2}{|c|}{ (c)- Asamblea del Culto } \\
\hline Dominio: & Religioso \\
\hline
\end{tabular}

${ }^{158}$ Ver Capítulo III.3. 


\begin{tabular}{|r|l|}
\hline $\begin{array}{r}\text { Variedad Lingüística } \\
\text { Usada: }\end{array}$ & Castellano/ Toba \\
\hline Contextos: & Formal \\
\hline & Privado \\
\hline & Interétnico \\
\hline
\end{tabular}

\begin{tabular}{|c|c|}
\hline - $\underline{\text { Acto: }}$ & Reunión de organización de la iglesia \\
\hline Duración del Evento: & $2 \mathrm{hs}$. aproximadamente \\
\hline Dónde se hace: & En la iglesia del barrio \\
\hline Motivo: & $\begin{array}{l}\text { Elegir las autoridades de la Iglesia Unida } \\
\text { Templo de Fe }\end{array}$ \\
\hline Participantes: & $\begin{array}{l}6 \text { hombres tobas } \\
1 \text { hombre blanco } \\
7 \text { mujeres tobas } \\
3 \text { mujeres blancas } \\
\text { (chicos y otros adultos que entraban y } \\
\text { salían) }\end{array}$ \\
\hline $\begin{array}{r}\text { Relación entre los } \\
\text { participantes: }\end{array}$ & $\begin{array}{l}\text { Miembros de la Iglesia Unida Templo de } \\
\mathrm{Fe}\end{array}$ \\
\hline $\begin{array}{r}\text { Quiénes no pueden } \\
\text { participar: }\end{array}$ & $\begin{array}{l}\text { La entrada no está prohibida para los no } \\
\text { creyentes; sin embargo, fue } \\
\text { principalmente una reunión } \\
\text { autoridades }\end{array}$ \\
\hline Lengua empleada: & $\begin{array}{l}\text { La reunión se realizó en castellano, pero } \\
\text { en varias ocasiones, el pastor se dirigió a } \\
\text { los presentes en idioma qom l'aqtaqa', } \\
\text { asegurándose que éstos habían entendido } \\
\text { el tema de discusión. }\end{array}$ \\
\hline
\end{tabular}

\section{El contexto:}

La reunión se desarrolló en octubre de 1996 en el obrador. Éste había sido acondicionado para tal fin: el espacio estaba despejado de herramientas, se encontraba adornado con guirnaldas de papel y un tablón de madera que decía: "Iglesia Unida Templo de Fe. Dios es amor"; una cajita con la leyenda "ofrenda"; una mesa de plástico que hacía de altar y un grabador con micrófono externo. Mientras se esperaba que llegaran los participantes, un grupo de siete hombres se disponían sentados en semicírculo mirando hacia el público; entre ellos, uno era no indígena. Como audiencia, sentadas en banquetas, las mujeres. La mayoría de ellas eran tobas y algunas sostenían en sus brazos a sus hijos. La reunión tuvo una duración de dos horas aproximadamente y participaron alrededor de veinte personas. El motivo de la convocatoria fue la elección de las autoridades de la 
Iglesia Unida Templo de Fe, las acreditaciones correspondientes y, en nuestro caso, se tuvo el rol de sacar las fotos para las credenciales.

\section{El desarrollo:}

La reunión estuvo encabezada por el pastor (JR). Se inició con un pedido de realizar una oración: - "Primero vamos a orar"-. Seguidamente, todos los fieles agacharon sus cabezas, cerraron sus ojos y comenzaron a orar en voz alta y al unísono. La oración tuvo una duración de unos cinco minutos; fue, aparentemente, la misma para todos, aunque muy pocas palabras se llegaban a comprender. Sólo se destacaba la voz de (JR) que enfatizaba en un tono de voz más elevado algunas palabras como "Señor", “Jesús". La oración, que en un principio comenzó en forma monótona, fue aumentando su intensidad, al punto de que algunos parecían implorar y hasta llorar, alzando los brazos con las palmas de las manos hacia arriba. En un determinado momento, (JR) dio la orden para finalizar: - "Amen”-, y todos callaron al mismo tiempo. Luego, continuó en español con el relato de la reunión que había tenido con las autoridades de la Iglesia Evangélica Unida (IEU) en Buenos Aires motivo principal de la reunión-. A medida que (JR) iba avanzando en su discurso, los fieles iban acompañando con ciertas exclamaciones tales como: “¡Amén!”, “¡Aleluya!”, “¡Amén hermanos!”. En especial, esta actitud era una característica de los no tobas. Una vez que (JR) terminó de explicar, siguió con su discurso en lengua toba. Se observó que a raíz de este cambio de código lingüístico hubo también un cambio de actitud por parte de la gente toba, quienes estuvieron más atentos e iban asintiendo con la cabeza; mientras que los no tobas permanecieron callados. En varias oportunidades intervino (DC), esposa de (JR), y solicitó que (JB) también hablara y relatara lo acontecido en la reunión, puesto que él también había estado presente. Éste, a diferencia de (JR), fue más tímido y su tono de voz más bajo. Por este motivo se le colocó el micrófono. Su discurso fue hecho en español, pero tuvo la particularidad de acabar cada reflexión o frase con un: "así escuché", "esto fue lo que escuché", "eso fue lo que dijo el pastor". Luego, continuaron orando, hasta que (DC) interrumpió para que se tomaran las fotos para las credenciales. Las fotos fueron tomadas afuera, en uno de los laterales del obrador. Primero, a los representantes de la iglesia (diáconos y diaconisas) y, luego, algunos fieles y sus hijos. Los hombres vistieron trajes para la ocasión y se fueron prestando la corbata.

\section{El análisis:}

En primer lugar, observamos que si bien hubo participación de gente no toba en la reunión y que ésta integra la junta directiva de la iglesia, la misma no tuvo un rol 
destacado. La reunión fue dirigida por el pastor toba y su esposa y quienes tomaron la palabra también fueron tobas. Los no tobas sólo acompañaron con algunas frases durante los discursos, pero no opinaron. La mayoría de ellos son vecinos del barrio y sostienen con los fieles y no fieles tobas una relación amistosa y de vecindad. Se mostraron respetuosos y tolerantes al momento de darse el cambio de código lingüístico, y también fueron invitados por el pastor a tomarse las fotos. A diferencia de la gente toba, éstos, y en especial las mujeres, fueron más locuaces, desinhibidas y realizaron comentarios y exclamaciones tales como: "sacame bien, eh?".

En segundo lugar, podemos destacar que, aunque se trató de una asamblea, tuvo la particularidad de conservar la estructura propia del culto. El pastor fue quien tuvo la palabra y fue su esposa quien invitó a otros a intervenir. Otra característica fue el uso del micrófono que, en las reuniones comunales, no se suele usar. Algunos fieles sostenían en sus manos una Biblia. Los discursos de (JR) y (JB) no fueron prédicas. Sin embargo, tuvieron el acompañamiento de la gente con expresiones tales como "amén”, "aleluya", que suelen realizarse durante las prédicas y testimonios que tienen lugar en los cultos. El discurso de (JB) fue de tipo testimonial, utilizando como recurso lingüístico las expresiones: "así escuché", "eso fue lo que dijo el pastor", como estrategia de dar más autenticidad a su relato. Cabe destacar que la solicitud de (DC) para que (JB) hable también y cuente los detalles de la reunión fue una forma de dar más credibilidad al pastor y dejar constancia de que éste decía la verdad. Esto se debió a que había cierta desconfianza por parte de algunos fieles y el tema era delicado: se trataba de tomar la decisión de asociarse a la Iglesia Evangélica Unida para poder tener el fichero y permiso correspondiente para el funcionamiento correcto de la iglesia.

Y, por último, aunque el español fue la lengua que dominó todo el tiempo, la lengua toba ocupó un rol esencial al momento de tener que tomar decisiones. Esto convirtió al evento en una situación comunicativa típicamente toba, aun con la presencia de no indígenas en la junta directiva y entre los fieles.

\section{- Sesiones de Culto}

En el Capítulo III.3 ya hemos descrito en detalle las características de las sesiones del culto toba. Durante las mismas se expresan diferentes eventos de habla, tales como la prédica que ejecuta principalmente el pastor; la plegaria en la que intervienen todos los fieles; la lectura de pasajes bíblicos; los cantos; y los rezos u oraciones. Las sesiones de culto tienen lugar en la iglesia del barrio por lo menos dos veces a la semana con una 
duración de dos a más horas. Están dirigidas por el pastor toba y asisten fieles tobas y no tobas, así como, en algunas ocasiones, invitados de otras iglesias de la zona, localidades cercanas o provincias. Cada una de las sesiones presentan diversos aspectos muy ricos de analizar; exponemos a continuación el análisis de una de estas sesiones a modo de modelo.

\begin{tabular}{|r|l|}
\hline \multicolumn{2}{|c|}{ Sesión de Culto } \\
\hline Dominio: & Religioso \\
\hline $\begin{array}{r}\text { Variedad Lingüística } \\
\text { Usada: }\end{array}$ & Castellano/ Toba \\
\hline Contextos: & Formal \\
\hline & Privado \\
\hline & Intraétnico \\
\hline
\end{tabular}

\begin{tabular}{|c|c|}
\hline - $\underline{\text { Acto: }}$ & $\begin{array}{l}\text { Movimiento Evangélico: visita de un } \\
\text { pastor del Chaco }\end{array}$ \\
\hline Duración del Evento: & Una semana \\
\hline Dónde se hace: & En la iglesia del barrio \\
\hline Motivos: & $\begin{array}{l}\text { - Renovar la fe. } \\
\text { - Recibir nuevos fieles y a quienes se } \\
\text { habían alejado } \\
\text { - Realizar Bautismos, Consagraciones } \\
\text { - Curar enfermos }\end{array}$ \\
\hline Participantes: & $\begin{array}{l}\text { - Un pastor proveniente del Chaco, con } \\
\text { su familia } \\
\text { - La gente del barrio (abuelos, adultos, } \\
\text { jóvenes y niños) y gente toba del Gran } \\
\text { Bs. As. }\end{array}$ \\
\hline $\begin{array}{r}\text { Relación entre los } \\
\text { participantes: }\end{array}$ & Fieles del culto evangélico \\
\hline $\begin{array}{r}\text { Quiénes no pueden } \\
\text { participar: }\end{array}$ & La entrada es libre, aunque "vigilada" \\
\hline Lengua empleada: & $\begin{array}{l}\text { Se realiza una alternancia entre el } \\
\text { castellano: lectura de la Biblia, actos } \\
\text { formales del rito evangélico, con la } \\
\text { lengua toba en partes de la oratoria del } \\
\text { pastor, preguntas dirigidas al público, } \\
\text { rezos, aclaraciones de pasajes bíblicos. }\end{array}$ \\
\hline
\end{tabular}

El contexto:

El culto se desarrolló un día domingo. Por la mañana había habido bautismos, aprovechando la presencia de un pastor que había venido de visita desde el Chaco. Esto 
motivó que se desarrollara un "Movimiento Evangélico" que tuvo una duración de más de una semana. El fragmento que presentamos a continuación corresponde al culto llevado a cabo por la tarde de ese día. Participaron alrededor de sesenta personas entre adultos, jóvenes y niños, la mayoría del barrio "Las Malvinas” y también algunos fieles tobas de las localidades del Gran Buenos Aires. Durante el mismo hubo consagración, reconciliación, Santa Cena e imposición de manos. ${ }^{159}$

Los fieles comenzaron a llegar alrededor de las $18 \mathrm{hs}$ convocados por los sonidos de la música y los cánticos de los coristas. Todos vestidos con sus mejores ropas; los niños recién bañados y peinados, y la mayoría con una Biblia en sus manos. En ese entonces septiembre de 1994- la iglesia funcionaba en el obrador: un espacio chico, con las herramientas de trabajo para la construcción arrinconadas, una pequeña mesa como altar y sillas y banquetas para los oyentes, de manera que quedara acondicionado para el culto. Una Biblia, un pan, una jarra con vino tapados con un mantelito y una bolsa tejida con fibras de colores de chaguar reposaban sobre el altar. Tres pastores tobas dirigieron el evento: el pastor 1 (P1) y el pastor 2 (P2) oriundos de La Plata y el pastor 3 (P3) del Chaco. El coro, ubicado atrás de los pastores, estaba conformado por jóvenes varones con guitarras y un bombo. En la primera fila, algunas niñas y adolescentes tocaban panderetas y cantaban acompañando al coro principal.

\section{El desarrollo:}

Los cánticos fueron invitando a entrar a los fieles mientras un portero los recibía en la puerta y los acomodaba. El lugar estaba colmado, con gente sentada y otra parada. De pronto, una de las canciones finalizó con un “jGloria a Dios! Amén” y el (P2) inició la reunión e introdujo al pastor que había venido recientemente del Chaco. Éste tomó la palabra. Mencionó un versículo de la Biblia y leyó un texto alusivo al primogénito. En la primera fila del público se encontraba sentada una mujer con su hijo pequeño. Le siguió una canción relacionada con el tema de la consagración: "Los niños salvados...directo a la gloria del Salvador”, al tiempo que el (P3) decía una oración. El (P1) alzó al niño y con los ojos cerrados invocó exclamando: - “invocamos a este niño, aleluya, bendice a este niño!”. El (P3) agregó: - “Amen. Puede entregar a la señora”- e inmediatamente, con tono de comentario, se dirigió al público en lengua toba. Al terminar, prosiguió en español; pidió que tomaran asiento, volvió a leer la Biblia y habló unos minutos sobre el tema de la

159 En el esquema que aparece en la Figura $\mathrm{N}^{\mathrm{o}} 10$, se destacan cada uno de los pasos que conllevó esta celebración, las actividades realizadas y se señalan los códigos lingüísticos utilizados. 
conciliación, y preguntó: - ¿Cuántos están contentos hermanos? Amén”- y todos levantaron la mano. Continuó diciendo: - “iHoy es necesario reconciliarnos con el Señor y consagrarnos!”, "los que nunca participaron de la gloria del Señor!”-. El coro volvió a cantar: "Una mañana Cristo vendrá...". Mientras tanto, un grupo de cinco personas conformado por adultos y jóvenes pasaron adelante y se colocaron en hilera frente al altar, al tiempo que el (P1) los ordenó y se colocó al lado de ellos. Hubo llantos. El (P3) se les acercó y habló al oído. La canción fue interpretada de manera elevada y, al finalizar, se oyeron llantos, gritos y gente orar. Entonces, el (P3) dijo en español: -“¡Aquí tengo un hermano que hace once años que dejó el Evangelio!”- y preguntó: - ¿¿Cuántos están contentos hermanos?”-, y todos levantaron la mano, y agregó: - “y este otro joven dejó un año y medio"-. El coro volvió a interpretar una canción: "Una mañana Cristo vendrá” y el (P3) comenzó a bailar con pequeños saltitos en el lugar. La canción finalizó y el (P3) se dirigió a su audiencia en lengua toba diciendo: - "les estoy hablando en el dialecto..."-. Los candidatos por reconciliarse se arrodillaron sobre una red hecha de chaguar de colores. El (P1) levantó su mano mientras oraba y el (P3) danzaba en el lugar sosteniendo la Biblia en su mano izquierda y el micrófono en la derecha. Algunos fieles lloraron y, de pronto, el coro se silenció y cada uno de los presentes comenzó a orar, sobresaliendo la plegaria del (P3). Los fieles levantaron su brazo derecho y bajaron la cabeza. El pastor terminó y todos callaron. El (P1) y el principal del coro se acercaron a los reconciliados y saludaron uno por uno con dos besos en cada mejilla y se dieron las manos. Luego, todos hicieron lo mismo.

A continuación, se inició una nueva canción cuyo estribillo decía:

"Cristo viene, Cristo salva, aleluya".

El (P3) también saludó dándole su mano a cada uno de los reconciliados y les decía:

-“'Aleluya hermanos! Ya han sido presentados”.

Y le siguió el (P1):

- “Gracias a Dios, hemos recibido un gozo muy grande de nuestro Señor Jesucristo.

Gracias por los hermanos al escuchar este mensaje a los reconciliados, donde la familia va creciendo".

Uno de los fieles exclamó:

-“'Gloria a Dios!”.

(P1) continuó: 
- "Claro que sí, le resta toda nuestra responsabilidad de que todos sigan el

Evangelio. Que vengan nuestras hermanas que tienen la responsabilidad de repartir el vino y el pan de nuestro Señor Jesucristo. Es mi esposa y, la otra, la esposa del pastor $x$ [P2]." - y entre ellos conversaron en lengua toba.

Seguidamente, el (P2) leyó el pasaje bíblico correspondiente a Corintios 23, mientras el (P1) bendecía el pan y el vino. Las mujeres desmenuzaron el pan que se encontraba en el altar sobre una bandejita. El (P1) realizó una plegaria en español y todos lo acompañaron con una canción. Una de las mujeres repartió a cada uno de los presentes, que habían sido bautizados, un trocito de pan y se lo quedaron en la mano. El (P1) dijo: - "seguimos la lección”- y ordenó: - “comemos todos juntos...”- y leyó: -“tomad y comed porque este es mi cuerpo"-. Los fieles comenzaron a agradecer en voz alta en una práctica de glosolalia y el (P1) agregó: - "si hay alguno que no alcanzó a tomar el pan que levante la mano”- y comenzó a rezar. Todos comieron el pan al mismo tiempo. Luego, el (P1) dijo una oración, tomó el vaso de vino y leyó: - "Tomó la copa diciendo... en memoria de mi”- y agregó dirigiéndose a los presentes: - "Este es un vaso en vez de copa; este es vino hecho de los hombres. Antes era jugo de uva, ahora le agregan alcohol y otras cosas..." - y finalizó: “como dice la Señora Escritura”. El (P3) leyó: - "esta copa es mi sangre...”- y a continuación todos dijeron una oración y cantaron a capella el Himno de Gloria: "Yo me acuerdo que Jesús por mí murió”. Mientras tanto, ambas mujeres repartieron el vino: una de ellas llevaba el vaso y lo entregaba a los fieles quienes bebían un sorbo y la otra sostenía una jarra con la cual se llenaba el vaso cuando se acababa su contenido. Una vez que todos bebieron el vino, se arrodillaron y empezaron a orar, gritar y llorar, cada vez más fuerte, llegando nuevamente al estado de glosolalia y alcanzando el gozo. El (P1) preguntó si todos habían participado y continuó su discurso en lengua toba hasta que le pidió, en castellano, al "hermano evangelista" (P3) que realizara una oración y que les diera "ánimo". Éste empezó una canción que fue acompañada con panderetas y palmas; el pastor danzaba efectuando pequeños saltos en el lugar y expresaba agregando a la canción: “'Aleluya!”, “'Gloria todos!”, “'Cristo vuelve!”, “'Este es el día que hizo Jehová!”, “'Todo el pueblo alaba a él”, “;Gloria a Dios, amén, amén!”. Y preguntaba: - ¿Cuántos están contentos cuando hay movimientos?"- y todos levantaban las manos y así juntos exclamaban: -“;Gloria a Dios!”. Algunas mujeres también empezaron a danzar al compás de la música con un brazo alzado y dando pequeños saltos. De repente, la canción finalizó y todos comenzaron a llorar, gritar y orar produciéndose un estado de glosolalia y éxtasis. Luego de unos minutos, uno de los pastores tomó la palabra mientras los fieles iban 
disminuyendo sus rezos, secaban las lágrimas y se acomodaban nuevamente en sus lugares, e invitó a uno de los presentes a pasar al frente para realizar una imposición de manos. Al finalizar, todos se saludaron.

El análisis:

Si bien esta fue una ceremonia particular, porque contó con la presencia de un pastor invitado proveniente del Chaco con el que se había generado y promovido una semana de "movimiento evangélico", los hechos ocurridos durante todo el evento fueron típicos de las sesiones de culto cotidianas. Generalmente, son dos o tres pastores los que ofician la ceremonia del culto y muchas veces hay pastores invitados o coros de las iglesias cercanas o localidades del Gran Buenos Aires. Las ceremonias cuentan también con una especie de "maestro de ceremonia", quien tiene el rol de planificar con antelación, junto con los pastores, los pasos a seguir; registrar los nombres de los invitados, los postulantes a ser consagrados y los fieles que quieren reconciliarse. También hay ensayos previos de los coristas que preparan las canciones alusivas para ese día. Todo esto se anota en un papel que se usa como guía durante la ceremonia. Es decir, todo está organizado previamente. Los pastores tienen muy en claro sus papeles y no se superponen. La lengua empleada es básicamente el español para cada uno de los pasos y eventos de habla que son propios del rito evangélico: lectura de la Biblia en español (aunque existe una versión de la Biblia en la lengua toba, no se utiliza); sermones o prédicas; plegarias; canciones; imposición de manos; reconciliación, consagración; Santa Cena; y, en especial, aquellos ítems léxicos que se repiten constantemente y que corresponden a exclamaciones de gozo, preguntas; expresiones que se repiten e incentivan a la gente y que son hechas tanto por los pastores como por los fieles oyentes, tales como: “AAmén hermanos!, “¡Gloria a Dios!”, etc. adquieren una finalidad retórica. Éstas se repiten continuamente y son parte de la estrategia comunicativa en el discurso evangélico. Los oyentes las repiten independientemente unos de otros, a medida que escuchan la prédica del pastor, como asintiendo sus palabras; al tiempo que los pastores las introducen para involucrar a la gente en su discurso y darles ánimos. Cabe destacar que éstas son frases "prestadas" e introducidas por el ritual evangélico, no propias del habla toba. Asimismo, durante las prédicas de los pastores éstos repiten frases y expresiones bíblicas de memoria o aprendidas de otros pastores. En algunas ocasiones entremezclan palabras como, en nuestro ejemplo: "como dice la Señora Escritura", en vez de las "Santas Escrituras". Por su parte, la lengua toba está también presente, aunque en menor grado y en relación a aspectos más íntimos que ocurren en cada 
uno de los eventos de habla del rito evangélico. Ésta es usada por los pastores para reforzar los mensajes que quieren transmitir en su prédica, en los momentos claves de mayor fervor, también para dirigirse entre ellos y ordenar los pasos a seguir en la ceremonia. Asimismo, algunas plegarias y rezos de los fieles también son hechas en esta lengua hasta llegar al punto de la glosolalia, donde es introducida. ${ }^{160}$

Es de destacar, además, que las sesiones importan un fuerte contenido emocional que conlleva a la unión y la solidaridad entre los presentes, o sea un estado de comunión provocado no sólo por los pastores sino también por los participantes. Desde que se inicia la ceremonia, una persona recibe a los fieles en la puerta, los hace pasar y ubica en las bancas -o lugar que le corresponda-. Los actos de presentación de un niño recién nacido a Dios, de reconciliación, hasta la misma sanación implican la idea de compartir todos juntos no sólo la misma ideología, sino también la misma comunidad, ser parte integrante de la misma. Esta idea se ve reforzada al momento de compartir el pan y el vino, donde el pastor pide a su audiencia que nadie coma hasta que todos hayan recibido su porción y ordena: "comamos todos juntos"; cuando se da la imposición de manos que dirige el pastor sobre la cabeza de quien se siente enfermo o es invitado a la comunidad evangélica, pero que, a la vez, es realizada por todos los presentes que acompañan con un rezo en voz alta y levantando su mano derecha; o cuando se saludan a los consagrados, reconciliados, sanados y se llora de emoción por ello.

En cuanto a los discursos hechos por los pastores durante la prédica, en general, son comentarios bíblicos que readaptan a situaciones y lugares del Chaco y de la vida cotidiana. Es frecuente que se hable de Jesús caminando por el desierto chaqueño o caminando y pescando por el río Bermejo. Suelen tener elementos que le dan carácter testimonial: "yo lo vi”, “yo lo oí”, se relatan experiencias personales. También observamos reflexividad cultural al realizar análisis metaculturales sobre pasajes bíblicos: "este es vino hecho por los hombres, antes era jugo de uva, ahora le agregan alcohol y otras cosas...”. Los discursos son cortos y cada tanto utilizan como recurso verbal la lengua toba.

\section{- Celebraciones}

Nos referimos con la categoría de celebraciones a aquellas situaciones comunicativas que convocan la participación de la mayoría de los integrantes de la comunidad toba del

\footnotetext{
${ }^{160}$ Cabe aclarar que no nos fue posible registrar con claridad este momento. Debido a que la gente está tan compenetrada durante la glosolalia, sólo se siente un gran bullicio que se va incrementando con frases ininteligibles, pero donde se pueden percibir léxicos tobas.
} 
Barrio "Las Malvinas" para el festejo de fechas prefijadas, consideradas importantes para el grupo y la etnia, y que se repiten anualmente. Estas son tanto cívico-comunitarias como religiosas.

\section{a) Celebraciones religiosas}

Una fecha celebrada todos los años es el 9 de Julio, pero la misma no alude a la fiesta cívica nacional, sino al Aniversario de la conformación de la iglesia del barrio: Iglesia Unida Templo de Fe.

\begin{tabular}{|r|l|}
\hline \multicolumn{2}{|c|}{ (a) Celebración Religiosa } \\
\hline Dominio: & Religioso \\
\hline $\begin{array}{r}\text { Variedad Lingüística } \\
\text { Usada: }\end{array}$ & $\begin{array}{l}\text { Castellano y también en } \\
\text { Toba }\end{array}$ \\
\hline Contextos: & Formal \\
\hline & Privado \\
\hline & Interétnico \\
\hline
\end{tabular}

\begin{tabular}{|c|c|}
\hline - $\underline{\text { Acto: }}$ & $\begin{array}{l}\text { Aniversario de la Iglesia Unida Templo } \\
\text { de Fe }\end{array}$ \\
\hline Duración del Evento: & Un día completo \\
\hline Dónde se hace: & en la iglesia del barrio \\
\hline Motivos: & $\begin{array}{l}\text { - Celebrar el aniversario de la iglesia y } \\
\text { afianzar la misma } \\
\text { - Recibir visitas } \\
\text { - Renovar el gozo y la fe } \\
\text { - Intercambiar experiencias }\end{array}$ \\
\hline Participantes: & $\begin{array}{l}\text { - El pastor del barrio } \\
\text { - La gente toba del barrio (abuelos, } \\
\text { adultos, jóvenes y niños) y gente toba del } \\
\text { Gran Bs. As., del Chaco y Rosario } \\
\text { - Vecinos fieles al culto, } \\
\text { - Pastores y miembros de otras iglesias } \\
\text { vecinas o invitadas } \\
\text { - Pastores del Chaco } \\
\text { - Integrantes del equipo de investigación } \\
\text { de la UNLP }\end{array}$ \\
\hline $\begin{array}{l}\text { Relación entre los } \\
\text { participantes: }\end{array}$ & Fieles del culto evangélico \\
\hline $\begin{array}{r}\text { Quiénes no pueden } \\
\text { participar: }\end{array}$ & La entrada es libre a todos los fieles \\
\hline Lengua empleada: & $\begin{array}{l}\text { Se emplea el castellano en todas las } \\
\text { instancias formales de la celebración. } \\
\text { Sólo el pastor proveniente del Chaco } \\
\text { realiza su oratoria en lengua toba }\end{array}$ \\
\hline
\end{tabular}




\begin{tabular}{|l|l|}
\hline & $\begin{array}{l}\text { públicamente. La lengua toba es utilizada } \\
\text { en circunstancias informales y entre } \\
\text { mujeres principalmente. }\end{array}$ \\
\hline
\end{tabular}

Cada aniversario es vivido como una verdadera fiesta. Las actividades en el barrio comienzan desde temprano y hombres y mujeres, creyentes o no, se dividen el trabajo para recibir y ofrecer a los invitados la mejor estadía. La iglesia se adorna con globos de color celeste y blanco y guirnaldas de papel; los encargados del culto organizan cada una de las presentaciones que se harán durante el día anotándolo en un papel. Las mujeres empiezan a cocinar desde temprano un gran banquete con el que se agasajará a los invitados y a todo el barrio. Generalmente, consiste en un suculento locro para el que se emplean dos grandes ollas de 20 litros cada una, torta frita y sopa paraguaya. En esta tarea suelen ayudar algunos vecinos no tobas. Todos se visten con sus mejores ropas. Algunos invitados - procedentes de diferentes localidades del Gran La Plata, Gran Buenos Aires, Rosario, Chaco y/o Formosa- traen consigo algunos regalos (una torta, un instrumento musical o una Biblia), comienzan a llegar alrededor de las $10 \mathrm{hs}^{161}$ y son conducidos al interior de la iglesia. Las filas de asientos están divididas por género: a la izquierda (mirando de frente al altar) se ubican las mujeres y a la derecha los hombres. Los invitados llegan solos o en pequeñas delegaciones que vienen en representación de otras congregaciones o iglesias. Éstas están conformadas por un pastor, algunos fieles y músicos. Una vez ubicados en sus lugares, comienzan a entonar algunas canciones encabezadas por el coro toba dueño de casa. Los pastores saludan y se van ubicando en un semicírculo detrás del altar y mirando hacia el público. A un costado espera ser partida una gran torta con tantas velitas como años se cumplen. El coro toba anfitrión se ubica a la derecha del altar (mirando de frente) conformado por hombres, jóvenes y adultos, con guitarras en mano, un bombo y, en algunas ocasiones, un acordeón (ver Gráfico $\mathrm{N}^{\mathrm{o}} 3$ - Plano de la iglesia). También las mujeres forman un coro. Se trata de niñas y adolescentes que ejecutan panderetas y las palmas, que cantan con una voz muy aguda, y que se ubican al otro lado del altar, pero en la primera fila del público. También asisten algunos parientes, amigos y vecinos no tobas.

Las celebraciones disponen de una estructura que se repite en cada una de ellas. No se trata de una sesión de culto normal; sin embargo, puede presentar algunos de los elementos de éste como el de la imposición de manos y sanación, prédica, plegaria, cantos, danza y glosolalia. Generalmente, un pastor anfitrión dirige la ceremonia siguiendo la lista de orden

${ }^{161}$ Quienes vienen de lejos se alojan en el mismo barrio, en la casa de algún familiar o amigo. 
del día, anima a la gente con las expresiones: “amén”, “aleluya hermanos”, “¿cuántos están contentos el día de hoy?" y presenta a los invitados. Así, uno por uno de los presentes va tomando la palabra. Los pastores realizan una prédica o plegaria de diez a veinte minutos de duración; los fieles representantes de otras iglesias traen el saludo y el agradecimiento de su congregación, dan algún testimonio de su fe y cantan alguna canción o alabanza. Luego de cada una de las presentaciones hay aplausos.

La lengua que domina, en general, es el español. No obstante, los pastores tobas suelen alternar en sus discursos con su lengua materna. No sólo la lengua toba ha sido utilizada, sino también el quichua y el guaraní. Más de un pastor ha pedido disculpas al público presente por dirigirse a ellos en su lengua:

- ..."Pido disculpas a los hermanos blancos porque algunos no les gusta que nos expresemos en lengua, se enojan. Pero la lengua nos la dio Dios, así como el castellano, y debe ser respetada"...

En los casos donde la prédica fue hecha en lengua vernácula, seguidamente, se hizo la traducción al español y también se apeló a la integración entre "blancos" e "indios":

-... "Estoy muy luchado... pero confío en Dios" ... "Estoy muy agradecido porque nuestros hermanos están con nosotros" [sigue en toba]... "Los hermanos blancos están acá con nosotros, porque no importa si son blancos, negros... todos somos blancos para el señor"162 [y a continuación hizo que todos se pusieran de pie, se dieran las manos o abrazaran] ... “¿¡Cuántos aman al Señor?!, ¡Todos somos hermanos!” [y todos juntos oraron].

\footnotetext{
162 Nótese que al querer decir que no importa el color de piel o la etnia a la que se pertenezca todos los hombres son iguales ante Dios, el pastor toma el lexema "blanco" como el paradigma del "deber ser" o "lo que se debe ser". De esta manera, se deja ver cómo el aceptar el evangelio significó "hacerse blancos".
} 


\section{Gráfico $\mathbf{N}^{\mathbf{0}}$ 3:}

Esquema de la iglesia durante la celebración del aniversario

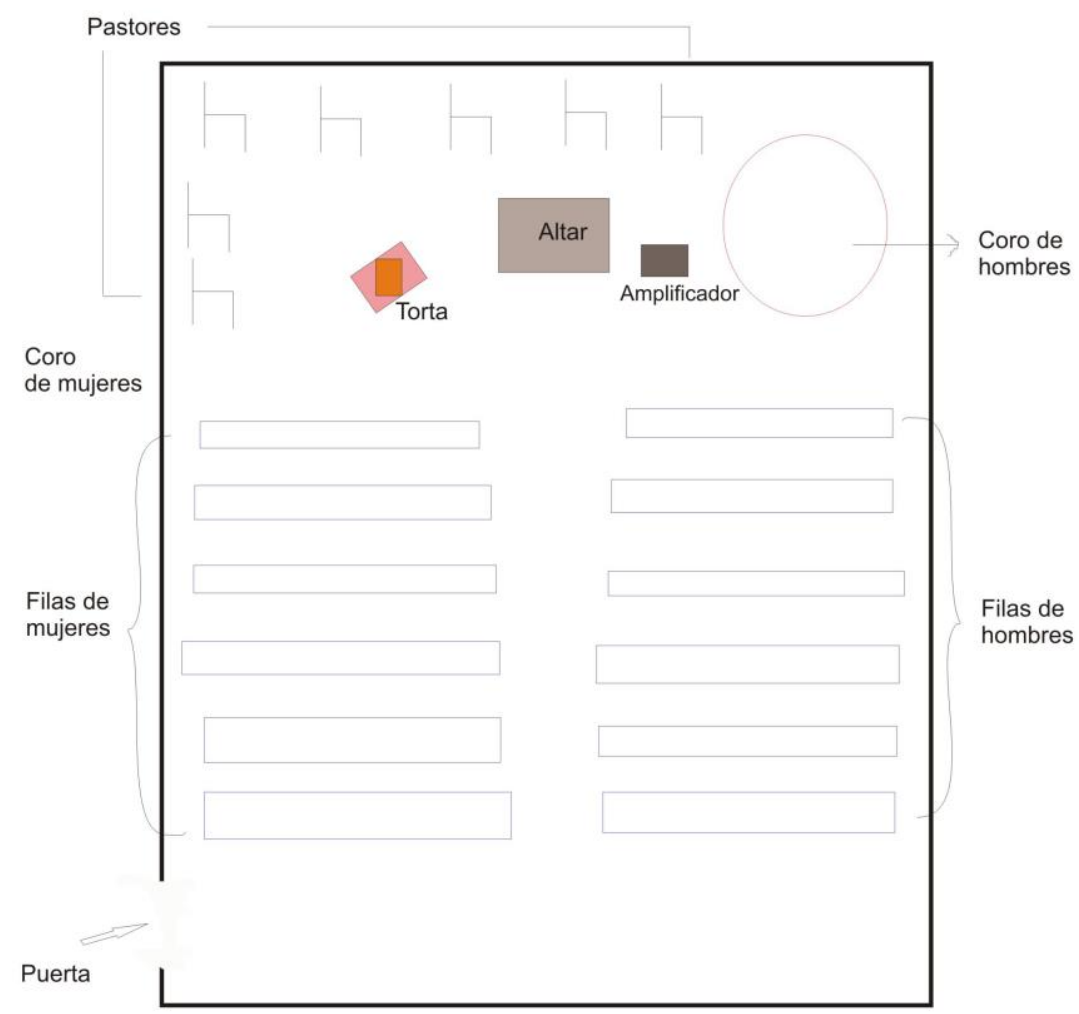

Otros pastores no indígenas han realizado también una alusión a la gente toba y su incorporación al evangelio durante su prédica:

- ... "Durante un tiempo los tobas fueron rechazados; hoy son príncipes, herederos, hijos de Dios"... ${ }^{163}$

${ }^{163}$ Con esto queda claramente expresada la idea de que el Evangelio salvó a los tobas. 
El público sigue atentamente cada una de las presentaciones, responden las preguntas hechas por los pastores en español o bien asienten durante los discursos con exclamaciones como "amén", "alabado sea el señor" -aun cuando el discurso es hecho en toba-, aplauden y realizan algunos comentarios entre ellos. Las mujeres tobas suelen expresarse en lengua materna entre sí.

En cuanto a las canciones interpretadas hay diferencias notables entre aquellas cantadas por los tobas y las ejecutadas por las iglesias no indígenas. En las primeras, predomina el ritmo al compás del bombo, panderetas y palmas, y las letras, aunque en español, son difíciles de comprender. La vocalización que utilizan -arrastrando y alargando las sílabas con un sonido gutural- hace que las palabras no se alcancen a entender con facilidad, se grita mucho, se utilizan los sonidos agudos. Al mismo tiempo, son más alegres, a nuestro parecer. En cambio, las segundas dejan comprender con mayor facilidad sus letras, pero ofrecen un ritmo más lento e inspiran menos entusiasmo. Los ritmos utilizados corresponden al folclore argentino y latinoamericano, e incluso al folclore norteamericano en las primeras, y baladas con melodías suaves en las segundas. Por el contrario, las canciones interpretadas por los tobas poseen un compás que se asemeja a aquellas típicas de la etnia.

El festejo dura todo el día. Después del mediodía se acondiciona la iglesia para brindar el almuerzo a los invitados. Se colocan mesas y sillas alrededor de las mismas. La música sigue sonando como fondo, ya sea en vivo o a través de un casete, pero siempre con canciones de la iglesia. Durante la comida se conversa y la lengua toba fluye y se deja escuchar. Esta es una ocasión en la que las familias tobas se ponen al día y se informan de los últimos acontecimientos en las otras localidades donde viven sus familiares y amigos. También, para que los jóvenes se conozcan y se formen parejas en el futuro. Luego, el culto vuelve a tomar forma; se vuelven a acomodar las sillas y continúan las presentaciones hasta que llega el momento de soplar las velitas. Se canta el feliz cumpleaños al compás de las guitarras y con música de la iglesia:

$$
\begin{gathered}
\text { "Que los cumplas feliz } \\
\text { y que Dios te bendiga } \\
\text { y te guarde hasta el fin" }
\end{gathered}
$$

Seguidamente se corta y convida una porción de torta a los invitados y se reparten los globos a los chicos. Al finalizar, todos retornan felices a sus casas. Al menos, después de 
compartir unas horas todos juntos, los problemas y sufrimientos cotidianos se olvidan y el grupo adquiere fortaleza y cohesión.

\section{b) Celebraciones cívico-comunitarias}

Una de las principales fechas a festejar todos los años es la del "Día del Indio". Éste es celebrado cada 19 de abril y ha tenido distintas modalidades de festejo: mediante una ceremonia de inauguración de las viviendas, discursos, charlas abiertas al público en general y a colegios, exposiciones de videos y debates, música, comidas y venta de artesanías. ${ }^{164}$ Lo particular en estos festejos es la participación no sólo de la gente toba del barrio y de las localidades del Gran Buenos Aires y Chaco, sino también de escuelas de La Plata, estudiantes de la universidad, vecinos y funcionarios públicos de la provincia; por lo que tienen carácter interétnico.

\begin{tabular}{|r|l|}
\hline \multicolumn{2}{|c|}{ (b)- Celebraciones cívico-comunitarias } \\
\hline Dominio: & Vecinal / Intervecinal \\
\hline Variedad Lingüística & Castellano \\
Usada: & \\
\hline Contextos: & Formal \\
\hline & Público \\
\hline & Interétnico \\
\hline
\end{tabular}

\begin{tabular}{|r|l|}
\hline$\bullet$ Acto: & Día del Indio \\
\hline Duración del Evento: & Un día completo (mañana y tarde) \\
\hline Dónde se hace: & Al aire libre y en el Obrador \\
\hline Motivos: & $\begin{array}{l}\text { - Celebrar el día con la comunidad y la } \\
\text { gente "criolla" que ayudó en la obtención } \\
\text { de las viviendas } \\
\text { - Mostrar y vender artesanías }\end{array}$ \\
\hline Participantes: & $\begin{array}{l}\text { - Toda la gente del barrio } \\
-\quad \text { Algunos familiares del conurbano } \\
\text { bonaerense y del Chaco } \\
-\quad \text { Funcionarios públicos, estudiantes, } \\
\text { invitados varios }\end{array}$ \\
\hline $\begin{array}{r}\text { Relación entre los } \\
\text { participantes: }\end{array}$ & $\begin{array}{l}\text { Vecinos, "paisanos", funcionario/ } \\
\text { adjudicatario, aborigen/ estudiantes, } \\
\text { vendedor/ comprador }\end{array}$ \\
\hline $\begin{array}{r}\text { Quiénes no pueden } \\
\text { participar: }\end{array}$ & \begin{tabular}{l} 
La entrada es libre \\
\hline
\end{tabular} \\
\hline
\end{tabular}

${ }^{164}$ Cada una de estas celebraciones fueron descriptas en el Capítulo III.4. 
Lengua empleada:

el castellano en todas las instancias. Sólo la lengua toba es empleada en conversaciones personales entre familiares y amigos.

Cada año, se contó con la presencia de la bandera argentina dándole oficialidad y jerarquía al evento. Ésta no sólo ocupa un espacio en el recinto donde se lleva a cabo la ceremonia, sino que cuenta con abanderados y su armado (colocación en un asta) es parte de la agenda de la celebración. En 1992 -primera celebración hecha en el barrio- el uso de la lengua materna fue significativo tanto durante el discurso hecho por el presidente de la asociación, como en la ceremonia de entrega de las llaves a los adjudicatarios.165 En ambas situaciones, el cambio de código y el uso de la lengua vernácula resultaron parte de la estrategia comunicativa del evento que estuvo presidido por una alta carga emotiva: por primera vez, y después de tanto tiempo y tanta lucha, las familias tobas recibían "un pedazo de tierra" y viviendas para desarrollar sus vidas en comunidad.

Una vez instaladas las primeras ocho familias y en plena construcción de las viviendas restantes, el tema central del festejo realizado en 1995 consistió en compartir con los vecinos de la ciudad de La Plata el esfuerzo para lograr lo obtenido. Una de las principales temática surgida a partir de la interacción social con los visitantes fue la discriminación. A continuación, reproducimos un fragmento de esa interacción.

\section{El contexto:}

En aquella oportunidad, las actividades duraron dos días. Durante el primero, reunidos todos en el obrador, alrededor de las $15 \mathrm{hs}$, se pasaron las filmaciones en vídeo realizadas en el marco del proyecto de investigación. Asistieron, además de la gente toba del barrio, vecinos de la ciudad, maestros, estudiantes universitarios y algunos funcionarios públicos. La lengua que predominó durante los días que duró el evento fue el español. La lengua toba sólo fue escuchada en el audio de las filmaciones y en conversaciones informales entre, principalmente, las mujeres del barrio. Si bien estuvieron presentes muchos de los integrantes del barrio toba, quienes se expresaron en voz alta y dieron su opinión al público fueron los miembros de la comisión directiva de la organización civil. No obstante, los discursos fueron agudos y precisos y respondieron las expectativas de los invitados.

Luego de ver los vídeos, se abrió el debate entre los presentes. El siguiente es un fragmento de la respuesta que da (JR) al tema de la discriminación que originó el debate

\footnotetext{
${ }^{165}$ Estas situaciones fueron descriptas en el punto 3. de este capítulo.
} 
por parte de una vecina no toba que no entendía por qué los indígenas eran o se sentían discriminados por la sociedad.

(...)

1. I: - ¿y la gente del barrio qué opina, se han sentido alguna vez discriminados?

[silencio ante la pregunta, pero los chicos hablan entre ellos, se escucha mucho bullicio, acomodan a los que están parados]

2. JR: - .. Bueno..// (L) le preguntó si hay alguna..// por ejemplo.. // alguna.. discriminación... sobre ehh. //de los hermanos criollos, //por ejemplo,// cuando vinieron acá,// cuando venden artesanias. .// o en alguna oficina...// yo,// yo que ando mucho,// ¿no es cierto?,// eh,// lamentablemente,// parece queee me dieron como un castigo [se ríe] para tener este trabajo//. Perol/, gracias a Dios//, en este momento//, por ejemplo//, tenemos algo a través de una organización..// porque..// todos nosotros estamos un poco confundidos//,

6. $\quad$ por ejemplo/l, en el Chacol/, como la pregunta de la hermanall, por ejemplo/l, que si hay alguna diferencial/, ino es cierto?//, entre esta comunidad//. Pero// yo voy a por una cosal/, no es cierto//, \{si no sentimos como argentinos\}//, creo que tenemos que luchar todos juntos//, ¿no es cierto?//, no tenemos que fijar en nada// ni la altura// ni el 10. color//, en nada//, eh..// como lo que está pasando en este momento/l, por ejemplo//. eh..//. por ejemplo..// esteee..// cuando ponen alguna bomba/l. estee.// en un edificio/l. en algún otro edificioll, o en otra cosall, tanto como los. militares/l, ponele/l, que.. parece que no sienten para nada//. Y // ¿sabés lo que yo siento?//, donde yo no soy nada//, no tengo estudio//, no tengo nada//, pero yo voy por mi experiencial/, y siempre escucho//, por ejemplo//, que me perdone alguno// si hay algún extranjero//, ¿no es

16. cierto?//, porque el extranjero//, pienso yo//, que viene acá para perjudicarnos//, ¿no es cierto?//, al argentino//. Yo pienso asi//. Porque no les importa//. Pero// si nosotros no sentimos como argentinos//, creo que nosotros tenemos que defendernos//. Mm?!//, a nuestra Patria/l, ¿no es cierto?// \{Como a nuestro chicos\},.// cuando hubo una guerra en Las Malvinas//, ¿no es cierto?..// \{y nunca se menciona que los tobas murieron 21. tanto//, no//, para nada//\}, con tal de que son argentinos $/ /$, punto..// mm?!..// Entonces//, hay veces//, uno tiene preguntarse//, yo mismo me pregunto..// qué piensa de la gente..// aquellas gente que ya nos conocen//.. que somos unas comunidad indígena..// o// por ejemplo//, pueden decir comunidad toba//, indio// o indigena//, por ejemplo//. Eso hemos más aceptado//, siempre//, le digo//, porque nos han bautizado los hermanos españoles// cuando vinieron aquil/ nuestro pais//. SNunca me he avergonzado/l, por 27. ejemplo//, de decir//, más que un argentino//, que// hasta el día de hoy// no tenemos tierrall, no tenemos lugar/l, eso es lo que a uno le molesta muchas veces//, a mi me molesta mucho//.\} Por eso// a veces// le pregunto a \{alguno\} de los políticos cuando vienen aquil/, a este lugar//, le digo..// ¿y por qué los indígenas no pueden mensurar tierras?// Mm?!... //IHabía una oportunidad//, está presente como testigo mi hermano carnal//, que el año antepasado prometieron ciento cincuenta mil hectáreas en el

33. Chaco//\}.. ¿Sabés por qué?// parece que// el gobierno dice que tiene plata para mensurar las tierras//. \{Pero// vienen los extranjeros//, vienen los gringos//, claro//, vienen con guita//, $y / /$, claro//, entonces//, tal vez//, le dan guita a nuestro gobierno// $y$ le dan tierra//, leguas y leguas// y el indio no puede tener eso//.\} Pero//, más adelante//, me doy en cuenta//... En este momento//, por ejemplo//, hemos empezado//, aqui // en este lugar..// para que// en este lugar// podemos lograr muchas cosas//.. pero si saben//.

39. por ejemplo//, cuidar//, si saben llevar al hombro sobre este trabajo los hermanos 40. jóvenes $/ /$, por ejemplo//... no solamente a la comunidad toba//. sino entre todos $/ /$. jóvenes presentes en este día..// Este día del indio//.. \{este día del indio// no se qué años aprobaron//, porque hay un encuentros aborígenes en otro pais//. No estoy seguro si en Canadá o Ginebral/ o si no en Bogotáll, no se muy bien/l, o en Méxicoll. Hay un encuentro mundial indigenas//\}. Entonces// uno de los delegados nuestro//, argentino//, ha participado a ese encuentro mundial//. Entonces// se hizo//, se eligió ese día 19 de 45. abril//, día del indio//, en ese encuentro//. Tenemos más o menos//, un poco de paz..// 

¿no es cierto?...// \{Entonces//, lo más lindo//, que siempre..// la gente lo ha mansado tranquilamente//\}. Primer lugar//, nosotros somos del Chacol/. \{Que somos del Chaco//, han organizado nuestros abuelos//\}, ¿no es cierto? Han enfrentados.. los militares//. Pero// siempre le digo//, \{/Dios es el único sabe//\}, que ellos se salvaron//,

50. no se cómo//, porque ellos tenían poderes//, ellos son brujos//, \{como ustedes le dicen//\}, son brujos//, ¿no es cierto?// nosotros les llamamos// nosotros// como nuestros médicos//.. \{ Y// lamentablemente// parece que esa fuerza va terminando// $\}$.. $\{\dot{c}$ Saben por qué va terminando?\}// Termina la bala/l. pero hay una cosita que nosotros//. por ejemplo//. no podemos //. por ejemplo//. en este momento//. enfrentar//.. acerca de las

55. leves//, es lo que nos están matando en este momento//. \{ Primer lugar//. la comunidad toba//f: nosotros estamos más bajos que todos//, no es cierto//... no tenemos estudio//.. Ahora// les decíal/ que los jóvenes que están creciendo a la orilla del pueblo/l, van a la escuela/l, van al colegio/l, pero// lamentablementel/, muchas veces//, ellos, estee..// dejan//, por ejemplo//. Será por la discriminación que hay en el colegio// como habrán 60. escuchado// ahil/ con en el pibe mio//, no es cierto//, cuando le preguntaron//. \{Claro que sí!\}// porque le ven que es morocho// y saben que es hijo de un tobal/ o sangre de [no se entiende]//y le preguntan//y le cargan//.. (..)

El análisis:

Luego que la vecina no toba introdujera su inquietud en torno a la discriminación y se estableciera un debate con algunos de los investigadores y estudiantes universitarios presentes se dirige la pregunta para que la gente toba exprese su opinión al respecto. El silencio generado - en el sentido de ausencia de quien tomara el turno de la palabra, ya que hubo un gran bullicio por parte de los chicos, se reacomodaron las sillas y se invitó a los recién llegados a ubicarse en un lugar- fue largo, hasta que (JR) tomó la palabra. Primero, y en forma muy pausada, repitiendo la pregunta e instando a que la gente del barrio hablara. Como nadie más se animó - $y$, quizás, sabiendo que ningún paisano se animaría a opinar- (JR) se coloca como referencia: “yo, yo que ando mucho" repite dos veces el pronombre personal "yo"; el primero como una forma de introducir su experiencia como queriendo decir: "en mi caso" y, el segundo, aseverando una característica de él: el andar mucho, tener contacto con mucha gente de diferentes profesiones y lugares, eso le da el "poder" de contestar con firmeza y verdad. Sin embargo, relativiza su situación mediante un chiste: el hecho de andar mucho, trabajar mucho, moverse de puerta en puerta solicitando que se respeten sus derechos, pareciera ser un castigo. E, inmediatamente, contrarresta el chiste hecho introduciendo el conector que alude al contraste "pero", invocando a Dios, y mencionando que gracias a lo mucho que anduvo es que hoy están organizados y lograron conformar el barrio. A continuación, cuando va a introducir una consecuencia, aumenta la velocidad del habla, sintetiza lo discutido hasta ese momento, menciona que hay confusión e introduce una idea que queda en el aire al aludir al Chaco. Vuelve a introducir un conector de contraste y agrega una nueva idea (7. a 10.): expresa su 
opinión donde no debería existir la discriminación porque somos todos argentinos y todos deberíamos estar todos juntos en oposición o enfrentando a los que vienen de afuera, los extranjeros. Hace referencia también a un hecho histórico: el trato que recibieron los jóvenes tobas que murieron en la Guerra de Malvinas: en este caso no se hicieron diferencias por razones étnicas. Para aquella ocasión, todos fueron argentinos. En la línea (26.), llega al clímax de su discurso. Utiliza un estilo indirecto para decir que sí hay discriminación hacia los indígenas; que nunca se avergüenza ni se cansa de decir que "los indígenas no tienen un lugar, no tienen tierra" y esa es una forma de discriminarlos. No importa si se los llaman toba, indio, indígena -lexemas cuyos usos suelen aparecer entre la gente como formas de dirigirse despectiva y/o prejuiciosamente-. En la línea (30.), el tópico pasa a ser el de los extranjeros que compran con su dinero las tierras que los indígenas no pueden comprar. Este tópico es planteado con mucho énfasis, con una alta carga emotiva y furor, y sintetiza la forma en que, sistemáticamente, los gobiernos y la sociedad toda excluyen y discriminan a los indígenas.

En la línea (38.) y aumentando la velocidad de su habla, coloca la experiencia del Barrio Toba de La Plata como una forma de superar esa discriminación y aconseja a los jóvenes que deben cuidar lo que han logrado. Y, a continuación, da como un giro en su discurso e introduce el tópico del Día del Indio. Trata de explicar a la gente por qué se celebra ese día haciendo uso de su memoria, y, a la vez, este tópico le sirve para explicar que el hecho de que la gente se interese por ese día es otra forma de superar la discriminación hacia el indígena. Utiliza el lexema "amansar" como sinónimo de adoptar o aceptar. La gente, los vecinos de La Plata han aceptado el hecho de que ellos vienen del Chaco, sin embargo, aún hay elementos de discriminación y eso lo viven sus niños en la escuela, motivo por el cual suele haber casos de deserción escolar. Otro de los factores que también coloca en desventaja a las poblaciones indígenas, y es motivo de discriminación, es la falta de estudios; el no poseer sus estudios completos y una profesión. Todos estos aspectos fueron planteados por (JR) de un modo sintético y preciso; utilizando muchos conectores de secuencia, adición, consecuencia, contraste y orden, aunque en este último caso sólo se utilizó como recurso el "en primer lugar". De la misma manera, utiliza las fórmulas del condicional sin terminarlas: "si nosotros no sentimos como argentinos, creo que nosotros tenemos que defendernos". Asimismo, observamos el uso de preguntas retóricas en estilo directo y dirigidas, por momentos, a una segunda persona del singular, que no esperan una respuesta inmediata del interlocutor, sino que son respondidas por el mismo hablante. Éste 
constituye un recurso fático, una forma de comprometer a la audiencia a seguir escuchando.

Terminado el debate, se salió con el público a recorrer todo el barrio. Durante esta instancia la conversación fue más informal, (JR) fue contestando cada una de las preguntas a medida que iba caminando rodeado por un grupo de jóvenes y vecinos. Los temas tratados fueron fundamentalmente aspectos relacionados con la construcción de las viviendas y la organización.

El segundo día que duraron los festejos del Día del Indio de 1995 hubo una participación más activa de los integrantes de la comunidad toba. En esta oportunidad, un grupo de mujeres y hombres tobas fueron dando su testimonio a los presentes; estos últimos, a su vez, realizaron muchas preguntas. En este caso, la lengua vernácula fue utilizada para hablar entre ellos, para solicitar o dirigir el turno en la participación. El tema del uso de la lengua también fue tópico de debate, ya que una de las jóvenes mujeres no se animó a hablar en voz alta un poco por vergüenza y por sentirse más segura hablando la lengua materna; en tanto que otra, contó los motivos por los cuales ya no hablaba la lengua. A continuación, reproducimos un fragmento de esa interacción verbal.

\section{El contexto:}

En este segundo día, la asistencia del público visitante también fue mayor. Mientras se pasaban los vídeos, un grupo de jóvenes tobas armaron la bandera argentina en un rincón del obrador. Al terminar, el presidente de la asociación tomó el micrófono y la palabra. Luego de comentar sobre los trámites requeridos para lograr entrar en el plan de viviendas y autoconstrucción, invitó a hacer preguntas e hizo que un grupo de jóvenes tobas presentes se ubicara delante del público para dar sus testimonios y contestaran las inquietudes de éste. No obstante, obligó, de alguna manera, a que los jóvenes tobas se expresaran primero.

\section{Fragmento:}

JR: [...] En esta tarde, por ejemplo, si hay alguna pregunta a través de estos casetes, de estos videos que estamos viendo en este momento.., como está escrito, por ejemplo, este afiche [se refiere a unos paneles elaborados por el proyecto de investigación que fueron también expuestos durante los dos días]... queee... no le entiendo muy bien, pero que está escrito de un debate, no es cierto,.. discutir un poquito, y está también la experiencia sobre el grupo, cómo estamos trabajando en este momento.. Ellos tienen experiencia a través de la lucha, a través del sufrimiento, para tener esta vivienda... Que hasta el día 
de hoy seguimos luchando, como siempre le digo. a todos. los jóvenes. no solamente a mi comunidad sino a ustedes también. [...] Pero gracias a Dios, estoy haciendo un esfuerzo muy grande a través del grupo, porque bien sabemos que si uno trabaja sólo, individual nada puede hacer.. pero en conjunto sí. Por eso es el propósito que hemos puesto el nombre a nuestra organización civil toba “ntaunaq nam qom”... Entonces el propósito que pusimos ese nombre, porque muchos nos preguntan qué quiere decir. Por qué, y hasta ahora estamos trabajando.. y entonces en esta tarde si hay algunas preguntas, podemos, si, por ejemplo, sí podemos contestar... .. o le damos el grupo que cuente un poco la experiencia... mm?.. Bueno, está presente la hermana (DM). Primer lugar, que cuente un poquito cómo está trabajando, porque ella tiene interés de tener una vivienda, entonces de acuerdo el plan de vivienda, por ejemplo, el pacto adjudicatario tiene que trabajar, poner el hombro para que el día de mañana tenga un buen testimonio porque el sacrificio lo está haciendo. Esta chica está trabajando porque tiene el interés de obtener una vivienda. La escuchamos.

... [hay silencio entre ellos, pero bullicio por parte del público, (JR) se dirige a (DM) en lengua toba y $(\mathrm{RC})$ traduce tímidamente:]

RC: expresa que no puede hablar en castellano

[hay algunas sonrisas]

OC: es tímida la chica

JR: bueno

[ante la negativa de DM, ER toma la palabra]

ER: buenas tardes, eh.., yo soy un componente de esta segunda etapa de vivienda.. como verán, eh.., en muchos de los casos es la mujer la que trabaja. Son jornadas duras, eh.., porque son jornadas que las tiene que hacer relativamente el hombre, porque es trabajo del hombre. Pero en todos estos años de lucha, que llevamos, y en esto fuimos [no se entiende] y esto recién comienza... eh. Como todos saben ustedes, hay una primera etapa que ya están habitadas las casas, y ustedes en muchas ocasiones ya visitaron a los dueños.. mm.. Fueron momentos duros, hubo gente que nos apoyó, que nos ayudó, pero que siempre nos mandaban al frente, los protagonistas éramos nosotros. La gente de afuera nos enseñaba la metodología, nos enseñaban:-esto es lo que tienen que hacer-, esto es lo que fuimos logrando gracias a estas personas... Y bueno, qué me quieren preguntar, qué les puedo decir. Nuestro objetivo es terminar el barrio, de ahí en más, bueno, seguir con otros proyectos que tenemos. Tenemos que dejar. eh. muchas cosas nuestras. Pero, ¿por qué las tenemos que dejar? Porque nosotros queremos [no se entiende] Tenemos costumbres que son nuestras que no nos pueden sacar y nosotros tampoco vamos a permitir que nos saquen como esto de integrarse, aislar, como cuando 
uno está en su tierra natal mantiene muchas cosas vivas. Pero la poca que tenemos la tenemos que mantener.. eh.. Una de las cosas que sí relativamente la tenemos que perder es. la lengua. Porque los chicos ya se integran a la escuela, si no hablan castellano no se les entiende.. eh.. tenemos muchos proyectos para contarles, eh.. maestros bilingües. Cosas que para los chicos la enseñanza del blanco sean mucho más llevadera, ¿no? pero, eso está totalmente lejos, pero pensamos que eso un día lo podemos lograr. Ninguno de los que estamos acá tenemos un grado relativamente alto, por decirlo así. Todos dejamos la primaria o los que empezamos la secundaria la tuvimos que dejar por motivos diferentes. Lo poco que sabemos es porque lo aprendimos de ustedes o de alguien que.. vio la necesidad de ayudarnos. Gracias a esas personas. Bueno, si me quieren preguntar algo estoy, si no.. yo ya dije.

P1: muy claro

P2: yo quería preguntar si ustedes no les enseñan el idioma a sus hijos.. en la casa

ER: yo eh.. te voy a responder eh.. mi caso. Eh.. Yo me crié to'. bah, hasta los veinte y pico de años acá [se refiere en Buenos Aires]. Mi mamá y mi papá hablaron entre ellos, pero eso de ponerte a enseñarte era muy reprimido porque ellos decían era mucho más importante que aprendamos la lengua. blanca para que nadie nos tomara el pelo. Es que la lengua, hablar el dialecto era algo, algo. bajo por asi decirlo. Claro, y yo a mis hijos no les puedo enseñar a hablar porque no la sé, me encantaría porque suena lindo. Hay casos de familias en que sí, los chiquitos hablan el idioma y es bien bonito.

P1: claro

ER: si, si.. yo quisiera que mis padres enmienden ese error enseñándoles a mis hijos... alguna otra pregunta más.

P3: ¿ ¿vos hablás toba? [contesta muy bajito con un sí tímido hasta que le acercan el micrófono] ¿y hablás con los chicos?

DM: sí hablo con los chicos

P3: y qué pasa? Ellos te responden en toba, hablan castellano?

DM: no más, no, los que son nacidos acá no hablan tanto.. pero ellos, creo que algunos

\section{entienden}

P3: y asi naturalmente en qué lengua te sale hablarles, en toba o en castellano?.. así espontáneamente

DM: en castellano

P3: porque pensás que te entienden más? [silencio de DM]

OC: es que entienden más en castellano, si acá nadie le habla en toba

DM: lo que pasa es que son todos nacidos acá, pero la mayoría son de acá.. 
P4: perdón, qué tipo de costumbres son las que más mantienen, en las familias [silencio] qué tipo de cosas mantienen que no se han perdido, si el idioma prácticamente no lo hablan, los que nacieron acá no lo conocen qué es lo que más se mantiene?

ER: lo que más se mantiene viva es la.. la fabricación de artesanias que es lo que más ha perdurado un montón

P4: con respecto a la alimentación?

ER: y.. con la alimentación nosotros sí o sí nosotros nos tenemos que adecuar con lo que hay acá, porque... nosotros nos alimentábamos de la pesca. Mi padre inclusive hasta ahora, yo me sorprendí va al monte, va de pesca, no sé, son esas cosas que nosotros actualmente no podemos hacer. Pero él después de un tiempo que ha vivido en la ciudad, vuelve al lugar natal y las sigue manteniendo [...]

P5: otra preguntita ¿tienen alguna reunión donde ustedes resuelvan cosas? A mí me importa la parte organizativa de ustedes [silencio]

ER: nosotros tenemos, por obligación, que hacer reuniones porque eso nos piden. Pero no en familia, estamos acostumbrados a tratar en grupo [...]

OC: yo, por ejemplo, bueno, yo soy OC, él es mi tío, ellas son mis primas, bueno, yo me crié acá, digamos que cuando yo tenía cinco, seis años, mi abuelo, mi tía me crió y acá vinimos para Buenos Aires.. pero yo la costumbre no la perdí, en el sentido, el toba yo lo sé hablar, me siento orgullosa. A veces me preguntan -¿de dónde sos?-, -Yo soy toba-, qué! Toba? A no, no parentás-. Pero yo no niego y hablar hablo. No sé si agradecer a mi abuelo, a mi tía o a mi mamá. Yo siento que ellos me criaron y les agradezco a ellos [...]

Luego de ésta hubo dos intervenciones más de gente toba dando su testimonio y otras preguntas del público. El evento terminó con el canto en lengua indígena de un hermano del Chaco que estuvo de visita. Éste pidió que las mujeres que habían dicho entender el idioma le fuera traduciendo sus cantos para que los presentes pudieran seguirlo.

El análisis:

Como podemos observar, el tema de la lengua constituyó una de las inquietudes principales por parte del público. De una manera somera, quedó planteada la problemática de la aparente y preocupante "pérdida de la lengua materna en la ciudad" a través de diferentes experiencias de vida. En la primera intervención, (JR) lo introduce indirectamente ya que "coloca a prueba a DM" -quien no quería hablar- y cambia de código lingüístico para dejar en claro que ellos tienen otra lengua y excluir así al público; sus compañeros la quieren ayudar o quieren "salvar" esa situación: uno traduciendo, el otro con un chiste "es tímida la chica" y el otro, finalmente, toma la palabra y se expresa en su 
lugar. Esta última se presenta como mujer, madre, trabajadora de la construcción y, seguidamente, se incluye como integrante del grupo y partícipe del proceso de organización del barrio. Agradece a quienes ayudaron en ese proceso, pero dejando en claro que recibieron ayuda de "los blancos" sin dejar de ser "los tobas" los protagonistas. (ER) se refiere explícitamente al tema de la lengua como un aspecto que, conjuntamente con otras costumbres, los identifica y no desearían perder. De aquí en más, la lengua se convierte en el principal tópico entre las inquietudes del público y la próxima intervención de (OC).

Otra actividad organizada para este día fue la exposición y venta de artesanías. En esta oportunidad, las mujeres lucieron los sombreros de paja en sus cabezas y los collares de semillas y barro en sus cuellos como otro modo de identificarse con lo propio.

Durante los festejos del Día del Indio del año 2001, se agasajó a los invitados con una comida. Se montó una larga mesa donde tobas, funcionarios públicos, investigadores, vecinos y profesionales compartieron todos juntos. La lengua que predominó en cada una de las conversaciones y diálogos fue el español. También se invitaron algunos colegios. Grupos de nivel inicial y primario llegaron con un horario acordado previamente, acompañados por los maestros y algunos padres. Los colegiales fueron llevados al salón de la iglesia y allí el presidente de la asociación civil les brindó una charla. La charla fue dada en español, aunque se intercalaron algunos vocablos tobas que se les enseñó a los niños. Luego, a la salida, se montaron algunas mesas con artesanías y allí los niños pudieron ver y comprar collares de semilla y animalitos de barro.

\begin{tabular}{|r|l|}
\hline \multicolumn{2}{|c|}{ (b)- Celebraciones cívico-comunitarias } \\
\hline Dominio: & Vecinal \\
\hline Variedad Lingüística & Castellano \\
Usada: & \\
\hline Contextos: & Informal \\
\hline & Público \\
\hline & Intraétnico \\
\hline
\end{tabular}

\begin{tabular}{|r|l|}
\hline$\bullet \underline{\text { Acto: }}$ & Día del Niño \\
\hline Duración del Evento: & Una tarde \\
\hline Dónde se hace: & Al aire libre \\
\hline Motivos: & $\begin{array}{l}\text { Entretener a los niños y homenajearlos } \\
\text { con juegos, juguetes y dulces. }\end{array}$ \\
\hline
\end{tabular}




\begin{tabular}{|c|c|}
\hline Participantes: & $\begin{array}{l}\text { - Todos los niños del barrio } \\
\text { - Las mamás que trabajan en el comedor } \\
\text { y mamás invitadas } \\
\text { - En algunas ocasiones empleados de la } \\
\text { municipalidad: profesora de educación } \\
\text { física, trabajadora social }\end{array}$ \\
\hline $\begin{array}{r}\text { Relación entre los } \\
\text { participantes: }\end{array}$ & Vecinos \\
\hline $\begin{array}{r}\text { Quiénes no pueden } \\
\text { participar: }\end{array}$ & $\begin{array}{l}\text { La entrada es libre; sin embargo, los } \\
\text { hombres no se hacen presentes. }\end{array}$ \\
\hline Lengua empleada: & $\begin{array}{l}\text { Predomina el castellano en todas las } \\
\text { instancias: juegos, reparto de juguetes, de } \\
\text { dulces. Sólo en una ocasión hubo música } \\
\text { (en castellano) y se presentaron un mago } \\
\text { y un grupo teatral. La lengua toba sólo es } \\
\text { empleada entre algunas mamás en } \\
\text { conversaciones entre ellas y las } \\
\text { encargadas de la cocina. }\end{array}$ \\
\hline
\end{tabular}

El Día del Niño constituye otra de las fechas especiales a celebrar colectiva y comunitariamente. Para esta ocasión, el primer domingo de agosto -como ya mencionamos en el Capítulo III- la mayoría de las mamás trabajan conjuntamente coordinando tareas para que todos los niños del barrio celebren su día: se juntan o confeccionan juguetes; se preparan tortas, galletas dulces, chocolate caliente y se compran algunas golosinas. Las tareas comienzan con unos días de antelación. Se presentan algunas notas a la municipalidad o alguna otra institución para recibir donaciones de golosinas y juguetes; en el taller de costura se reciclan algunos muñecos; y en el comedor comunitario se preparan los dulces y bebidas. Llegado el día, las actividades comienzan alrededor de las 15-16hs. Cada año tuvo una modalidad particular de festejar el día. Destacamos en cada una de las celebraciones el uso del español en todas las instancias de comunicación con los niños: al repartir la bebida y la comida, durante las órdenes para que se coloquen en fila o en ronda, en el guiado de los juegos y la repartición de los juguetes y golosinas. Esto se debe a que, generalmente, quienes coordinan y ayudan en estos menesteres son las mamás jóvenes y algunas adolescentes que se destacan por una competencia lingüística más fluida en español. No obstante, la lengua toba está presente en los diálogos que sostienen el resto de las mamás -que sí tienen una competencia lingüística en esta lengua- mientras los niños juegan o comen. 


\section{- Las Visitas}

Señalamos las visitas como eventos comunicativos significativos para la recreación y reproducción de la lengua toba. Éstas se realizan entre vecinos, particularmente por las tardes, y todos los días, al terminar las jornadas de trabajo. En los días de calor los anfitriones y las visitas se reúnen afuera, en la puerta de las casas; se comparte el mate o el tereré y pasan horas dialogando calmadamente de lo sucedido en el día o recordando algunos hechos del pasado. A estas reuniones suelen agregarse las visitas propiamente dichas, es decir, familiares o amigos llegados de las otras localidades del Gran Buenos Aires, de Rosario o del Chaco y Formosa que permanecen por cortas o largas temporadas hospedados en alguna de las casas del barrio "Las Malvinas". En este caso, la lengua nativa sirve también para intercambiar noticias de aquellos lugares.

Cabe aclarar que durante estas instancias, los niños juegan alrededor $y$, aunque pocas veces participan directamente en los diálogos, escuchan y están atentos a los mismos. Así también, cuando llegan las visitas del Chaco, éstas vienen acompañadas por sus hijos y, generalmente, los niños recién llegados sólo hablan la lengua toba o tienen una mayor competencia lingüística en la misma. Estos niños juegan con los niños del barrio "Las Malvinas" e intercambian conocimiento y prácticas lingüísticas.

\section{- Actividades comunitarias}

Con este ítem nos referimos a todas las interacciones verbales que se ejecutan durante las tareas relativas al trabajo en la huerta, en el taller de costura, en la elaboración del pan, en la cocina del comedor comunitario; es decir, en todas aquellas reuniones organizadas que se desarrollan colectiva y comunitariamente.

Las tareas de la huerta fueron de competencia tanto de hombres como de mujeres tobas y han estado supervisadas por la comisión directiva de la organización civil. Las labores comenzaban muy temprano y estaban divididas -como ya mencionamos en el Capítulo III.4 - en dos turnos. Destacamos que las tareas siempre han sido grupales y en ellas las charlas informales han fluido en lengua vernácula. Lo mismo sucedió con el taller de costura. Cuando las mujeres se reunían se daba la tendencia de dialogar "en lengua" a excepción de los momentos en que participaba una profesora de costura que no era toba. Además, se daba la particularidad de trabajar en parejas y esto propiciaba el uso de la lengua toba. En algunas ocasiones, cuando la profesora escuchaba "parlotear" la lengua, 
solía acercarse y trataba de involucrarse en la conversación con la siguiente expresión: " $-A$ ver, a ver.. estoy buscando mi diccionario en mi bolso" y las mujeres se reían. ${ }^{166}$

Lo mismo ocurría durante la elaboración del pan y en el comedor comunitario donde las mujeres son las principales participantes. Las horas que pasan juntas son bastantes y las conversaciones también y éstas se efectúan preferentemente en lengua materna. ${ }^{167}$

\section{- Reuniones y Talleres Interétnicos}

Ya hemos mencionado en líneas anteriores algunas reuniones llevadas a cabo en el barrio, tanto en el obrador como en la oficina de la asociación civil. Entre éstas, destacamos las numerosas reuniones celebradas con la gente del plan de Pro-Tierra de la Secretaría de la Vivienda, donde participaron funcionarios públicos, asistente social, arquitectos, entre otros, con el objetivo de coordinar las tareas para la autoconstrucción de las viviendas. También fueron importantes las reuniones convenidas con la municipalidad y el INTA para la organización de la huerta comunitaria. Las mismas fueron dirigidas tanto por alguno de los representantes de los organismos nombrados, como por el presidente o miembros de la comisión directiva de la asociación civil. Además, debemos considerar las diversas reuniones que nuestro proyecto de investigación coordinó con la gente toba con el objetivo de intercambiar opiniones y comunicar los avances del mismo. En todos estos casos predominó el uso del español.

Cada una de estas instancias convocó la realización de talleres. Cabe aclarar que sólo describiremos aquellos relativos al proyecto de investigación puesto que no pudimos registrar los relacionados a las actividades de la construcción y la huerta.

En el marco del proyecto de investigación mayor consideramos talleres de discusión en torno a temáticas como tierra, lengua, educación, salud y organización. Se trabajó con algunas fotos y papelógrafos, donde se expusieron los objetivos y los aspectos desarrollados en cada una de las áreas mencionadas. Se programaba el día y la hora del

\footnotetext{
166 A partir del año 2007, al no contar ya con un subsidio de trabajo, la huerta no pudo seguir siendo sustentada con recursos propios. De igual forma, el taller de costura ya no funciona más.

${ }^{167}$ De igual modo, podemos caracterizar las instancias de la autoconstrucción de las viviendas como espacios significativos de uso de la lengua. D. Pellicer (1988) denomina estos tipos de eventos comunicativos como "cotorreo en el trabajo"; es decir, el uso frecuente y cotidiano de la lengua indígena en el lugar de trabajo de los participantes que contrarrestan las actitudes pasivas y los juicios pesimistas sobre la misma. A esto, debemos agregar que estos tipos de diálogos en lengua vernácula no sólo se dan durante las instancias de trabajo en el barrio, sino también en los hogares entre los matrimonios y entre vecinos cuando se visitan.
} 
taller con los miembros de la comisión directiva de la asociación civil. Aunque éstos pasaban el aviso con anterioridad, cada vez que llegábamos debíamos esperar que "se fuera a buscar a la gente" antes de empezar. La convocatoria era para todos; sin embargo, sólo participaban algunos jefes/jefas de familia. ${ }^{168}$ Una vez empezado el taller, exponíamos los objetivos y planteábamos una pregunta general. Los miembros de la comisión directiva siempre eran los primeros en hablar. No obstante, éstos hacían que todos los presentes expusieran sus puntos de vista, siendo ellos quienes controlaban los turnos de la palabra. En todas las situaciones, la lengua que predominó fue el español.

\section{- Charlas y Conferencias}

Las charlas y conferencias ofrecidas a diferentes tipos de públicos: vecinos, visitantes, maestros y estudiantes, extranjeros, etc. han constituido una situación comunicativa constante entre la gente toba. Éstas han sido dictadas tanto en las instalaciones del barrio "Las Malvinas", como fuera del mismo: en la radio, en escuelas, en congresos y en cualquier lugar que se los invitara.

\section{a) En el barrio}

Ya hemos mencionado las charlas ofrecidas, especialmente por miembros de la comisión directiva, a niños escolares durante la celebración del Día del Indio. Las mismas han tenido una duración de no más de media hora. Las charlas fueron dictadas en español, pero la lengua toba es utilizada en varias oportunidades, en especial, cuando hay referencias a actividades desarrolladas en el campo, en el Chaco. De modo tal que la mención de la lengua indígena sirve para incentivar a los niños a conocer y aprender algunas palabras.

Asimismo, se han ofrecido charlas a un grupo de estudiantes universitarios norteamericanos. ${ }^{169}$ Las mismas estuvieron a cargo de algunas mujeres y jóvenes y contaron con la presencia de los niños del barrio. Generalmente, tuvieron una duración de una hora.

\footnotetext{
${ }^{168}$ Una de las principales razones de la poca participación estaba relacionada con la cuestión del trabajo. Solamente los días domingos por la tarde se podía reunir a más interesados.

${ }^{169}$ Estas charlas fueron organizadas en el contexto del dictado del Seminario: "El impacto de la modernidad en las poblaciones indígenas de Argentina" Programa de Estudiantes Extranjeros del Instituto IES La Plata (Institute of European Studies) for the International Education of Students, de la UNLP, en 1997, 1998 y 1999.
} 


\section{b) Fuera del barrio}

Muchos integrantes de la comunidad toba del Barrio "Las Malvinas" han sido invitados a dar charlas en algunas escuelas de la ciudad de La Plata con motivo de celebrarse fechas como el Día de la Raza (12 de octubre) o Día del Indio (19 de abril). Éstas tienen una duración de una hora aproximadamente, son ofrecidas en español y, como describimos para el caso de las charlas a las escuelas visitantes, también se suele usar la lengua nativa para enseñar algunas palabras a los niños que suelen preguntar con alguna curiosidad. Es costumbre, además, llevar artesanías y exponerlas durante el evento.

En algunas oportunidades, y en ocasión de las mismas fechas mencionadas arriba, han sido invitados por algunos medios radiales o televisivos para hablar sobre la cuestión indígena y la experiencia de autoconstrucción de las viviendas. Éste, en realidad, es otro tipo de evento comunicativo donde predominan más las preguntas-respuestas rápidas y en poco tiempo.

Las conferencias dictadas en el contexto de un congreso de antropología o coloquio sobre la temática indígena también han sido numerosas. En varias oportunidades, los discursos comenzaron los primeros minutos en lengua toba para luego continuar en español y tuvieron una duración de quince a veinte minutos aproximadamente.

\section{- Situaciones educativas}

El dictado de clases constituye otra de las situaciones comunicativas frecuentes en el barrio "Las Malvinas". Por un lado, esta actividad ha sido realizada por una docente no toba que ha tenido a su cargo la Escuela de Adultos. Asimismo, ha sido una tarea de algunas jóvenes tobas que suelen dar clases de apoyo a aquellos niños que presentan alguna dificultad en la escuela. Y, por otro lado, debemos mencionar las clases de lengua toba que, en algunas ocasiones, se han dictado tanto a los niños del barrio como a nosotros.

La enseñanza de la lengua toba merece un análisis particular. Podemos distinguir en el acto de enseñanza-aprendizaje la aparición de dos planos de significación:

- la selección del léxico y

- el contexto explicativo del léxico enseñado.

En primer lugar, la selección del léxico en el proceso de enseñanza ha tenido una estrecha relación con la cosmovisión toba. En este proceso nuestra profesora fue seleccionando palabras que describían esa comunicación del hombre y la naturaleza cuya 
interacción ha sido, durante siglos, directa y diaria (Miller 1979). ${ }^{170}$ Es decir, el léxico que fue apareciendo en el acto de enseñar implicó eventos metaculturales y metacomunicativos, donde, de alguna manera, se reconstruyó el lugar de origen describiendo el paisaje del Chaco: geografía, flora y fauna, como así también los distintos aspectos socioculturales: del "antes" (el pasado) y el "ahora" (el presente); lo que sucede con la gente hoy día en el campo; la comparación con los que viven en la ciudad y, a su vez, el relato de todas las vicisitudes que se fueron presentando en contacto con los no tobas, tanto en el pasado como en el presente. Desde luego, se compararon las características fonéticas y sintácticas de las lenguas, incluido el inglés. Esta descripción del mundo toba no estuvo dada, solamente, por la simple mención del léxico, sino que cada uno de los lexemas fueron acompañados por una explicación del por qué de su razón de ser, del contexto en que se gestaron.

Por ejemplo, en las primeras clases, el léxico seleccionado se basó en todo lo relacionado con los miembros de la familia, siendo mencionados en el siguiente orden: ${ }^{171}$

$\begin{array}{ll}\text { - abuela } & \text { qome }^{\prime} \\ \text { - abuelo } & \text { yape' } \\ \text { - madre } & \text { chera } \\ \text { - padre } & \text { taxare }^{\prime} \\ \text { - hijo } & \text { yalec' } \\ \text { - hija } & \text { yale }\end{array}$

Podemos interpretar que el que se haya dado en ese orden: primero los abuelos, y, en especial la abuela, y, luego, los padres, estaría significando el grado de prioridad y respeto hacia los mayores que, en general, es propio de las culturas aborígenes. Luego, fueron los saludos, tanto el que se da cuando una persona llega a un lugar como cuando se despide. $\mathrm{Al}$ ir practicando la fonética toba, fueron apareciendo distintas palabras que delimitan los "etnoambientes" definidos por los tobas en su entorno natural (Wright 1985) ${ }^{172}$ y las especies que en ellos habitan. Pero, a su vez, esa enumeración fue describiendo lo que el

\footnotetext{
${ }^{170}$ Cabe aclarar que no hubo condicionamiento alguno de mi parte para la aparición tanto de los temas como del léxico que se fueron seleccionando durante el transcurso de las clases.

${ }^{171}$ Cabe señalar que la grafía que se utiliza es aquella empleada por nuestra profesora de toba, (JG).

172 Pablo Wright (1985) utiliza el término "etnoambiente" para referirse a aquellos espacios del entorno natural que definen los tobas, explotados en forma diferencial de acuerdo a sus características peculiares. Identificándose: el monte, el campo, la laguna, etc.
} 
hombre hace en esos etnoambientes, en qué momentos realiza esas actividades y por qué las realiza.

En un segundo momento, aparecieron los préstamos del español, vocablos que la misma persona que enseñaba señaló que eran nuevos, que se habían incorporado por influencia de "los blancos" y que por eso eran muy similares al castellano como:

$$
\begin{aligned}
& \text { - huaca por "vaca”, } \\
& \text { - caỹo' por "caballo". }
\end{aligned}
$$

O bien, aparecieron otros que no tenían parecido alguno con la palabra castellana pero que, igualmente, se trataba de una influencia del mundo de los blancos. Como se dio el caso de la aparición de la palabra qasoxonaxa $^{173}$ cuyo significado es doble: trueno y elefante. La explicación fue que:

- “...elefantes en el Chaco no hay, así que cuando llegó por primera vez el circo al Chaco, y los paisanos vieron y escucharon el ruido que hacía el elefante, lo asimilaron al trueno, por eso lo llaman 'qasoxonaxa' que significa trueno".

Así, como éste, aparecieron otros ejemplos, como el que las abuelas llamen a la "heladera": aloñe laỹe', cuya trascripción sería "lugar donde se guarda adentro la helada", etc.

Como se puede ver, cada una de estas explicaciones van acompañadas por una reflexión por parte de la persona que enseña tanto del mundo al cual pertenece como de sí misma, de su bagaje histórico-socio-cultural. Es así como aparece en el acto de enseñanza el segundo plano de significación mencionado en párrafos anteriores: el del contexto explicativo. Cada palabra toba mencionada encierra una historia que implica presentar, por parte de quien enseña, el contexto en que suele ser empleada:

$\checkmark$ Se reflexiona, así, sobre el porqué y/o el momento de la aparición, en el discurso toba, de una palabra determinada en una situación social dada;

$\checkmark$ Paralelamente, durante esa reflexión, intervienen factores personales en relación a esa situación señalando el momento de su vida o las circunstancias en que tal palabra se incorporó a su léxico;

$\checkmark$ Se reviven vivencias personales, cuentos, anécdotas en relación a esa palabra.

\footnotetext{
${ }^{173}$ La trascripción fonética, según Klein, sería [qa'sogonagá].
} 


\section{IV.7. Niños, LENGUA Y SOCIALIZACIÓN}

En los puntos anteriores hemos hecho una descripción de la competencia y actuación lingüísticas, así como de las actitudes hacia la lengua toba y el español de los adultos y ancianos tanto hombres como mujeres, pero ¿qué sucede con los niños y los jóvenes? Hemos reconocido tres grandes tipos de hablantes respecto de su competencia en toba: a) hablante fluido del toba, b) entiende toba y c) entiende toba con limitaciones. Este último grupo comprende niños y jóvenes que sólo se expresan en castellano y que poseen un conocimiento parcial o incipiente de la lengua toba. Asimismo, incluimos dentro de este grupo a los criollos o no tobas que conviven en el Barrio Toba "Las Malvinas". La observación sistemática de estos hablantes durante los juegos, en las reuniones realizadas en el barrio, en las visitas a los hogares, en las clases de Apoyo Escolar, ${ }^{174}$ durante la realización de algunas actividades en una de las escuelas donde, según un relevamiento previo, asistía la mayoría de los niños en edad escolar del Barrio Toba -expuesto en el Capítulo III- y el trabajo de recopilación de palabras tobas con los propios niños y jóvenes, nos permitió visualizar y contrastar el conocimiento que este grupo de hablantes posee de la lengua toba y sus actitudes respecto a la misma. Los padres de estos niños, según la distribución del Cuadro $\mathrm{N}^{\circ} 1$ (en el punto 1. de este capítulo), pertenecen a los grupos: $\mathrm{B}$, C, D, E y F y se caracterizan tanto por hablar fluidamente la lengua toba como por entenderla. En este último caso se trata de padres que no les han transmitido la lengua toba a sus hijos. No obstante, como veremos, si bien los niños no tienen un uso real de la lengua vernácula, sí poseen conocimiento de gran parte de su léxico y son capaces de comprender algunos mensajes emitidos en diferentes contextos, en especial el familiar o doméstico y el barrial. Por eso nos preguntamos: ¿por cuál vía los niños han incorporado parte del léxico qom l'aqtaqa?

La respuesta se encuentra al observar aspectos del proceso de socialización de estos niños. Por una parte, la participación de los abuelos es constante en este proceso y éstos son quienes tienen una competencia y actuación de la lengua de origen. Muchas veces, los

\footnotetext{
${ }^{174}$ El Apoyo Escolar fue pensado en un comienzo como una tarea de devolución en el marco de la extensión universitaria, para luego convertirse en un espacio de investigación antropológica y educativa que nos permitió efectuar una observación controlada en el marco de lo que se denomina "lógica experimental". Una instancia en la que, a través de diferentes actividades, se induce la emergencia de saberes propios, se visualizan dificultades, se detectan formas alternas de resolución de problemas; es decir, nos acercamos a la "Zona de Desarrollo Próximo" para favorecer el desarrollo cognitivo (Vygotsky 1995; Wertsch 1995; Moll 1993; Baquero 1997) (Ver García, Tamagno, Ibáñez Caselli y otros 2003).
} 
nietos quedan al cuidado de los abuelos tanto en el Chaco como en La Plata o el Gran Buenos Aires. Como consecuencia, los niños internalizan -mediante experiencias de vida, consejos, advertencias- las normas y los valores propios de la sociedad toba, incluida la lengua. Lo que es más, aun en aquellos casos donde se ha evitado enseñar la lengua a los hijos por diferentes causas: vergüenza, temor, discriminación, para no ser identificados como indígenas, "para progresar", la misma se sigue empleando en el contexto familiar, en las reuniones organizativas, en las visitas al Chaco o a través de las visitas recibidas del Chaco, en los movimientos religiosos, en el culto. En todas estas situaciones, los niños y jóvenes encuentran un contacto permanente con la lengua toba.

Por otra parte, los niños cuyos padres hablan el toba con mayor frecuencia que el castellano -en especial, los del grupo $\mathrm{D}$ del Cuadro $\mathrm{N}^{\circ} 1-$, durante sus primeros años de vida tienen su socialización en esa lengua. Sin embargo, a medida que van entrando en contacto con los demás niños del barrio -hermanitos mayores, vecindad y escuela- el castellano se hace dominante. De todas formas, resaltamos que, durante todo ese tiempo, la lengua materna está presente en el contexto familiar y en el barrio, por lo tanto, sigue acompañando todo el crecimiento del niño.

De manera tal que los niños se socializan en un contexto bilingüe. El conocimiento que este grupo posee de la lengua toba consiste en palabras sueltas que tienen que ver con órdenes y expresiones que reciben los niños de sus padres y abuelos; saludos; nombres de cosas, de animales, del sistema de parentesco y partes del cuerpo, como por ejemplo: ${ }^{175}$

\begin{tabular}{|c|c|}
\hline \multicolumn{2}{|c|}{ Órdenes/ Expresiones } \\
\hline anso'oñe' & sentate \\
\hline anachañe' & parate \\
\hline auloguí & fijate \\
\hline qolac & vamos \\
\hline$q a \tilde{y} c a$ & no hay \\
\hline 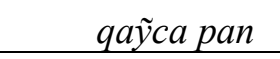 & no hay pan \\
\hline do'oche' & a dormir \\
\hline a' huoche' & duérmete \\
\hline ñiaché & gracias \\
\hline so'onaxaỹ & qué lindo \\
\hline
\end{tabular}

\footnotetext{
${ }^{175}$ Para la transcripción, he respetado la ortografía del miembro de la comunidad que ha cumplido el rol de enseñar la lengua $(\mathrm{JG})$. No se consideran aspectos fonético-fonológicos en este trabajo. El grafema $\tilde{y}$ se lee según (JG) como $i$, y $d$ como $r$.
} 


\begin{tabular}{|c|l|}
\hline \multicolumn{2}{|l|}{ Saludos } \\
\hline la'a & hola \\
\hline nale'em & adiós \\
\hline
\end{tabular}

\begin{tabular}{|c|l|}
\hline \multicolumn{2}{|l|}{ Parentesco } \\
\hline qome $^{\prime}$ & abuela \\
\hline$\tilde{y} a p e^{\prime}$ & abuelo \\
\hline chera $^{\prime 176}$ & madre \\
\hline taxade $^{\prime}$ & padre \\
\hline$\tilde{y}$ alec $^{\prime}$ & hijo \\
\hline$\tilde{y}$ ale & hija \\
\hline
\end{tabular}

\begin{tabular}{|l|l|l|}
\hline \multicolumn{2}{|c|}{$\begin{array}{c}\text { Vocabulario recogido por } \\
\text { una joven }\end{array}$} & $\begin{array}{c}\text { Escritura según } \\
(J G)\end{array}$ \\
\hline pajarito & coio & qoỹo \\
\hline perro & pioc & pioc \\
\hline caballo & callo & caỹo' \\
\hline conejo & sógna & soxona' \\
\hline gallina & ólga & olxaga' \\
\hline ñandú & mañec & mañeq \\
\hline elefante & casogná & qasoxonaxa' \\
\hline tortuga & potagnat & potaxanaxat \\
\hline sapo & cologloglo & qoloxoloxo' \\
\hline grillo & mille & milec \\
\hline
\end{tabular}

\begin{tabular}{|c|c|}
\hline \multicolumn{2}{|c|}{ Partes del cuerpo } \\
\hline cabeza & $n c a \tilde{y} c$ \\
\hline cabello & nahue' \\
\hline cara & nashec' \\
\hline ojos & na'aite' $^{\prime}$ \\
\hline boca & anap \\
\hline nariz & $n^{\prime} m i q^{\prime}$ \\
\hline orejas & $n^{\prime}$ tela' \\
\hline
\end{tabular}

No es común que los niños utilicen o nombren espontáneamente estos lexemas en sus juegos o en sus charlas, pero éstos aparecen cuando se les pregunta y los dicen sin pensar demasiado, aunque muy vergonzosamente. $\mathrm{Y}$ si se les pregunta y no se acuerdan o no saben, salen corriendo a buscar a la abuela o mamá o tía, es decir, a la persona más cercana que están seguros que es fuente de ese conocimiento. También conocen y saben cantar la canción de cuna en toba. Generalmente, ésta se la cantan sus abuelitas, mientras que las

\footnotetext{
${ }^{176}$ La transcripción fonética, según H. Manelis Klein (1981), sería [tagaré] donde el fonema /g/ es sonoro, post-velar.
} 
mamás les cantan el "arrorró" en castellano. El siguiente es un diálogo sostenido con una niña de seis años de edad:

$[\ldots]$

$\mathrm{N}$ - Alolé ahuoché qoray qole'..., alolé ahuoché qoray qole'...después no me acuerdo, alololé ñapiolé... ${ }^{177}$ y sigue

I- ¿se duerme tu hermanito con eso?

$\mathrm{N}-$ Así canta mi abuela

I- ¿Y tu mamá?

N- Mi mamá no,

I- ¿No le canta nada?

$\mathrm{N}-$ Le dice: arrorró mi niño, arrorró mi niño, arrorró mi niño de mi corazón. ${ }^{178}$

I- ¿Qué lindo! ¿Y vos le cantás algo a tu hermanito o no le hacés dormir?

N-sí, le digo: noni, noni, noni duérmase Pilucho, duérmase Pilucho de mi corazón. Este ya se duerme, noni, noni, noni, noni, noni, noni, noni, noni, nooo 179

I- Pilucho le dicen?

$\mathrm{N}-\mathrm{S}$ í, o si no le dicen $\mathrm{X}$, porque tiene todos los pelos parados.. ${ }^{180}$

Además de la lengua, los niños han internalizado discursos que transmiten aspectos relevantes de la cultura toba, tales como cuentos, leyendas, consejos, dichos. Estos elementos también les son transmitidos por los abuelos, como así también a través de las visitas que reciben de niños que provienen del Chaco o las que ellos mismos hacen a esa provincia. Una de las leyendas que relatan las niñas con más frecuencia es la de "la sirena que vive en la laguna” y contextualizan esta laguna en la Provincia del Chaco.

Tradicionalmente, las principales actividades de supervivencia o reproducción del pueblo toba han sido la caza, la pesca y la recolección. Si bien en la ciudad no hay lugares para realizar tales prácticas, podemos observar que muchos de los niños poseen conocimiento de cómo cazar y pescar y de las armas o herramientas que se utilizan para tales fines. Incluso, se los ha visto jugando en las zanjas cercanas a sus casas "cazando" renacuajos. Asimismo, conocen de las técnicas de modelado y cocción de la cerámica, ayudan en la confección de collares y pintan algunos de los animalitos y platitos de barro que se confeccionan para la venta de artesanías -fauna típica de la zona chaqueña. Muchos

\footnotetext{
${ }^{177}$ Lo expresa entonando una música.

178 Ídem 66.

179 Ídem 67.

${ }^{180}$ Referencias: $\mathrm{N}=$ nena; $\mathrm{I}=$ Investigador.
} 
de ellos, poseen habilidades para el dibujo, la pintura y el modelado y son muy observadores, prolijos y cautos.

Por ejemplo, en una experiencia que realizamos en la Escuela $\mathrm{N}^{0} 52$ en 1993, pudimos observar cómo a través de canciones en toba y fotografías del barrio y de sus artesanías, los niños eran capaces de contar a sus compañeros de aula lo que entendían de las canciones y sobre su historia: desde la llegada al barrio, la construcción de las viviendas y sus diferentes etapas, cómo cazar y cómo pescar, con qué elementos hacer esos trabajos hasta cómo confeccionar un collar con cuentas de barro cocido. Por otra parte, -como ya hemos mencionado- suelen reproducir la práctica del modelado cuando juegan con barro.

Asimismo, debemos destacar que el Chaco está siempre presente en los niños. Saben que en ese lugar se encuentran sus abuelos o sus padres o tíos y algunos se refieren a éste como "mi Chaco", aunque muchos no hayan estado nunca en él.

Por su parte, podemos destacar que el modo de habla de los niños se corresponde con la de los padres y abuelos, aunque no se expresen en toba. Su castellano es típicamente "chaqueño" y predomina un hablar pausado, sin mucha variedad en el vocabulario. Las observaciones que hemos realizado sobre el comportamiento de los niños en la escuela nos han hecho notar que existen mayores dificultades en el área de lengua que en el de matemáticas. ${ }^{181}$ Las frases que realizan los niños, en general, son cortas y les cuesta mucho relatar una historia larga. Este aspecto fue observado a través de una experiencia realizada en el propio barrio con niños en edad escolar como cierre de fin de año del Apoyo Escolar. La experiencia consistió en repartir algunas escenas con dibujos que los niños debían ordenar y, luego, armar una historia o relato. A los mayores de diez años se les hizo narrar la historia en forma escrita y a los menores, en forma oral.

Ejemplo 1: Relato oral, niño de 6 años de edad

I: A ver, contame, ¿qué hay ahí?

M: Están peleando

I: ¿y quiénes están peleando?

M: el zorro y el tigre

$\mathrm{I}: ¿$ y por qué pelean?

M: porque ese le está espiando

${ }^{181}$ Destacamos el trabajo que la Prof. María del Carmen García se encuentra realizando en el Barrio Las Malvinas en torno a los conocimientos de matemática que poseen los niños, desde los saberes propios de la cultura toba, con una perspectiva Etnomatemática. 
I: ¿y por qué?

M: porque le tenía güergüenza de comer y después miró para otro lado

Ejemplo 2: Relato oral, niña de 6 años de edad

I: ¿qué pintaste ahí, qué es esto?

C: no se

I: ¿y esto?

C: no se

I: ¿y esto?

C: no se

I: ¿y esto sabés?

C: una sirenita

I: ¿y qué está haciendo la sirenita?

C: está agarrando el pescado

I: ¿y por qué lo agarra?

C: ...(no responde)

I: ¿Y el pescado qué hace?

$\mathrm{C}$ : quiere escapar

I: ¿y dónde ocurre eso?

C: por ahí...

Ejemplo 3: Relato oral, niña de 8 años de edad

I: Pensá una historia, un cuento, ¿qué está pasando acá?

L: una vez un perro, una vez un perro, se, iba caminando, se le cayó un pájaro muerto y se arrebató las plumas

I: ¿jeso pasó?!

L: sí

I: ¿y dónde pasó eso?

L: en la selva

I: ¿y la selva donde está?

L: ah?

I: ¿dónde está la selva... y cuándo fue eso?

L: en la calle

I: ¿y fue hace mucho tiempo, poquito tiempo, hoy?

L: ¡hoy!

I: ¿y en dónde?

L: en la selva

I: ¿y la selva queda muy lejos? 
L: ah?

I: ¿cuánto de lejos?

L: hace miles, tenés que caminar como mil tiempo...

I: ¿y qué otras cosas hay en la selva?

L: hay tigres, monos,

Como se puede observar, los niños individualmente describen sólo lo que ven -o interpretan lo que ven- y no inventan o recrean la historia agregando otro vocabulario. En todos los casos hubo que guiarlos con preguntas como: qué veían, dónde ocurría la escena, el cuándo, el porqué, con el fin de ampliar el conocimiento de los niños. En muchas ocasiones contextualizaron las escenas en el bosque o la selva (puesto que eran dibujos de animales en su mayoría) y refirieron a la selva en el Chaco. En varias oportunidades, mientras el niño al que se le preguntaba respondía casi vergonzosamente al investigador, los que estaban alrededor iban interviniendo, agregando, aclarando, corrigiendo algunas de las expresiones o conceptos que se decían; de modo que las narraciones se enriquecían colectivamente. Con respecto a los relatos escritos, éstos fueron pocos. La mayoría prefirió sólo pintar y, luego, las narraciones fueron hechas de forma oral y a pedido del investigador. A continuación se transcriben algunos ejemplos.

Ejemplo 4: Relato escrito, niña de 10 años de edad

"habia una vez un pajaro que vivia en el bosque y estava paseando y se paro serca de los pinos y justo un zorro levio al pajaro el rremalo casi le izo caer en el varro"

Ejemplo 5: Relato escrito, niña de 10 años de edad
"habia una vez una sirena
se metio adentro del agua y
bio unos pescados y los toco y se los comio"

\section{IV.8. Definiendo la Comunidad de Habla Toba}

En consonancia con el Cuadro $\mathrm{N}^{0} 1$ expuesto en la página 145, reconocemos tres tipos de hablantes en relación a su competencia de la lengua toba: hablante fluido de la lengua toba, entiende la lengua toba y entiende la lengua toba con limitaciones. Estos tres tipos de hablantes se corresponden con los tres subgrupos delimitados a continuación:

a) Hablantes Bilingües con Dominio de la Lengua Toba: adultos y jóvenes adultos nacidos en el Chaco, que han migrado en diferentes momentos (algunos hacen más de 30 años, otros recientemente), que manejan ambas lenguas, aunque con una mayor fluidez el toba. Prefieren usar esta última en 
los dominios de uso doméstico y de parentesco, y de vecindad; es decir, en el ámbito barrial. Son los casos de los grupos: A, B, C, D, F del Cuadro $\mathrm{N}^{\mathrm{o}} 1 \mathrm{de}$ la página 145 .

b) Semi-hablantes con Dominio del Español: jóvenes y adultos nacidos en el Chaco, pero que han migrado siendo niños o adolescentes a Buenos Aires. Poseen una comprensión casi total de la lengua toba, pero no la hablan con fluidez. Prefieren, en cambio, usar el español en todos los dominios. Se trata de los casos: E, G.

c) Bilingües casi pasivos con Dominio del Español: niños, jóvenes y adultos, nacidos tanto en el Chaco como en el Gran Buenos Aires, que han tenido su socialización en la lengua toba o en español. Hablan sólo en castellano en todos los dominios. Sin embargo, tienen incorporado parte del léxico toba y entienden cuando se dirigen a ellos en esa lengua. Consideramos dentro de este grupo a H, I, J y K.

Nótese que, por un lado, no encontramos monolingües en toba entre los habitantes del Barrio Toba "Las Malvinas". Este caso se da únicamente entre algunas visitas que llegan del Chaco, tanto adultos como niños. Estos suelen quedarse algunas semanas e incluso hasta meses visitando a sus parientes. Durante ese tiempo, estos niños toba hablantes juegan con los del subgrupo c) y comienzan a asimilar el español; mientras que los segundos también incorporan léxico del toba. Por otro lado, está el caso de los no tobas: esposo/a criollos que conforman matrimonios mixtos a los que también incluimos dentro del grupo de los bilingües casi pasivos puesto que han incorporado algunos vocablos del léxico de la lengua vernácula y entienden, aunque con limitaciones, por el contacto cotidiano y porque el esposo/ esposa le enseña y, sobre todo, porque comparten las estrategias discursivas del grupo.

Puesto que los subgrupos b) y c) no hablan la lengua toba y, en cambio, son hablantes fluidos del español, ¿los podemos considerar como miembros de la comunidad de habla toba?.

En primer lugar, los miembros del Barrio Toba "Las Malvinas" comparten una serie de rasgos, reglas, normas, costumbres, ideas, origen e historia en común, como así también vivencias particulares; en tanto que, en lo lingüístico: recursos verbales y estrategias comunicativas y metacomunicativas también comunes. En segundo lugar, esta serie de elementos usuales los hace diferentes de otros grupos vecinos. En tercer lugar, dada la 
importancia de la autoconstrucción de las viviendas, el Barrio "Las Malvinas" se ha convertido en un referente importante en relación a otros grupos de familias indígenas y no indígenas que luchan por obtener un espacio propio. Cada uno de los integrantes se reconoce como parte del mismo y se autodefine como miembro de "la comunidad toba de La Plata". Si bien los habitantes del Barrio Toba "Las Malvinas" comparten elementos comunes, también presentan diversidad; no conforman un todo homogéneo. Además, la comunidad tiene fronteras: espacios que se construyen simbólicamente en la interacción (Cohen [1985] 1992), así podemos señalar las fronteras religioso-espiritual, organizacional-laboral, generacional, de género y étnico-social. Fronteras que de ninguna manera son estáticas, sino que sus miembros pueden traspasarlas según el rol social que ejercen en el momento. Los miembros pueden compartir los mismos símbolos, pero los significados que le atribuyen a los mismos son diferentes, sin que ello signifique dejar de ser toba. Esto último, nos lleva a plantear el conocimiento que los tres subgrupos de hablantes reconocidos en el Barrio "Las Malvinas" poseen de la lengua toba.

Estos hablantes no sólo son participantes de la comunidad, sino integrantes de la misma, por compartir la misma competencia comunicativa. Esto quiere decir que los miembros de la comunidad de habla toba comparten la habilidad receptora $\mathrm{y}$, sobre todo, el conocimiento de las normas sociolingüísticas. Al tiempo que poseen un acceso diferencial a los usos disponibles de esa lengua. Según la definición que hemos dado y empleamos de comunidad de habla - expuesta en el Capítulo II.2.3.- ésta incluye a los hablantes que pueden ser ubicados dentro de los tres subgrupos diferenciados. En el Barrio Toba "Las Malvinas" la comunicación se da en toba entre los que están incluidos en el subgrupo a); en tanto que predomina el castellano para los del b) y c). Aun no compartiendo aspectos de la competencia y actuación lingüística, resaltamos que lo común entre estos tres tipos de hablantes con habilidades lingüísticas diferentes consiste en el hecho de compartir las mismas estrategias comunicativas y metacomunicativas. A esto se suma toda la dinámica sociocultural que caracteriza al grupo, que no se agota en lo lingüístico y que hace que estos hablantes se autodefinan y sean definidos y percibidos por los demás (no tobas) como una comunidad.

La consideración de la situación de los niños y jóvenes tobas - nacidos tanto en el Chaco como en Buenos Aires- que, en general, no dominan la lengua qom l'aqtaqa, pero que entienden y comparten "las pautas comunicativas y metacomunicativas" que operan en el grupo, nos permite dar otro paso en la investigación. Esta perspectiva de análisis nos 
permite incluir a los hablantes con competencias de comprensión y (meta) comunicativas. A pesar de su falta de fluidez, comparten el conocimiento del cuerpo de reglas y normas que hacen al correcto comportamiento durante cada uno de los eventos comunicativos significativos para el grupo. Todos estos elementos los hace pertenecer también a la comunidad de habla toba e identificarse con el grupo.

\section{IV.9. Los SignificAdos Sociales del USO de LA LENGUA (IDEOLOGÍA)}

Dentro del interés por aportar a la comprensión entre los vínculos que existen entre las formas sociales y las formas del habla, en la confluencia entre el lenguaje y el comportamiento social, la ideología lingüística resulta un concepto fundamental. Entendemos por ideología del lenguaje el sistema cultural de ideas, es decir, las representaciones, que se construyen sobre las relaciones sociales y lingüísticas, en su intersección en el mundo social (Woolard 1998:3). Esta concepción permite comprender cómo la ideología de un grupo - especialmente la del grupo social dominante- puede ser empleada para influir en las prácticas sociales y lingüísticas de los demás grupos dominados. Las ideologías tienen un gran impacto en las actitudes, o "la disposición de responder favorable o desfavorablemente hacia una lengua, una persona, una institución o un evento" (Baker y Prys Jones 1998:174, en Coronel y Grabner 2005:15-16). En este sentido, esto es lo que ha ocurrido a lo largo de la historia con las lenguas indígenas en América Latina, en general, y en Argentina, en particular. Los grupos dominantes de habla hispana han construido y alimentado social e históricamente ideologías que han inducido a manifestar actitudes negativas hacia las lenguas y las culturas de los pueblos originarios.

Como ya se ha señalado, el prejuicio y la discriminación han sido tan fuertes que han llevado a que estas poblaciones a lo largo de las generaciones dejaran de expresarse en su propia lengua y aparecieran como abandonando, o suplantando sus costumbres y creencias. No obstante, frente a esta actitud, debemos considerar también la otra cara de la moneda, la otra ideología: la de la resistencia lingüística y social. A pesar de adoptar la lengua del dominador, muchos pueblos indígenas aún mantienen viva su lengua y su cultura, habiendo resignificado muchos de los elementos foráneos que fueron tomados e impuestos por el sector hegemónico de la sociedad. Así, la lengua toba se mantiene vigente tanto en el Chaco como lejos de su lugar de origen, en Rosario (Provincia de Santa Fe) y conurbano bonaerense y La Plata (Provincia de Buenos Aires) y sus hablantes luchan para que la misma no se pierda. 
En la ciudad de Rosario (Provincia de Santa Fe) existen al menos dos escuelas con maestros auxiliares bilingües tobas: una en el barrio de la Av. Rouillón y la otra en exEmpalme Graneros, que son el resultado de una larga y constante lucha de la gente toba de Rosario (ver Ibáñez Caselli 2004, Arias 2005 y 2006). En la Provincia de Buenos Aires, que no se cuenta con escuelas con un enfoque bilingüe e intercultural para los niños tobas de los distintos barrios y asentamientos, la preocupación existe y está latente; y los padres se han movilizado en búsqueda de mejoras en la calidad de la educación de sus hijos (Ibáñez y otros 2004). En los dos barrios tobas organizados que existen en esta provincia podemos desatacar algunas experiencias interesantes que permiten observar la ideología de la resistencia lingüística y cultural. Así, en el barrio de Derqui se han dado algunas experiencias de enseñanza de la lengua toba con el apoyo de un equipo de investigación de la Universidad de Buenos Aires (Messineo y otros 2002, Messineo 2003). En el Barrio "Las Malvinas" de la ciudad de La Plata también han habido algunas experiencias lideradas por una mamá quién ha tomado la iniciativa de dictar algunas clases-taller a los niños del barrio. Frente a estas experiencias de enseñanza de la lengua materna, sobre todo, resaltamos la preocupación y el interés manifiesto por revalorar la lengua y la cultura de los mayores para que lo niños y jóvenes las conozcan, las aprendan y las reproduzcan. ${ }^{182}$

\section{IV.10. RECAPITULANDO}

A lo largo de este capítulo hemos caracterizado al Barrio Toba "las Malvinas" como una comunidad de habla. Hemos identificado los roles sociales de sus integrantes y los usos que tiene la lengua toba, como así también los recursos verbales y las estrategias comunicativas y metacomunicativas que comparten sus miembros.

Con el fin de caracterizar las modalidades discursivas que caracterizan a esta comunidad de habla analizamos las prácticas sociales y discursivas que se dan tanto hacia el interior

\footnotetext{
${ }^{182}$ No podemos menos que incorporar una información reciente. Desde el LIAS, en el mes de julio de 2007 se organizó un viaje en conjunto a la Provincia del Chaco. Viajaron cinco jóvenes y una mamá tobas, tres becarios y un investigador. El objetivo: visitar los lugares de origen y poner en práctica conocimientos adquiridos en un curso de computación que tuvo lugar durante el 2006 en la Facultad de Ciencias Naturales y Museo. El material se comenzó a procesar en medio de las emociones del encuentro con los parientes y del llevar y traer saludos que en formato digital se vieron en la notebook utilizada a tal efecto. Como resultado de esta experiencia, los jóvenes tobas, de entre 15 y 17 años se han propuesto prestar más atención a la lengua de sus mayores, incentivados por la observación de la vigencia de la lengua toba, sobre todo en Pampa del Indio, uno de los epicentros de la dinámica sociocultural y lugar del cual provienen la mayoría de los parientes.
} 
del grupo como en su articulación con el afuera, abarcando tanto los discursos públicos como los privados. De esta manera, nuestro punto de partida fue el discurso entendido como el nexo, la expresión concreta y actual de la relación lengua/ cultura/ sociedad. En seguimiento a los planteos de Sherzer (1987) y Fairclough (1992), el discurso crea, recrea, focaliza, modifica y transmite tanto la cultura como la lengua y su intersección. Se ha considerado al evento discursivo como una pieza de texto, como un ejemplo de práctica discursiva y como práctica social. A través de los discursos analizados se ha mostrado cómo los mismos constituyen modos de acción y formas de representación, formas por las cuales la gente puede actuar sobre el mundo y sobre sí misma. Y, a la vez, mantienen una relación dialéctica con la estructura social. Por un lado, la estructura social moldea los discursos y, por otro, los discursos se construyen socialmente. Además, los cambios en el uso del lenguaje se relacionan con procesos sociales y culturales.

Asimismo, hemos identificado ocho tipos de situaciones comunicativas: 1) Asambleas, con sus tres variantes (generales, de la asociación civil y de la iglesia), 2) Sesiones de culto, 3) Celebraciones de la iglesia y cívico-comunitarias, 4) Reuniones comunales, 5) Visitas, 6) Reuniones y talleres interétnicos, 7) Charlas y conferencias, 8) Actividades educativas. En cada una de ellas se reconocen los siguientes eventos de habla: consejos y advertencias, enseñanzas-transmisión de conocimientos tobas y no tobas, conversaciones, chismes y chistes, narraciones, oratorias y prédicas.

Finalmente, hemos abordado algunos aspectos de la ideología del lenguaje considerando tanto la vigencia de la lengua toba como las prácticas de enseñanza de la misma como expresiones de una resistencia lingüística y social del pueblo Toba. 


\section{CAPítulo V}

\section{LENGUA/ IDENTIDAD /MigRACIÓN: CONSIDERACIONES FinALES}

"No se sabe qué pasará en el barrio en el futuro. Al ser poquitos y estar lejos del lugar de origen, puede ser que algunas cosas: lengua, costumbres, se pierdan, pero los chicos van a ganar, porque van a entrar a la facultad, van a estudiar y después ellos van a volver para atrás y van a reivindicar y lograr los reclamos de los indígenas. Eso no se va a perder" (Testimonio DR, LP 2001).

\section{V.1. Los Usos Y “DeSusos" De la Lengua Toba En EL CAMino de la MigRaCión}

El análisis de los datos sociolingüísticos obtenidos a lo largo de esta investigación reveló y constató la vigencia de la lengua originaria en las afueras de la ciudad de La Plata, a más de mil kilómetros de distancia del Chaco. El avance del castellano como lengua dominante ha restringido los dominios de uso de la lengua toba. Sin embargo, observamos el uso de la lengua materna principalmente en los dominios doméstico, de parentesco y de vecindad. La lengua toba se habla en algunos hogares en el nivel intramatrimonial y entre las primeras generaciones de migrantes, en el nivel intervecinal -aunque no en todo momento- y acompaña las principales actividades comunitarias que se realizan en el barrio.

Estas prácticas de resistencia lingüística y cultural emergen especialmente en situaciones comunicativas intra e interétnicas que guardan una gran carga emotiva. Al hacerlo se superan aquellos momentos en que, no sin dolor, los mayores optaron por no transmitir la lengua a sus hijos y nietos, tanto en el Chaco como en el trayecto de la migración. Fue significativo el uso de la lengua materna durante la ceremonia de inauguración de las viviendas y la entrega de llaves; cuando se recibió la visita del coro toba Che'lalapi de Resistencia o del pastor que generó la Campaña Evangélica. Es la lengua que ayudó y sostuvo, a la vez que ayuda y sostiene, las importantes decisiones y acuerdos que se han tomado en la organización del grupo durante las asambleas y reuniones. Además, fluye con naturalidad en muchas de las conversaciones que tienen 
lugar en las situaciones de visitas. También es la lengua que presenta al grupo en tiempo y espacio frente a los otros, tanto en el ámbito público como privado.

El haber logrado "un pedacito de tierra donde vivir todos juntos y desarrollar la lengua y la cultura" ha permitido que la lengua continúe teniendo vigencia y se genere un espacio favorable para su desarrollo, animados incluso por el orgullo frente al logro. Ejemplo de esto, como ya se ha señalado, son las experiencias de dictado de clases de lengua toba a los niños de una manera sistemática por parte de una mamá y como signo de preocupación e interés para que las nuevas generaciones reivindiquen lo propio; o el interés por crear una escuela primaria para el barrio con un enfoque intercultural y bilingüe. Planteo que fue hecho en diferentes situaciones comunicativas y en distintos contextos, tanto públicos como privados, en los que se ha expuesto la necesidad de crear una escuela con maestros indígenas que enseñen la lengua y la cultura tobas no sólo a los niños tobas del barrio sino para todos, también para los "criollos" -como una expresión de lo intercultural.

Las familias tobas de la ciudad de La Plata no se encuentran aisladas. Mantienen el contacto con las otras familias tobas que se ubican en distintas localidades del Gran Buenos Aires, Rosario, Chaco y Formosa, sosteniendo lazos de amistad, compadrazgo, parentesco, fraternidad religiosa $\mathrm{y}$, sobre todo, compartiendo la misma "lucha por una reivindicación étnica". A pesar de la distancia, se piensan como un sólo pueblo: el Pueblo Toba. Este hecho también propicia que la lengua toba mantenga su vigencia, se revitalice, sea un elemento de identidad y cohesión.

Aunque el contacto que tienen los niños tobas con otros niños que sólo hablan español en la escuela, en los juegos- y la influencia de los medios de comunicación y entretenimiento poco favorecen el fortalecimiento de la lengua toba, observamos que los niños y adolescentes tienen conocimiento de una parte de su léxico y entienden algunos aspectos según las circunstancias, porque escuchan la lengua en diferentes instancias de lo cotidiano, tanto en sus hogares como en el barrio. Además, los niños y adolescentes participan en todas las actividades que se desarrollan en éste y están presentes en todas las situaciones comunicativas que en él acontecen; escuchan lo que se dice y observan con precaución, curiosidad y extrañeza a quienes se acercan a visitarlos. Muchas veces acompañan a sus mayores a dar una charla en una escuela o alguna entrevista y conocen la historia del grupo. Todos estos elementos nos permiten corroborar una de las principales hipótesis que nos planteamos al principio de nuestra investigación. El logro de condiciones 
materiales de existencia que posibilitan el desarrollo de lo comunitario y lo colectivo, posibilita también la revitalización y recreación de la lengua materna.

La reconstrucción de las redes de relaciones sociales nos permitió interpretar el rol de la lengua toba a lo largo del camino de la migración de las familias tobas que hoy residen en la ciudad de La Plata. Así, vimos que en el Chaco, y en las zonas rurales, la lengua ocupaba todos los dominios de uso. Luego, la migración a las ciudades cercanas (Castelli, Roque Sáenz Peña, Resistencia) y el trabajo asalariado especialmente de los hombres implicó el aprendizaje del español y su uso en el ámbito laboral. Sin embargo, la lengua toba mantenía algún predominio en los diferentes contextos de interrelación con la gente toba: familiar y de parentesco, religioso-espiritual, vecinal, de aprovisionamiento e intercambio. En cambio, la llegada a la Capital Federal significó el empleo del español en la mayoría de los dominios de uso. Llegar a la gran ciudad no significó estar solos y abandonar sus orígenes, su lengua y su cultura, sino que las familias tobas se buscaron y se mantuvieron unidas o cercanas y en relación cuando las condiciones así lo permitieron. Comenzaron a organizarse en función de un objetivo en común. Hasta que en 1991 un grupo llegó a la ciudad de La Plata. El español fue la principal lengua para relacionarse con "el blanco", aprender de él y organizarse legalmente; en tanto que la lengua toba fue la lengua que hizo a la cohesión del grupo y la lucha por el espacio propio. Una vez que las viviendas fueron terminadas y habitadas, los proyectos comunes que fueron surgiendo y se desarrollaron facilitaron el trabajo conjunto y fortalecieron la identidad del grupo y, con ella, la lengua. Se dieron las condiciones necesarias que motivaron la revitalización de la lengua y la cultura tobas, al punto de querer enseñar sistemáticamente estos aspectos a los niños y adolescentes. Esto último nos permite, a la vez, confirmar otra de las hipótesis planteadas en los inicios de la investigación: "la neutralización del prejuicio y la subestimación desde la sociedad total hacia los grupos indígenas posibilita también la generación de espacios para la actualización y recreación de la lengua como expresión de lo colectivo y lo comunitario". El Barrio Toba "Las Malvinas" se ha convertido, así, en un importante referente y ejemplo de organización y autonomía ante otros grupos indígenas que luchan por la obtención de las tierras; siendo un ejemplo de organización para otros grupos no indígenas que se acercan a preguntar cómo hicieron para lograr lo que tienen. Son convocados por las escuelas o visitados por diferentes sectores de la sociedad, lo que ha generado una articulación positiva que ha disminuido, en alguna medida, la negación, discriminación y subestimación histórica sobre los pueblos originarios. Como bien nos indica el Sr. DR (1991) no sabemos qué pasará en el futuro, sin embargo, podemos 
sostener que están dadas las condiciones para que la lengua y la cultura tobas se sigan recreando y actualizando.

\section{V.2. El Barrio TOBa "LAS Malvinas": UnA COMUnidad de Habla}

Se ha planteado que, para los fines de nuestra investigación, el hecho de analizar la situación de bilingüismo del Barrio Toba "Las Malvinas" como una realidad caracterizada por diversas competencias lingüísticas -en el seno de una sociedad plural y compleja y de los contactos interétnicos-, la consideración de la inclusión/ exclusión, la pertenencia o no a una determinada comunidad de habla/ discursiva de sus hablantes nos abrió algunos interrogantes: ¿Cómo definimos comunidad, en general, y comunidad de habla/ discursiva, en particular?; ¿quiénes integran o no la comunidad de habla toba?, ¿quién dispone la pertenencia o no a esa comunidad?; ¿cuáles son sus límites?; ¿esas fronteras son estáticas o flexibles?; ¿se puede entender la comunidad en términos de heterogeneidad?.

Para esclarecer estas inquietudes, realizamos un relevamiento sociolingüístico del Barrio "Las Malvinas" y la sistematización y el ordenamiento de los datos obtenidos nos permitió distinguir tres subgrupos de hablantes que caracterizarían a este barrio como una comunidad lingüística y discursiva. El primero de ellos es el de los hablantes bilingües con dominio de la lengua toba que corresponde a los casos de los grupos: A, B, C, D, F del Cuadro $\mathrm{N}^{\mathrm{o}} 1$ de la página 145 . Se trata de la primera generación de migrantes del Chaco que tienen un dominio tanto de la lengua toba como del español, aunque prefieren el uso de la lengua toba. El segundo subgrupo es el de los semi-hablantes con dominio del español identificado con los grupos E y G. Éstos comprenden la lengua toba casi en su totalidad, pero no la hablan fluidamente, prefiriendo expresarse en español. Y, por último, el subgrupo de los bilingües casi pasivos con dominio del español compuesto por niños, jóvenes y adultos que sólo se expresan en castellano, pero que están familiarizados y entienden parte del léxico toba. Grupos H, I, J y K del mismo cuadro. En este último subgrupo hemos considerado a los no tobas: esposo/a criollos que conforman matrimonios mixtos, puesto que por el contacto cotidiano y la convivencia han incorporado algunos vocablos del léxico de la lengua vernácula y entienden, aunque con limitaciones, compartiendo las estrategias discursivas del grupo.

Dadas estas particularidades entre los hablantes, fue imprescindible para este estudio definir la comunidad de habla toba. Y, para ello, nos preguntamos si podíamos considerar a estos dos últimos subgrupos de hablantes con competencias de comprensión y (meta) comunicativas como miembros de la misma. 
Como ya se ha dicho, los miembros del Barrio Toba "Las Malvinas" comparten una serie de rasgos, reglas, normas, costumbres, ideas, origen e historia en común, como así también vivencias particulares; en tanto que, en lo lingüístico: recursos verbales y estrategias comunicativas y metacomunicativas también comunes. El compartir estos elementos los distingue y los hace diferentes de otros grupos vecinos. Sin embargo, no se trata de un todo homogéneo sino que presenta, a la vez, diversidad. Al mismo tiempo, el Barrio "Las Malvinas” y la experiencia de autoconstrucción de viviendas son considerados como referentes importantes de aquellos que luchan por obtener un espacio propio. Incluso, sus miembros se reconocen como parte del mismo. Asimismo, la comunidad tiene fronteras: religioso-espiritual, organizacional-laboral, generacional, de género y étnicosocial. Fronteras que no son estáticas, sino que sus miembros pueden traspasarlas según el rol social que ejercen en el momento.

Hemos señalado, además, que si bien los miembros comparten los mismos símbolos, los significados que le atribuyen a los mismos pueden ser diferentes. Y esto último no significa “dejar de ser toba”. Esta consideración resultó clave para indagar sobre el conocimiento que los tres subgrupos de hablantes reconocidos en el Barrio "Las Malvinas" poseen de la lengua toba.

Los miembros de la comunidad de habla toba comparten la habilidad receptora y, sobre todo, el conocimiento de las normas sociolingüísticas. La comunicación se da en toba entre quienes tienen un dominio de la lengua toba; en tanto que predomina el castellano entre quienes poseen competencias de comprensión y (meta) comunicativas de la lengua qom l'aqtaqa. Lo común entre estos tres tipos de hablantes con habilidades lingüísticas diferentes es el hecho de compartir las mismas estrategias comunicativas y metacomunicativas.

En una primera etapa de esta investigación observamos la significación de la posibilidad de mantener la lengua como "modo de identificación y expresión de la visión de mundo" del grupo y destacamos la función de cohesión. Incluso, se indicó que la experiencia de autoconstrucción, considerada como un proceso de construcción social del espacio y de la identidad del grupo, había generado un ámbito propicio para que la lengua se actualice y se revitalice.

La consideración de la situación de los niños y jóvenes tobas -nacidos tanto en el Chaco como en Buenos Aires- que, en general, no dominan la lengua qom l'aqtaqa, pero que entienden y comparten "las pautas comunicativas y metacomunicativas" que operan en el 
grupo, nos permitió dar otro paso en la investigación; esta vez a la luz del concepto de comunidad de habla y su revisión (Dorian 1977, 1982; Romaine 1982; Ibáñez Caselli 1997; Golluscio 2002, 2006). Como resultado de esta revisión pensamos que hablar en toba puede no ser indispensable para la comunicación intragrupal toda vez que se supiera cuándo hablar y dar una respuesta correcta en el momento indicado, aunque la lengua utilizada sea el español. Es decir, desde la perspectiva de análisis que hemos seguido, ya no sería indispensable saber cómo se dice algo -el código-, sino más bien cómo decirlo apropiadamente - el uso- a los efectos de poder comunicarse según la necesidad y la situación. Así, la fluidez en la lengua toba y el conocimiento de la gramática no son requisitos imprescindibles para ser miembros de la comunidad de habla toba. Esa condición está dada especialmente por compartir ciertas habilidades receptivas y normas sociolingüísticas. El conocimiento de las reglas comunicativas permite que el individuo realice un enunciado particular en el momento correcto, según una situación dada y un tema singular; compartiendo, además, -y esto es sumamente significativo- un conjunto de actitudes sociales y lingüísticas durante la comunicación. Así, por ejemplo, en el Barrio Toba "Las Malvinas", observamos una modalidad particular en la atribución y toma de turnos en las interacciones cara-a-cara y comunicativas. En las asambleas y reuniones barriales son los hombres y, en especial, los de más edad, quienes tienen la palabra, en tanto que las mujeres se mantienen en silencio y sólo intervienen cuando se les pregunta directamente -si bien su opinión es considerada como valiosa y fundamental para tomar las decisiones del devenir del grupo-; cuando se reciben visitas, si la mujer está sola actúa de anfitriona, abarcando todos los temas libremente; sin embargo, cuando está presente el hombre, la mujer cambia su actitud dejando que el hombre tome la palabra, pero permanece atenta y crítica a la conversación.

Por lo tanto, incluimos a los semi-hablantes y bilingües casi pasivos en la comunidad de habla toba. A pesar de su falta de fluidez, como consecuencia de una menor actuación y competencia lingüística - uso real y conocimiento de la lengua respectivamente-, estos individuos pueden entender gran parte de lo que se dice y no pierden el sentido de un "chiste" o los significados que se manejan en una conversación; participan de tales conversaciones contestando en la lengua que sí dominan con una correspondencia semántica; se sabe cuándo se debe hablar y cuándo se debe callar; cuándo es un ofrecimiento o un rechazo; los momentos de silencio; se comparten las tonalidades de la voz; los temas que deben -o no- tratarse en determinadas ocasiones; en fin, hay un conocimiento de las normas que operan durante la comunicación. Es decir, comparten el 
conocimiento del cuerpo de reglas y normas que hacen al correcto comportamiento durante cada uno de los eventos comunicativos significativos para el grupo. Todos estos elementos los hace pertenecer también a la comunidad de habla toba e identificarse con el grupo, aún cuando una primera observación podría hacer suponer lo contrario: "si hablan castellano es porque han perdido su identidad”. Entendemos que el conjunto de normas y pautas comunicativas compartidas son producto de un largo proceso histórico y social que se fue generando a partir de las características originarias de la comunicación toba en el Chaco y que se fue recreando en el proceso de migración hasta la conformación del grupo como tal. Éstas se siguen reactualizando en la actualidad dado el dinamismo de la lengua en la sociedad. Es decir, la comunidad de habla es una síntesis de las diversas características lingüísticas y sociales individuales - pero con una trayectoria social similar- de sus integrantes, y de los habitus colectivos objetivados e internalizados histórica y socialmente -y en constante cambio según los procesos de aceptación/ rechazo (Tamagno 1995).

Así, entendemos -a la luz de las últimas teorías sociolingüísticas- que el hecho de haber identificado hablantes con competencias de comprensión y (meta) comunicativas e incluirlos en la comunidad de habla toba, se convierte en un aspecto importante de tener en cuenta a la hora de reflexionar sobre las políticas educativas que implican a su vez una política y planificación lingüísticas para la región. En este sentido, el saber que los niños no hablan la lengua materna, pero que la entienden debe obligar a reconocer esta situación frente al diseño de políticas educativas. De esta manera, reconocerlos posibilita considerar un número mayor de hablantes potenciales de la lengua toba.

\section{V.3. Modalidades Discursivas y CONSTRUCCIÓN SOCIAL de La IDENTIDAD TOBa}

El punto de partida de este estudio fue el discurso entendido como el nexo, la expresión concreta y actual de la relación lengua/ cultura/ sociedad. El análisis de los discursos registrados en el Barrio Toba "Las Malvinas" nos ha permitido visualizar cómo los mismos constituyen modos de acción y formas de representación, formas por las cuales la gente puede actuar sobre el mundo y sobre sí misma, manteniendo una relación dialéctica con la estructura social.

A lo largo de nuestra investigación hemos reconocido ocho tipos de situaciones comunicativas: 1) Asambleas, con sus tres variantes (generales, de la asociación civil y de la iglesia); 2) Sesiones de culto; 3) Celebraciones de la iglesia y cívico-comunitarias; 4) Reuniones comunales; 5) Visitas; 6) Reuniones y Talleres Interétnicos; 7) Charlas y Conferencias; 8) Actividades Educativas. A su vez, en cada una de ellas se reconocen los 
siguientes eventos de habla: consejos y advertencias; enseñanzas-transmisión de conocimientos tobas y no tobas; conversaciones; chismes y chistes; narraciones; oratorias; y prédicas.

Particularmente, analizamos los discursos generados en algunas de estas situaciones comunicativas. En este sentido, la recurrencia de ciertos temas junto con la configuración de un nosotros, nos permiten caracterizar los modos en que el grupo expresa a través de lo discursivo los procesos de construcción de su propia identidad.

\section{- La construcción de un nosotros}

La gente toba construye un "nosotros" presente en estrecha vinculación con el pasado y a la vida antigua con la cual se está emparentado. Este pasado se ubica, por lo general, en el Chaco. Observamos que entre la gente adulta ese pasado es relatado en tiempo presente y se relaciona en varias oportunidades a hechos de su niñez y juventud. En donde, por momentos, se trae un discurso ajeno: lo que la mamá/ papá o abuela/ abuelo les decía cuando eran niños.

Ej. “...porque hay muchas mujeres que ya son, vamos a decir que viejas, y dicen que porque nosotros no vamos a estar llegará el momento que termina nuestra vida y se quedan ustedes.

Por eso es que ustedes tienen que aprender a hacer las cosas. Y asi fue..."

En cambio, la enunciación que realiza la gente más joven está hecha en un tiempo pasado, en un pretérito imperfecto y comparan el pasado con el presente -lo que se hacía con lo que se hace en la actualidad, producto del contacto con la sociedad no toba: "claro, las enseñanzas se iban pasando de generación en generación", "no había nada escrito", "no habia hospitales", "no necesitaban anteojos" como ahora. De esta manera, se recurre como estrategia discursiva a la reflexión metacultural.

Si bien encontramos diferencias en el uso de los tiempos verbales entre las distintas generaciones, ambos grupos construyen un nosotros sobre la base de una historia en común caracterizada por enseñanzas de padres a hijos, experiencias pasadas y sucesos acaecidos en las poblaciones indígenas, en general, y en la gente toba, en particular. Es decir, en la construcción del presente -el "ahora"- siempre está reactualizado y es partícipe de esa construcción el pasado del cual se proviene -el "antes"-. Pasado y presente se interrelacionan en proyección hacia el futuro: "Nosotros, yo soy uno que no tengo estudio pero estoy luchando para el bien de nuestros hijos, para los presentes, por el porvenir estamos pensando siempre. Siempre, porque así fueron las ideas de nuestro héroes pasados...”; “...nuestra organización se llama Asociación Civil Ntaunaq Nam Qom. 
Muchos preguntan... significa trabajar todos juntos unidos, con un sólo pensamiento, un sólo sentir, para que vayamos adelante, porque así nos enseña la vida de nuestros héroes pasados, siempre han trabajado todos juntos...".

Al mismo tiempo, se trata de un nosotros que se construye por lo que se posee y lo que no: “...estamos aquí en La Plata porque no tenemos tierras en el Chaco, porque siguen todavía arrinconando a los indígenas...”; “...no tenemos propiedad...”; “...sin organización, lo que yo veo en este momento, creo que no se puede hacer nada...” “...debemos organizarnos para ser escuchados...”; “...Sin leer, sin saber palabra en castellano, por eso ellos perdieron muchas cosas. Primer lugar tierras, porque ellos no saben hablar en castellano. No saben número alguno, eso dicen, esa la causa más grande de la comunidad toba....".

\section{- La recurrencia de ciertos temas como signos ideológicos}

Del análisis de los discursos se desprende la recurrencia de algunos temas que -en relación con aquellos vigentes en el contexto de la sociedad nacional- reciben un acento valorativo particular, constituyéndose en signos ideológicos. Éstos construyen la identidad de la comunidad toba de La Plata. Temas tales como:

$>$ la lucha por la tierra,

$>$ la organización

$>$ el trabajar todos juntos,

$>$ la necesidad de tener estudios

$>$ ser protagonistas de su propia historia,

$>$ el vivir en el Chaco y en la ciudad.

Todos ellos aparecen en los discursos de ambas generaciones y también se los ha observado en los niños a partir de lo que dicen y de algunas representaciones gráficas que elaboran. Entre estos últimos, es frecuente la representación de las viviendas actuales (casas de ladrillo y techo de teja), mujeres u hombres que visten las artesanías que hacen y venden sus padres, acompañan estos dibujos inscripciones tales como: "el indio toba", "el pueblo toba", "el barrio". Manejan los términos propios elaborados en el proceso de construcción de las viviendas: “...ahora estamos en la segunda etapa...”; o se refieren al Chaco como "mi Chaco". 
La aparición de estos temas se da tanto en los discursos de orden público, en situaciones comunicativas que ocurren dentro del barrio, como en aquellas que se dan fuera del mismo, en un nivel interétnico.

\section{- El silencio como estrategia comunicativa}

Observamos que los silencios son significativos y expresan significados. Su utilización es más frecuente en las situaciones de visitas y cuando el tema de conversación es el Chaco. Es común que lo ejecute la gente mayor, introduciéndolo en el momento de tomar su turno en el habla y acompañando con un gesto de cabeza como asintiendo y quedándose pensando.

\section{- Los elementos de la prosodia}

La velocidad en el discurso aumenta cuando los hablantes hacen referencia al presente y a la vida en la ciudad de La Plata, en tanto que disminuye cuando hablan del pasado y de la vida en el Chaco. Asimismo, las vocales se alargan en este último caso, y el habla se hace más pausado. También aparecen los usos de los silencios.

El alargamiento de las vocales es otro elemento y se da especialmente cuando se está aludiendo al pasado.

Entre las mujeres, destacamos la disminución del volumen de la voz, fenómeno en el que se invierte la corriente de aire egresiva normal en el habla por una ingresiva.

\section{- Los cambios de código como estrategia discursiva}

Los cambios de códigos lingüísticos son frecuentes. Estos ocurren cuando se está hablando en lengua toba y se incorpora a la conversación un no toba. Inmediatamente se cambia a la lengua que sí domina la persona invitada (cambio situacional). No obstante, en un discurso en español puede recurrirse a la lengua toba ya sea porque la temática así lo requiere, porque se expresan aspectos muy íntimos propios de la cultura (cambio metafórico) o porque se quiere excluir de la conversación a los no hablantes (cambio intencional).

\section{- La hipercorrección}

Hemos observado situaciones de hipercorrección en los discursos de los adultos hombres en los momentos en que se realiza una oratoria o una prédica ante un público presente. Las mismas consisten en la incorporación o ausencia de las "eses" en los 
artículos, sustantivos y adjetivos perdiéndose la correspondencia entre ellos -según la norma del castellano.

\section{V.4. SOBRE LA IDEOLOGÍA DEL LENGUAJE}

Dentro del interés por aportar a la comprensión entre los vínculos que existen entre las formas sociales y las formas del habla, en la confluencia entre el lenguaje y el comportamiento social, la ideología lingüística se convirtió en otro de los conceptos significativos para este estudio. Hemos entendido como ideología del lenguaje las representaciones que se construyen sobre las relaciones sociales y lingüísticas, en su intersección con el mundo social. Como ya hemos mencionado, el prejuicio y la discriminación han sido tan fuertes que han llevado a las poblaciones indígenas, en general, y a los tobas, en particular, a dejar de expresarse en su propia lengua. Sin embargo, frente a esta actitud, hemos encontrado y registrado una serie de situaciones que nos permiten plantear la otra ideología: la de la resistencia lingüística y social. Son ejemplo de ello las numerosas experiencias educativas tobas que se dan en las provincias de Chaco, Formosa y Santa Fe lideradas por maestros auxiliares bilingües tobas, como así también los intentos de implementar una educación bilingüe e intercultural en la Provincia de Buenos Aires. Así, la lengua toba se mantiene vigente tanto en el Chaco como lejos de su lugar de origen, en Rosario (Provincia de Santa Fe) y conurbano bonaerense y La Plata (Provincia de Buenos Aires) y sus hablantes luchan para que la misma no se pierda.

\section{V.5. CONSIDERACIONES FinALES}

A lo largo de esta investigación, desde una aproximación interdisciplinaria, hemos podido constatar la vigencia de la lengua de origen en un grupo de familias tobas provenientes del Chaco y que hoy viven en la periferia de la ciudad de La Plata. De manera tal que el haber migrado y encontrarse lejos de su lugar de origen no ha implicado "pérdida de identidad". La vigencia de la lengua toba, el vivir todos juntos de un modo colectivo y comunitario, la importancia de la organización para lograr los objetivos planteados por el grupo y el reconocerse con una historia y un origen en común, son elementos que nos permiten afirmar que la gente toba del Barrio "Las Malvinas" no ha perdido su identidad; sino, por el contrario, la misma se refuerza y se construye en el día a día.

Destacamos los usos y la función de la lengua vernácula a lo largo de la migración y su papel cohesionador en la conformación del Barrio Toba "Las Malvinas". Al mismo tiempo, señalamos la diversidad lingüística que presenta el mismo. Diversidad reflejada 
básicamente en tres subgrupos de hablantes: hablantes bilingües con dominio de la lengua toba, semi-hablantes con dominio del español y bilingües casi pasivos con dominio del español. La revisión del concepto de comunidad de habla y discursiva-conceptos claves para este estudio- nos ha permitido plantear una comunidad de habla toba que incluye a los tres subgrupos de hablantes reconocidos. De esta manera, la presencia de niños y jóvenes que ya no hablan la lengua toba con fluidez y que se expresan en español, pero que entienden y están familiarizados con parte del léxico toba; que participan de las reglas y normas sociolingüísticas que rigen en el grupo; como así también, que comparten un conjunto de recursos verbales y estrategias comunicativas y metacomunicativas, son elementos que nos permiten superar la noción, tan fuertemente marcada en la literatura antropológica y lingüística, de "muerte de lengua" -lo cual conlleva la idea de pérdida de identidad y de cultura-. La lengua, al igual que la cultura, es dinámica y, por ende, cambiante. $\mathrm{Y}$ el hecho de que haya cambios no quiere decir que la cultura y la lengua vayan a desaparecer. Todo dependerá de las actitudes que los miembros de la comunidad de habla toba del Barrio "Las Malvinas" tomen respecto de su lengua y cultura en el futuro, de la superación del racismo y la discriminación aún presentes y de la concreción de políticas públicas, en general, y educativas, en particular, que coadyuven en ese sentido. Las observaciones hechas en este estudio indican que estarían dadas las condiciones para que la lengua y la cultura toba se recreen y reactualicen. 


\section{REFERENCIAS BIBLIOGRÁFICAS}

\section{ALBÓ, XAVIER}

1999, Iguales aunque Diferentes. Cuadernos de Investigación 52, Ministerio de Educación - UNICEF - CIPCA: La Paz.

ARIAS, NORA

1996, El Barrio Toba de la ciudad de Resistencia: Cuestión de estigma, juego político o diversidad cultural. Tesis de Maestría. P.P.G.A.S/M.N./U.F.R.J. Rio de Janeiro, Brasil.

2005, Vueltas y revueltas estratégicas de los tobas rosarinos -de Resistencia a Rosario. Tesis Doctoral. PPGAS/M.N., Univ. Federal de Río de Janeiro, Brasil.

2006, Los consejos de idioma y cultural en las escuelas bilingües toba de Rosario, Ponencia presentada en VII Congreso Latinoamericano de Educación Intercultural Bilingüe, Cochabamba, 1-4 de octubre.

ANDERSON, BENEDICT

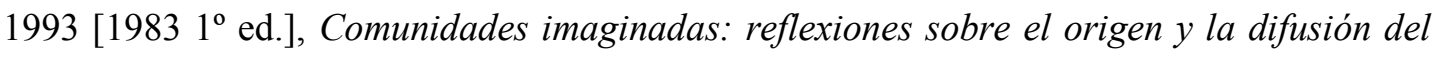
nacionalismo, FCE, México.

BAKHTIN, MIKHAIL

1981, The dialogic imagination: four essays, Ed. M. Holquist, University of Texas Press, Austin.

\section{BARTH, FREDICK}

1976 (1969 $1^{\circ}$ ed.), Los grupos étnicos y sus fronteras, Fondo de Cultura Económica México.

1984, "Problems in conceptualizing cultural pluralism, with illustrations from Somar, Oman", in The prospects for plural societies-Maybury-Lewis. American Ethnological Society.

BAQUERO, RICARDO

1997, Vygotsky y el aprendizaje escolar, Aique Grupo Editor. Buenos Aires, Argentina. BARLEY, NIGEL

1989, El antropólogo inocente, Ed. Anagrama, España.

\section{BARTOLOMÉ, LEOPOLDO}

1972, "Movimientos milenaristas de los aborígenes chaqueños entre 1905 y 1933", en Suplemento Antropológico, vol. VII, No 1-2, Paraguay.

BARTOLOMÉ, MigUEL

1997, Gente de Costumbre y Gente de Razón. Las identidades étnicas en México, Siglo XXI-INI, México. 
2000 "En defensa de la etnografía. El papel contemporáneo de la investigación intercultural", en Actas CAAS 2000- Mar del Plata, Argentina.

2002, Librar el camino. Relatos sobre antropología y alteridad, CONACULTA-INAH, México.

BATESON, GREGORY

1972, Steps to an Ecology of Mind, Ballantine, Nueva York.

BAUMAN, RICHARD

1975, "Verbal Art as Perfomance", American Anthropologist 77:290-311.

1993, "Disclaimers of Perfomance", in HILl, J. Y J. IRVINE (EDS.) Responsibility and Evidence in Oral Discourse, Cambridge University Press, Cambridge, [pp: 182196].

BAUMAN, RICHARD Y JOEL SHERZER

1975, "The Ethnography of Speaking", Annual Review of Anthropology 4:95-119.

BERGER, PETER Y THOMAS LUCKMANN

2001 [17 edición], La construcción social de la realidad, Amorrortu Editores, Buenos Aires.

BIGOT, MARGOT

2004, Contacto lingüístico-cultural, bilingüismo, diglosia y vitalidad etnolingüística en grupos de indígenas 'qom' (tobas) asentados en Rosario (Empalme Graneros y Los Pumitas). Tesis de Doctorado. Universidad Nacional de Rosario, Argentina.

BIGOT, MARGOT, GRACIELA RODRÍGUEZ Y HÉCTOR VÁZQUEZ

1991, “Asentamientos Toba-Qom en la ciudad de Rosario. Procesos étnicos identitarios", en América Indígena 51 (1): 217-251, México .

1992, "Los asentamientos tobas en la ciudad de Rosario", en RADOVICH, J.C. Y BALAZOTE (COMPS.) op.cit. [pp: 81-100].

BIGOT, MARGOT Y HÉCTOR VÁZQUEZ

1999, "La convergencia lingüístico-cultural en la construcción de los procesos étnicos identitarios de los indígenas tobas asentados en Empalme Graneros (Rosario)", en Actas del Congreso Internacional de Políticas Lingüisticas para América Latina, Rosario [pp.:111-124].

BLOM, JAN-PETTER AND JOHN GUMPERZ

1972, "Social meaning in linguistic structure: Code-switching in Norway", en GUMPERZ, J. Y HYMES, D. (EDS.) op. cit. [pp. 407-434].

BLOMFIELD, LEONARD

1933, El lenguaje, UNMSM, Lima.

BOLAÑO, SARA

1982, Introducción a la teoría y práctica de la sociolingüistica, Trillas, México. 
BOURDIEU, PIERRE

1985, ¿Qué significa hablar? Economía de los intercambios lingüísticos, Akal Universitaria, España.

1989, O poder simbólico, Difel, Lisboa.

1990 [1984], "Lo que quiere decir hablar" en BourdieU, P. (COMP.) Sociología y cultura, Ed. Grijalbo, México.

1991[1980], Le sens practique, Minuit, París.

2000 [1999], Intelectuales, política y poder, EUDEBA, Argentina.

BouRdieu, PIERRE Y JEAN-CLAUde PASSERON

1975, El oficio del sociólogo, Siglo XXI, España.

Bourdieu, Pierre, Jean-Claude Passeron and Monique de Saint Martin

1994, Academic Discourse, Stanford University Press, Stanford.

BOURDIEU, PIERRE Y LOḮ J. D. WACQUANT

1995 [1982], Respuestas. Por una Antropología Reflexiva, Grijalbo, México.

BRAUNSTEIN, JOSÉ

1983, "Algunos rasgos de la organización social de los indígenas del Gran Chaco", en Trabajos de Etnología, Instituto de Ciencias Antropológicas, UBA, Argentina.

1992, "Presentación”, en Hacia una Nueva Carta Étnica del Chaco, Vol. IV, C.H.A.C.O., Las Lomitas, Argentina.

1999, “Ethnohistorical Introduction”, en MiLlER, E. (ED.) op. cit, [pp:1-22].

BRAUNSTEIN, JOSÉ Y PABLO WRIGHT

1990, "Tribus toba. Entre la historia, la demografía y la lingüística", en Hacia una Nueva Carta Étnica del Chaco, Vol. I, C.H.A.C.O., Las Lomitas, Argentina.

BRIGGS, CHARLES

1992 [1986 $1^{\circ}$ edición], Learning how to ask. A sociolinguistic appraisal of the role of the interview in social science research, Cambridge University Press, Cambridge.

BRIONES, ClaUdia y LUCÍA GOLLUSCIO

1994, "Discurso y Metadiscurso como procesos de producción cultural”, en Actas Segundas Jornadas de Lingüística Aborigen, Fac. de Filosofía y Letras, UBA.

BROW, JAMES

1990, "Notes on Community, Hegemony and Uses of the past", in Anthropological Quarterly 63:1 [pp:1-7].

BRUNER, EDWARD

1986, "Ethnography as Narrative", en V. TURNER and E. BRUNER (Eds.) The Anthropology of Experience, University of illinois Press, Urbana \& Chicago [pp: 139-155]. 
BRUNATTI, OLGA

1999, El acceso a la tierra y a la vivienda urbanas y su vinculación con las políticas públicas. Informe Final Beca de Perfeccionamiento, UNLP. (mimeo.)

BUCKWALTER, ALBERTO

1980, Vocabulario Toba, Talleres Grancharoff, Buenos Aires.

CARDoso de Oliveira, RoBerto

1976, Identidade, etnia e estrutura social, Biblioteca Pioneira de Ciencicias Sociais, Sao Paulo.

1992, Etnicidad y Estructura Social, CIESAS, México.

CENSABELla, MARISA

1996, El toba. Estudio fonológico de las variedades regionales habladas en las provincias de Chaco y Formosa. Informe CONICET, Argentina.

1999a, "Derivación verbal en toba (familia guaycurú): agentivo, instrumental, causativo y factitivo. Actas III Jornadas de Etnolingüistica, UNR, Rosario.

1999b, Las lenguas indigenas de la Argentina. Una mirada actual, EUDEBA, Argentina.

Chafe, Wallace

1994, Discourse, Consciousness, and Time, University of Chicago Press, Chicago\&London.

CHOMSKY, NOAM

1973 (1965) Aspectos de la Teoría de la Sintaxis, Ed. Aguilar, Madrid.

CitRo, SILVIA

2003 Cuerpos significantes. Una etnografía dialéctica con los Toba Takshek. Tesis Doctoral. Facultad de Filosofía y Letras, Universidad de Buenos Aires.

COHEN, ANTHONY

1985 (1992 $3^{\circ}$ edición), The symbolic construction of community, Routledge, London and New York.

COLÁNGELO, Adelaida

1995, Informe de Beca Comisión de Investigaciones Cientificas de la Provincia de Buenos Aires, Argentina.

1996, "Atención de la salud infantil en una comunidad toba de un medio urbano". Ponencia presentada en Simposio "Los pueblos indigenas y la salud", Academia Nacional de Medicina y Sociedad Argentina de Pediatría, Buenos Aires.

COLMan, O.

1978, Naturaleza del conocimiento cientifico en las ciencias sociales, Escuela Superior de Economía, México.

\section{CONKLIN, HAROLD}

1975, “Etnografía”, en LlOBERA, J. (COMP.) op.cit. 


\section{CORDEU, EDGARD}

1967, Cambio cultural y configuración ocupacional en una comunidad toba. Miraflores Chaco, Informe preliminar: Comisión Nacional del Río Bermejo, Presidencia de la Nación, Departamento Jurídico, Publicación No $123 \mathrm{~J}$.

1969-70, “Aproximación al horizonte mítico de los Tobas", Runa, vol. 12, partes 1 y 2 , Buenos Aires [pp:67-176].

\section{CORDEU, EDGARD Y SUSANA SIFFREDI}

1971, De la algarroba al algodón. Movimientos milenaristas del Chaco argentino, Juárez Editor, Buenos Aires.

\section{CORONADO, GABRIELA}

1996, "El Bilingüismo como Alternativa a la Diversidad", en MUÑOZ, H. Y LEWIN, P. (COORDS.) op. cit. [pp. 49-66].

\section{CORONEL-MOLINA, SERAFÍN}

2005, "Lenguas originarias cruzando el puente de la brecha digital. Nuevas formas de revitalización del quechua y el aimara”, en CORONEL-MOLINA, S. Y GRABNERCORONEL, L. (EDS.) op. cit. [pp:31-82].

\section{Coronel-Molina, Serafin y Linda Grabner-Coronel (EDS.)}

2005, Lenguas e identidades en los Andes. Perspectivas ideológicas y culturales, ABYA YALA, Ecuador.

COURTIS, CORINA Y ALEJANDRA VIDAL

(en prensa) “Apuntes para una revisión crítica del concepto de 'muerte de lengua' ”, en Golluscio, L. Y P. DReIDEMIE (COMPS.) Prácticas comunicativas indígenas en contextos urbanos: exploraciones teóricas y metodológicas. Volumen Temático de Signo y Seña $\mathrm{N}^{\mathrm{o}}$ 17, Instituto de Lingüística, Facultad de Filosofía y Letras, Universidad de Buenos Aires, Buenos Aires.

\section{DORIAN, NANCY}

1977, “The problem of semi-speaker in language death", in Linguistics.

1981, Language Death. The Life cycle of a Scottish Gaelic Dialect, University of Pennsylvania Press, Philadelphia.

1982 "Defining the speech community to include its working margins", en RoMAINE, S. (ED.), Sociolinguistic Variation in Speech communities, Edward Arnold, London.

DURANTI, ALESSANDRO

1992, "La Etnografía del habla: hacia una lingüística de la praxis", en NEWMEYER, F. (COMP.) op. cit. [pp: 253-273].

1997, Linguistic Anthropology, Cambridge University Press, Cambridge.

DURANTI, ALESSANDRO Y CHARLES GOODWIN (EDS.)

1991, Rethinking context, Cambridge University Press, Cambridge. 


\section{FAIRCLOUGH, NORMAN}

1992, Discourse and Social Change, Polity Press, Cambridge.

FISHMAN, JOSHUA

1972, "Domains and Relationship between Micro and Macrosociolinguistics", en GUMPERZ, J. Y HYMES, D. (EDS.) op. cit., [pp: 435-453].

FORT, MARIO

1989, "Milenarismo y conflicto social: los tobas" en Colección Conflictos y procesos de la historia Argentina contemporánea, №27, CEAL, Buenos Aires.

FOUCAULT, Michel

1972 [1970 1ºd.], La Arqueología del Saber, Ed. Siglo XXI, México.

FULLER, NORMA (ED.)

2002, Interculturalidad y política. Desafios y posibilidades, Pontificia Universidad Católica del Perú, Lima.

FUSCALDO, LILIANA

1982, "La relación de propiedad en el proceso de enfrentamiento social", en Cuadernos del CICSO, Argentina.

1987, "El proceso de constitución del proletariado rural de origen indígena en el Chaco", en LischetTi, M. (COMP.) Antropología, EUDEBA, Buenos Aires [pp. 337-359].

\section{GARBULSKY, EDGARDO}

1994, “Cuestión Étnica - Cuestión Social. Las fronteras contemporáneas de los grupos toba (Qom) en Rosario en el umbral del siglo XXI", en Andes, Antropología e Historia $\mathrm{N}^{\circ}$ 6, CEPIHA (Centro Promocional de Investigación de la Facultad de Humanidades), UNSa, Argentina.

\section{GARCía, MARÍA DEL CARMEN, Stella MARIS GARCÍA Y LiLIANA TAMAGNO}

1998, "Una primera aproximación al aprendizaje de la matemática en niños toba de la ciudad de La Plata”, en ACTAS Firth International Congress of Ethnomathematic, España.

\section{GARCÍA, STELLA MARIS Y OTROS}

1994, "Etnicidad y Educación: Una experiencia de Extensión Universitaria", en Actas IV Congreso Argentino de Antropología Social, Olavarría.

\section{García, STElla Maris, M. AMALIA IBÁÑEZ CASElli y OTROS}

1994, La escuela: ámbito de diferencias y desigualdades sociales. Fundamentos de Cartilla Didáctica. Material producido como resultado del desarrollo del Proyecto de Extensión: "Los tobas del barrio Las Malvinas: su proyección a nivel regional” UNLP (inédito).

García, Stella Maris, Liliana TAMAgno, M. Amalia IbáÑEz CASElli y Otros

2002 "Educación/ Diversidad/ Desigualdad. Indígenas Toba más allá de los Territorios de Origen" en CD-Room serie Educación, Red NAYA, Argentina. 


\section{GARCÍA CANCLINI, NÉSTOR}

1991, “¿Construcción o Simulacro del Objeto de Estudio? Trabajo de Campo y Retórica Textual, en Alteridades, México [pp: 53-64].

1992, “Antropólogos Bajo la Lupa. (o cómo hablar de las tribus cuando las tribus son ellos mismos)", en Ciencia Hoy, Vol. 4, № 20, Set./ Oct. [pp:53-58].

GARVIN, PAUL Y YOLANDA LASTRA

1974, Antología de estudios de Etnolingüística y Sociolingüistica, UNAM, México.

\section{GERZENSTEIN, ANA Y OTROS}

1998, La educación en contextos de diversidad lingüistica. Documento fuente sobre lenguas aborígenes, Ministerio de Cultura y Educación de la Nación, Buenos Aires (mimeo).

GODENZZI, JUAN CARLOS

1996, "Introducción/ Construyendo la convivencia y el entendimiento: Educación e Interculturalidad en América Latina”, en GodenzzI, J. C. (COMP.) Educación e Interculturalidad en América Latina, CBC, Cusco, Perú [pp:11-22].

\section{GOFFMAN, ERVING}

1979, "Footing", Semiotica 25:1-29.

1981, Forms of talk, University of Pennsylvania Press, Philadelphia.

\section{GOLLUSCIO, LUCÍA}

1988, La comunicación etnolingüistica en comunidades mapuches de la Argentina. Tesis doctoral. Univ. Nac. de La Plata. (Inédito)

1994, "Socialización lingüística y competencia metacomunicativa". Presentado en $I$ Jornadas de Adquisición del Lenguaje y Enseñanza de la Lengua, Univ. Nac. de Rosario (Inédito).

2002, Etnografia del Habla. Textos Fundacionales, EUDEBA, Buenos Aires.

2006, El Pueblo Mapuche. Poéticas de pertenencia y devenir, Ed. BIBLOS, Buenos Aires.

\section{GOLLUSCIO, LUCÍA Y CLAUDIA BRIONES}

1997, "Pragmática de los sentidos de pertenencia y devenir", en Actas II Jornadas de Etnolingüistica, Univ. Nac. de Rosario, Santa Fe.

GOLLUSCIO, LUCÍA Y OTROS

1997, "El discurso en los procesos de formación de comunidad", en Actas de Lengua y Literatura Mapuche, Univ. de la Frontera, Temuco.

\section{GORDILLO, GASTÓN}

1994, "La presión de los más pobres: reciprocidad, diferenciación social y conflicto entre los tobas del oeste de Formosa", en Cuadernos del INAPL 15:53-82.

1997, "El aliento de los diablos. Una experiencia cultural de explotación y terror", Ponencia presentada en $V$ Congreso Argentino de Antropología Social, La Plata (inédito). 
GOODENOUGH, WARD

1965, "Rethinking status and role: Toward a general model of the cultural organization of social relationships", in The relevance of models for social anthropology, Tavistock, London.

GREGORES, EMMA

$\mathrm{s} / \mathrm{f}$, Pautas para el relevamiento etnolingüistico, Buenos Aires, (mimeo).

GREENBERG, JOSHEPH

1987a, Language in the Americas. Stanford University Press, Stanford.

1987b, "Language in the Americas: Author's précis", Current Anthropology, 28:647-652.

1989, "Calssification of American Indian Languages: A reply to Campbell". Language 65:107-114.

\section{GUEVARA, MIRJAM}

2007, Estudio de valores y anti-valores de los pueblos y nacionalidades indígenas de la Amazonía. Informe Final de Consultoría EIBAMAZ-UNICEF, Perú (inédito).

GUMPERZ, JOHN

1962, "Types of linguistic communities", in Anthropological Linguistics 4, 1 [28-40].

1971 (1968), "The Speech Community", in GUMPERZ, J. Language in social groups [pp: 115-127]

1982, Discourse Strategies, Cambridge University Press, Cambridge. [2000, Traducción española en Estudios sobre Contextos II, Compilación de la Cátedra de Etnolingüística, OPFyL-UBA Buenos Aires.]

1991, "Contextualization and Understanding”, en DuRANTI, A. Y GoOdwIN, CH. (EDS) op. cit. [pp: 229-252]. [2000, Traducción española en Estudios sobre Contextos II, Compilación de la Cátedra de Etnolingüística, OPFyL-UBA, Buenos Aires]

1996, "El Significado de la Diversidad Lingüística y Cultural en un contexto postmoderno", en MUÑOZ, H. Y LEWIN, P. (COORDS.) op. cit. [pp: 33-48].

GUMPERZ, JOHN Y ADRIAN BENNET

1981, Lenguaje y Cultura, Anagrama, España.

GuMPERZ, JOHN AND DELl HYMES (Eds.)

1972, Directions in sociolinguistics. The ethnography of communication, Basil Blackwell, Oxford/New York.

HALLIDAY, M. A. K.

1998 (1978 1 ed.), El Lenguaje como Semiótica Social, FCE, México.

HAMEL, R. ENRIQUE

1982, “Constitución y análisis de la interacción verbal”, en Estudios de Lingüística Aplicada $\mathrm{N}^{\mathrm{o}}$ 2, enero, UNAM, México [pp:31-80]. 
1998, "Políticas del lenguaje y estrategias culturales en la educación indígena", en IEEPO (Ed.) La Educación indigena hoy. Inclusión y diversidad, Oaxaca, México [pp:106-136].

\section{HAMEL, R. ENRIQUE Y M. AMALIA IBÁÑEZ CASELlI}

2000, "La lecto-escritura en la lengua propia: Educación Indígena Bilingüe en la región P'urhepecha de México", en Actas III Jornadas de Etnolingüistica, Departamento de Etnolingüística, Escuela de Antropología de la Facultad de Humanidades y Artes, Universidad Nacional de Rosario, Argentina [pp: 44-58].

\section{HANKS, WILLIAM}

1989, “Text and textuality", in Annual Review of Anthropology 18: 95-127.

1996, Language an communicative practices, Westview Press, Boulder.

HANNERZ, ULF

1980, Exploring the city. Inquiries toward an urban anthropology, Columbia University Press, New York.

1997, "Fluxos, fronteiras, hibridos: palabras clave da antropología transnacional", en Mana. Universidad Federal de río de Janeiro.

Heise, María, Fidel Tubino y WiLfRedo ARdito

1994 (1992 1ºd.), Interculturalidad. Un desafio, CAAAP, Lima.

HELBERg CHÁVEZ, HELBERG

2001, Fundamentación Intercultural del Conocimiento, Programa FORTE-PE, Perú.

2007, Dimensiones de la realidad, Programa de EIB, Fac. de Educación, UNMSM, Perú.

HOCKETT, CHARLES

1971 [1958 1 ed.], Curso de Lingüistica Moderna, EUDEBA, Argentina.

HUDSON, R. A.

1981 (1980 1ºd.), La Sociolingüistica, Anagrama, España.

\section{HYMES, DELL}

1963, "Objectives and Concepts of Linguistic Anthropology", en MANDELBAUM, D. G. LASKer, G. W. Y AlBert, E. M. (EDS.) The Teaching of Anthropology, American Anthopological Association, [pp. 275-302]. Memoir 94.

1964, Language in Culture and Society, Harper \& Row, New York.

1972 ( $1^{\circ}$ Ed), "Models of the Interaction of Language and Social Life", en GuMPERZ, J. Y HYMES, D. op. cit., Cap. 1:35-71. [1986, Versión Ampliada y corregida. 2002 Traducción al español en Golluscio, L. op. cit. pp: 55-89].

IBÁÑEZ CASELLI, M. AMALIA

1995, "Sobre los usos de la lengua madre en una situación de bilingüismo en la realidad de un grupo de gente toba del barrio Las Malvinas en la ciudad de La Plata", en Actas: 
Segundas Jornadas de Lingüistica Aborigen, Instituto de Lingüística, Universidad de Buenos Aires, [pp: 413-425].

1997, "Prácticas sociales y discursivas: el caso toba del barrio Las Malvinas", en Actas II Jornadas de Etnolingüistica, UNR. [pp:265-272].

1998, "Estrategias discursivas entre la gente toba del barrio Las Malvinas", en Actas III Jornadas de Lingüistica Aborigen, Instituto de Lingüística, Facultad de Filosofía y Letras, UBA. [pp:427-434].

1999, "Políticas lingüísticas y territorio. Una reflexión a través del caso de indígenas toba migrantes", en Boletim do Museo Paraense, Vol. 15, diciembre, Belém, Brasil, [pp: 251-270].

2000, "La interculturalidad: ¿una moda? Alcances e implicancias políticas en Argentina”, en Seminario Andino «Conflictos y Políticas interculturales: Territorios y Educaciones», Coordinación: Pablo Regalsky, CEIDIS, Cochabamba, Bolivia.

2001, "Los usos de la lengua materna y el español en la realidad de indígenas toba migrantes en la Provincia de Buenos Aires. Argentina”, en Anuario de Lingüística Hispánica, N ${ }^{\circ}$ 14 (1998), Universidad de Vallodolid, España, [pp: 229-243].

2003, "La educación intercultural bilingüe en Argentina: un desafío", en Rev. QUINASAY Año 1, No 1, Cochabamba, Bolivia [pp:71-78].

2004, Políticas lingüisticas e Interculturalidad. Experiencias educativas para y con indigenas tobas de Argentina. Tesis de Maestría en Ciencias Sociales. CBC-FLACSO Ecuador (Aceptada para su publicación).

2006, "La interculturalidad: ¿Una moda? Alcances e implicancias políticas en Argentina”, en Cuadernos del Instituto Nacional de Antropología y Pensamiento Latinoamericano (INAPL) 20, 2003/2005, Argentina (pp: 149-162).

IBÁÑEZ CASElli, M. AMAlia, MarCEla AlaniZ y otros

2004, "Reflexiones para una propuesta educativa para las comunidades Toba migrantes en la Provincia de Buenos Aires-Argentina”, en Solís FonseCA, G. (Comp.) Cuestiones de Lingüística General Hispánica y Aplicada, Serie Coediciones. GTZ-PROEIB ANDES-UNMSM Fondo Editorial, Lima, Perú [pp: 459-482].

IÑIGO CARRERA, NICOLÁS

1983, La colonización del Chaco, CEAL, Argentina.

KAHN, J. S. (COMP.)

1975, El concepto de cultura: textos fundamentales, Editorial Anagrama, Barcelona.

\section{KAUFMAN, TERRENCE}

1990, "Language history in South America: what we know and how to know more", en PAYNE, D. (ED.) «Amazonian Linguistics. Studies in Lowland South American Languages», University of Texas Press, Austin, [pp:13-67]. 


\section{KEARNEY, MICHAEL}

1975, "World View Theory and Study", in Annual Review of Anthropology, pp:247-270.

\section{KERSTEN, LUDWIG}

1968, Las tribus indigenas del Gran Chaco hasta fines del siglo XVIII: Una contribución a la etnografia histórica de Sudamérica. Resistencia, Universidad Nacional del Nordeste, Chaco, Argentina.

\section{KLEIN, HARRIET}

1981, Una gramática de la lengua toba: morfología verbal y nominal, Universidad de La República, Fac. de Humanidades y Ciencias, Dpto. de Lingüística, Montevideo, Uruguay.

\section{KLEIN, HARRIET Y CRISTINA MESSINEO}

2003, "Coherencia temporal en toba. Su continuidad en el contacto con el español”, en Memorias del Congreso de Idiomas Indígenas de Latinoamérica-I (23-25 de octubre de 2003), University of Texas at Austin [pp:1-14].

LAVANDERA, BEATRIZ

1990 (1985 1ºd.), Curso de Lingüistica para el Análisis del Discurso, CEAL, Argentina.

1992, "El Estudio del Lenguaje en su Contexto Socio-Cultural”, en NEWMEYER, F. (COMP.) op. cit. [pp:15-28].

LABOV, WILLIAM

1972, Language in the Inner City: Studies in the Black English Vernacular, University of Pennsylvania, Philadelphia.

LÉVI-STRAUSS, CLAUDE

1984 [1958], Antropología Estructural, EUDEBA, Argentina.

\section{LIAS-UNLP}

2002, Lo Onataq na qom llacpi. Trabajo de los hijos tobas, Vídeo, Argentina.

LLOBERA, JOSÉ (COMP.)

1975, La Antropología como Ciencia, Ed. Anagrama, España.

LOUKOTKa, Cestmír

1968, Classification of South American Indian Languages, University of California, Los Ángeles. [Latin American Center References Series 7].

LUCY, JOHN (ED.)

1993, Reflexive Language: reported speech and metapragmatics, Cambridge University Press, New York.

MC. KEANEY, JOHN

1968, Tipología constructiva y teoría social, Amorrortu, Buenos Aires.

MALINOWSKI, BRONISLAW.

1973 [1922], Los Argonautas del Pacífico Occidental, Ed. Península, España. 
MANDRINI, RAÚL

1987, "La sociedad indígena de las pampas en el siglo XIX" en LISCHETTI M. (COMP.) Antropología, EUDEBA, Buenos Aires.

MARTÍNEZ SARASOLA, CARLOS

1992, Nuestros paisanos los indios, Emecé, Argentina.

MAYER, A.

1980, "La importancia de los cuasi-grupos en el estudio de las sociedades complejas", en BAnton, M. (COMP.) Antropología social de las sociedades complejas, Alianza, Madrid.

MENDOZA, MARCELA

1987, "La reproducción de los actores sociales en familias toba del Gran Buenos Aires: estudios de casos". Primeras Jornadas de Indigenismo, Santa Fe, 22-24 de octubre.

1989, "Estrategias adaptativas de migrantes tobas en el Gran Buenos Aires", en Acta Psiquiátrica Psicológica de América Latina.

1999, “Argentina's Eastern Toba: Vitalizing ethnic consciousness and determination”, en MiLlAR, E. (ED.) op.cit.

Mendoza, Marcela y Pablo Wright

1985, "El fracaso escolar en comunidades aborígenes toba", presentado en II Simposio Nacional sobre trastornos del aprendizaje escolar, UBA, Argentina (mimeo).

MENÉNDEZ, EDUARDO

1972, "Racismo, colonialismo t violencia científica", Rev. Transformaciones $\mathrm{N}^{\mathrm{o}} 47$, CEAL.

MESSINEO, CRISTINA

1989, "Lingüística y Educación Indígena. Una experiencia en comunidades Toba de la Provincia del Chaco (Argentina)", en Pueblos Indígenas y Educación, $\mathrm{N}^{\circ} 12$, ABYAYALA, Ecuador, [pp:9-27].

2000, Estudio del toba hablado en la Provincia del Chaco (Argentina). Aspectos gramaticales y discursivos (Tesis Doctoral), UBA, Argentina.

2002, Indigenas en Buenos Aires: contacto, continuidad y transformación del toba hablado en Derqui (Buenos Aires), Proyecto CONICET 2002-2004.

2003 "Del Gran Chaco al Gran Buenos Aires. Programa Participativo de Capacitación y Fortalecimiento de la Lengua y la Cultura Toba en una Comunidad Indígena Urbana (Derqui, Argentina)", en Memorias del Congreso de Idiomas Indígenas de Latinoamérica, Austin. 


\section{MESSINEO, CRISTINA, ANA DELl ARCIPRESTE Y OTROS}

2002 "Programa participativo de preservación de la lengua y la cultura toba en una comunidad indígena urbana (Derqui, provincia de Buenos Aires, Argentina)", Ponencia presentada en Jornadas de Lenguas Aborigenes, Salta, Argentina.

Messineo, C. Y Equipo Docente

1998, Diagnóstico Lingüistico Educativo de la UEP No 30 "Aída de Florito, Barrio Toba, Resistencia, Chaco (mimeo).

\section{MÉTRAUX, ALFRED}

1946, "La Etnografía del Chaco", en STEward, J. (COMP.) Handbook of South American Indian, Vol. I.

\section{MILLER, ELMER}

1971, "El Servicio Religioso Evangélico de los Toba de la Argentina”, en Ethnology, Vol. X, $\mathrm{N}^{\circ} 2$, April, [pp: 149-159]

1979, Los tobas argentinos: armonía y disonancia en una sociedad, Siglo XXI, México.

1980, A critically Annoted Bibliography of the Gran Chaco Toba, HRFlex Books, SI12-002, New Haven, Connecticut, [Introducción].

1996, Ethnographical Images of Gran Chaco Toba: An Historical Perspective, Seminar on Argentine Ethnographical Literature, University of Maryland at College Park.

1999, Peoples of Gran Chaco, Bergin\&Garvey, London.

\section{MOLL, LUIS C. (COMP)}

1993, Vygotsky y la educación. Connotaciones y aplicaciones de la Psicología sociohistórica en la educación, Aique Grupo Editor, Buenos Aires, Argentina.

MuÑOZ, HÉCTOR Y PEDRO LEWIN (COORDS.)

1996, "El Significado de la Diversidad Lingüística y Cultural”, Investigaciones Lingüísticas 2, UAM-INAH, Oaxaca, México.

\section{NADEL, SIEGFRED FREDERICK}

1974, Fundamentos de Antropología Social, FCE, España.

\section{NEWMEYER, FREDERICK (COMP.)}

1992, "Panorama de la Lingüística Moderna de la Universidad de Cambridge. IV. El Lenguaje: contexto socio-cultural", Visor Distribuciones, Madrid.

PACHECO DE Oliveira, JoAo

1998, "Uma etnologia dos "indios misturados"? Situação colonial, territorialização e fluxos culturais", en MANA, Estudios de Antropología Social, vol.4, n 1.

1999, A viagem da volta. Etnicidade, política e reelaboração cultural no Nordeste Indígena, Contra CAPA, Livraria, Brasil.

PANOFF, Michel y FRANÇOISE PANOFF

1975, "Para qué sirve la etnografía", EN LlOBERA, J. op. cit., [pp: 79-83]. 
PEIRANO, MARISA

1995, A Favor da Etnografia, Relume-Dumará, Brasil.

PELLICER, DORA

1988, "Los migrantes indígenas en la ciudad de México y el uso del español como segunda lengua” en Hamel, R. E., LAStra, Y. y MuÑOz CruZ, H. (EDS.) Sociolingüística Latinoamericana, UNAM, México [pp:147-170].

PIVETTA, BIVIANA

1999, Migración a Rosario y memoria toba, UNR Editora, Rosario, Argentina.

POPLACK, SHANA

1980, "Sometimes I'll start a sentence in Spanish y termino en español: toward a typology of code switching", en Linguistics 18:581-618.

PRATT, MARY LOUISE

1997 [1992 1 Ed.], Ojos Imperiales. Literaturas de viajes y transculturación, Universidad Nacional de Quilmes, Buenos Aires.

RABINOW, PAUL

1992, Reflexiones sobre un trabajo de campo en Marruecos, Júcar Universidad, España.

RADOVICH, JUAN CARLOS Y ALEJANDRO BALAZOTE (COMPS.)

1992, La problemática indígena. Estudios antropológicos sobre pueblos indígenas de la Argentina, CEAL, Buenos Aires.

ROBINS, ROBERT

1976, "Malinowski, Firth y el 'contexto de la situación'”. En ARDEnER, E. Y OTROS, Antropología social y lenguaje, Ed. Paidos, Buenos Aires.

RODRÍGUEZ MIR, JAVIER

2006, Los Wichi en las fronteras de la civilización. Capitalismo, violencia y shamanismo en el Chaco argentino. Una aproximación etnográfica, ABYA YALA, Ecuador.

ROMAINE, SUSSANE

1982, "What is a speech community?" en RomaInE, S. (ED.) Sociolinguistic Variation in Speech communities, Edward Arnold, London [pp:13-24].

SAPIR, EDWARD

1994 (1954 1º ed. Español, $19211^{\circ}$ ed. Inglés) El Lenguaje, Brevarios FCE, México.

SCHIEFFELIN, BAMBI Y ELEANOR OCHS

1986, “Language Socialization”, en Ann. Rev. Anthopol. 15: 163-191.

SCHIEFFELIN, BAMBI, KATHRYN WOOLARD Y PAUL KROSKRITY

1998, Language Ideology: Practice and Theory, Oxford University Press, New York Oxford. SCHIFFRIN, DEBORAH

1992, “El Análisis de la Conversación”, en NewMEYer, F. (COMP.) op. cit. 
1998 (1994 1ºd.), Approches to Discourse, Blackwell Textbooks in Linguistics, Oxford, UK-USA.

\section{SCOTTON, CAROL MYERS AND WiLliam URy}

1977, "Bilingual strategies: The social functions of code-switching", en Linguistics 193:520.

SHERZER, JOEL

1987, "The discourse-centered approach to language and culture", en American Anthropologist 89:285-309.

1992 (1983, $1^{\circ}$ ed.), Formas del Habla Kuna, ABYA-YALA, Quito.

\section{SHERZER, JOEL Y REGNA DARNELL}

1972, "Outline Guide for the Etnographic Study of Speech Use", en GUMPERZ J. Y HYMES, D. (EDS.) op. cit. pp. 548-554. [2002, Traducción al español en Golluscio, L. op. cit. Pp: 165-187]

\section{SieRra CAMACHO, M. TERESA}

1987, "El Ejercicio Discursivo de la Autoridad en Asambleas Comunales (Metodología y Análisis del Discurso Oral)", en Cuadernos de la Casa Chata 146, CIESAS/SEP, México.

SiLVERSTEIN, Michael

1993, "Metapragmatic dicourse and metapragmatic function". En LUCY, J. (ED.) op. cit. [pp: 33-60].

TAMAGNO, LILIANA

1986a, Informe sobre la situación del grupo toba de Quilmes, Subsecretaría de Promoción Comunitaria, Municipalidad de Quilmas, Argentina.

1986b, "Una comunidad toba en el Gran Buenos Aires: su articulación social", en Actas del II Congreso Argentino de Antropología Social.

1988, "La construcción social de la identidad étnica", en Cuadernos de Antropología № 2 , Univ. Nac. de Luján, EUDEBA, Argentina.

1991, "La cuestión indígena en la Argentina y los censores de la indianidad", en América Indígena Vol. LI, ${ }^{\circ} 1$, México, [pp: 123-152].

1992a, "Ser Indio Hoy: Gente toba en la Provincia de Buenos Aires", en RADOVICH BALAZOTE (COMPS.) op. cit.

1992b, "Bilingüismo, Identidad y Discriminación: Reflexiones en pos de una política cultural”, en América Milenaria, $\mathrm{N}^{\circ}$ 2, [pp: 29-32].

1995, "Bilingüismo e identidad entre los toba de la provincia de Buenos Aires", en BARTOLOMÉ M. (COORD.) Ya no hay lugar para cazadores recolectores. Procesos de extinción y transfiguración étnica en América latina, ABYA YALA, Quito. 
1996, "Legislación indígena, dificultades para su reglamentación y aplicación: El caso de la provincia de Buenos Aires", en VAresse, S. (Comp.) Pueblos Indios, Soberanía y Globalismo, Editorial ABYA YALA, Ecuador.

2000, Indígenas tobas en la ciudad. Identidad étnica, identidad de clase social e identidad religiosa, Tesis Doctoral, FCNyM, UNLP, Argentina.

2001, Nam Qom hueta'a na doqshi lma'. Los tobas en la casa del hombre blanco. Identidad, memoria y utopia, Ed. Al Margen, La Plata, Argentina.

2004, "Religiosite indigene et identite ethnique. Le pentecotism chez le peuple toba" Recherche Amerindiennes Au Québec. Vol. XXXIV Nº. 2.

2006 "Interculturalidad. Una revisión desde y con los pueblos indígenas", en Suplemento $N^{o}$ 39 del Boletín Diario de Campo - Coordinadora Alicia Barabas, CONACULTA INAH, México .

TAMAGNO, LILIANA, Olga BRUNATTI Y ADELAIDA COLÁNGELO

1994, "Identidad e Historia: una construcción colectiva a través de testimonios". Ponencia presentada en IV Congreso Argentino de Antropología Social, Olavaria (Inédito).

TAMAGNO, Liliana Y M. AMALIA IBÁÑEZ CASELli

1993, "Lenguas en contacto: el caso del toba-castellano en el área del Gran La Plata", en Actas Primeras Jornadas de Lingüistica Aborigen, Instituto de Lingüística, UBA, [pp: 255-260].

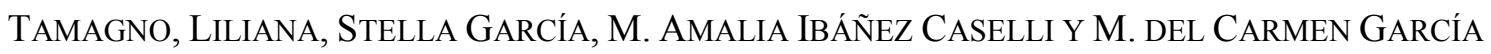

2005 "Testigos y protagonistas: un proceso de construcción de conocimiento conjunto con vecinos qom. Una forma de hacer investigación y extensión universitaria”, en Rev. Argentina de Sociología (RAS), nov.-dic., año/vol. 3, № 5, [pp:206-222].

TANNEN, DEBORAH (ED.)

1982 (1981 1ºd.), Analyzing Discourse: Text and Talk. Georgetown University Round Table on Languages and Linguistics, Georgetown University Press, Washington DC [pp: 323-334]. [2002 Traducción al español en Golluscio, L. op. cit.]

Tannen, Deborah. and M. Saville Troike

1985, Perspectives on silence, Nowood, N. J., Ablex.

TERUEL, ANA

1999, La frontera occidental del Chaco en el siglo XIX. Misiones, economía y sociedad. Tesis doctoral. Fac. de Humanidades y Ciencias de la Educación, UNLP, Argentina. TOVAR, ANTONIO

1961, "Bosquejo de un mapa tipológico de las lenguas de América del Sur. Thesaurus", Boletín del Instituto Caro y Cuervo, No 16, [pp:452-470]. 


\section{TOVAR, ANTONIO Y CONSUELO DE TOVAR}

1984, Catálogo de las lenguas de América del Sur, Ed. Gredos, Madrid.

TRINCHERO, HuGO

2000, Los dominios del demonio. Civilización y barbarie en las fronteras de la Nación - El Chaco central, EUDEBA, Argentina.

TUBINO, FIDEL

2002, "Entre el multiculturalismo y la interculturalidad: más allá de la discriminación positiva”. En FULLER, N. (ED.) op. cit., [pp:51-76].

\section{URBAN, GREG}

1991, A discourse-centered approach to culture. Native south american myths and rituals, Univ. of Texas Press, Austin.

VIEGAS BARROS, PEDRO

1993, “Existe una relación genética entre las lenguas mataguayas y guaycurúes?”, en Braunstein, José (ED.) Hacia una Nueva Carta Étnica del Chaco, C.H.A.C.O., № 5, Las Lomitas [pp:193-213].

\section{VOLOSHINOV, VALENTIN}

1992, El marxismo y la filosofía del lenguaje, Alianza Universidad, Madrid.

\section{VYGOTSKY, LEV}

1995, Pensamiento y Lenguaje, Ed. Paidós, Barcelona, España.

WEBER, MAX

1978, Economía y Sociedad, FCE, México.

WEINRICH, URIEL

1970 [1953 1 ed.], Languages in contact, Mouton, The Hague, París.

WERTSCH, JAMES

1995, Vygotsky y la formación social de la mente, Ed. Piados, Barcelona, España.

\section{WHORF, BENJAMIN}

1956, Language, Thought and Reality, Cambridge, Ma, M.I.T. Press. [Trad. al español: 1971, Lenguaje, pensamiento y realidad, Seix Barral, Barcelona].

\section{WOOLARD, KATHRYN}

1998, "Introducción: Ideología del lenguaje como campo de investigación”, en SCHIEFFELIN, B., WOOLARD, K. Y KROSKRITY, P. op. cit.

WORSLEY, PETER

1966, El tercer mundo, Siglo XXI, España.

WRIGHT, PABLO

1985, "Los conceptos 'trabajo' y 'marisca' como etnocategorías de los tobas de Formosa”, trabajo presentado en el Primer Congreso Argentino y Latinoamericano de Antropología Rural, Olavarría. 
1988, “Tradición y aculturación en una organización socio-religiosa toba contemporánea", en Rev. Cristianismo y Sociedad, No 95, Bs. As.

1994, "Perspectivas teóricas en la Antropología de los Movimientos Sociorreligiosos", EN BARABAS, A. (COMP.) «Religiosidad y resistencia indígenas hacia el fin del milenio», ABYA YALA, Quito.

1997, Being-in-the-dream. Postcolonial explorations in toba ontology, Ph. D. Disertation, Temple University, USA.

1999, "Histoires of Buenos Aires", en MiLlER, E. (COMP.) op.cit. [pp: 135-156].

\section{ZACARÍAS, DAVID}

1995, Qom lataxac qataq la'aqtaqa. Lengua y cultura toba. Un aporte para la Educación Bilingüe Intercultural, Ministerio de Educación, Cultura, Ciencia y Tecnología. Instituto de Nivel Terciario CIFMA, Argentina. 


\section{FigurAS}

Figura $N^{0} 1$ : Región del Gran Chaco

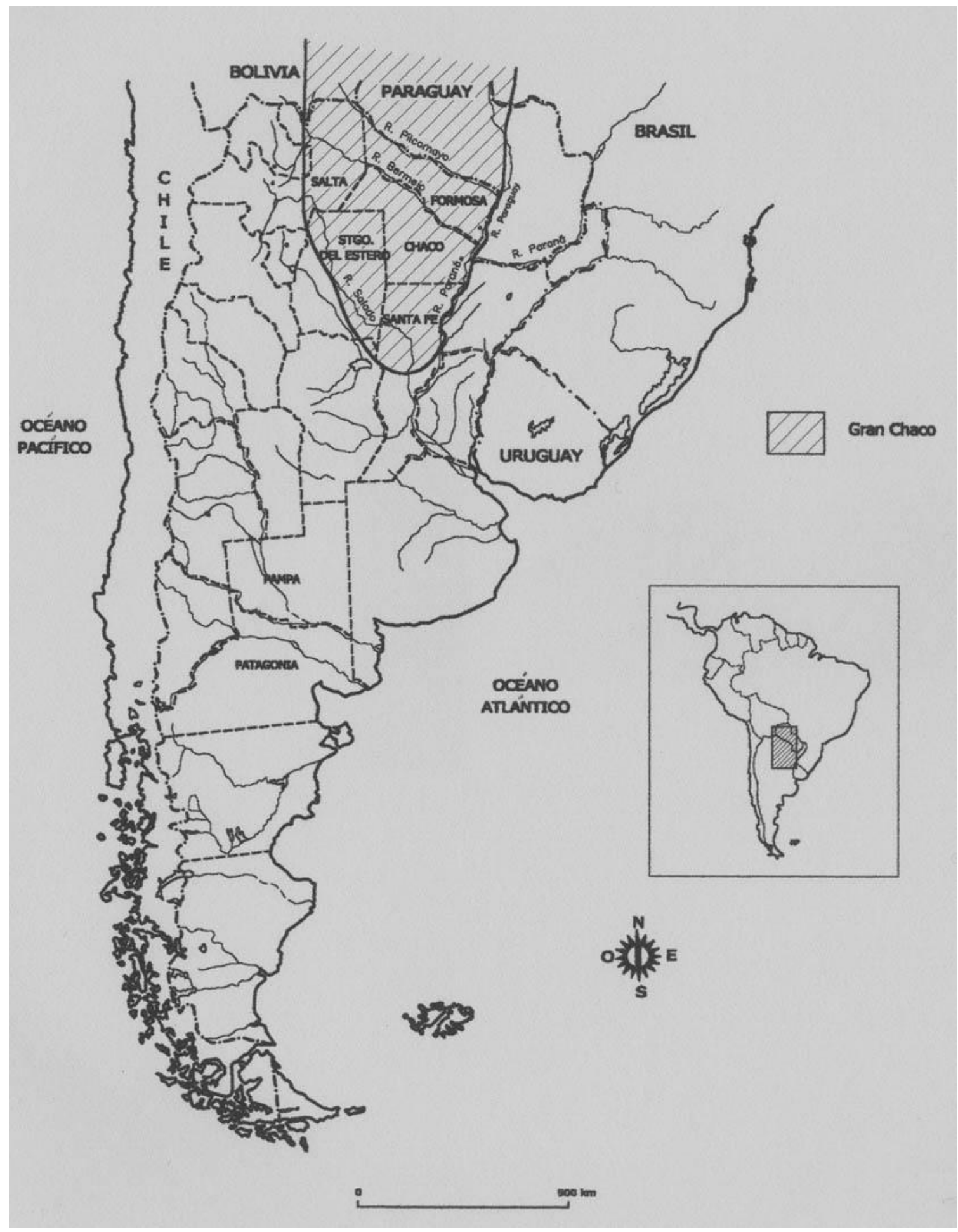


Figura $N^{\circ}$ 2: Migración del Pueblo Qom a la ciudad

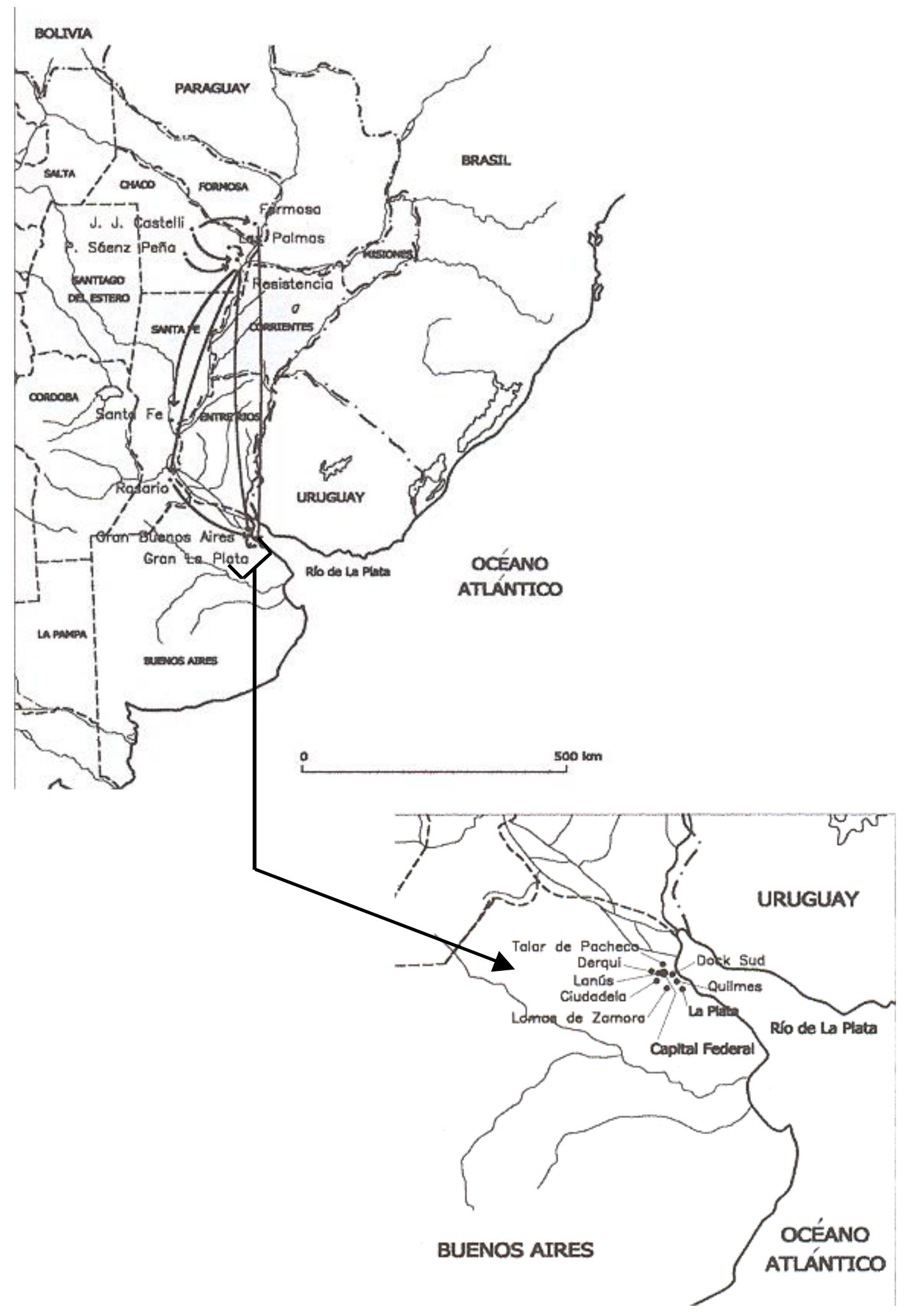


Figura $N^{\circ}$ 3: Principales localidades de Chaco y Formosa

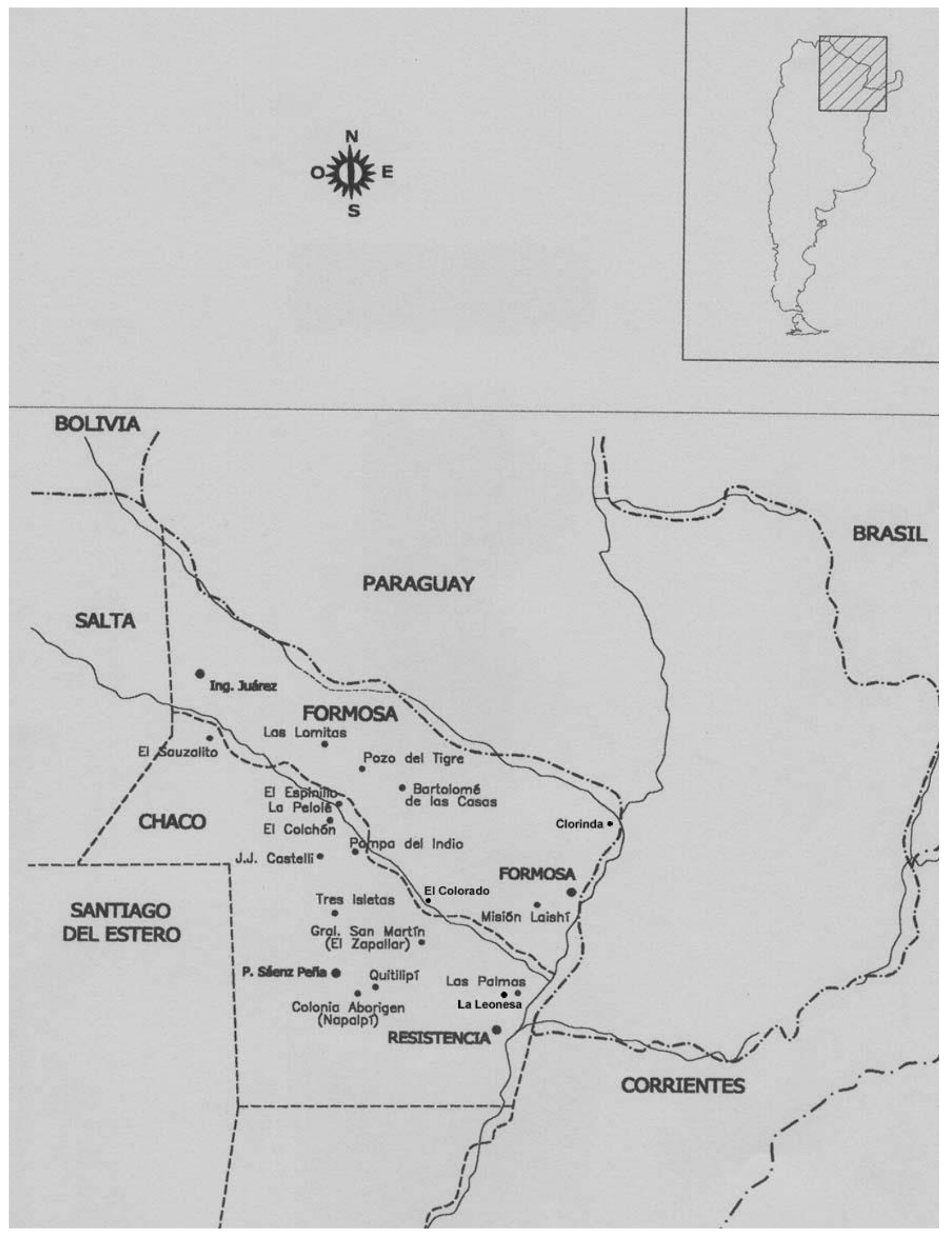




\section{Figura No 4: Plano de la ciudad de Resistencia y ubicación del Barrio Toba}

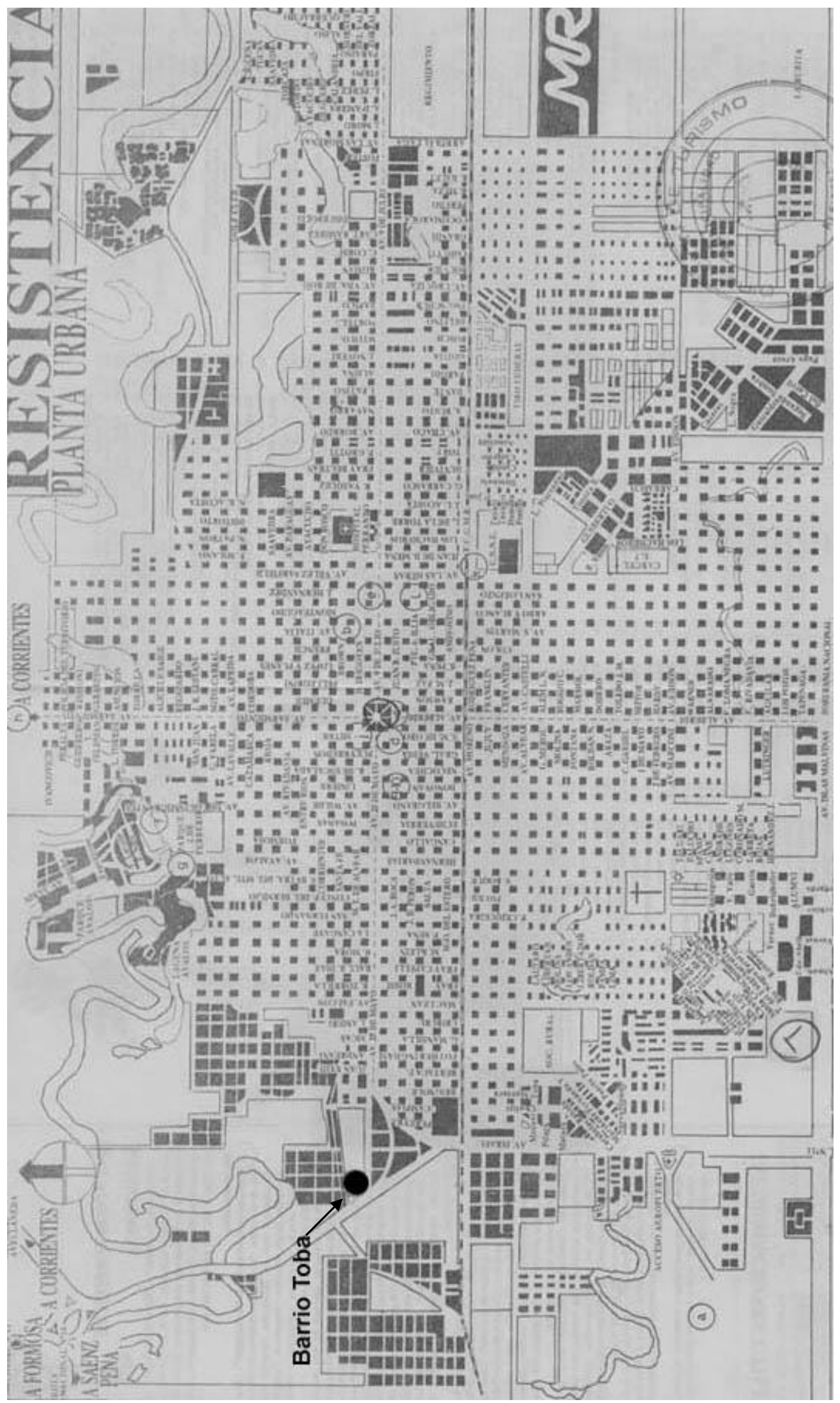


Figura No 5: Nucleamientos Tobas Ex Empalme Granero y Barro Toba de la calle Rouillón de la Ciudad de Rosario

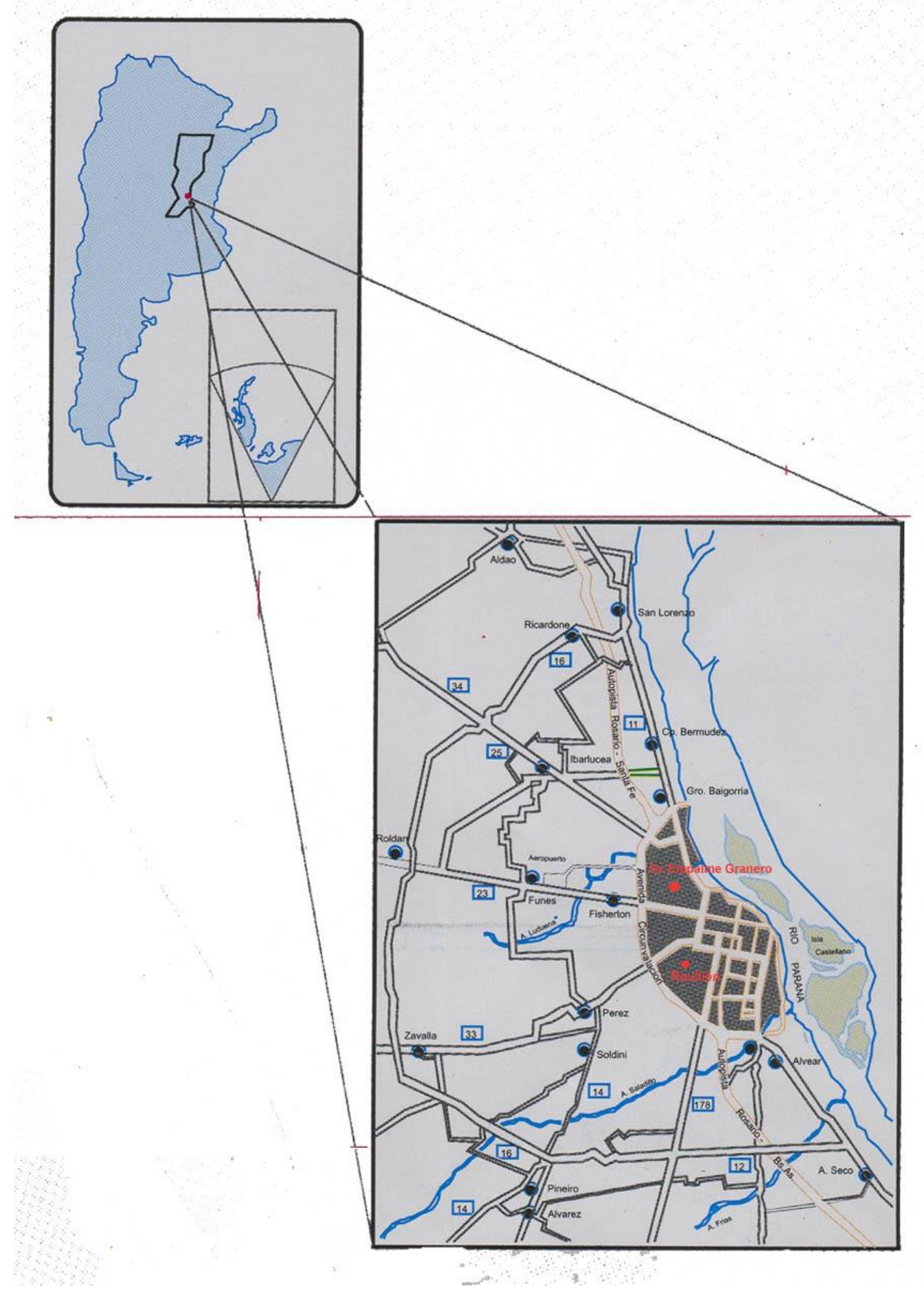


Figura $N^{\circ}$ 6: Vista aérea de la ciudad de La Plata - Ubicación del Barrio Toba "Las Malvinas"

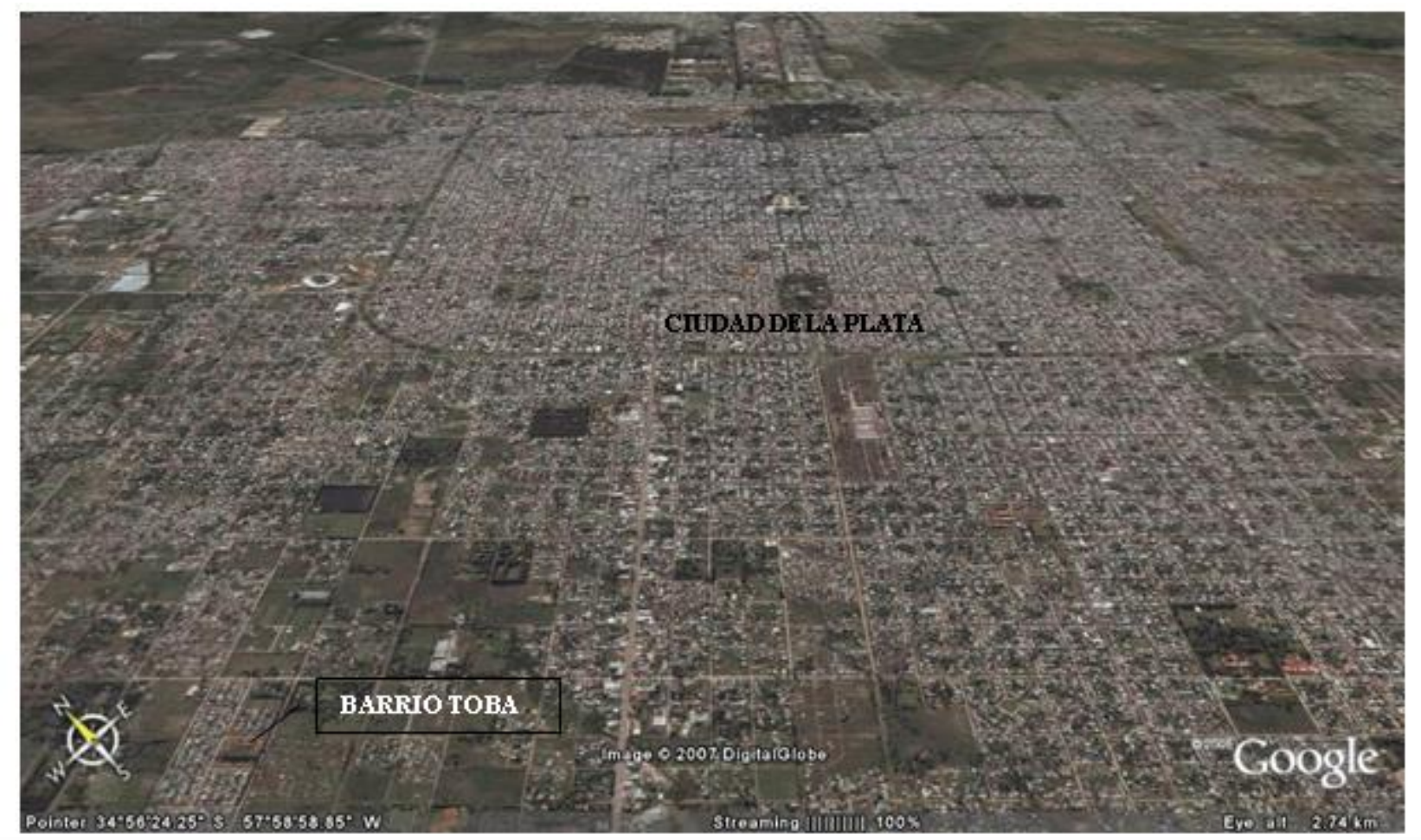

Figura No 7: Vista aérea del Barrio "Las Malvinas" (Plan de 540 viviendas) y Barrio Toba

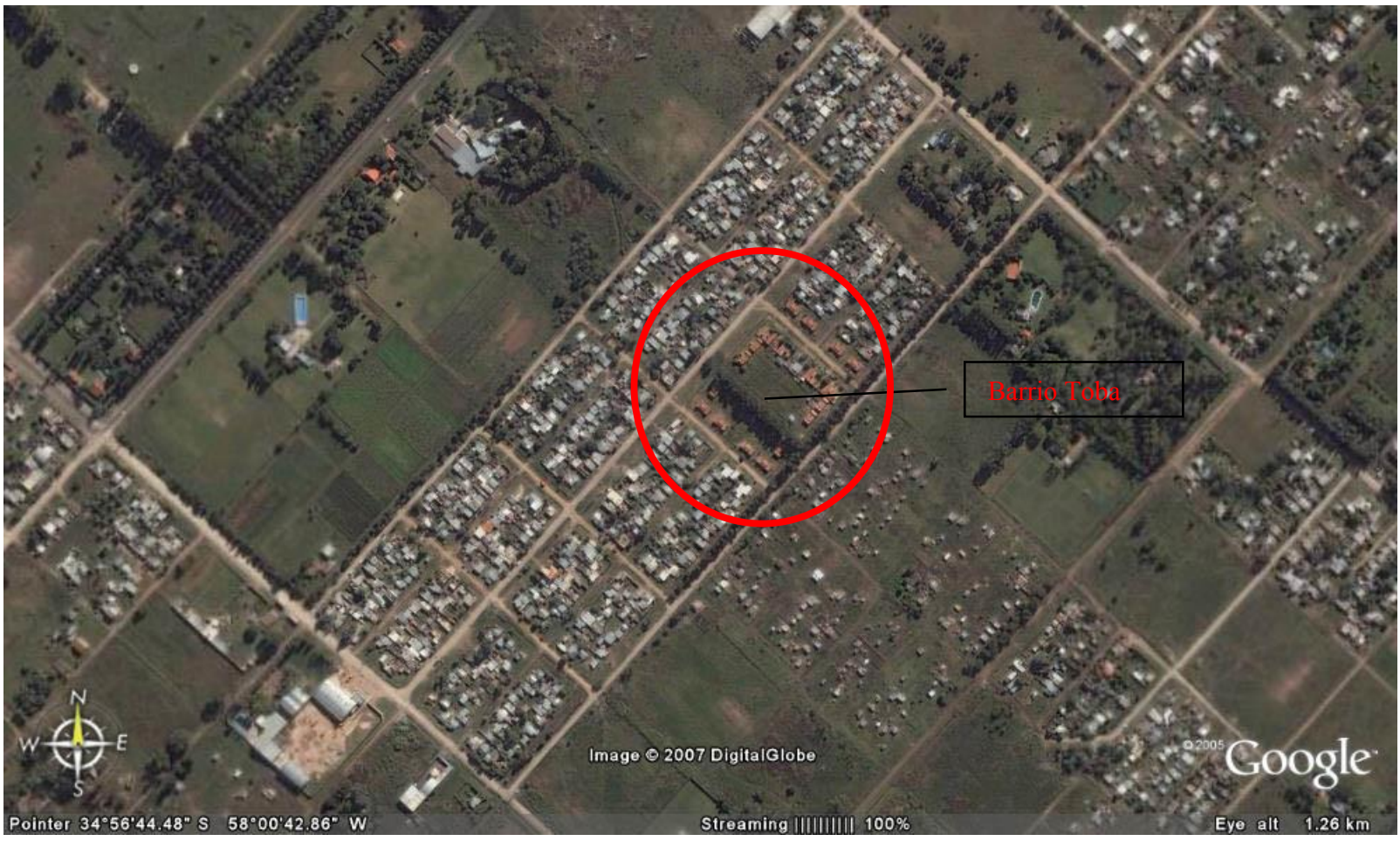


Figura $N^{\circ}$ 8: Vista aérea del Barrio Toba "Las Malvinas"

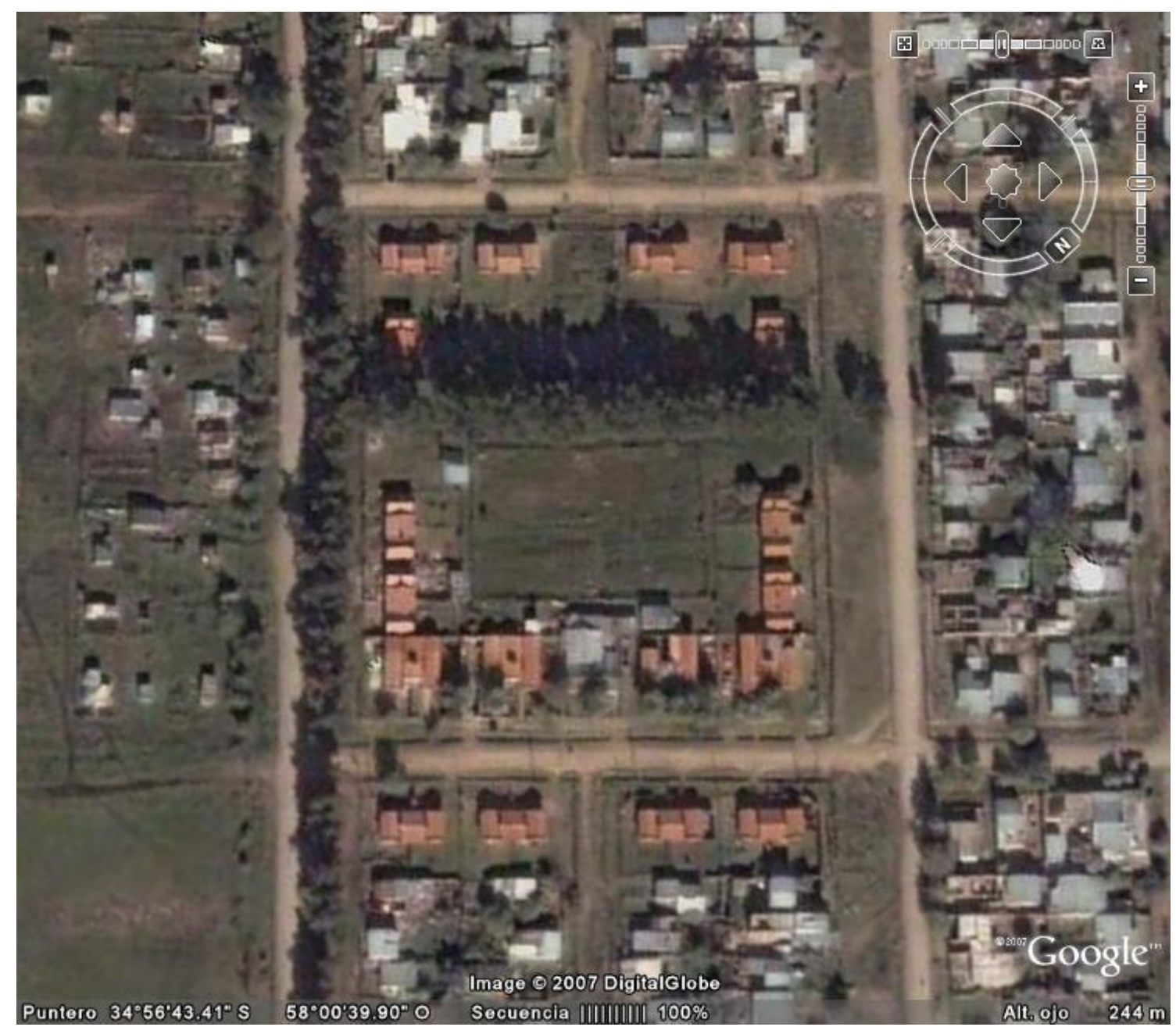


Figura No 9: Plano del Barrio Toba "Las Malvinas" -Disposición de las 36 Viviendas-

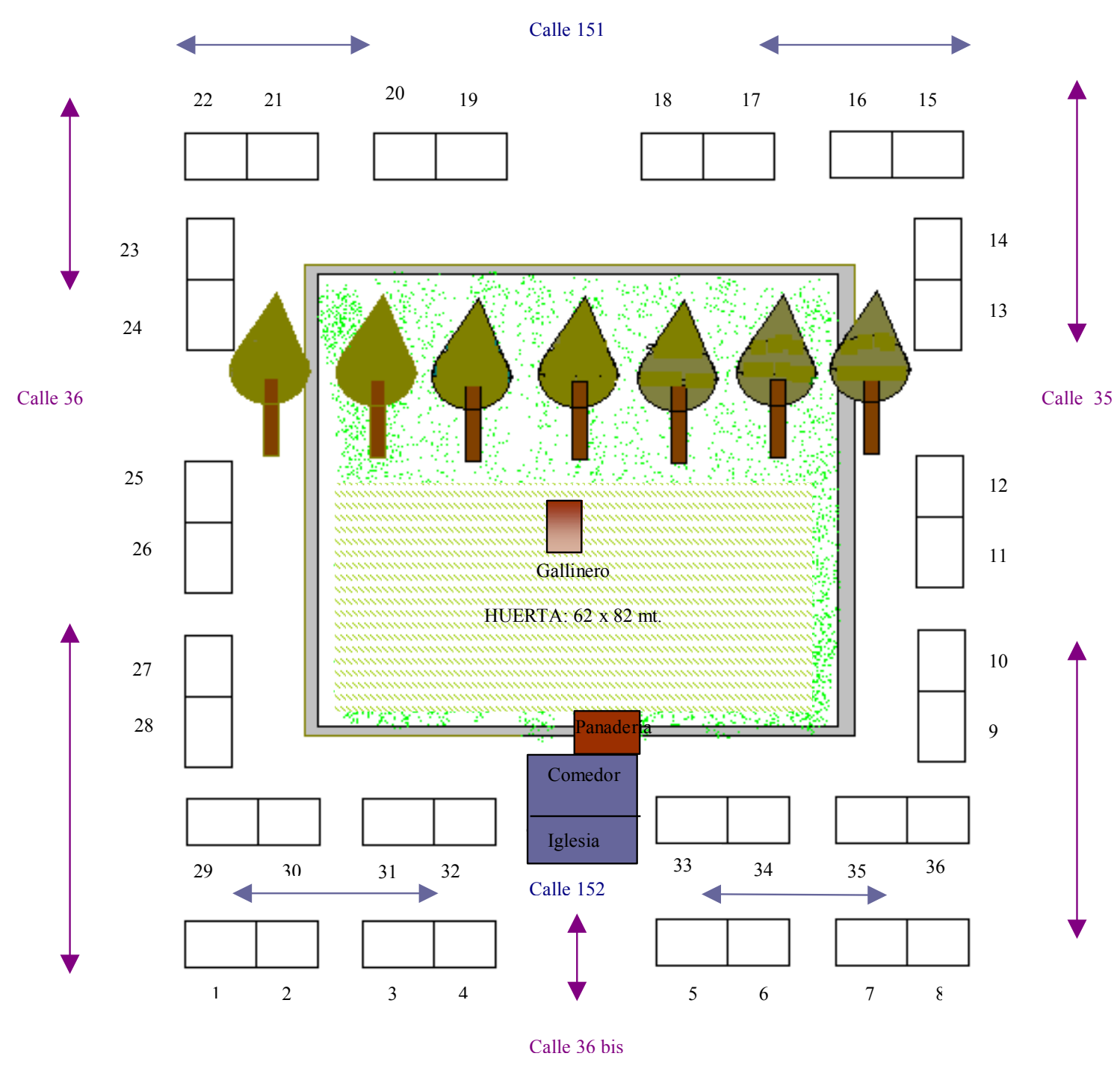

Dibujo: María Amalia Ibáñez Caselli 
Figura $N^{\circ}$ 10: Esquema del Movimiento Evangélico de 1994

Pasos

1) Consagración:

2) Conciliación:

3) Reparto de pan y vino

\section{Actividades}

Lengua

Lectura de versículo de la Biblia

Canto alusivo

Se presenta el niño

Invocación

Oración (entre todos)

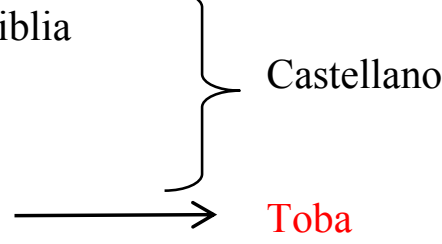

Lectura de Biblia

Comentarios del pastor

Se acercan los reconciliados al frente

$\mathrm{y}$ hablan con el pastor

Canción (gritan, lloran, oran, bailan)

Oración (entre todos)

Se arrodillan los reconciliados

Imposición de manos/ Danza del pastor

Glosolalia (sin música) con imposición

de manos de todos

Saludos a los reconciliados

Canto

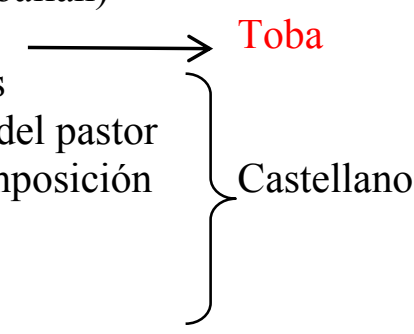

Bendición del pan y el vino (pastor)

Se desmenuza el pan (mujeres)

Plegaria

Canto y se reparte el pan

Lectura de Biblia

Comen todos juntos

Glosolalia: se agradece

Canto sin música

Se reparte y bebe el vino

Glosolalia: Gozo

Pregunta el pastor

Canto/ Danza del pastor

Danzan algunos fieles

Glosolalia: lloran

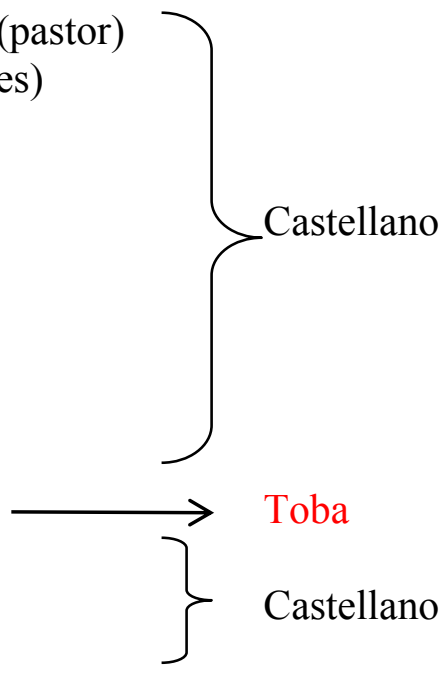

4) Imposición de manos
Castellano

Toba y

Castellano
Se convoca a una persona

Oran los pastores

Imposición de manos

Saludos 
Foto $\mathrm{N}^{\mathrm{o}}$ 1: Vista cercana de las viviendas del Barrio Toba "Las Malvinas" en construcción - (MAIC)

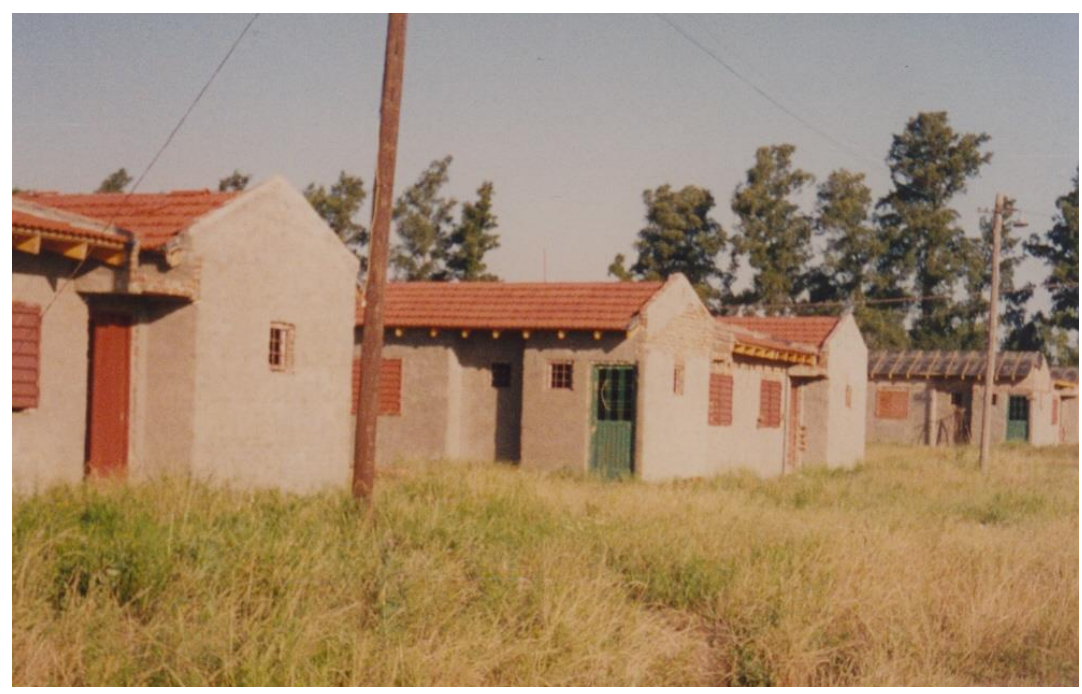

Foto $\mathrm{N}^{\mathrm{o}} 2$ : Mujeres trabajando en la huerta - (MAIC)

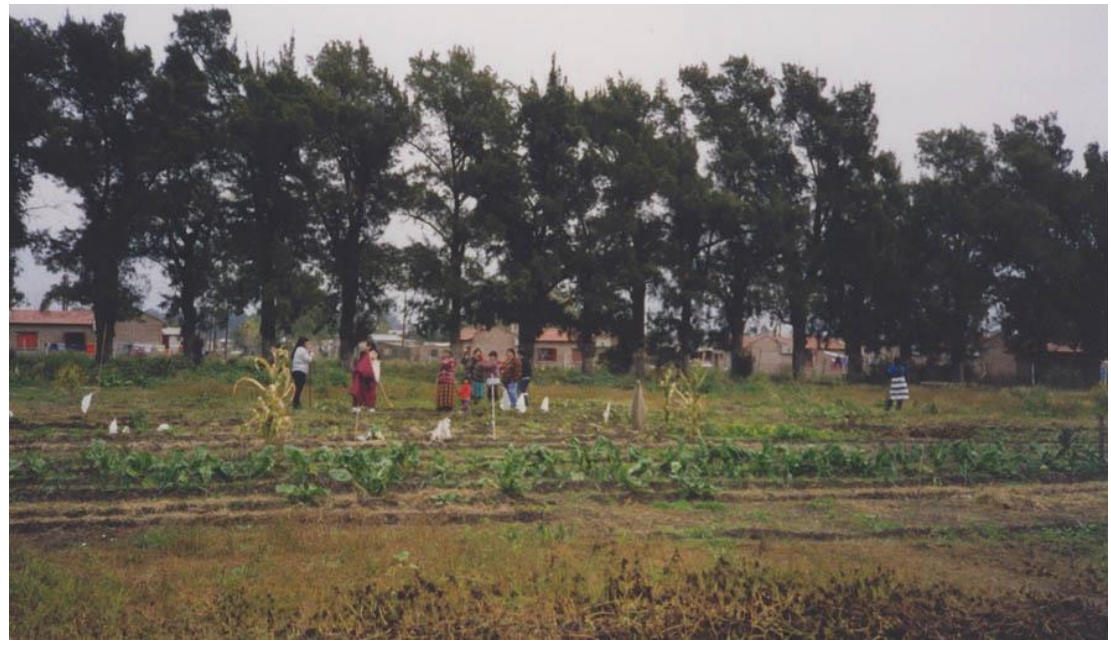

Foto $\mathrm{N}^{\mathrm{o}}$ 3: Comedor Comunitario Qom Llalacpi - (MAIC)

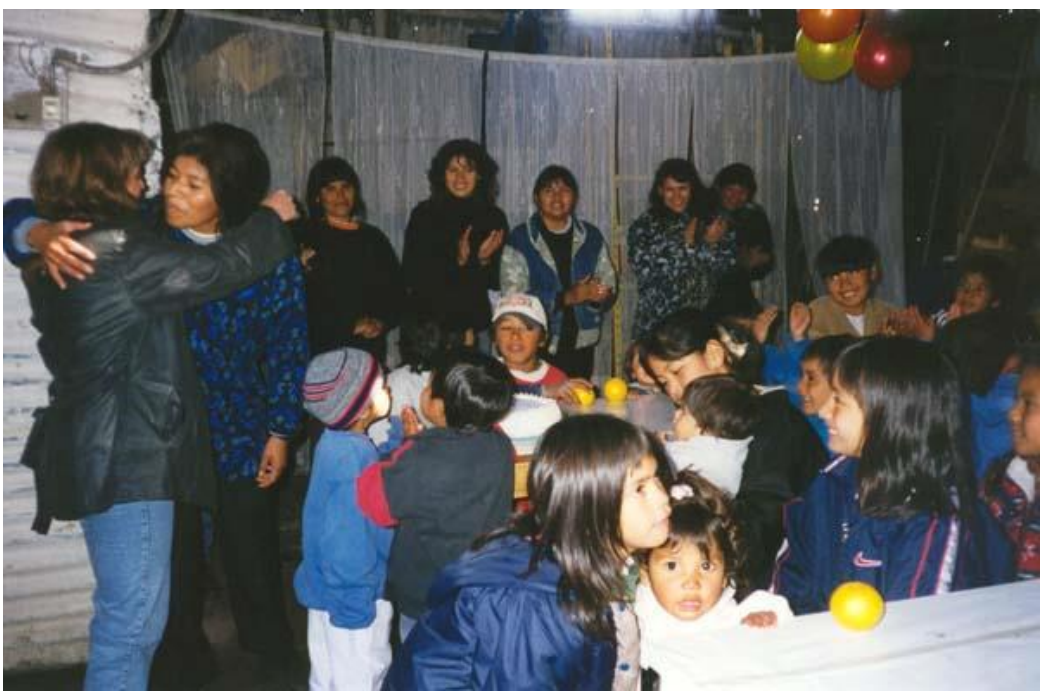


Foto $\mathrm{N}^{\mathrm{o}}$ 4: Comedor Comunitario Qom Llalacpi - (MAIC)
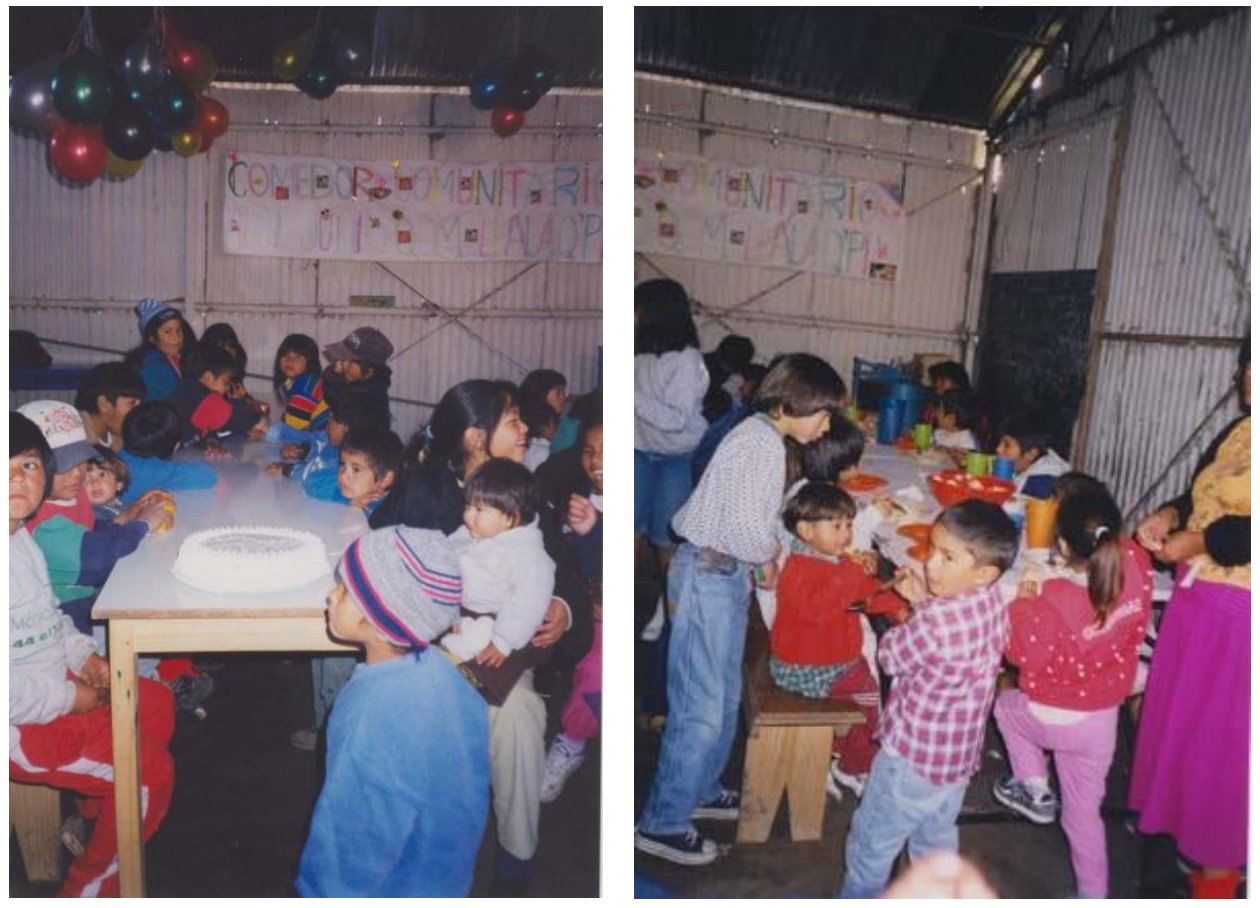

Foto $\mathrm{N}^{\mathrm{o}}$ 5: Taller de Costura - (MAIC)

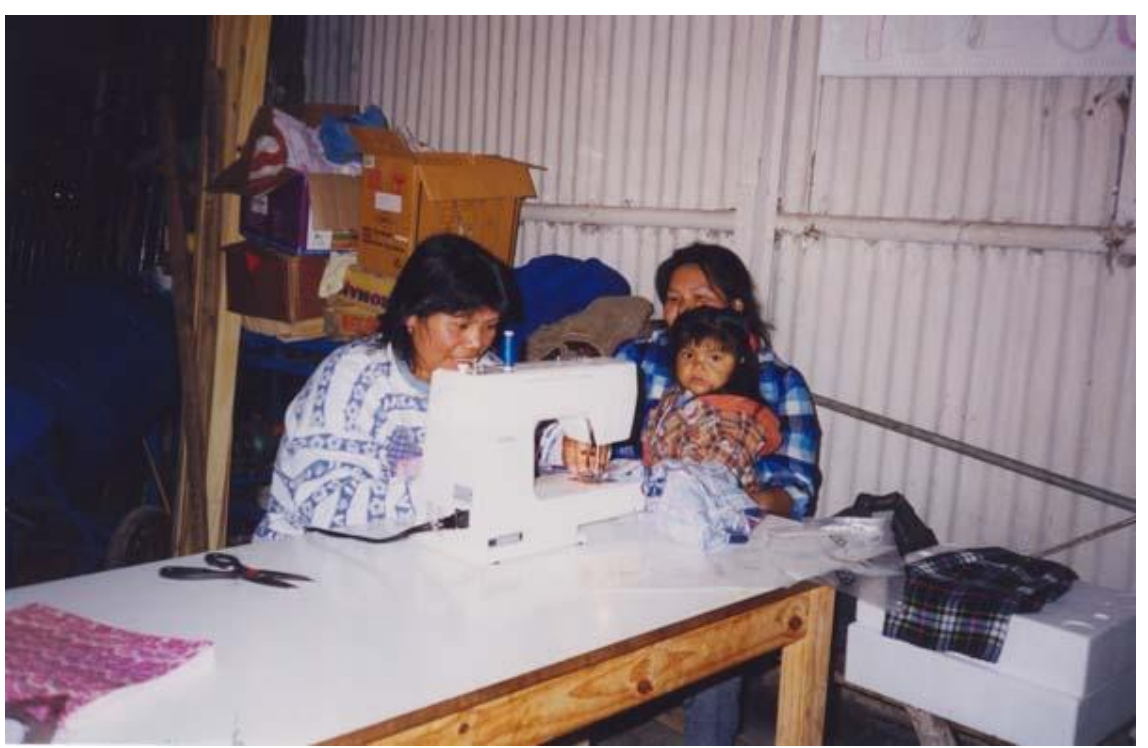


Foto $\mathrm{N}^{\mathrm{o}}$ 6: Horno de barro - (MAIC)

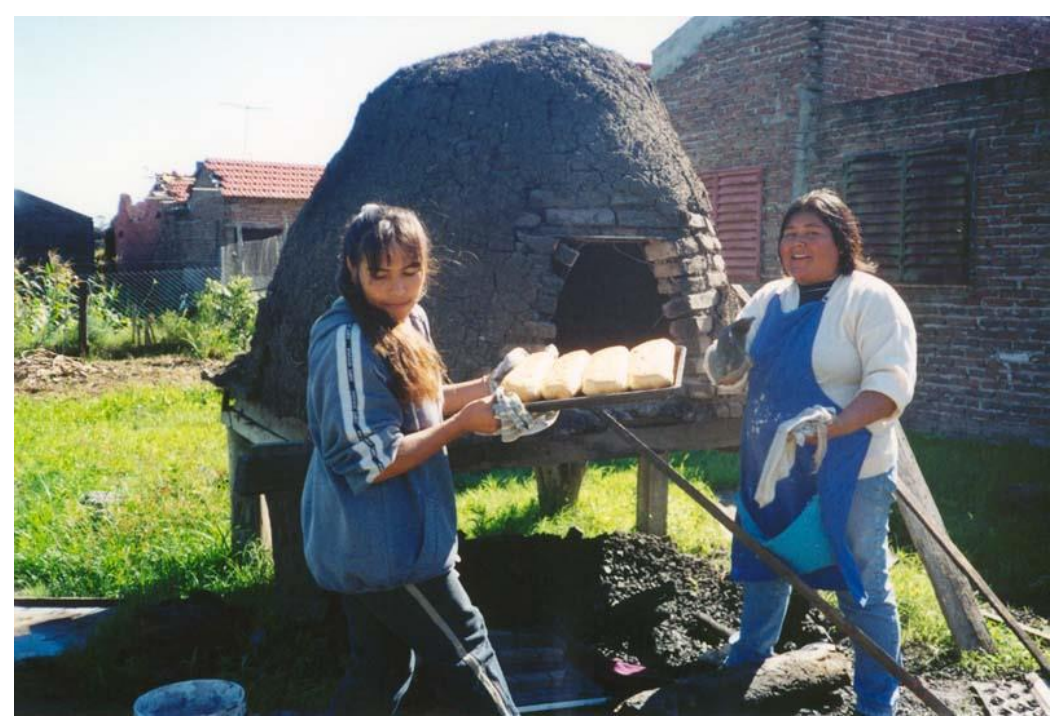

Foto $N^{o}$ 7: Santa Cena - (MAIC)

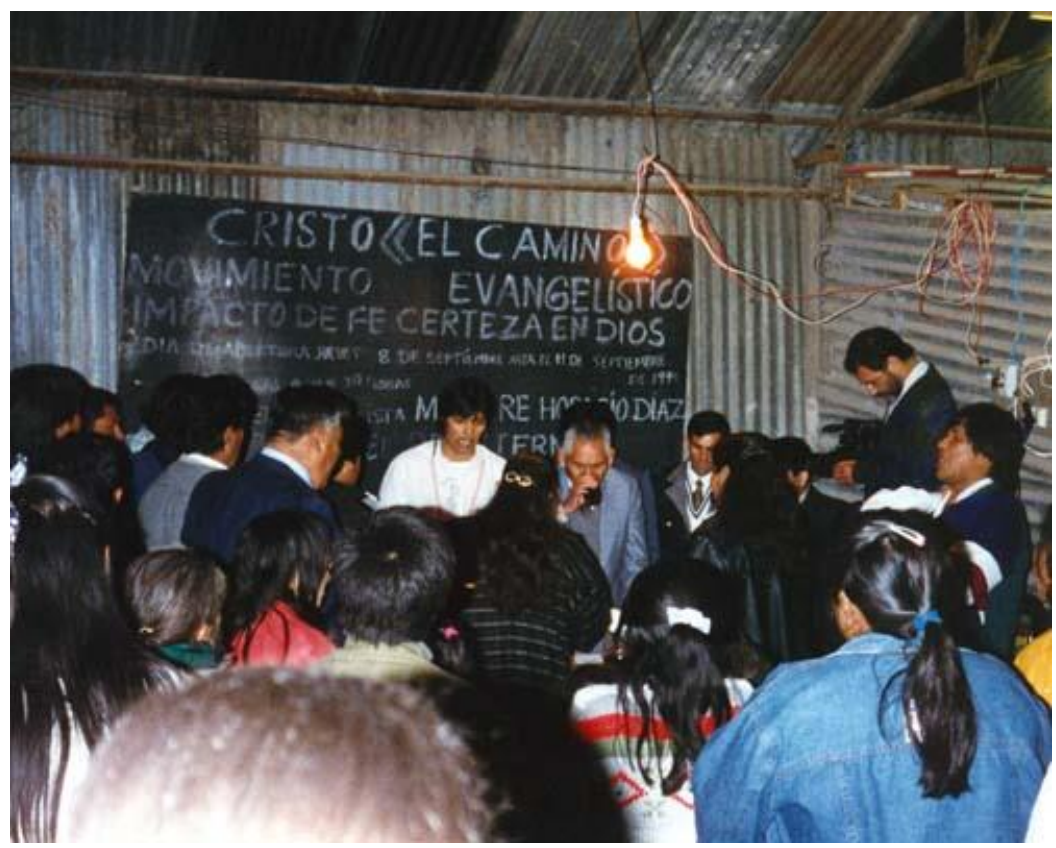


Foto $\mathrm{N}^{\mathrm{o}}$ 8: Bautismo - (MAIC)

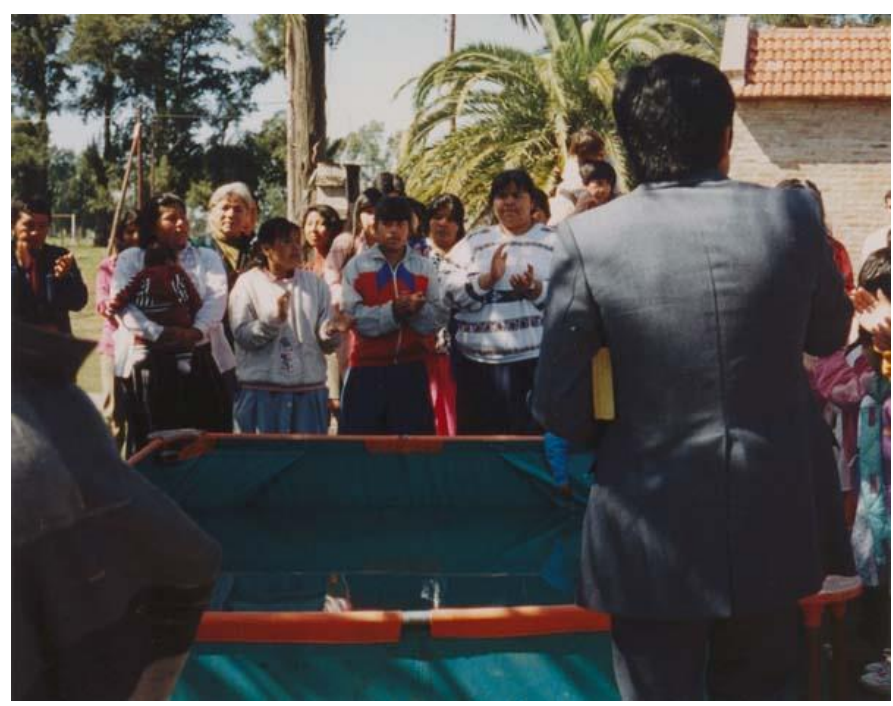

Foto $\mathrm{N}^{\mathrm{o}}$ 9, 10 y 11: Aniversario de la Iglesia - (MAIC)
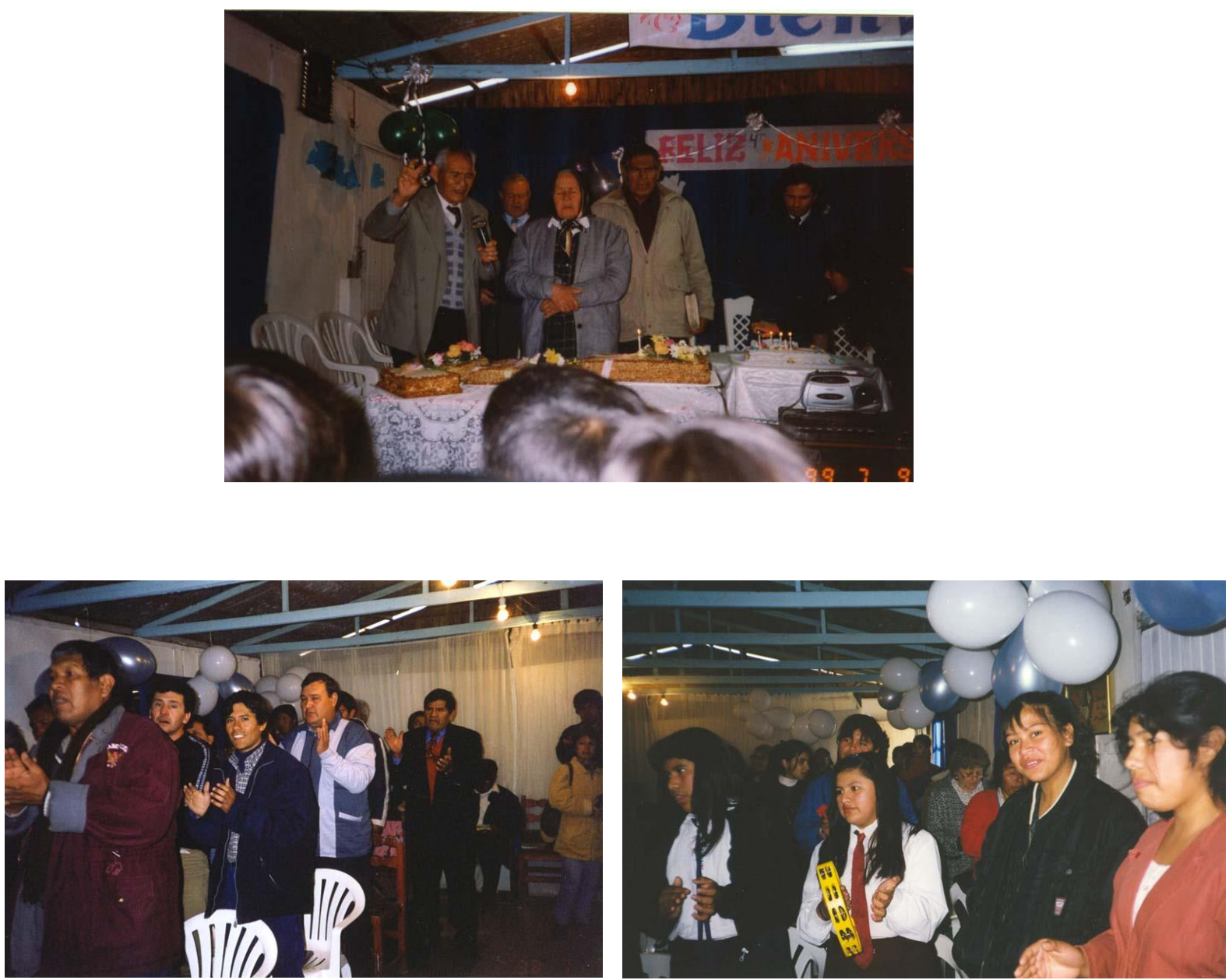
Foto $\mathrm{N}^{\mathrm{o}}$ 12: Festejo del Día del Indio - (MAIC)

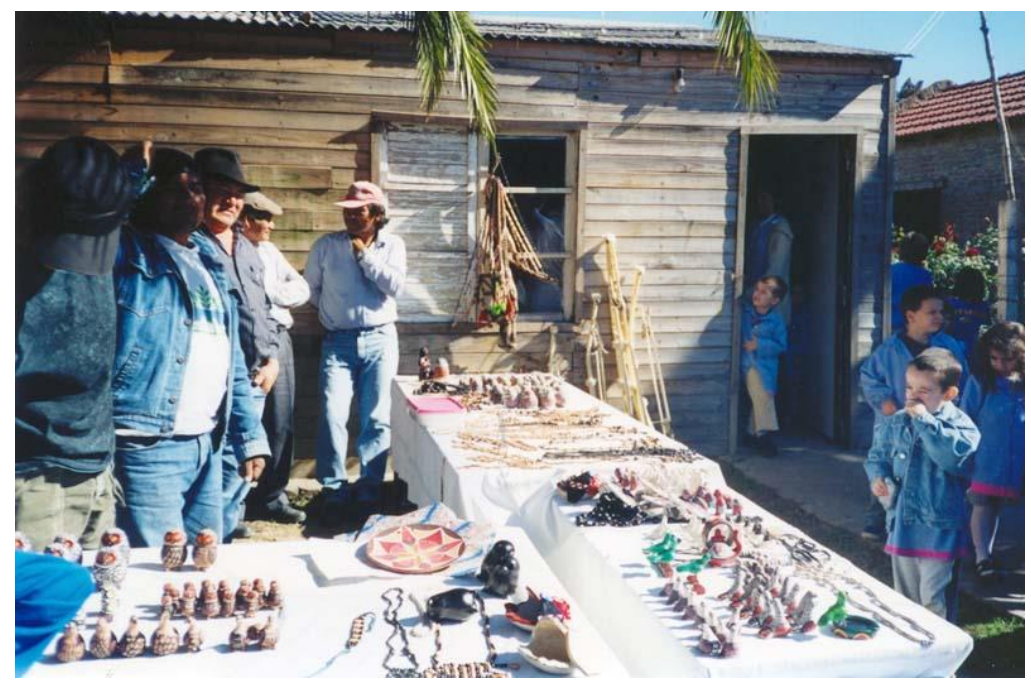

Foto $N^{o}$ 13: Festejo del Día del Niño - (MAIC)

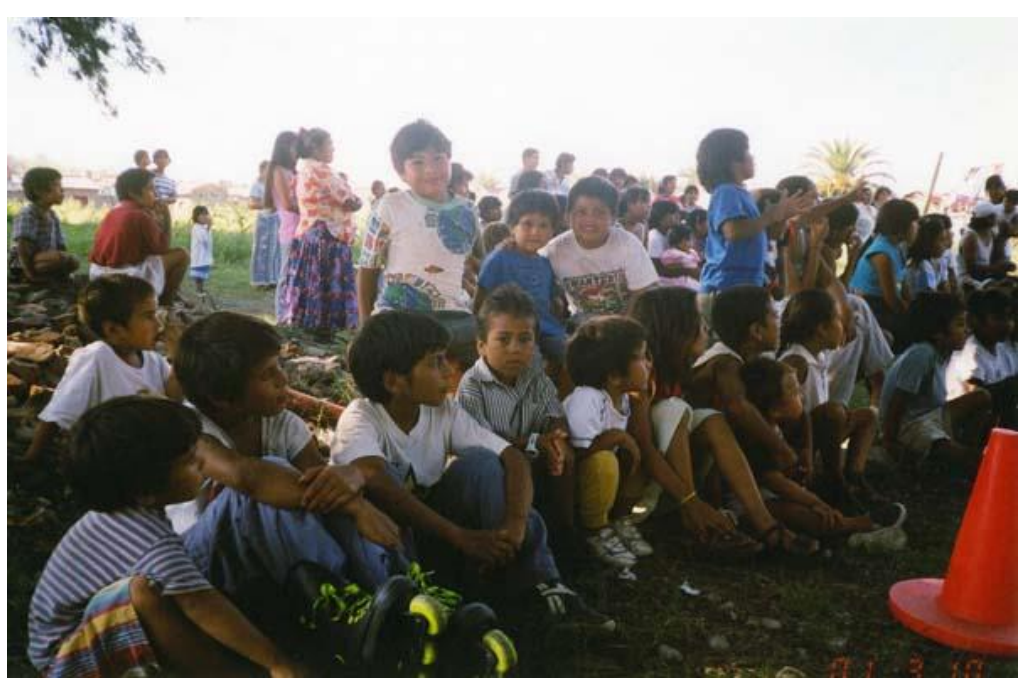

Foto $\mathrm{N}^{\mathrm{o}}$ 14: Niños jugando - (MAIC)

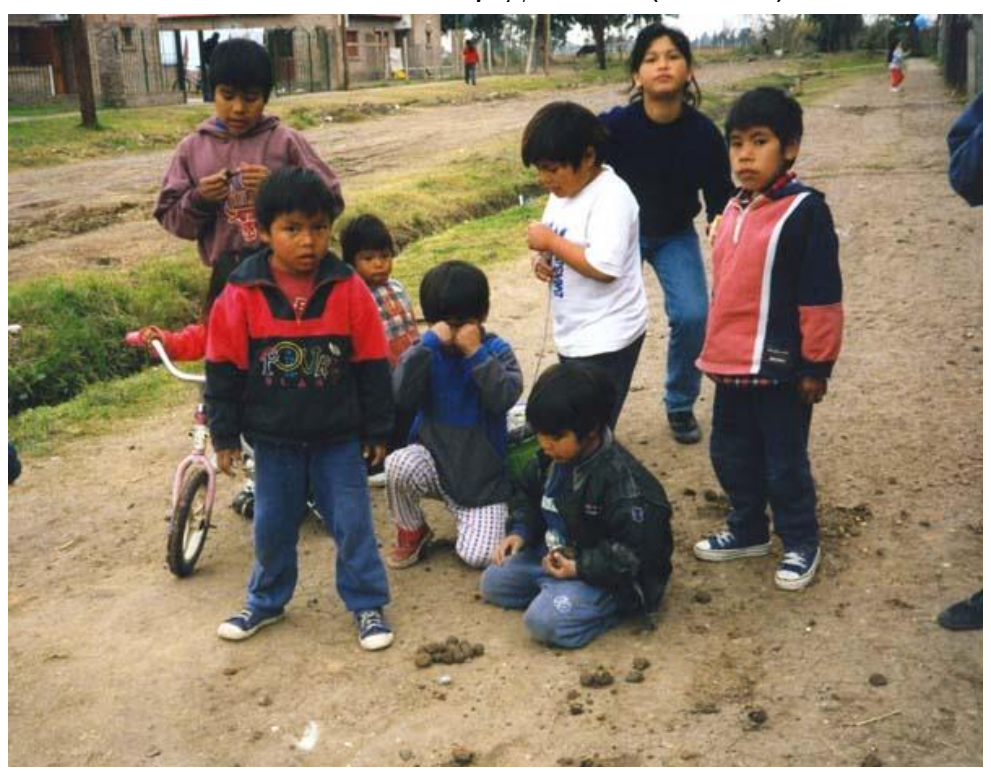


Foto $\mathrm{N}^{\mathrm{o}}$ 15: Jardín de Infantes Josefina Bakhita - (MAIC)

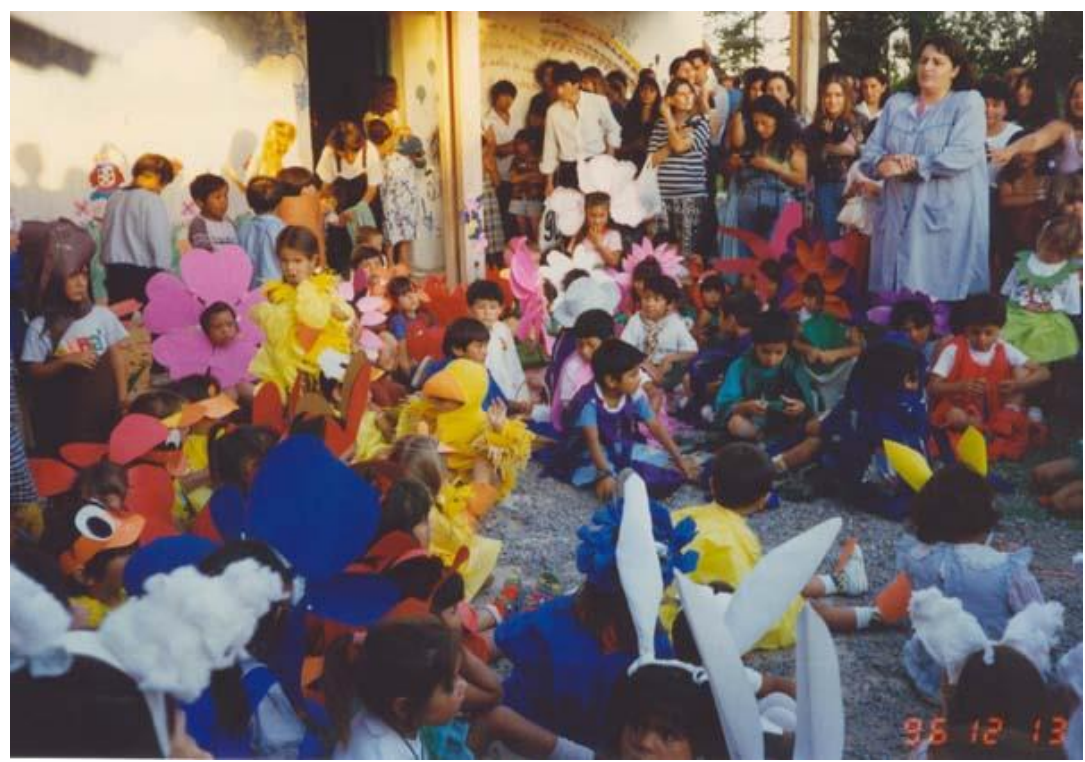

Foto No 16: Visita: Reunión de hombres - (MAIC)

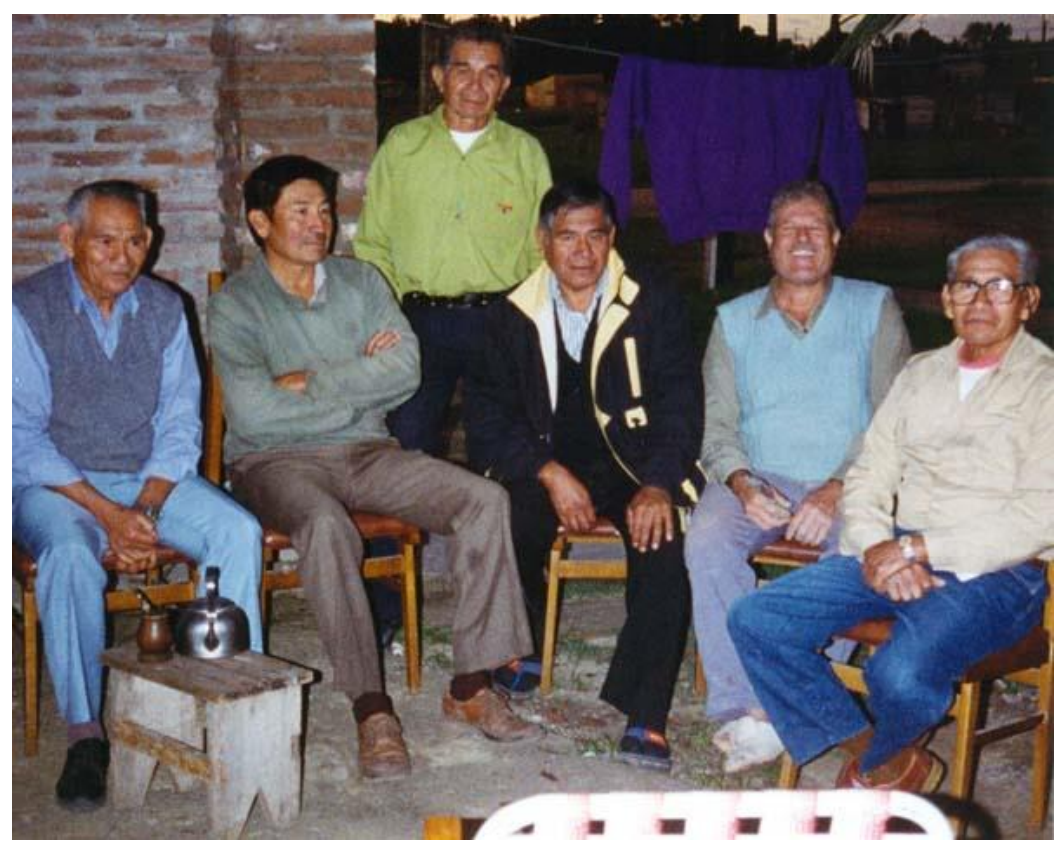




\section{ANeXo 1:}

\section{Planilla de Cuestionario № 1}

$\underline{\text { ENCUESTA }} \underline{N^{\circ}:}$

FAMILIA:

I-MIGRACIÓN:

$\underline{\text { Llegada a La Plata: }}$

$\underline{\text { Lugar de origen: }}$

Tiempo que salió del Chaco:

II-COMPOSICIÓN DEL GRUPO DOMÉSTICO:

Nombre: Edad: (Rel. refer.) Ocupación:

IV-EDUCACIÓN:

Ahora: $\quad \underline{\text { Nivel: }} \quad \underline{\text { Lee }} \underline{\text { Escribe: }}$

V-LENGUA:

Habla:

Entiende:

Con quién:

Cuándo aprendió el castellano:

Gustaría hablar la lengua:

$\underline{\text { Interesa que los chicos aprendan la lengua: }}$

Qué hacer para que no se pierda el idioma:

VI-RELIGIÓN:

VII-SALUD:

OBSERVACIONES: 
ANEXO 2

Guía PARa el Relevamiento Sociolingüístico Del BARRIO TOBA "LAS Malvinas"

\begin{tabular}{|c|c|}
\hline \multicolumn{2}{|c|}{ 1: Nivel individual } \\
\hline \multicolumn{2}{|c|}{$\underline{\text { Datos Personales }}$} \\
\hline \multicolumn{2}{|l|}{ Nombre: } \\
\hline \multicolumn{2}{|l|}{ Grupo Doméstico de pertenencia: } \\
\hline Edad: & Ocupación: \\
\hline Educación: & Servicio Militar: \\
\hline $\begin{array}{l}\text { Rol/es actuales que desempeña en el } \\
\text { barrio atribuidos por él mismo: } \\
\text { y que le asignan los demás: }\end{array}$ & \\
\hline \multicolumn{2}{|c|}{ Lengua } \\
\hline \multirow[t]{2}{*}{ Lengua Materna: } & Monolingüe/ Bilingüe: \\
\hline & Grado de bilingüismo: \\
\hline \multicolumn{2}{|l|}{ Observaciones: } \\
\hline \multicolumn{2}{|c|}{ Origen y Migración } \\
\hline Lugar de Origen: & Fecha de Migración: \\
\hline \multicolumn{2}{|l|}{ Motivo de Migración: } \\
\hline \multicolumn{2}{|l|}{ Con quién se realizó la Migración: } \\
\hline \multicolumn{2}{|l|}{ Con quién se conectó a su llegada: } \\
\hline \multicolumn{2}{|l|}{ En qué lugares vivió: } \\
\hline \multicolumn{2}{|l|}{ Regreso al Chaco: } \\
\hline \multicolumn{2}{|c|}{$\underline{\text { Viviendas }}$} \\
\hline \multicolumn{2}{|l|}{ Cómo se enteró del Plan de Viviendas: } \\
\hline $\begin{array}{l}\text { A qué integrantes del barrio conocía } \\
\text { previamente: }\end{array}$ & \\
\hline
\end{tabular}




\section{2: Nivel Comunitario o Grupal}

Dominio:

Variedad Lingüística Usada:

Contextos:

\begin{tabular}{|l|l|l|} 
& & \\
\hline & formal & \\
\hline & público & informal \\
\hline intercomunitario & privado \\
\hline
\end{tabular}

\begin{tabular}{|r|l|l|}
\hline \multicolumn{1}{|l|}{ Acto: } & Público & \multicolumn{1}{|l|}{ Privado } \\
\hline Dónde se hace: & \multicolumn{2}{|l|}{} \\
\hline & Formal & Informal \\
\hline Motivo: & \\
\hline Participantes: & \\
\hline Qelación entre los participantes: & \\
\hline Quiénes no pueden participar: & \\
\hline Duración del Evento: & \multicolumn{2}{|l}{} \\
\hline
\end{tabular}

- Actos en los que el hecho de habla es lo central:

* Oratoria

En qué ocasión se hace:
Quién la hace:
En qué lengua:
Duración:

* Narración de cuentos/mitos/ leyendas/ chistes

\begin{tabular}{|r|l|}
\hline Cuándo se hace: & \\
\hline Quién sabe: & \\
\hline Quién lo cuenta: & \\
\hline Quiénes escuchan: & \\
\hline En qué momento del día se & \\
cuenta: & \\
\hline Dónde se cuenta: & \\
\hline Tipo: & \\
\hline Temas: & \\
\hline Duración: & \\
\hline Lengua utilizada: & \\
\hline Chismes & \\
\hline
\end{tabular}




\begin{tabular}{|c|c|}
\hline Cuándo se hace: & \\
\hline Entre quienes: & \\
\hline Quién lo hace: & \\
\hline Temas: & \\
\hline En qué lengua: & \\
\hline * Otros géneros & \\
\hline Cuándo se hace: & \\
\hline Entre quienes: & \\
\hline Quién lo hace: & \\
\hline Temas: & \\
\hline En qué lengua: & \\
\hline - Contextos en los que no se habla & \\
\hline Porque no se acostumbra: & \\
\hline Porque está prohibido: & \\
\hline $\begin{array}{r}\text { Sólo algunos participantes pueden } \\
\text { hablar: }\end{array}$ & \\
\hline - Contextos en los que sólo se pue & de hablar en una lengua: \\
\hline En qué lengua: & \\
\hline Participantes: & \\
\hline Temas: & \\
\hline Motivos: & \\
\hline
\end{tabular}




\section{Los niños y la lengua}

* Lugar que ocupan los niños en la comunicación:

- ¿Pueden los niños participar de las conversaciones de los adultos; de qué modo?

- ¿En cuáles no pueden participar, por qué?

- ¿Cuál es la actitud de los niños cuando los adultos hablan en la lengua; pueden seguir la conversación?

- ¿Se dirigen los padres a sus hijos en la lengua toba aunque éstos no la hablen?

* Particularidades de los niños y la lengua

- ¿Qué cosas saben los niños en la lengua?

- ¿A qué juegan los niños?

- Cuando juegan: - ¿en qué lengua hablan?,

- ¿utilizan alguna/s palabra/s en toba o hacen alguna referencia a la lengua?

- ¿Cuáles palabras utilizan?, ¿en qué contextos?

- ¿Qué nombre tienen los juegos?

- ¿Existen juegos típicamente tobas? ¿Cuáles?

\section{* Características propias de la socialización}

- ¿En qué lengua les hablaron y les hablan las madres a sus bebés?

- Registro de las primeras palabras que dijeron sus hijos, teniendo en cuenta la edad y las primeras frases completas que dijeron.

- Registro del habla particular de los niños por edades (en español)

- ¿Qué influencia reciben los niños de sus abuelos?, ¿participan los abuelos en la socialización de los niños?

\section{* Lugar que ocupan los niños en la comunicación:}

- ¿Pueden los niños participar de las conversaciones de los adultos; de qué modo?

- ¿En cuáles no pueden participar, por qué?

- ¿Cuál es la actitud de los niños cuando los adultos hablan en la lengua; pueden seguir la conversación?

- ¿Se dirigen los padres a sus hijos en la lengua toba aunque éstos no la hablen? 


\section{* Particularidades de los niños y la lengua}

- ¿Qué cosas saben los niños en la lengua?

- ¿A qué juegan los niños?

- Cuando juegan: - ¿en qué lengua hablan?,

- ¿utilizan alguna/s palabra/s en toba o hacen alguna referencia a la lengua?

- ¿Cuáles palabras utilizan?, ¿en qué contextos?

- ¿Qué nombre tienen los juegos?

- ¿Existen juegos típicamente tobas? ¿Cuáles?

\section{* Características propias de la socialización}

- ¿En qué lengua les hablaron y les hablan las madres a sus bebés?

- Registro de las primeras palabras que dijeron sus hijos, teniendo en cuenta la edad y las primeras frases completas que dijeron.

- Registro del habla particular de los niños por edades (en español)

- ¿Qué influencia reciben los niños de sus abuelos?, ¿participan los abuelos en la socialización de los niños? 


\section{ANEXO 3}

\section{REFERENCIAS ESQUEMAS GENEALÓGICOS No 1 Y No 2}

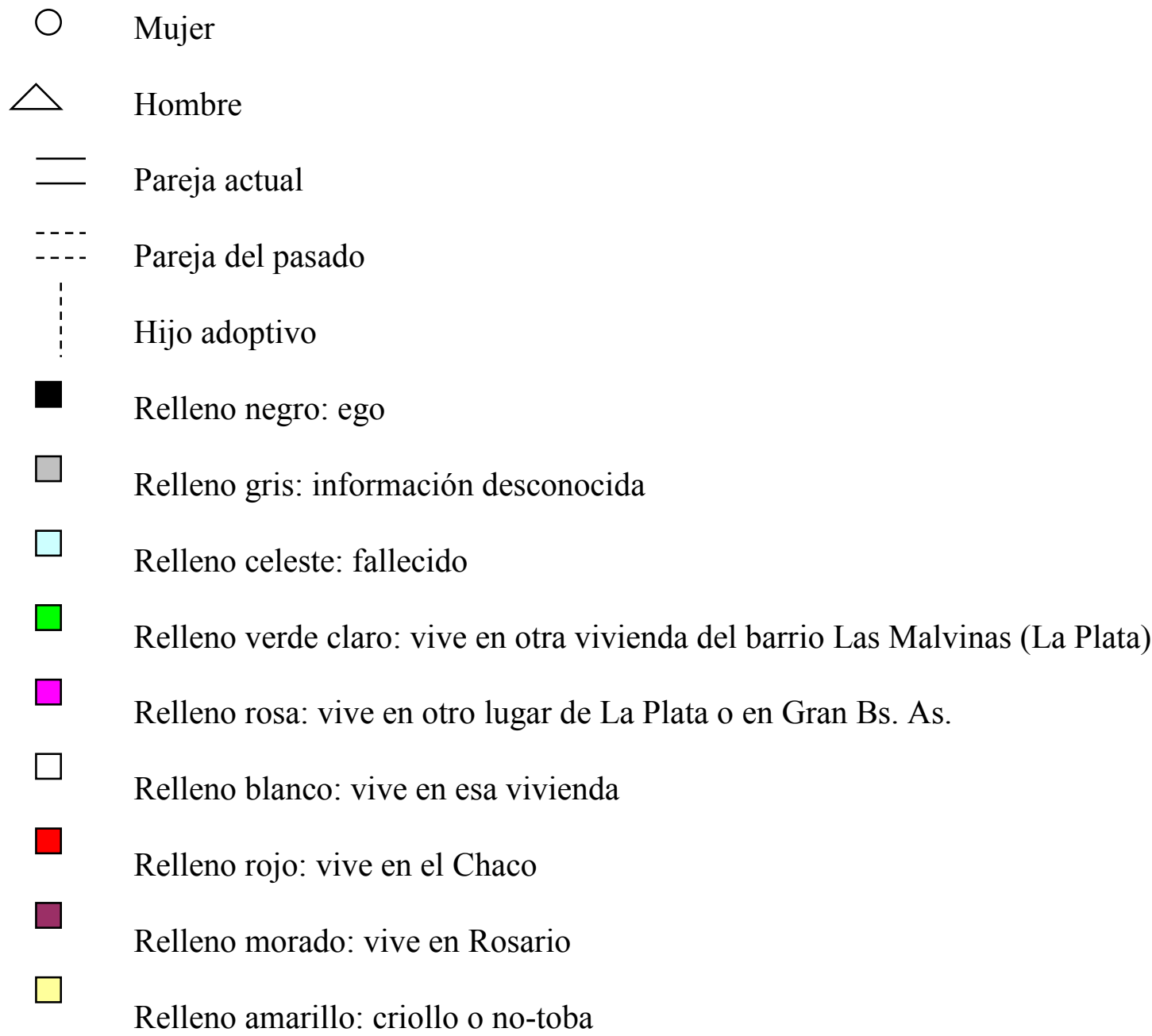


Esquema Genealógico No 1

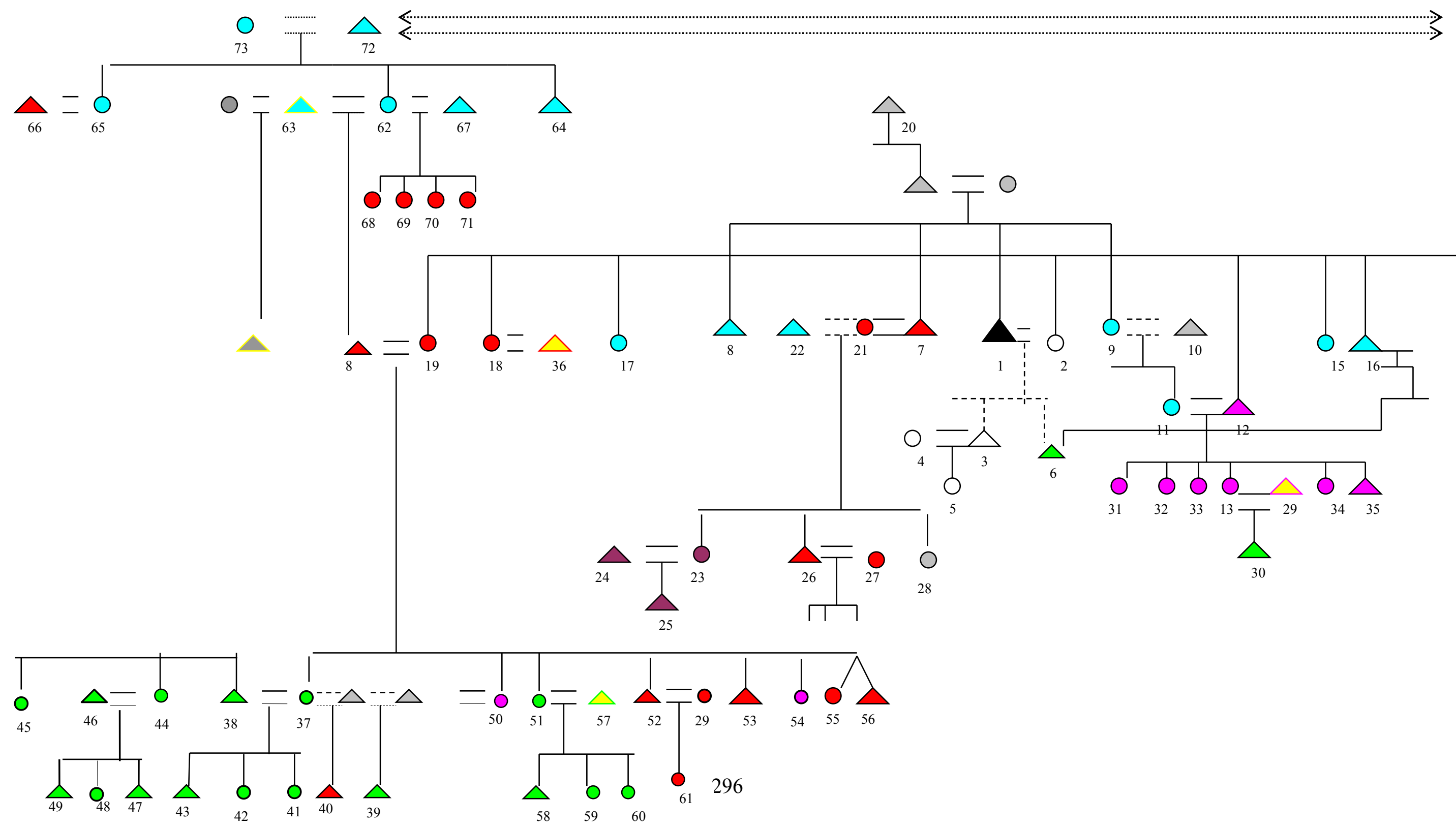


Lengua e Identidad en el camino de la migración de indígenas tobas:

Una perspectiva interdisciplinaria
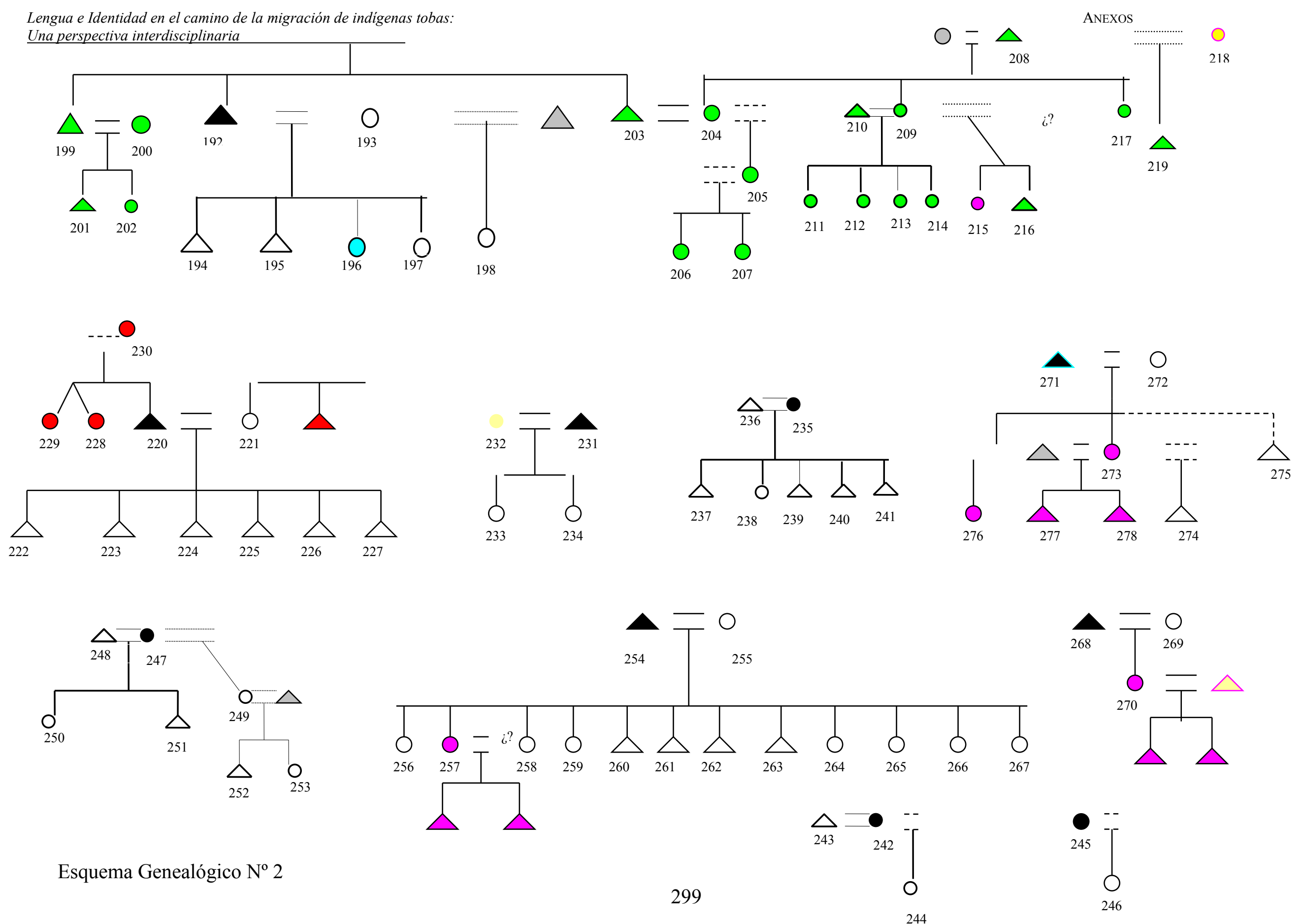

Esquema Genealógico No 2 
